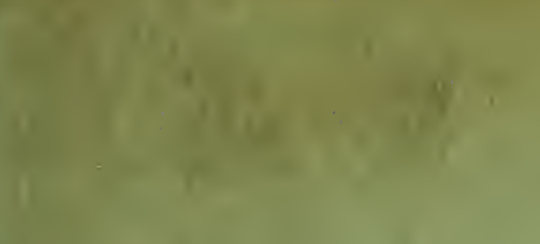




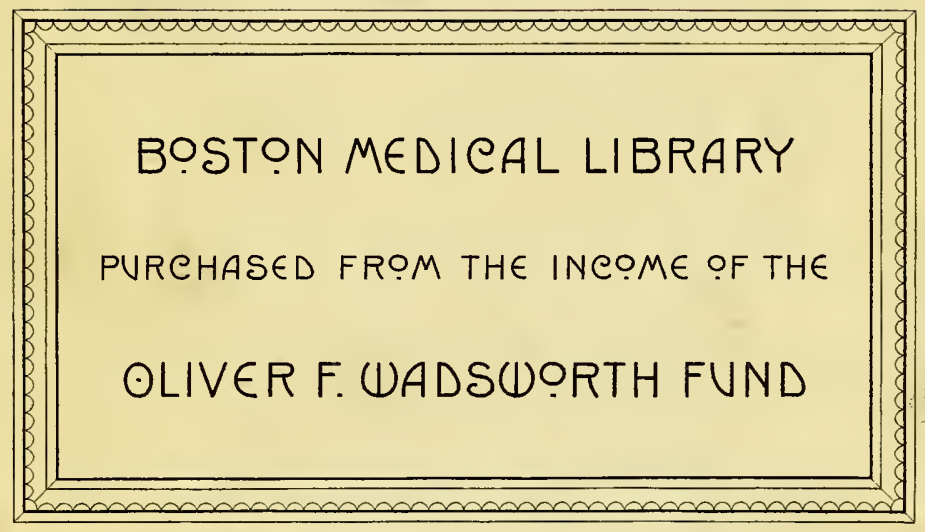


Digitized by the Internet Archive in 2011 with funding from

Open Knowledge Commons and Harvard Medical School 
lyegiata. 


\section{HIERON Y MI \\ MER C V R I A L I S \\ VARIARVM LECTIONVM \\ LIBRI QVATVOR.}

In quibus complurium, maximeq́. medicinae Scriptorum infinita paenè loca vel corrupta reftituuntur, vel obfcura declarantur.

$A L E X A N D R I T R A L L I A N I$ $D E L L M B R I C I S$ E P I S T O $L \mathcal{A}$

Eiufdem Mercurialis opera, \& diligentia Graecì, o Latinè nunc primùm edita.

CVM PRIVILEGIO.

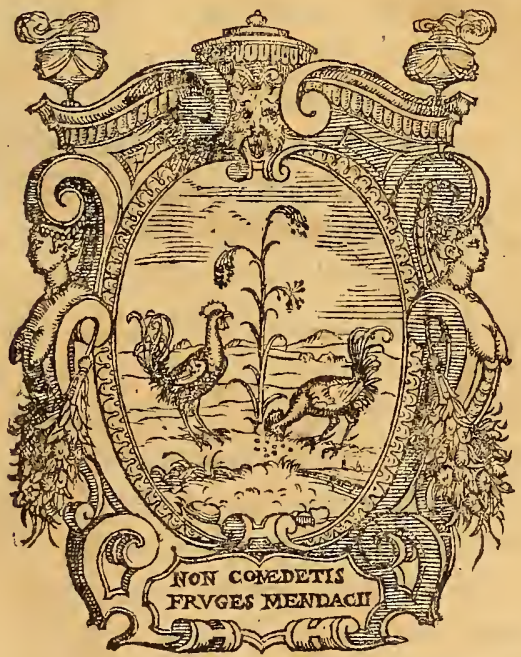

$V$ E N TIIS, Gratiofus Perchacinus excudebat,

Sumptibus Pauli \& Antonij Meieti frat.Librarij Patauini M D LXX I. 
I $7 \times$ VO SIIH

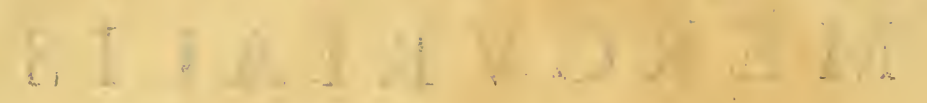

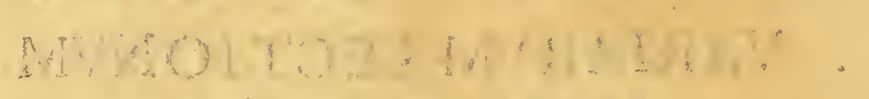

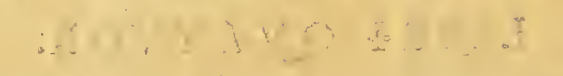

$$
13292 \sqrt{64} 3,19
$$


MO

MO

ILLVST RISS. ET REVEREND.

SANCT. ROM. ECCLESIAE

C A R D I N A L I

\section{ANTONIO PERENOTTO}

A R C H I E P I S C O P O

MECLINIENSI \&c.

\section{ANDREAS SILVIVS BRVGENSIS S. P. D.}

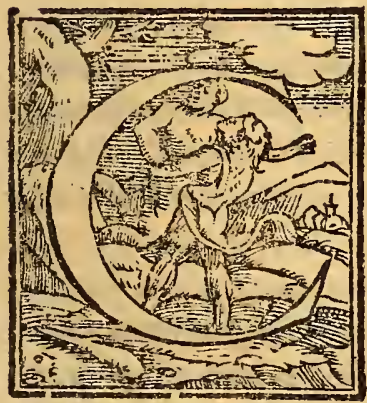

$V$ м multa Cardinalis Amplifime pro dita de Principe Philofophorum Socrate egregia ac penè diuina accepimus ; tvm verovel illud in primis, quod eos accufare grauißimè fapien tißimus vir folebat, qui rerum atq; verborumfcienitam, coharentes na tura res atg; copulatas, opinione difraxiffent. Huivs.n.opinionis per. uerfitas, quantum femper detrimentiartium optimarum fu dyjs importarit, etfiobfcurum effe nemini poteft; ea tamen $\ddot{y} s$ plaga fuperioribus feculis aliquot eft iniecta, vinungumid clarius, quam nunc potuerit perßici. Fuit enim, fuit quoddam tempus auorum nofrorum memoria, cum bomines, qui adveritatis inuefigationem, atq; ingujfitioncm operam om. nem, diligentiamğ fuam contuleraist, rudes, inexercitati, communium literarum, atq; humanitatis omnis expertes, ad capeffenda Sapientice fudia accedebant. Que cum eorum virorum foriptis memoric prodita continerentur, ad quos illi propter infcitiam apirare non poffent; amifja rectif. 
fona fapicntice via, quamveteres illi philofophitritam, atque munitam reliquifent; dum deuigs itineribus fruftra $p h i$ lofophiam confectintur, in captiones quafdam, vnde fe extricare non poffent inducti, in fophifmatilus, quafis in dumetis atatem omnem confunebant. A quo errore dum aucrtcre bominum animos fitudent, ecce tibi aly, in contrariam partem omnia non minus graui opinionis prauitate rapuerunt. Dum enim inverborum intelligentia, atque linguarum cognitione, pofitum effe ad doctrinarn momentum omne arbitrantur, fophifices odio, veram quoque Philofophiam exterminarunt. Itaq. differendi, difceptandiós totius artis ignari, nibil in $M$ athematum ftudys, nibil in nature indagatione verfati; que quaji exercitatione quadam predifcere, ac meditari ad grauiorum rorum contemplationem, antiqui illi Sapientes nos volebant; alij Iureconfulti, alï. Medicire. pente facti funt; aly in rerum diuinarum inquifitionis pene. iralia irruperunt. Ex quo illa opinionum portenta, atque fla gitia orta funt, quibus nunc perturbatas omnes difciplinas videmus. Quid enim aliud facerent homines, qui nulla diffe rendivia, atque arte, nullo diputandi vju, de rebus grauifis inis vaticinantes, fortirentur quid dicerent, non dijudicarent? 2uorum audacia, atque impudentia quantam in bominum animos confufionem, quantamós perturbationem immiferit, vtinam effet maturius animaduerfum. Plures enine diuinum illud socratis confalium fecuti, iter id ingreßsi effent, quod nunc vix pausi quafidefertum, atque obfeptum tenerepotuerunt: Quicumexcellentibus ingenijs prediti ad bee artium optimarum fudia acceßjffent; negue ita in linguarunz cognitione verfarentur, vt in $\dddot{y} s$ quafi fopulis quibufdam adherefcerent; neque dum earum difcendaruin laborem fugiunt, peciofum rerum nomen, ignauid, defidiaǵg fue. pretenderent. Nam orlinguarum intelligentia grauiorsin rerum contemplationi quafi inf rumentum comparanda efi; ơ illa de qua se iactant rerum cognitio, neque percipi nifi vo: cibus 
cilus intellect is potef ; neque tradifordidis, atque inquinat is verbis debet. Itaque illwd in omni foudiorum ratione tenen. dum eft, vi do vocum cognitio cum reruns intelligentia, or rerum fcientia, cum notitia verborum, ita vtinaisura coniun cta junt, atque colligata, itidem à nobis conferuentur. Quod. qui affecutifunt, eos, cum ego admirari atque fuspicere vebementer foleo, tum vero is effe mibi Hieronymus M ercurialis videtur, inquem verißime conueniat illud Hippocratis.

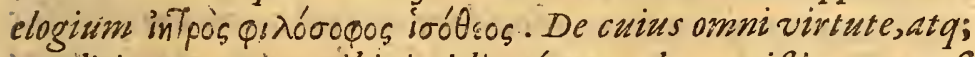
eruditione parcius mibi timidiuság agendum exiftimarem, $\int$ e. verendum mibi effet, ne de tali viro plus dicerem quàm aut. tu, profingulari tua erga eum humanitate, de eofentias, aut commemorari apud te libenter fis auditurus. Quapropier. hoc dicam, quodvel iniquißimis eius confiteri eft neceffe; ad eum dignitatis gradum, in quo ipse in Academia Patauina à SenatuV eneto, fumma fuacum laude, ac gloria eft collocatus, neminem vnquam omnibus vel nature, vel doctrins prefidijs para tiorem acceßiffe. Cuins primum curriculum omne in his fudÿs excolendis ita eft elaboratum, vt cum greie, atque latine lingus fingularem intelligentiam, cum fumma Philofophice cognitioni coniunxiffet, vtraque ea ad ornars dam atq; amplificandam fcientiam Medicine traduceret. In qua cum it a excelleret, vt comparari cum eovix pauci poffent, ad Alex. Far.Card.amplifs. Romamprofectus, ita fe fe in illo amplisimo orbis terrarum theatro tractauit, vt non fo. lum propter fingularem eruditionem, cum omnibus fumma in laude, verum etiam propter morum incredibilem fuautatem, maxima in gratia effet. Patauium vero vt venit, $c-$. quis aut in eu Academia, aut V enetiis fuit, qui modo exift mare aliquid de literis his elegantioribus pofset, qui non ap. petendam fibi omniftudio eius amicitiam arbitraretuir ? $N$ i oveterum medicorum foripta in Scholis ita explicantem, of prinatim ita de Medicina repondentem audiebant, nibil vo eruditius, nibilprudentius cogitaripofet; $\&$ in arte ip $\sqrt{ }$ a fi- 
cienda tanta non folum fcientia, atq; confilio, fed etiam felicitate verfarividcbant, vt $\ddot{y}$ agribeatißimi viderentur ad quos ille curandos quamprimum accederet'. Scriptorum vero eius, quibus maxime atq; graujßime in vniuerfamedicina diputationes continentur, ea cim eruditio; atq; fubtilitas, tüm eleganita eft, vt non tantum, cum ea perpolierit, remime, dicäfummotere illuftratura, fed \& gloriä eius cü omnipofteri tate conisiciara videantur. Verum vt honorati ac Principis vi ri domsm non ̈̈s tanium abundare oportet, quorum oft $v$ us advidum culium; receffarius; fed \& auro, atq; argento magriffcè ac preciasè celato, vefte stragula, reliquaǵ fupellectile, que curn quadam fplendoris pecie moueat oculos atq; deledtei. Ita Mercurialis ex immenfis illis ingenÿ Juidiuitÿs, quaf delicias quaf a.t licerariz in quattuor libros V ariarü leaicin anie àliquot annos coniecerat. Nonillas quidem, quod edendas boc tempore, quo grauioribus occupationibus eft adfrictus,exifimaret: Sed cim, ita vtifit, amicis quibufda eas legeret, quibus \& ille veherienter probarentur, o perpectan plane effet; ac cognitum quint um non folum delect atiosis, fed etiam vtilitatis preclari illi eius de Gymnaftica librilectoribus attuliffent:grauare quidem ille, fed tamen impetrari à fepafus eft, vt eas ego emitterem. Eum verolibrum amplisime Cardinalis, cur in tuo potifimum nomine apparerc voluerim caufa eft, quod is est glorie tue, ex administrato tot annos terrarum orbis imperio plendor, ea amplitudo, giu adfe colendam, atq; venerandam omnes non focordes de beat excitare. Habet enim iuftam venerationem prestans, at gue exiellens virtus, prefertim in altißimo dignitatis gradu ob multa, atq; preclara in Rempub. beneficia, pofita.Itaq; wt ea, quorum diuturnitati at; incolumitaticonfielere volumus, confecrare Dïs insmortalie us folemus, quorum religione tista, atque integra conferucntur; Iia ego cum in varias horninum partiminiquorum,partim inuidorum reprehenfiones la-

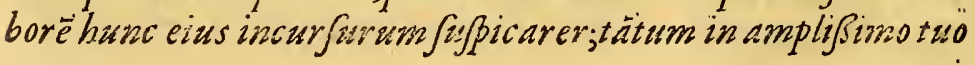


nomine prafidiy pofitum efecxiftimaui, vt ad reprimendos, at: que retaraiados omes omniü impetus faits eßse futurumexifti marem, fite illipatronum adoptaßem. Quo etiam accedit, guod cum multa fint, que vrbis Rome recordationem Mercuriali iucundisimam faciant; twm veropucipua fit benignitas illa incredibilis, atq; amor fingularis, quibus tu illum femper es complexus; Quibus ille fe tibi ita deuinctum atque obligatum intelligit, vt agnofcendi ea, ac voluntatis fuc deilarandefacultatem, optare nunquam definat; confequife vnquampoße non peret.Vt dubit andum mibi non eßset quin boc meum dedicationis huius offrium gratißimum illi efeet futurum;quod fininus plenam, atq; cumulatam, at certè aliquam haberet fignificationem preclare illius erga tevoluntatis, opptinniǵs de omni tua virtute indicy. Meum enim studium om ne ad amplitudinem, ac gloriawn tuam omni laude, atg; honore amplificandam conferre vt debeam; \& communi patrice mex nomine impellor, quam tu omnibus beneficys complexus amplipimam emper, atque honestipimam e. Re voluisti; orve ro propria, ac mea adducor ob feruantia, atique aduerfus farniliam wniuerfan vestram rewerentia, Clarisimi atque ampliffimivirifratris sui Thome Perenotii fingulari bumanitate, obenesolentis in me propè incredibili excitata. Vale, Venetÿs DecimoKal.Decembr. M D LXX. 



\section{CATALOGVS AVCTORVM QVORVM LOCA VEL EXPLI.}

CANTVR, VELEMENDANTVR.

Aetius.

Aefchilins.

Aclius Promotus.

Aefchines.

Agatarchides.

Alcxasider Trallianus.

Antigonus.

Apollonius.

Apfyrtus.

Apuleius.

Ariftoteles.

Arrianus .

Ariftophanes.

Archigenes.

Archeftratus.

Archefilaus.

Afclepiades.

Athenodorus .

Athenaeus.

Aurelius Prudentius.

Auroes.

Aufonius.

Auicenna.

Auenzoar .

Cato.

Caclius Aurelianus .

Callimachus.

Casfius Medicus.

Catullus.

Cusfiodoruse

Chalcidius.

Cicero.
Clemens Alexandrinus.

Cornelius Celfus.

Columella。

Cratinus.

Democritus.

Demolthenes.

Diuus Hieronymus.

Dion Casfius.

Diofcorides.

Diphilus.

Diodes.

Diogenes Laertius.

Dydimus.

Diodorus Siculus.

Empedocles.

Ennius.

Erafiftratus.

Erotianus.

Eradius:

Fauorinus .

Galenus.

Gellius.

Gregorius Nazäzenus.

Gregorius Nyffenus.

Haliabbas.

Heraclitus.

Herodotus.

Heraclides Tarentinus.

Hefiodus.

Herophidus.

Hefichius .

Hiparchus. 


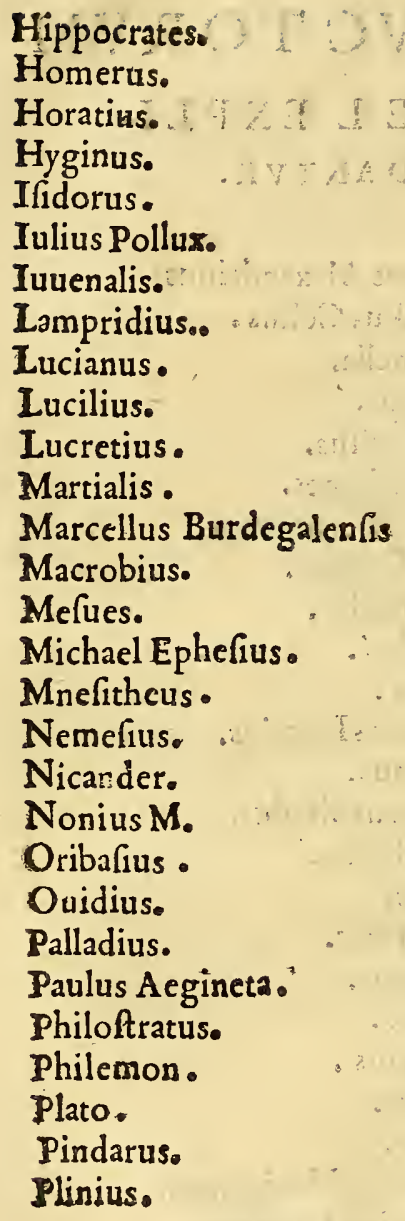

Plutarchus.

Plautus.

Porphyrius.

Polybus.

Praxagoras.

Rabi Moyfes.

Ruffus Ephefius.

Scribonis Largus.

Serenus.

Seruius.

Seneca.

Serapion.

Soranus.

Spartianus.

Stephanus.

Stobaeus.

Strabo.

Suidas.

Themifon.

Theodorus Prifcianus.

Theopompus.

Tibullus.

Thucydides.

Varro.

Virgilius.

Vitruuius.

Vulpianus.

Xenophon.

Zonara. 


\section{NDEX CAPIT VM LIBRORVM.}

L I B R I P R I A

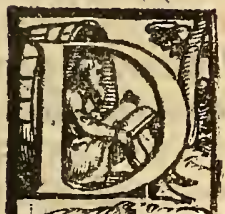

E Oefophago, of stomacho locus Galeni emendatus, ơ S Liftoteliconciliatus, Lucretius defenfus, Pollus cis locus correCtus; or alter Hippocrat is indicatus de concoltione. cap. I.

car.I

De rabie, fine hydrophobia, clephantiafi loci Ariftotelis, \& Medicorum explicati.cap.2. $\quad$ c.2 Restitutus Galeni locus de palmulis, \& alter declaratus: nonnulla de oliuis.cap.3.

Galeni locus emendatus in 12. Meth. ov alter in 13 .melius quàm $\dot{a} L \dot{L}$ nacro interpretatus. cap. 4 .

c.6 Archigenis locus emendatus apud Galenum:ac de bulbis nonnulla non poenitenda contexuntur.cap.5.

Locus Galeni de foecundis correctus: E nonnulla ad id ex Lucretio, \& Panllo.cap.6.

c.8

Quid fit recentatum apud Alexandrum Trallianum, \& que antiquorum propomata.cap.7.

c.8

De varÿs antiquorum refrigerandi uina, of aquam modis: de decocta, o quefuerit calda.cap. 8 .

c.9 Loci Aristotelis émendati ex Theophrasto, of locus Platonis exami. natus.cap.9.

c.I I

Loca Galeni, \& Caelï Sureliani expofita de Angina, \& fomno forbili. cap.ı.

c.1 2

De ificüs, itrüs, \& libis uarie obferuatiōes, explicationes.c. I I.c. I 3 De pane furnaceo error in Galeni interpretatione explicatus, of alter de Myrtidano Plinï deteCtus. Quid fit traẼa, Plinio, \& A thenaco. cap.ia.

c.I 4

De aquis Veficarüs, of Caeretanis : Galeni locus de tểplo $\mathrm{P}$ acis male à Giraldo intellectus.cap. I 3 .

Errorin Aetio correctus de ficubus, \& alia de ipfis: Columelle de em bammaie locus emendatus.cap. I. 4 c.16 


\section{I $\quad N \quad D \quad E \quad X$}

Locus Plutarcbi de T itbógÿs"emendatus, É de festo prime $\mathcal{A} u g u s t i$ diei.cap.15.

De oleo, \& butyro, aphrogala peria Galeni, \& alierum, explicata.Plinïlocus correctus. cap. 16 .

c. 18

De vina dulci, \& de coitu Ariftotelis, é medicorum explicatiloci. cap. 17.

De uarïs Vini ansiquorum temperaturis pulclbra quaedam:locus Hippo cratis illustratus, \& alius $\mathscr{A}$ thenaei corre $C t u s, H i$ fiodiq. Sententia in terpretatur. cap.18.

c.20

De infibulatione; $\mathcal{O}$ quid fit apud Galenum dicere pedem.cap. 1 9. c.22 Ramex quid fit apud Plautum, bistoria Dominini, nonnulla de uaricibus, ¿́o de birudinibus.cap. 20.

c.23

Locis At thenaei correelus ex Ariftotele, \& nonnulla de canitie, of de capitibus Aegyptiorum ex Herodoto. cap.2 1 .

c.24

De menfuris poitus antiquorum: do ordine earundem.cap.22. $\quad c .25$ Loca Hippocrat is de aqua of bile explicata:de bile Anaxagorae, ơ Aristotelis fententia examinata, aliáque ad idem.cap. 23.

c.26

De aere Romano, \& morbis eius:de At benienfi Lucret ï locus, de movis, ferico aliqua noiatu digna. cap.24.

c.27

Cur pifces me dici antiqui facile concederent agris:pifces tintinn.bulo uendi folitum fuife:quis fuerit Hoedus ex Ambracia apud Gelliü, o nonnulla alia de Hoedo.cap.25.

\section{LIBRI SECVIDI}

$\mathrm{I}$

Oca Galeni, \& Tlinï emendata:Nonnulla de Mangonib.c.r. c.32 Morem Tbufcorum vrendi pueros fuiffe antiquum:Herodoti locus notatus, Go quadam de Scytbis, ex Hippocrate.cap.z.

c. 33 Sententia Galeni ex Herodoto comprobata: De fjymea: De partitione anni fecundum Hippocratem:error facerdotim Ammonis.:a.3.C. 34 Theopbrafti loca, ex Atbenaeo, é Plutarcho correcta, de fida, de le guminibus, de pediculis:Theophrafti, \& Galeni contradictio de fcor pionibus.cap.4.

$c .36$

De uarïs antiquorum eduliys, $\mathcal{A}$ ristotelis locus examinatus, de carne Camelina, de fumine, de turta nomine. cap.5

Quae fint apud Platonem ficus, đo ung generofe ex Galeno:de pane fabaceo, É faba Aegyptia: locus Mnefithei de ficubus. cap.6. c. 38 De pulmonis carne Galeni contradictio ex Aetiofublata, de carnele. porina 


\section{I $\quad \mathrm{N} \quad \mathrm{D} \quad \mathrm{E} \quad \mathrm{X}$}

porina, o de unlpina, \& tenera carne locus Galeni reftitutus. cap.7.

c.39

Locuis Hippocratis emendatus; Gulenilocus defenfus de opio. Plinij loci emendati, alter Herodoti de medicls Aegyptiorum examinatus, \& correctus.cap.8.

c.4.

De aquarum per plumbum ductarum pranitate, \& quod Romae ex fon tibus potarent, locus $\mathrm{P}$ aterculi emendatus. cap.9.

c.42

De cicuta locus Lucretÿ explicatus Arifotelis, \& V Varroszis.de Capris loca examinata, nonnulla de anatome. cap. 10.

c.43

Hippocratis locus emendatus, locus Diog.Laertï ex Galeno mut:tus. Galeni de urinae Sedimeniorum nigredine, \& de lapide neficae error. cap.t.t.

c. 44

Celfi locus ex Hippocrate notatus, of emendatus, contradictio Galen examinatur.nonnulla de pulfi, item de Heropbilo, of Afclepiade. cap.1 2.

c.46

De cundituris uinorum, de vino piccante, de uino Maßilienfi, lochs Galeni emendatus.cap. I3.

Defenditur Plinius in tractatione argenti uiui, \&obydrargyri. locus Theopbrastireftitutus.cap.14.

De tempore coitus Plutarchi locus restitutus. Hippocrates, \& Arifo teles collatus. Error Gazae detectus. De fitu corporis in fomno. Ev-ror Alexandri contra Hipp. cap. I 5.

C.5 I

De vua taminia, \& labrufca, Tlinï locus examinatus, \& emendatus. cap. I6.

c.52

De vua theriacae:de mulfo quaedam, ¿́ Plutarcbi error de uino maßi co, \& cur ninumpercolaretur; TPlinï locus restitutus. Theodori error.cap.i 7.

c. 53

Medicinam, eiufque regulas ab $\mathscr{A} g \mathrm{~g}$ pto manaffe; locus Hippocratis, Herodotis Arisiotelis, Plutarchi, of Celfi in id, de purgatione, Aeliani improbatio de lingua Hippocratis, ơ de Acrone medico. cap.18.

c.55

De unguentis, ó quid Hippocrati fignificet unguentum $\mathscr{A}$ egyptium, de Metopio locus Hipp. emendatus:quaedam ex Plutarcho de unguentis, \& myrrba.cap. 19.

c.57

Morborum raxa quedam genera ex Hippocrate Agatarcbide, Plutarcho, ¿o Galeno:locus Hippocratis restitutus, \& alter Platonis indi catus.cap. 20.

De ÿs qui $\int e m e l$ in die cibos capiunt.cap. 2 I.

c.60 


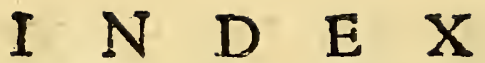

De Caryce, ef carycia, de Apro, E Lumbo.cap.22.

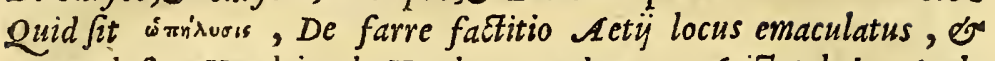
quod far Hordei, de Hordeo quaedam ex Aristotel.\& Apollonio.cap.23.

c.62

Locus Ariftotelis de melle correEtus; \& expofitus, quod mel conferuet mortua corpora, \& alia quaedam.cap. 24

$c .63$

Locus Theophrafti Apollonio collatus, de Helleboro quaedam; alter Theopbrafti locus non integre à Plinio expreffus.cap. $25 \quad 0.64$ Locus Hippocratis de Hippace Herodoto collatus: de lactis coagulatione; Ctefiae locus de radice vinum coagulante :muria dura, \& marinae.rfus.cap. 26

c.66

Sententia $\mathrm{Plin} \ddot{j}$ defendit ur de lino uino, $\mathrm{\sigma}$ ex aliis comprobatur, quid fit Scribonio foenicium.cap. 27

$c .70$

\section{IIBRI TERTII.}

Loca oribas ü, ex stobaco restituta.cap.I.

c.72

De Cyphoide, \& Cyphi Galeni, Plutarcbi, \& Herodoti loca collata, emé data, E explicata:de nerbo rápuxusv in condiendis corporibus mor. tuis ufurpato.cap.2

$c .73$

De turdis Horat $\ddot{y}$, \& Martialis difenditur iudicium, \& Galeni Sententia improbatur, modus coquendi phafianos.cap.3.

c.74 De Aconitinomine ex Antıgono; de codem $A$ thenaei locus emendatus, item alter Theophrasti melius quàm à Gaz̨a interpretatus : de cicuta quaedam, Error Macrobï.cap. 4

$c .74$

Macrobijerror ob imperitiam medicin ae: quod potus ad pulmonem pertingat non unum Platoners dixifse: Plutarchi locus ex Macrobio emendatus.cap.s

c.76

I ucretï locus de peste Hippocrati collatus, \& eius defenfio.cap.6.c. 78 Hippocratis, \& Herodoti lo ca de morbo Scytharum foemineo collata:de Amazonibus.cap.7

Iecur anferinum in precio fuiffe antiquitus : de carne fuilla locus Plutarchi. Caupones Ital os folum immerito damnaria Plutarcho.cap. $8 \quad c .8 \mathrm{t}$ DeMeliloto Cratinus expofitus:De coronis:de lemnifcis. cap. $9 \quad c .82$ Dlinï, 0 Galeni loca de doloribus:Pro oculis vflio uenarumi temporalium; Lotiopedum : Origanus : fordes aurium in morientibus $\checkmark$ grales. cap.io c. 83 De 


\section{N D $\mathrm{E} \quad \mathrm{X}$}

Decarbonibusloca Galeni,Cafs̈̈, Lucretü, \& Theophrasti: Delumbricis locus Plinü,ex Theophrafto correctus:Error Gazae.cap.II c.84 Thucididis locus à Lucretio expreffus, ac illustratus. cap.12. $\quad c .85$ Locus Virgilï, fecus quàn à Grammaticis ex Aristotele declaratus : cur ab ipfo medicina ars muta nocatafit.cap.13. $\quad c .86$ Loca Ariftotelis of Strabonis de generatione animalium in nine, o igne collata, atque examinata : locus Ariftotelis emendatus. cap.i 4. $\quad 0.87$

In faniae genus ab Areteo medico de criptü, \& möstratum.cap.1 5.c.88

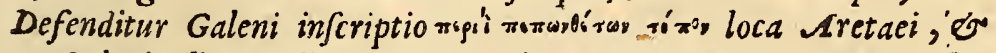
Galeni collata de $\ddot{j} s$, qui corde patiuntur.cap.16

c.89

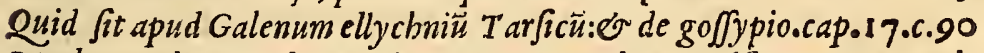
Morbus Deliorum ab Aefchine defcriptus:locus Celfi notatus, $\mathcal{O}$ alter 'Nonï emendatus, contradictio Herodoti, \& Plinü.cap.I 8.c.91 Heracliti morbus : eius, \& Afclepiddis fententia de Vrina. Galeni ad idem locus notatus, de Iberis dentes vrina lauantibus.cap.19.

c.92

Aetius redarguitur cur caftrati non fiant leprofi : locus AriStotelis de Satyriafi : De manu Gregorï NYyfeni Sententia nona.cap. 20.

De cretae generibus locus Plinï explicatus : fafciae . toga, mappae cretatae:error Cornarii; de gypfo Tymphaico Theophrafti loci corre Eti, \& alier Plin̈̈ notatus. cap. $2 \mathrm{I}$.

c.94 Menecrates Medicus quis fuerit.Medici Clinici, locus Plinü mutatus, de pofca locus suetonï.cap.22.

c.96

\section{LIBRI QV $A R T I$.}

Vi fuerint apud Veteres archiatri, \& archiatrorum comites, 2 quodve corum munus.cap.I.

c.98

De Cydni fluü̈ aqua loci Plutarcbi, Galeni, er aliorum collati. Locus Plutarchi ex Galeno restitutus, locus Hippocratis emendatus. cap. 2.

c.lot

Zoci Aristotelis, E Herodoti collati.Darÿluxatio a medico Graeco cu rata.cap.3.

Hippocratis, A vistotelis loci collati.Galent de demonftrationibus li bri qui fuerint, \& quae Jymphonia a $\mathrm{N}$ emefio citata.cap.4. $c_{0} 103$ De putaminibus fabarum. E quidfit oonpar At thenaeo.cap.5. c.IO4 


\section{N D E X}

In Acrotboracis fignificatione Clementis Alexandrini locus emacula tus; cur Laurifolia post coenam adbiberêttur:ebrietatis praecautiones:Tlinülocus emendatus.cap.6.

c.104

Tuberes apud Antiquos qui effent.locus Plin̈̈notatus. cap.7.c.105 De Menta locus Ariftotelis, ex Hippocrate illustratus, of correetus. Plinï alter ad idem notatus, é ex Lucretio explicatus. cap.8.c.106 Aristotelis error de epilepfia.Hippccratis locus ad id notatus. Seruij error. Aristotelis alter error de Sale, \& nitro: brenis adnotatio. de caufis res duratas diffoluentibus.cap.9.

- c.107

Locus Hippocratis ex Gellio restitutus, \& alter defenfus.ca. io.c. Io 9 Quae fint paleales vuae, \& fabriles apud Caelium Aurelianum. Quae menferfrigidae Plutarcbo. \& eiuslocus emendatus. cap.I I.c.IIO 2ui fint apud medicos icloores.locus Iulij Pollucis de morbis emendatus.Fanorini erratum. fudor fanguineus.cap. 12.

c.II I

Galeni explicatus locus.alter Plutarcbi mutatus, \&uex Celfo, atque Galeno explicatus.Hisioria Sabini pxoris notatu digna.ca.13.c.112 Plutarcbi locus restitutus de fignis pestis ex inefiodo, \& Hippocrate. Strabonis ad idem locus: Empecioclis Historia dinerfo modo à Plutarcho, \& Laertio relata. Quid fuerit «ँสrss. Empedoclis, o Laertio: ¿ Galeiro.cap.14.

c.IIS

Plinïlocus emendatus, Hippocratis locus à Plinio citatus, ơ explicatus.cap.15.

c.116

Loci Hi ippocrat is restituti, \& collati Lucretio: $\mathcal{A}$ ristotelis locus restitu tus, ¿i alter defenfus. cap. 16.

Quoties veteres in dic manducarcnt.cap. 7 . c. 120

De ptiffana, \& aquabordei Arabum.cap.19.

C.120 


\title{
RERVM NOTABILIVM
}

QVAE IN TOTO HOC

\author{
OPERE CONTINENTVR \\ I N D E X
}

LOCVPIETIS I M VS.

A

击

BSyntbium Tonticum bilem compefcere. fol. 27.6 fol.1 3 I.b Aconito non uefci turdos, sed cicuta. Acron medicus cur infignis fuit. Acron quis fuerit.

A egyptü omnium uirorum Janißimi. Aegypto familiaris elephantiafis. Acetaria in vltimo coenae poni, Dt lactucä. fol. I I I.a.

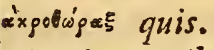

Aconitum quibus noceat.

Aconiti nomen à quo accepit.

Aer Romanus quis, \& quimorbiexeo.

fol.104.6

Aer quomodo purgandus, \& cur.

fol.74.6

fol.74.a. fol. 75.6 fol.56.6 fol.57.a fol. 34.6 fol.93.6 fol.27.b. \& $28 . a$ Aestatis pestiferae figna duo ex $P$ lutarcbo, or num alterum uerum fit. $\therefore$ fol. 115 .a

Aefculap̈̈̈templum cur extraurbem.

«'vé

fol.28.a

Acidorum punicorum uires.

Aegrian clinici dicerentur ì Romanis.

fol.120.a Alexander magnus cur conuulfione, É tremore, torporenéfuerit ca ptus.

Alcmaeumprimum anatomen monstrafe . fol.36.6 Alexandri Aphrodifienfis error circa fomnum. Andromachuscurarcbiatros. fol.10 i.a fol.44.g fol.52:a ....efol.99.4 c Anato. 


\section{I $N \quad D \quad E \quad X$}

Anatomes cognitio apud neteres per manus accipiebatur, or quomodo. fol. $44 \cdot a$

Animal nullum ab bomine calculofum euadere.

Animalia quaedam ex nine, atyue igne orivi.
Animalia in cruribus bominum nata effe apud quos legatur, o eorum

fol.45.b. nomina: \&ucur.

Animalium partes quae, o guo tempore manducaricoeperunt. fol. 37.6

Antiquorum medendimodus.

Antonius Fracantianus eius praeceptor.

Animalia quae medulam 5.a sw'́n habent.

fol.56.3

Angina nums morbus fit acutus. fol. 40.6 ¿'opós quae nutriant. fol.12.a. fol.t2. Appetitus temperaturas, \& temperaturae morbos consequuntur. fol.39.a

Aqua coEta ex farina bordei quae.

fol.122.6 Aquae feratae quae. Aquae calidae ufus, \& quando. Aqua bordei priffana etiam dicebatur. fol.15.6 Aqua dura quae, \& eius natura. Aquae ex bordeo confectio.

Aquam calidam post ficus exbibcndau, quac rationes. - Aquas per plumbum decoetas effe perniciojas. Archegenes medicus clarißimus Hadriani Imperatoris. Arcbigenis remedia pro animi deliquio ex fame.

Aristo. locus.5.probl.primo emendatus. fol. $7, a$ Arifto ex aliorum relatione anatomen didiciffe. fol.10.b\& 11.a fol. $\times 20.6$ fol.67.6 fol.122.a fol. $17 . a$ fol. $43 . a$ fol.7.a fol.codem. fol.11.b Argentum viuum effe diftinctum à bydrargyro ó quomodo. fol.49.a Argentum uium toxici uenenum debellare apud A usonü filium. fol.5o.b.

Arcbiatros quid indicet.

fol. 98.4

Archiatri munus. fol.100.4 aproscrspuqia quae. Arcbelaus quis. Arbercocos Alexandrinos effe tuberes. fol.38.à Aristotelis didtumnon effe uerum bommes folos epilepfia tentari. fol.107.b.

Arist.contradictio de bordeo, er triticos 


\section{I $N$ D E X}

Aegyptiorum medendimodus.

\section{Ars quid faciat.}

fol. 56.8

fol. $50 . a$

Ars chymica Aristo.tempesiate ignorata. fol.199.a Áriftotelïignotum fuife fiftiles liquari, \& cur.

fol.108.6 Lrist.opinio de eminis decifione.

Arbores ó berbae, quibus non decidant folia.

fol.11 $7 \cdot a$ Archefilai diCtum, nemo lanam nondum carminatam ad fullonis offici namportat.

fol. $45 . a$ Arifto.poft Hippocratem annis, tantum fexagintafloruife. fol.46.b Smazonum" genus quod.

Apri conditurae apud ueteres ufitati.

fol.81.a Argentaria creta quae.

fol.62.a inrous Empedoclis. fol.95.a Afclepiades quo tempore ÿoruit, ó quae cius doctrina. fol. 1 t 5.6 Afiani femper regum imperüs fubiecti.

$\mathcal{A}$ fclepiadem pulfunm artem, ut fuperuacuam damnaffe. Afianos artibus, \& mente excellere.

fol.47.a fol.103.6 fol.47.a fol.103.b Afiani, \& Europaei,qui o quomodo polleät ingenio, \& fortitudine. fol.ro3.b

Afiae regio temperata.

fol.103.6 Ifperam arteriam à Polluce uocari stomacum, of literam ipfius effe mendofam.

Affata elixatis bumidiora.

$\mathscr{A} \int$ elus pifcis an cor in uer triculo babeat. fol.2.a Affuetudo quantum ualeat in affumendis medicamentis. Athlet ae cur non offendantur qualitate ciborum. fol.11 8.6 fol.64.6 fol.61.a

\section{B}

$\mathrm{B}$ Sinearum aquae plunianae, \& quae. Balneae ceretaneae quae, of earum 2 fus. fol.15.a Bdirise quae.

Bibendiufus in conuiü̈s.

Ribendi modus Regum Indorum. fol.16.a fol.24.a fol. 26.6 Biliofis aquam in bilem uerti, é cur. fol.eodem. Bilem, feu bilis receptaculum acutorum morborum caufam, quomodo in telligendum. Botargarum inuentor quis. fol.27.a
quomodo in
fol. $27 . a$
fol. 13.6 


\section{N D E X}

Bruta plurimam temporis partem corpore ualere, dum uterum gerunt, $\therefore$ mulieres verò magna ex parte aegras degere.

Butyri uaria genera, er ufus.

Bulbacea omnia lento quodam bumore praedita.

Bulbi ueverem excitant.

Butyrumper oleo in ungendis etiam corporibus. fol.3.3.a Butyrum in conuitio non parari.

Butyrinatura ex Plinio. fol.18.b. fol. 7.6 fol.eodè fol.18.b fol.19.a fol.r $9 . a$

\section{C}

Aere cinitasnobilissima. Camelarum carnes o lac, 2 fque quo conceperint, omnium fuariffima.

Camelinas carnes in ufu extitiffe.

fol: $37 \cdot a$

Canes foli an rabie tententur.

fol. 37.6

Cañitiei caufa recitata ex $\mathcal{A}$ risto. ab Atheneo non eft ipsius, \& cur. fol:24.b.

Capras non naribus, pt caetera animalia, sed auribus spiritum ducere. fol. $44 . a$

Capras nutriri cicuta apud Lucretium, \& caufam.

Capita Perfarum, ac Aegy'tionian cur in duritic differant. fol.25.b.

Cardant error circa manducationem.

fol.i 19.8 ка $\alpha_{\text {gvkn }}$ eduliumquid. fol.6r.6

Carnes quomodo effe debeant in diuerfis naturis, of aetatibus.. fol.40.b.

Carbones, \&o balitus syrorum Jpeluncarum cur interficiant. fol.84.6 Cafei condenfandialius modus apud ueteres, \& cur. fol.66.b Catonis praeceptum circa uina. fol.22.6

Catulorum lactent ium carnes laudabiles, \& contrariae uarys aegritu ... dinibus.

Caepas coctas dyfentericis exbibere. fol.37.a.

Cepbalos, or lupos omnium optimos effe ex Ambracia. fol.z I.a Cerufae ufiss.

Coina quae apud neteres. fol. 94.6 Cicuta quomodo malum fit irremediabile, or quomodo castigetur. fol. 76.9 . 


\section{$1 \mathrm{~N} \quad \mathrm{D}$ E X}

cicutafturnos nutriri, ¿́ canfam .

fol. 43.6

Cimolia creta quae, et eius species.

fol. 94.6 fol. 55.6 xuriy quid o apud $\mathcal{A}$ cgyptios.

Chondrum coctum.

fol.121.a

Cinis glandis fagineae cui profit .

fol. 41.6

Clementis Alex.diZtum de uoracibus.

fol.1 18.6

Clinici qui uocati.

fol.97.a

Clinice quae medicinae pars, of quando reperta.

fol.103.4

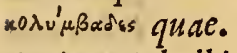

Cocleae es bulbi quod nam nutrimenti afferant.

fol.5. .

Cocleae \& bulbi pro stomachicis.

fol. 76.6

Coloris duo prima genera.

fol.eodem

Columellae locus inintelligibilis caftigatus.

fol.86.ab

fol.17.b.

Colymbades gratiores stomacbo, \& uentrem retinent.

fol.s.b

Eoagulum ex quo fiat.

Coitus à tergo iunare ad concipiendum.

fol.67a

fol.s.b

Coitum quandoque leuare morbos, è febres.

fol.20.6.

Comes medicus quis, \& eius munus.

fol.100.6

Comedere femel in die, quae vitia confequantur ex Arift. fol.60.b

Concreta à frigido ficco quomodo liquentur.

fol.i 08.6

Concreta a frigido ficcomoderato à quo foluantur:

fol.eodem

Concreta ab immoderato frigido infolubilia, or fi foluantur à quo. fol.eodem.

Concreta à calido ficco moderato à quio foluantur.

fol.eodeme

Concreta ab eodem immoderato infolubilia $\sqrt{2}$ foluuntur, à quo. fol.eodem.

Confuetudinem maxime refpiciendam effe.

fol.29.6

Coppetae quae.

fol. 13.6

Coronae quae, \& exquibus.

fol.83.6

Clinici cuiufdam infcriptio Romae marmore infculpta • .. fol.97.a

Coronae laneae.

fol.82.6

Cornelij Celsi locus emendatus de natura.

fol.46.e

cretae tria genera.

fol.94.a.

upoinus quae.

fol.6.6

Creta uilifsima quae.

fol.95.6

craterquis.

fol.26.a.

Cremor ptiffanae quis.

fol.122.a

Cruciatus afperrimi qui。

fol.83.b

Con- 


\section{I $N \quad D \quad E \quad X$}

Conuulfioni puerorum remedium.

fol. 33.6

cyphoides quid, or quibusprofit.

fol.72.a

cyphiquid.

fol.eodem

cypbi ufus, of quibus modis paretur.

fol.eodem

cyplicos odorem capitis inducit dolorem, quomodo intelligantur. fol. $73 . a$

cybeles facerdotes qui.

Cydnusfluuius.

fol.89.a

cydnifluuij uires.

Cunnelingi frequentißime diffamari.

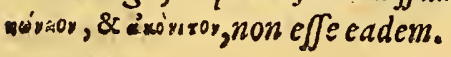

fol.ror.a fol.eodem fol. 113.6 fol. 75.6

D Arï luxatio oßis tali.\& curatio. Deliorum pestiferus morbus quis. Decoctas aquae ufus apud Romanos. Delus infila quo tempore paffa fit.

Democedis Crotonenfis curatio faCta Regi Dario.

Diei é noctris tempora, anni temporibus comparata.

fol.soz.a fol.g1.6 fol. 0.6 fol.92.6 Differentiae plures terrarum in Melo, \& in Samo. fol.1 $103 \cdot a$ fol.70.6 Dif crimen interria

Difeiplinas ordine quodam effe apprehendendas. fol.96.a fol.89.6

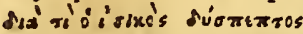
fol. 44.6

Dicercm pedem, iocus Gal.interpraetatus.

fol.1 $3 \cdot a$ fol.23.a Dormire quomodo poßint, qui à destillationibus infestantur. fol. 5 r.b

Dolore capitis nullum interü]feneque feipfum accidiffe.

Dolori capiti remediumi.

Drupae quae, \& natantes oliuae.

fol. 83.6 fol.eodem fol.5.6

$\boldsymbol{E}$

G Brienti quae conferant.

- Elefbantiafi correptos multo Semine non abundare.

fol.ro5.b Elepbantiafis A rabum lepra, Latmorum Satyriafis, \& quando incepit. fol.4.6

Empiricitaltum ante Hippo. \& Heracliti tempiora.

fol.92.6 $E^{n} \lambda^{\prime}$ - 


\section{I $N \quad D \quad E \quad X$}

Eo $\lambda \mu$ sves lumbricorum genus. $\quad$ fol.85.a Elephantiafi oppreßi ueneris appetitu stimulentur. fol.94.a Ellychnium Darfenfe quid.

Empymatis reniedium ex oraculo. fol. 90.6 E'rsxols qua.

fol.23.6

Epilepticos uino arcendos.

fol.1 $14 . a$

Etefios aduerfus uebementer flantes remedium Empedoclis.fol. $x$ I 5.6 Euirati qui, \& cur, \& morbi illius uera origo. .

Eunuchifrigidi, O bumidi.

Europoeiliberi, ơ nulli fubditi.

Eunuchi cur Elephantiafi non laborent.

E'vojopívey quid.

E'vфnia figuraquae.

Exta non prandentium celerius fenefcere.écur.

Extenuatorum corporum duo genera.

fol.79.6 fol.93.b fol.t03.6 fol.93.6 fol. 32.6 fol.27.6 fol.116.6 fol.32.a

\section{F}

F Abac an fint inter legumina.

Fubae $\mathcal{A}$ egyptiae quae, ¿o corum quantitas.

fol.39.e

Fabae Aegyptiae pordus.

Fagum uebementius robore adftringere.

Far an res fitfactitia.

fol.3 9.6

Far quid, \& eius confectio.

fol. 39.6

fol.41.6

Fabarum putamina quardo radicibus, aut germinibus nitam tollunt: fol.62.6 fol. $304 \cdot a$

Farris nomen quid.

fol.63.6

Foeminam multo minus coitu delectari, quàm uirum, pluri autem tempore.

Fellisabsentia animalia diuturne niuere.

fol. 117.6

Felea amarißima dulcia à Graecis nominarifolere,

fol.27.b

Ficus aceto macerati, o cur.

Ficus uirides fitim fedare.

Ficus post quid exbibendum.

fol.27.b

fol.17.6

fol.17.6

Ficus post an calida, an frigida aquafit bibenda.

fol.eodem Fortunam apud unlgares tantum valere", ut naturam, fed non apud prudentes artifices.

Fontes plurimi Roma.

fol.46.a fol. $43 \cdot b$. 


\section{I $\mathrm{N}$ D $\quad \mathrm{E} \quad \mathrm{X}$}

Foenicium quid.

Frigidam bibipoft ficus, quae rationes.

Fridericum Oenobarbum Imperatorem ob cydnum flunium interü $\int_{5}$. fol.101.a.

Fanorinus quod de ichore erratit.

Foetus ne animetur post coitum, remedia ex $\mathcal{L}$ rifto.

fol. I I g.a.

Funiculi luccrnarum ex quibus fiebant.

Furor quis inter morbos ab Hippo. fol.109.b. fol.68.6 fol.89.6

\section{G}

Gienilocus lib.6.de lo. affe Ctis dilucidatus. Galeni fententia de urinae generatione.

Galenus de animae fubstantia, \& operationibus.

Galenum natinum argentum uiuum non ignorafje.

Galenus contra Diof.de Butyro .

fol:6.ia

fol.93.a fol.103.a.b fol. 49.6 fol. ig.a Galeni error circa iurdorum, \& paferculorum naturam. fol.73.6 Galeniliber de demonstratione tractare quid potniffet contra communem fententiam.

fo. $104 . a$

Gangraena quae.

fol.92.a

Gallinae utefcentes putaminib. fabarum num sterilescant. fo.s 04.6 Geniturae asfimilatio à quo.

Goßipium quid Latinorum. fol. 117.6 fol.90.6 Granum Gnidium quid, \& eius ufus. fol.85.a Graecorim didum in medicos loquaces. fol.87.6 Graecos ueteres non cognouife factitiun argentum uiunm. Graecorum mos in comedendo. fo. 49.6 fol.119.a Gregorï Girardi error de Tacis templo. fol.16.a Graecimedī inter $\mathcal{A} f$ ianos, \& Europocos non minus artibus, \& intellectu, quàm armis, \& animorum uiribus.

Grues non comedi, ¿f cur. fol.103.b Gula pro ftomacho.

Gulae Jummum, fances, extremum stomachus. Gutta nocatum quid. fol. 37.6 fol.1.b fol.2:a fol.5 8.6. $H$

H Alicam cum uino multum nutrire. fol. .7 .6 Halican folam tarde nutrire. fol.eodem Helobo 


\section{I $\mathrm{N} \quad \mathrm{D} \quad \mathrm{E} \quad \mathrm{X}$}

Helebori biftoria baufti ab Eudemocbio,qui licet in potione per $22 . u i$ ces nna die fuerit alfumptus, tamen ipfum purgare nó potuit. $f .64 .6$ Herodotus Hippocraticoxteneus. fol.42.a Halicae forbitio. fol. I 2 I.6 Hemitritaeum nomen \& cur. fol. $28 . a$ Hcfiodum, む Homerum quadringentis annis praeceßiffe Hippocratem. fol.35.a

Heraclyti quaefitum, dum aegrotaret, aduerfus medicos.

Heraclytus quo morbo laboraret.

fol.92.6 Hippo.locus lib. de locis in bomine circa inflammationem oculorum castigatus.

Hippo.annum in feptem partes diuififfe.

Hippo.cur Doricus, lingua Ionica fcripfit.

Hippo.difcendi gratia multum peragrafle.

fol.eodem

Hipp.excufatio à crimine contra iufiurandum in abortu famulae gra uidaie.

fol.41.a fol. 35.6 Heropbilus in tractatione pulfium Arcbigeni praelatus.

Hippicis berbae natura.

Hippaces quid apud Scytbas, \& quomodo conficiebantur, fol.66.a Hipanos lotio proprio mane ad abstergendum nocturnas fordes uti. fol.93.au

Hifpanis multitudinem mufcarum peculiarem non effe.

Hieronymus Meus.

fol. 109.6

Hoedus melicus quis.

Hoedorum caro caeteris iucundior.

fol. I 15.6 fol.1 I1.b Hoedus quis.

Hordeo ex Acbilleio primo factos effe panes: fol.30.a fol. 30.6 fol.30.a Hominem dे rabido cane commor fum neque rabie corripi, neque interive, quomodo intelligendum, \& num litera Aristotel.fit corrupta. fol.2.b

Hydrophobiam, EN Elephantiafim effemorbos nouos.

Hydrophobiae nullum effe remedium ex.Ouidio, \& alÿs, licet postea multa inuenta jint.

Hydrargyrumquid.

Tcur anferis in menfis celebre.

Ientaculo, \& commefJatione qui uterentur.

fol.81.6 fol.1 $20 . a$ d ispal 


\section{I $N$ D E E X}

Sisp'yóros quis.

Ichores qui, ex Homero Hippo.Platone, \& alïs.

foloios.a

Ichoris duplex genus ex Ari.

fol.uni.b

IG orum dignotio.

fol.eoderiz.

Ignem citius ab aceto, ơ nino extingui, quam ab aqua.

fol.riz.b.

Infibulatio qua o cur, oj quibus.

fol. 84.6

Infames quando, cum ante coenan comederint. fol.22.6

Infaniae genus umin eorum, 'qui membra fibi ipfis amputant; \& cur, fol.88.6.

Imperatores non unum, fed plures fimul Archiatros babuifje. fol.99.6

Ioannes Vincentius Pinellius.

Ificia que, \& quot, o quomodo conficiebantui.

fol.95.6

irrosov quid.

Itria quae fecundum Gal.

fol. 3.6

Iudaei cur carnibus fuillis abftineant.

Iunenum of senum opera que.

fol. 13.6

isices ab Hippo. dici Harices.

fol.eodem

Ientaculum, \& prandium idem.

fol.8 $\mathrm{r}, \mathrm{b}$

Icbores in Sanguinem Secundum Medicos non uerti, of quomodo idem Sentiat Arift.

fol.II $3 \cdot a$

$\mathbb{K}$

xpcrisaiv quid.

fol. 2.6

$L$

Iadis equini apparatus apud Scythas.

fol.66.a

Lavria quid indicet.

fol. 5 ! .6

Lazkśa u uox quid indicet.

Lactis coagulatio d̀ qua nàm causa fiat.

Labrufca que.

fol. $20, a$

Languentes apud ueteres quandoque in templis detentoseffe. fol.67.a foi.r 6.6

Lanae, of pelles lupinos dentesi expertae an pediculos gignant. fol. 30.6

Lapis in intesiints, ac ueficis an gignantur.

fol.59.t

Lapis carystius quis, et eius linea adnata, ex quibus mantilia nentur, ac iexuntur.

Lapidis neficae gencratio.

Laurifolia cur post coenam adbibebantur.

fol.68.a fol.45.6 fol.ı5.a 


\section{N D E X}

Ienones qui dicebantur.

Leguminum, \& frumentorum difcrimen.

fol. 32.6 fol.39.a fol.68.b

Lapis caryftius quo loco gignatur.

Lemnifciqui. fol.83.6

Iepori cur primas dent.

Leuce, Seu, uitigo, qua Delï affligebantur, an talis foret. fol. 39.6

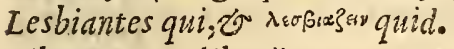

Liba quac, e libarü.

Libellus de piritu falso Aristoteli adfcriptus.

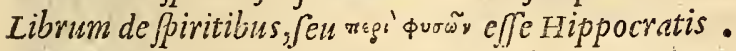

Librum de natura pueri partem effe libri de genitura. fol.92.a fol. I 3.6 fol.r. $a$ fol. 46.6 fol. 77.6 fol.1: 7.6 Linum Hinum quid.

Loca quae corporibus pariantur affectiones.

fol.68.a Locusiarum multitudo, \& qui eas come dant, \& quid efficiant. fol. 59.6 o.60.a

Locustarum natura.

Locus peculiaris in quaque domo pro infirmis.

Lucationis auxilia, \& num ea fit difficilis curatu.

fol:codem

Lucius.P.Vitellÿ filius perinfamis', \& cur.

Lucerna inesting uibilis an ostenderet anni inaequalitatem. fol.36.a

Lucretium ab Hippo.accepiffe de pefte.

Iumborum apparatus.

fol.16.6

Iupi morfus quid efficiat. fol. 78.6 fol.6. fol. 30.6

1. Acrobü error de nirtutibus naturalibus.

Macrobio cur gratiae fint babendae.

Matutino tempore quac proneniant.

fol. 76.6 fol. $77 \cdot a$ fol. $70 . b$

Manducationes uices apud ueteres tempore Hippo.non fuiffe certas. folot 18.6

Mangones qui.

fo.3 2.6

Marigones, \& Gymnaftae quid faciebant in extenuandis corporibus. fol.32.6

Marinae aquae ufus.

Matutinum tem pus bumidum o calidum.

Martialis uixit eodem tempore, ut Plutarchus.

mare, or omnis aqua fuapte natura alba uidetur.

fol.67.6 fcl.70.b fol.11.a appas ex quofactitatas. fol.86.6 fol.68.a

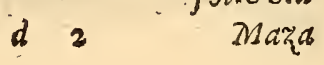




\section{I $N \quad D \quad E \quad X$}

Mazaquae.

Medicamentis uchementioribns cur uterentur ueteres.

fol.1 20.6

Medullam intelligere $P$ latonem cerebrum.

fol.65.a.

Medici cur pifcibus alerent aegros.

Membrum depafcens quando, -j cur amputandum.

fol.1 $2 . b$.

Medicinamab 1 egyptïs ortum habuifJe.

M.Antonius Muretus.

Medicus cum Deo comparatur.

Manus à natura bomini cur imbutae.

Melcbior Guillandinus.

fol.2 $9 . b$.

fol. 85.6

fol. 55.6

fol.1 8.6

fol.93.a

fol.94.a.

Mellis vires, atque natura.

Medicorum ftipendia apud principes.

fol. 16.6

fol.64.a

Medici Romae diuites enafiffe:

Melilotum cur Cratinus semper custodem nocarit.

fol.101.a

Melle ine briari, \& quomodo.

fol.97.a

fol.82.b

Mellis quando copiofus prouentus, \& quo loco colligatur. fol.63.6 64.a

Mellis ufus.

Mare atrum aquilonibus flantibus fieri, or cur.

fo.eodem

Menfae frigidae quae.

Mcl iudeos in Sacrificÿs non adbibere.

Medicamentum pro tumefaciendo corpore.

fo.86.a

fol. I i 1.a

fol. 54.6

Medici apud Romanos, \& Graecos partialibus membris medentes. fol.41.b.

Menecratis epitapbium Romae.

Menta cur tempore bellinon fereretur.

Mentae uires.

Menecrates medicus quis à Gal.nominatus.

Megaleum, \& Mendifium vinguenta quae.

Medicinam cur mutam artem uocet Virglius.

Merenda quae, or ufus.

Merum nonmullos post ficus potafje, do cur.

Meridies aeftati compariata.

Mollities inter morbos quae.

fo.96.b

fol.100.b

fol.eodem

fol. 96.6

fol. 58.6

fol. $87 . a$

fol. $120 . a$

fol. $17 . a$ fol. 70.6

fol.89.a

Morbi a fpiritu cur non cunctis animalibus, fed alicui ipforum generi contingant.

Mori albae principium, \& ortus.

Mororum fractus an podagram arceant.

fol. $78 . a$

fol.39.a

fol.28.6 


\section{N D E X}

Mora Stomachos aesiuantes.reficere.

Mortuos à putredine Salc prae Seruare antiquos.

fol.28.6

Morbos nouos diucrfis zaufis nafsi poffe.

Mulfum maximo in bonore fuiffe, o cur.

Mullum quomodo fiat optimum.

fol. $73 . a$ fol.3.b. fol. $54 . a$

Mulieres, \& wiri quigenerent.

Mulieres Romanas uinum non bibiffe, fed pafum.

fol.54.6.

Mufcae quo loco capiantur, \& uendantur.

Mufcae araneis fimiliores.

Muretz epistola de loco Hippo.libro de alimento.

fol.8.

f0.20..

fo.t 15.6

fol.eodem

Muria dura quae, \& conficiendi modus.

fol.109.b

Mures ex quibus gignantur.

Myagrum effe Deum mufcarum apud Elaeos, \& cur.

fol.67.6

Myrrbam aprid $\mathscr{A}$ egyptios Bal uocari.

fol.1 15.6

fol. 15.6

fol.59.a

\section{$\mathfrak{N}$}

Nati octauo menfe non fuperuiuunt.

Natura nibil minus arte poteft.

fol.sog.6

fol.46.a

Neme ius de bominis natura, o multa ex Gal. commentarÿs de deimonstrationibus excerp?it.

Nemefius quando floruit.

Nerui, s calor natiuns quando ualde offenduntur.

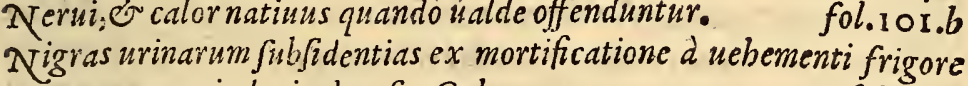
nequaquan induci aduerfus Gal.

Nigricoloris dinifio.

fol.86.a fol. $45 . a$ Nitrum \& fal non folo bumido frigido, ut uolu it S rifl:sed \& bumido calido diffolui.

fol. 108.6

Nociurnus aer eft commixto, ac temiperamentum muliorum iuminumb. fol. 72.6

\section{0}

Ctimestris partus potius abortus, quàm vera generatio. fo.log.a. Oisesa'yos quis.

Oculorum fluxionibus remedium.

fol.t.a

olerm glescinum, \& iixiuium.

oliuxe nigrae ftomacbo minus aptae, or caput grauant.

fol.83.b.\& $84 . a$ fol. 19.6 fol. 5.6

olius 


\section{N D E X}

ol in ae premadiae quae apud 2 icandrum.

oliua paufia quae.

fol. 5.6

olinae aibae quae.

Olinae nirides quae.

fol.eodem

fol.s.a

fol.eodem

oliuae nigrae quae.

olinae albae ftomacho utiliores, of cur.

oliuae albae an condercritur é quiomodo.

fol.eodem

fol.eodem

Oleumi tnfarum corpori feruenti applicatum.

fol.codem

olcum occludit meatus extcrnos.

fol. $27 . \bar{a}$

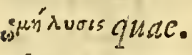

Oliuarim conditura apud Átbenienfes, \& alios. fol.i 8:b. fol.62.a Opium Qivomodo exbibendum.

fol.5.6

opium in affe Ctibus oculor um, caftigatum trädi.

fol.4i.b

oposaquiae.

fol.eodem

Ordinem addifcendarum difciplinarum in omnibus seruandum.fo.45.a

origani potus an oculis obfit.

"orspor quid.

fol.84.a

Ostrea in principio cenae parari.

fol.1 04.6

Oues, of naxime capras cpileptico morbo tentari, o cur.

Oxygala; oraplorogalaquid.

fol.tII.a fo. 107.6 fol.19.2.

P. Almae maris, atque foeminae amicitia.

Talmae faeminae fructus quando retinentur.

fol.6.a

$\pi \alpha g^{\prime} \mu \pi \tau \omega \sigma$ os que fecundum Evafif Rratim.

fo.eodem

Panis quis optimus, s qui ab eo deficit. fol.11 4.6

Panis clibanitis à furnaceo distinctus. fol.I 4.a.b.

Palmule num uaporibus fuperiora tentent.

Panes ex bordeo acbilleio qui, e corum qualitas. fol. I 20.6

Panis uaria coctura.

fol.eodem

Pediculi ex quibus gignantur.

fol. 14.6

Pediculos in morituris capita corum deferere, atque in puluinaribus inueniri.

fol.36.6

Telles an fint ex animalibus ferro ingulatis, uel fponte mortuis, ualde referre.

Pestis quae, s origo ex Hippo. fol.30.6

Phoenicum libido. fol. $77 . b$

Thbrenitidis diffinitio ex Afclepiade. fo.1 13.6 fo. I. 1.4.6. 


\section{N D E X}

Phoeniciffantes qui.

affandas cur o leo inungere foleanto

Tifcibus cur nunc aegri non ue cantur.

fol. 18.6

Pifcestintinnabuli fonitu uendi folitum.

fo.29.b

Plenü error circa Piperis ufum.

fol.29.b

Petri Apponenfis error de coitu.

fal. $15 . a$

Peftis ä Thucidide defcripta an fit ea Hippo.

fo. $20 . b$

Plumbinocumenta.

fo. 86.6

Plato primus ó folus an dixerit potum per afperam arteriam ad pulmo fo. 42.6 nes defcendere. fo.76.6 Pleuriticos pblobotomatos peius fe babuife Romae, \&j Atbenis. fol.28.a.

Platonem mirari siculos, \& Italos bis in die comedere.

fol. I rg.a

Plutarchi error de mulfo.

fol. 54.6

Polia an canitiem inducant.

fol. 24.6

Podagricus morbus Artbenis ortus.

fol. 28.6

Pofca quae; oreius ufus.

fol. $97 . b$

Polenta quae, \& Romanis olim ignota; Graecis celebrata. fo. $20 . \bar{b}$ Porcae nuper foctae apparatus pro cibario.

Potum calidum effe contra naturam.

fol. $37 . b$

Ptiffanae fub nomine quace.

Ptiffana fimpliciter quae.

fol.1 0.6

Ttiffanae confectio ex Galeno, G A A

fo. $121 . \pi$

Ptiffanae uaria conditura.

fol.eodem.b

Ptifana quae, ó ex quibus.

fo. $221 . a .6$

fol.122.a

Propomata qriae, \& ufus corum.

fo.1 20.6

Pulfus nomen ante Hippo.ignotum ex Gal.cum idem contrarium Jentiat.

fo.46. a

Pulmonem iecore faciliorem effe coctu, minus nutrire; tofuri.

fol.39.6

P.ythagoreos mulieribus fabarum efum uetafe, \& cur, of namid uerumfit.

fol. $104 . b$

\section{$R$}

$\mathrm{R}$ Abieimorbus ignotus tempestate Arifotelis

Rabiem antiquitus extitife morbum sedignotum.

$f \circ ! \cdot 3 \cdot d$

Rabimo/es cur libros de lo.affectis Jcientiarum libros nominet. fol.o. 


\section{I $\mathrm{N} \quad \mathrm{D} \quad \mathrm{E} \mathrm{X}$}

Ramices quae, o apud Plautum, ubilocus eius explanatur. fol. 23.6 Ranarumi carnes antiquitus inemine comeftas effe. fol.37.b Ranae uentrem quid int clligendum. fol.37.6 Remedia pro conferuanda uoce comaedorum, ac tragaedorum. fol.22.6 Remediumaduerfus mala capitis ex pituita in pueris. fol. 33.6 Recentatum quid.

Recentare quid. fol.8.6 Remedium contra aconitum. fol.9.a $R e \int p i r a t i o n e s$ odoriferas unguentorum, florum pratorum non minus ad fanitater, quadm ad uoluptatem conferre.

Rbododendon quid.

Romanorim ufus in comestione.

Romae qui medicam artem exercerent.

Rubificantia, er ueficas inducentia ex quibus.

fol.59.a fol.116.a folisig.b fo.98.6 fol. 1 ×5.a

\section{S}

SAbini Ronani uxoris uteritumor ab ea abfonditus, \& quomodo fol. I $4 . a$

Sacerignis quis.

Sangribine coagulato dias effe fubftantias tenues.

fo.1 $08 . a$

sanguinem quomodo aliqui fident.

salubritas aquae babetur ex ipfius ductibus, \& cur. fol.42.b. Sanitas in facriancïjs, lustrationibus, \& uiltu non inferior sanctitate. fol.56.a

Sacerdotibus cur caro caprina uetabatur.

sericus color quis.

Semen uiri à quo burnido excernatur ex Hippo.fententia. folat $17 . a$ series quot uicibus cibandi.

- arúp:aris, \& oaruglas "quace.

serici prouentus quando inceperit.

sericum rarum apud antiquos.

seruorum praecia imminui ob Alopeciae turpitudinem.

semen quid.

fol.107.b

Sericum rerißimum fuiffe apud ueteres.

fol.119.6 fol.94.a fol.eodem fol.29.a fol. $33 . a$ fol.93.6 Sextans, Deunces, e Triens menfurae, \& quibis utcbantur. fol. 25.6 scytbartm uates qui.

scythartm morbi qui. ol.8 $1 . . a$ fol. $71.80 .8 \mathrm{r}$ sidac 


\section{N D E X}

sidae quae, \& quando funm perficiunt fructum. $\quad f_{0} \cdot 36$.

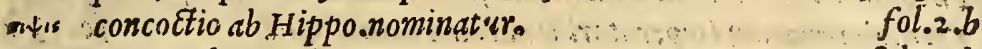
Sinapis ad Embammata. fol. 7.6 Scytharum remedium ad crurium, of coxarum imbecillitatem. fol. $34 \cdot a$

scytharum uittus.

Scythae feruos omnes cur orbent. :

fol.67.a

Solis lumen unum, \& per Aetherem cerni.

fol.66.6

socratis mors.

Sordes in auribus amarae, morituris dulces fiunt.

fo. 72.6

fol.76.a

sorbilis fopor quis.

Sordes mantilium quomodo eluebantur.

fol.84a

fo. 3.4

stamnea uafa cur fugienda.

fol.68.2

fol. $43 . a$

Stomaci uocabulum pro uentriculo.

fol. $1, b$

Stomacus rarò os uentriculi,plerumque uel totum uentriculum, uel gu-

lam proprie fignificat.

rimaxos quis.

Sterilitatis caufae quo ad genituram.

Stomacus pro ore uentriculi.

fol.2. at

spafmus cynicus quis.

suilla caro an fit commendanda.

Suis natura quae.

Sumatae quae, \&o unde.

succus ptiffanae quis.

sumeri quid, o inter delicatiores cibos reponi.

synacbicis num uenae fub lingua fint pertundendae.

fol.i. $b$

syncopis remedium Galeni.

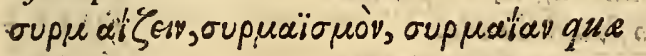

fo.107.a fol.1.b fol. 97.6 fol.8 1.b fol.82.a fol. 37.6 fol.121. fol. $38 . a$ fol.1 2.6 fo. 7.6 fol. 34.6

7 Abcllae cumi friptionibus curationum. fol.16.

Tabcllas cum infcriptionibus curationum in $\mathcal{L}$ fculap y. aedibus pendi diffe.

Tarfusciuitas quae. fol. 10.6 Theophrasti fententia de opora anni tempore, o eius temperie. $f .35 .6$ Theophrasti alter locuste fabis castigatus. $f o .36 .6$ e Theo- 


\section{N D E X}

Theophrasti, \& Galeni contrariae fententiae de iẗu fcorpionü. fo. 3 a Tetrapharmacum Imperatori Hadriano carim quid.

Theophrafti locus de fida castigatus.

Telas, \& uela ex quibus maiores texerunt. fo.13:6 Temporum uenas ureve remedium aduerfus capitis dolorem, \&o oculorumfluxiones.

Terras alias arte fieri, \& alias /ponte nafci.

Theriacac uariae compofitioses, of plures.

Theriacam bibi, o quomodo. fo.36.a Therach fol.53.6 Timocbares cur à deftillatione fuerit percoitum liberatus. fo.51.b Tineas, \& lumbre quae nationes babeant, \& quae non. fol.85.a Tircfias iudex Iouis \& Innonis de concubitu.

Tituli declaratio libri Gal.de locis affectis. so'sra quae, os an fit noftra torta.

Teneritudinem carnium effe ueluti putredinem. fo.117.6 fd.? g.b. fol. 38.3 Tragicas, o comicas fabulas, al ta uoce o cantiapud ueteres recitafol. $40 . a$ ri.

Tracta quae.

f0.22.6

Tuberum frultus dulces, \& quo tempore ferantur; \& fub quibus inferantur. $\quad$ fol.106.b

Tuberes qui ueterum of ex quo loco primumaduectio fol.505.a

Tuberum duo genera. fol.806.b

Turdorum impinguandi modus apud ueteres.

f0.73.6

$V$ Aticanus fit pestilentior, of infalubriora alìs Romaelocis.fol. $28 . a$ Yeneris.templum Ŕomae ubi erat.

$V$ enenis edendis an bomines affucficri poßint. fol. $7 . \mathrm{a}$ $V$ enus coitus quando fit ad bibendus. fol.65.6

$V$ ermes or animalia ex niue, \& igne oriantur. fol.5:1.a $\gamma$ eficae calculos in fenibus ob frigiditatem nö gigni aduerfus quofdä fol.45.b

Veteres cur coron is utebantur. fol.83.a Veterum christianae religionis orbatorum facinora immanißima fub religionis titulo

Vina cur condirent antiqui.

Yinumpicans, ¿̇ recens quid. fol.89.0

Vinsm edentulum quid.

Vinis quonodo inducebant antiqui uetustatews.

fol. $47 . b$ fol. 47.6 fol. 88.6 fol.eodem Vins 


\section{N D E X}

Vina Maßilienfium quae.

Vinum Marficum quid.

Vina Tetbalaffomena quae.

fol. 48.6

fol.eodern

fol.eodem

$V$ ina noua à Graecis bibita, ơ eorum noxas.

fo.t8.a

Vinalia festa quo tempore.

Vina poft annum Romanos bibije.

Vina apiana que.

Vinum cur ajperfuns euitet carbonum sroxaso

Vina cur facculo percolant.

Vinum falernum non faccarum.

Vinum falernum indomitum cur.

Vinum oligophorum.

Vinimixtio, E cur.

$\checkmark$ inum in anxietate, of citatione, \& borore quid.

ina \& aquam quomodo refrigerabant antiqui.

Pinum dulce an inebriet.

inum aquae quis primum mifcuit.

Virsum protropum, seu prodromum.

Vini genus adeo exiccatum, ut gladïs abrafumb bibatup.

fol.17.6.6. 18.6

fol.17.6

fol.i 105.6

fol.84.6

fol. 55.0

fol.eoden

fol:2 I.

fol.eodem.

fol.eodem

fol.22.eb

fol.g.a.b.E 10.a.b

fol. 19.6

fol.20.6

fol.19.6

$V$ ina prana ad excitandum uomitum, \& cur.

Winum bebracos magna in existimatione tenere.

Vinum acinaticum quid,

fol.67.6

fol.9.6

fol. 54.6

Vinum maficcum, fiue marficum quid.

$V$ inorum praeparandi modus, o conferuatio.

Vitis fyluestris quae.

folor d ove

Viticem apud medicos in ufiu ad urendum.

Vnguenta tam potibus, quam cibis seteres admifcuiffe.

fol. 55 漏

fol.tir 0.6

fal.52.6.85 53.6

Vunguentorum mixtiones ab Acgyptïs excogitatas.

Viguentorum quot genera apud Hippo o alios.

fol. $34 . a$

fol. 57.4 fol. 57.8 fol.eodem Vrinae materiam effe fubstantiam potulentam. fol.93.4 $\checkmark$ rinae generatio fecundum Heraclitum, quem iufequitur $\mathcal{A} f$ clepiades fol. $93 . a$

$V$ uarum feruandarum modus.

$\checkmark$ uas paleales bonas pro aegris.

fol. 110.6

$V$ ua taminia que.

fol. 110.6

$\checkmark$ ude forcus ge nerefac afpellatae quae

fol.52.a

fol. 38.6

Yuas fabriles comme edari in cacliacis, alijs uettris a defluxionibus, \& cur.

fol.110.6 


\section{IXN D.E X}

Viatheriacae que

Tua palëalis, \& una fabrilis quae

Vua refipina

V'uam absque acinis fieri, ơ quomodo

Vulpium carnes. quando palato gratißimae. fint

$$
x
$$

fol 5 ; 3.6

fol.til 0.6 fol.eoder fol.11.7. fol. 40.4

Xenocritem aegris dedife stercora uoranda, \& a Galeno damnatum. C. fol.tiz.b sylinuin linum quid. "zoroaftri uictus quis. fol.givi.
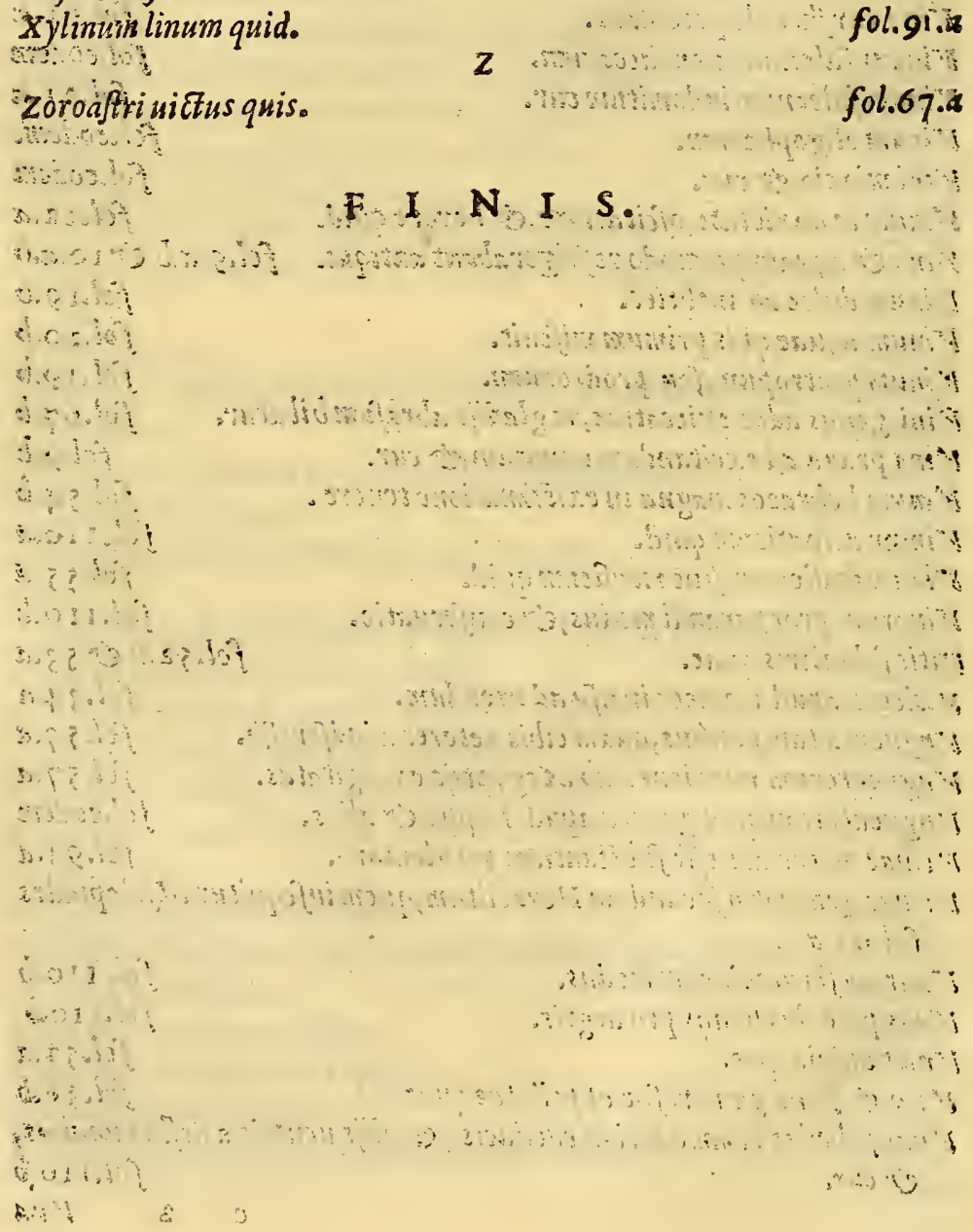


\section{Errata fic corrigenda à benigno lectore.}

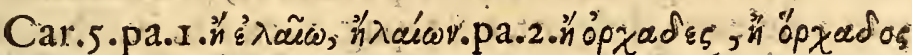
c.6.pag.2. Gaiuana, Gaitana.c.7.pag.2.cui fe, cui fi.c.8. pag.r.cap.8.cap.6.c.9.pag.r.cibus, cibos. c. 10.pag.r. feneftris uentos,feneftris ad uentos.pag.2. मे, Hัv. pag.2. quam ut, quamve.pag.2 folevt, foleve.pag.2.ullum, ul-

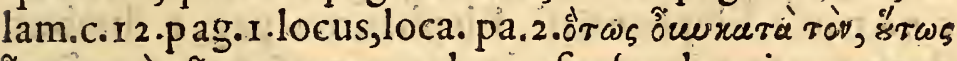

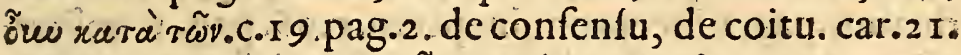

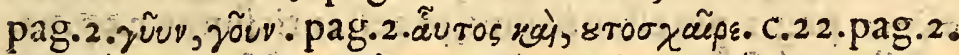

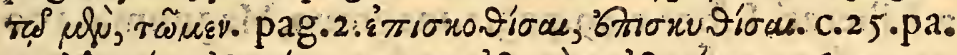

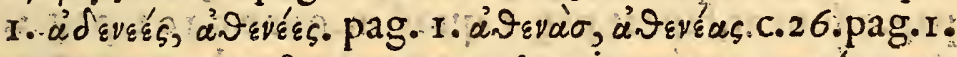
quam, vt, quam \&.c.30.pag. I.in 3.in 4. pa. I.xea ád erøe,

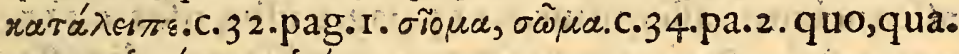

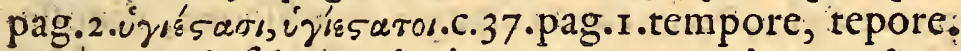
c.38.pag.1.infcientes, incientes.c.41.pa.1. 0 $\vartheta \alpha \lambda \mu \omega ั \nu \tau \alpha$

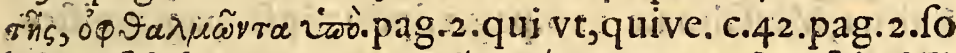
lubre, falubre.c.46.pag.2:apowa.c.47.pa r.Laefcio, Ni cefio.c.50.pag. I.águpov, áprupov.pag. I refiftu ta, reftitu-

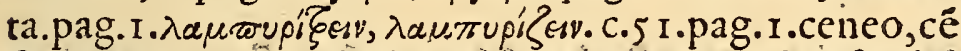
feo.pag.2:externa, hefterna.c.52.pag.I.Lambrufca, labrufca.c.5 3.pag. I affeuerit, afleuerat.pag.2.Palladio in febr.vario, Palladium in Februario.c.5 4.pag. I.Plutarchus, cur Plutarchus.pag.2.multum, mulfum. c.56. pag. I.condenfantur, condéfatur.c.58.pag. I. \& mendo fium, \& Médefium.pag. I. Mendofij, Mendefij.c.6o.pa.

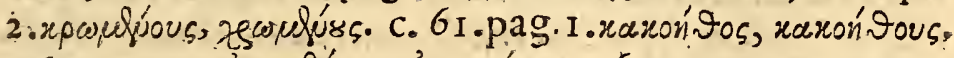

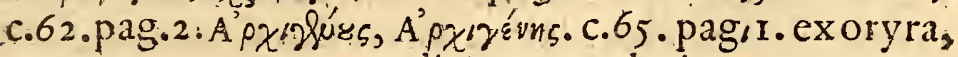
ex oryza.c.64.pag.2.audiciores, audaciores. pag. 2.re-

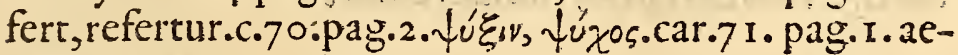
quo, aeque.pag.2.Latini, Latine.c.73.pag.2. ueram, cu ram.pag.2.Flauus, Flaccus. c. 75.pag. 2. Antigonum Agatarcum, Aneigonum non Agararchum.c. 26. pr.x. uenificium, uenificum.pag. 2. clamabant, clamabuac, 
c.79.pag.1.amaronibus, Amazonibus.c.81. pag.2. fide dignis, fide dignus.c.82.pa.r. posfideat, posfideät.c.83. pag.2.dcleant, doleant. c.85. pag. r. ex lib. ix. lib.c. 86. pag.2.то'тй, тоे ни..c.87.pag.r.oppofitiffime, appofitiff-

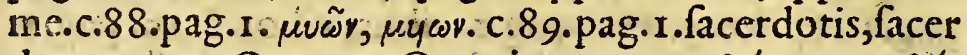

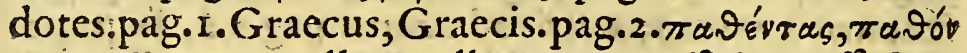
tas.c.93.pag.I.nullus, nullum.pag.2.affectus, affectos. c.94.pag. I.Elephantiafi, Elephantici. pag. I. duobus; duabus.pag.2.inceptum, ineptum. c.96.pag. I . roũrov; $\tau \tilde{8} \tau \omega$. pag. I.praeftantisfimi, praeftantisfimus.c.97:pa. 2.Liberati, Liber.c.99.pag. I.magnum,Magnum.c. I00 pag. I. foueat, faueat.pag.r.quod in, quae.c.102.pag.2. $\delta \varepsilon \mu \varepsilon p o ́ v t \omega r, \gamma_{\varepsilon} \operatorname{có}_{\tau} \tau \omega v$.c. I. I I.pag.I. depas, dapes, pag.2. affequebatur, affequitur.c. I I 3.pag.2.ufus, ufos. c. I 15 . pag. 2. ڤp'sns, vpiórs.car.I I 6.pag.2.demiflerint, dimifferint pag.2.quia, qui a.c. I 17.pag.2.Pli.plant.pa.2.Mef. Salina,Meffalina.c.1 20.pag.i.ipfius, ipfis.pag.r.piftos, piltor.pag.I.quae, q;. pag. I.ut,atq, pag.2.communis, cauffis:

\section{Errata in Epiftola Alexandri fic corrigito.}

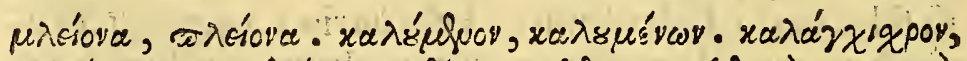

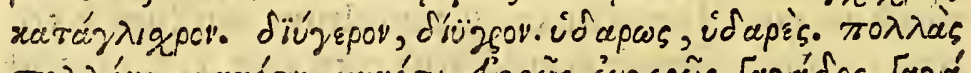

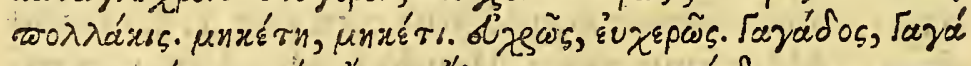

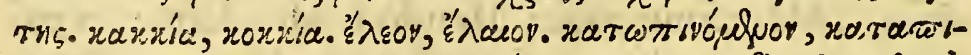

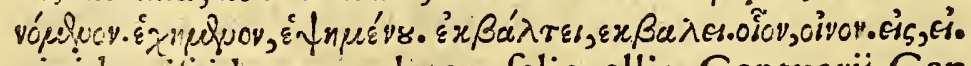
uivida, uifcida.tatos, latos. falia, allia. Centuarij, Cen taurij. indifferentes, indifferenter. 
-

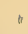

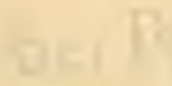

$+2$ 



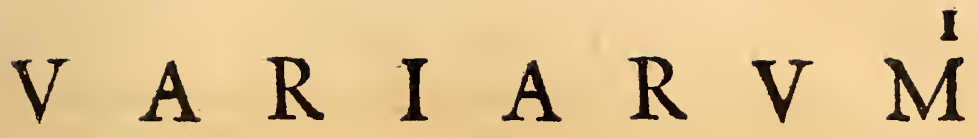 \\ I $\mathrm{N}$}

\section{MEDICINAE AVCTORIBVS}

\section{ET ALIIS LECTIONVM Liber Primus.}

De OeJophago, \& fomacho locus Galeni emendatus, \& $A$ ristoteli conciliatus, Lucretius defenfus, Pollucis locus correEtus, \& alter Hippocratis indicatus de concoctione Cap. I.

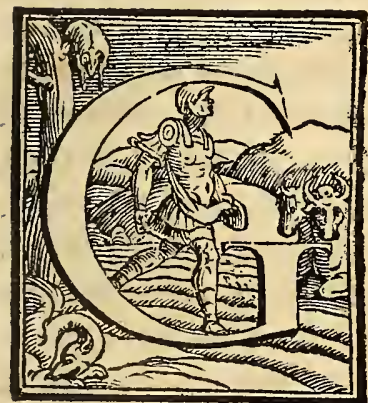

A LEN V S quinto de locis affe ctis cap.5. fcriptum reliquit ueteresinterftitium illud quod inter fauces, \& uentriculum collocatur oiropáyov nominaffe. pofteriores uero Ariftotelè idem sóna xov dixilfe, quamquam \& Homerum in 17 . Iliados fic locutum inuenio, ubi fcribit.

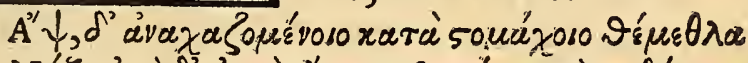

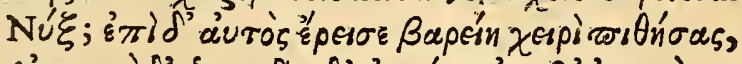

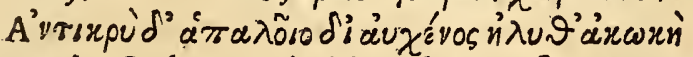
Subiungit Galenus Ariftotelem ipfum eã partem femper antiquo nomine uocaffe: quae uerba occafionem multis dederunt, ut Galenum calumniarentur : fi quidèm Arift. infrequentius in ea parte nominanda ciroocé z: uoce ufus reperitur, quàm souáxy : is enim primo de hifto. animal. cap. 12. 15. 16.\& ultimo:2. de hifto. cap. 17.4.de hift.cap.2 3. \& faepius totum illud fpatium fauA cium 


\section{L $\begin{array}{lllll} & \text { I } & \text { E } & R\end{array}$}

cium, \& oris uentriculi, quod nos gulä diximus, 50 ma zor appellauit: at $\mathrm{I}$. de hift. animal.cap.6. tertio de partibus animalium cap. I r. in eadem parte nominanda óroopá-

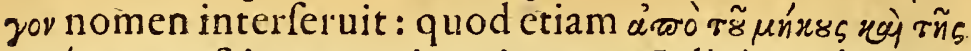
ระ ขórทтоร nefcio qua ratione ita uocatú dixit;unde cuiq. perfpectum effe poteft, aut Galenum erraffe, aut illius. philofophi fcripta of citanter admodum perlegiffe: quo rum vtrunque cùm ego à medicorǘn prîncipe, $\&$ in pe ripatetica dootrina maxime verfato, longe alicnum putem, ad credendum potius inducor textus omnes vulgatos vnius vocalae 8 z defectu fuiffe deprauatos; \& pro

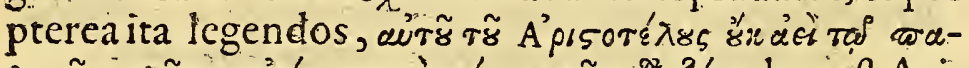

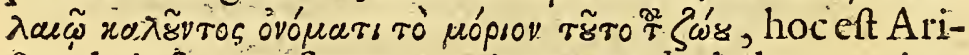
ftotele ipfo non femper antiquo vocabulo hanc anima lis partem nominante: Ad hoc aũt iudicandum primo ea ratione moueor, quod uerifimile non uidetur Galenum fcriptorem omnium fere pof homines natos diligentiflimum in re adeo clara ita dormitaffe; deinde fi eius mentem attentius contemplari uelimus; id innuere uoluiffe uidetur, quod ueteres eam partem orropájov, pofteriores Ariftotele sóma zor nominarint: Ariftoteles vero tanquam inter hos tempore medius utroque nomine vfus fit. Illud interim non tacebo Latinos ferè omnes qui ornatc, \& pure dicendi fudium amplexi funt ftomachi vocabulum pro ventriculo vt plurimum acce piffe. Lucretius in 6 .

Flagrabat stomacho flamma vt forriacibus intus.

Horatits Ieiunus stomacbus.raro vulgariatemnit.

Idem Columella : clarus eft Celfus lib.r. cap.2. \& 8. S lib.4.cap.5. qui tamen lib.4.cap.I.gulam ftomachum, fed quafi populusita loqueretur, nominauit, qui etiam aliquando, pro ore vétriculi ea voce ufus videtur, quod

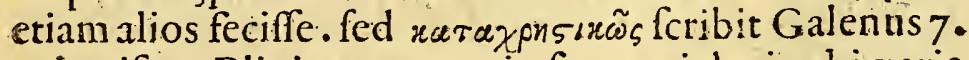
aphorif. 5. 6.Plinius quoque in fexcentis locis vbi varia 
pro ftomacho remedia proponit, fere femper ventriculum intelligit, \& fi aliter fenfffe ab aliquibus male credatur lib. I 1. cap. 37. quando dixit fummum gulae fauces, extremum tomachus: Caelius A urelianus frequen tiffime pro ventriculo, \& praefertim vbi de fómachicis tractat in 3 chronicarum paffionum, pro gula interdum ftomachum accepit. Serenus pro ventriculo toto,
Qu stomachum regem totins corporis effe
Contendunt, vera niti ratione videntur;
Huius enim validus. firmat tenor omnia membra,
Et contra einfäem firmantur cuncta vigore

Cur igitur Lucretius in transferendis Thucydidis uerbis ávi rap f'as quae os ventriculi ipfi fignificabat, cor, \& non fromachum, dicere maluit, haec ratio fufficere docto cuidam uiro ipfum criminanti debebat, quod fto machus raro os uentriculi; plerunq; ucl totum ventriculum, vel gulam ipfam proprie fignificarct Latinis. Quo modo etiá Nicander in Alexipharmacis sopáxoso Soxuénv vocari id à nonnullis dixit : quafi fit per quod fomachus recipit. Ac ne quis Pollucem in 2. lib-mihi adducat, vbi fomachú afperã arteriam quoq. vocatam dicere videtur, fciri velim apud ipfum ftomachum eo in loco pro gulae principio, quod ductibus ambobus quafi cōmune eft capi;vbi etiā litteram Pollucis mendofam

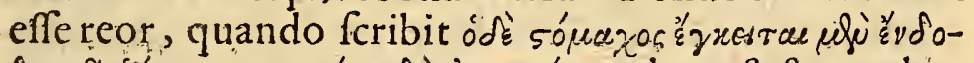
$\theta \varepsilon v, \pi \tilde{n}$. páx intus quidem incumbit fpinae, pertinetq. ad pulmo- nem quo in loco legendum credo eis usi $\lambda_{i a}$; nam ex his fubfequentibus uerbis fic effe legendum apparet $\tau \tilde{\delta^{\prime}} \delta \delta_{\varepsilon}^{\prime}$

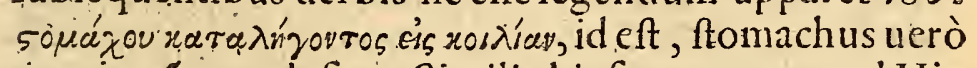
cum in vétrem definat. Similia his funt, quac apud Hip pocratem in libello de Anatome fcripta habentur hoc

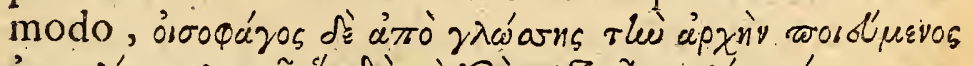

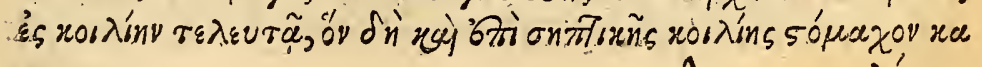
A $2 \quad \lambda^{\prime} \varepsilon \sigma / \gamma$ 


\section{I $B$ E}

$\lambda_{\varepsilon}^{\prime} 8 \sigma$ เv. id $e f$, Oefophagus auté fumpto a lingua initio in uentré definit, qué in uentre putrefactorio ftomachü nominant. Ná $\sigma u_{\text {ł }}$ v more antiquo ab Hipp. concoctio né vocari in noftris Hippocraticis adnotationibus móftramus, vt nemo mirari debeat, quod ventr iculum, vbi

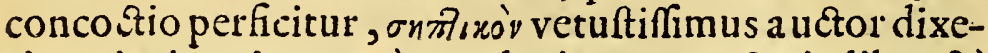

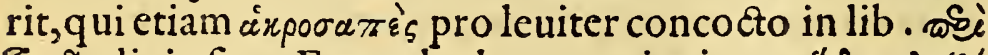

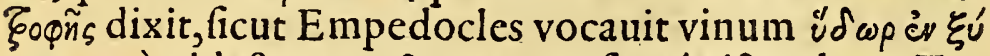
$\lambda \omega \sigma \alpha \pi \Sigma v$, ideft co ncoctum, vt refert Ariftoteles 4 . Topic. cap. 5. \& Plutar chus cap. 2. lib. de caufis nat. vbi frib it coctionem effe putrefactionem.

De rabie, fiue bydrophobia, \& elephantiafi loci Avistotelis, or Medicorum explicati. Cap. 2.

Pud Ariftotelem 8. hiftor. animal. cap. 22. fcri7. 3. ptum inuenitur hominem inter cetera animalia the à rabido cane commorfum, neque rabie corripi,

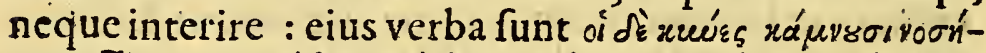

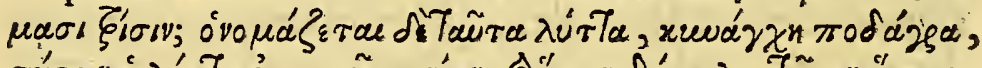

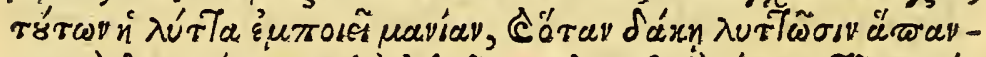

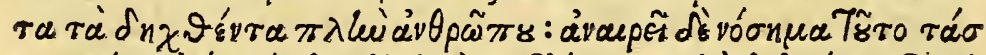

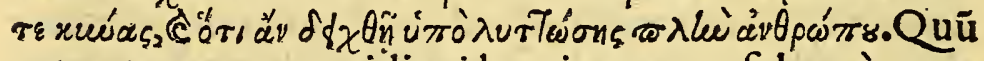
autem euentus quatidiani hominem non folum à cane, verum etiam ab alijs rabidis animalibus commorfun male affici, atque iugulari(vt Caelius A urelianus 3.acu torum fcripfit) manifelto declarent; multi vt Ariftotelem ab erroris fufpicione vendicarent in eo interpretādo laborarunt. Iulius Pollux in 5. fententiam philofo-

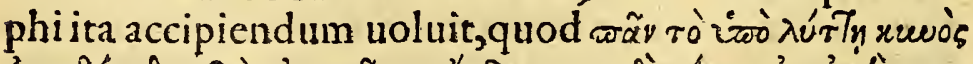

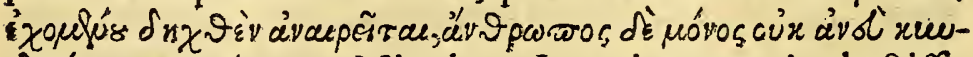

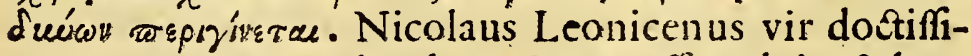
mus contextum potius depraviatum effe uoluit, \& loco - $\lambda$ reveffe legendum wiv quati homo commorfus in rabiem, \& mortem deueniret utique, fed pofterius ceteris animalibus;quãdo Galenus aliquos poft fextum, \& octa- 


\section{$P_{R}$ I $M$ V s.}

octa uum à morfu accepto annum, Albertus polt duodecimum co morbo laboraffe, \& necatos fuiffe tradunt. Non defuerunt quĭ $\pi \lambda$ iw $x$ nvòs legendum maluerint, rudi quadam experientia ducti, quòd anferes faepenumero mordeantur, \& nullum ex ijs interire con fpiciatur. Auguftinus Sueffanus in cómentariis fuper li bros de animalibus fententiã Ariftotelis iccirco ueram putauit,quia unus homo ratione praeditus medicamen torum ope feruatur:quo minus vel non rabie capiatur, vel captus euadat:quamuis non omnes illud obtineant. Hieronymus Fracaftorius diuerfa à cunctịs uia incedens cetera animalia rabire ob fer itatis confortium quod illis cum cane eft, hominem uero ob temperaturae ab illis multum difcrepantis excellentiã minime ei aegritudini fubiici ex Ariftotelis mente credidit.Sed ego cum in vetuftiffimum codicem manufcriptum inci-

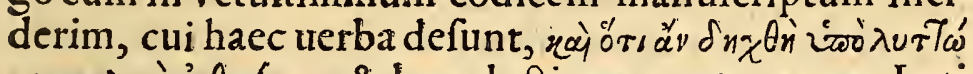

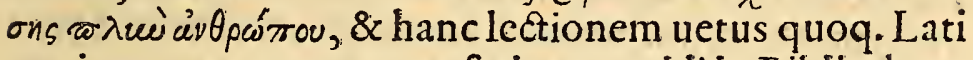
nus interpres quen manufcriptum uidi in Bibliotheca quam Io.Vincentius Pinellus uir doctiffimus, \& omniü bonorum patronus in ufum eruditorū magnis fumptibus inftruit, fecutus fit, puraui facile contingere potuif$\mathrm{fe}$, ut etiam antiquis temporibus ea uerba, quac litigan di occafionem dedere, ab aliquibus librariis ex marginibus interferta fint, eo pracfertim quòd antiquus auctor Antigonus in fynagoge paradoxarum hiftoriarũ vbi multa ex Arift.fideliffime recitat, id folü inquit uo-

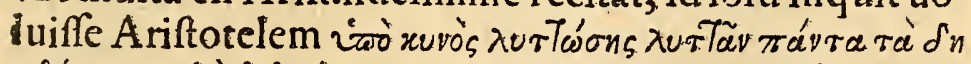

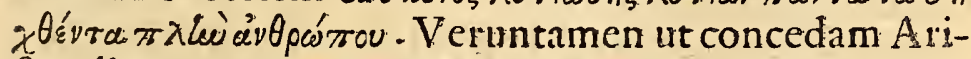
ftotelicum contextum nihil omnino immutandum, ne minem adhuc eorum ueritatem ufquam affecutum exi ftimo ; propterea quod tempeftate Ariftotelis morbum hunc in homine nondum cuiquam innotuife inuenio: unde iure ipfe fcriptis mandauit, folum hominem com 


\section{I B E R}

morfum à rabido cane illaefum permànere : An uero il lud ita fuerit, quod eo tempore morbus ille nufquam ef fer,fed poftortum habuerit; an quod eflet quidem, fed minime cognoferetur, forfan dubitari poffit. Atta: men vtrunque ficri potuiffe exiftimo. Plutarchus enim 8. fympofiacorum problcm. 9. hydrophobiam ; \& elephantiafim morbos fuiffe nonos Afclepiadis tempore, qui fub Pompeio Magno Romae in arte medica claruit, ex fentetia A thcnodori medici teftatum fecit; ubi fimiles morbos, atq; etiam alios caufis diuerfis poffeno uiter oriri difputat: nihilominus haud rationi quoque difonum mihi uidetur mórbũ antiquitus etiam extitiffe, neque tunc innotuiffe; propterea quod homines eo morbo multis poft acceptum morfum dicbus occuparé tur; \& iccirco à Medicis eius caufa non aducrteretur; vt cumque fit, Ariftotelis certè tempore minime cognitú fuit hominem commorfum à rabido cane ullo morbi aut fymptomatum pranorú genere; \& praefertim aquae timore capi; quod \& aliae practer Plutarchi modo cita tum teftimonium, rationes mihi perfuadent : Nam ex uetuftioribus Afclepiade fcriptoribus neminem adhuc inueni, qui huiufe mali mentionem vllam expreffam fecerit: quod fi manifeftum fuiffer, acquum erat ab aliquibus, \& faltem ab uno Hippocrate nominari nempe qui in commentaris epidemicis, \& alibi uaria, ac prope incredibilia morborum genera recenfuit. Nicander item Colophonius, qui ante Pompeij tempora fub Attalo eius generis poftremo Pergami rege floruit; cum omnia venena, ac letalia homini fiue ex potu, accibo, fiue ex morfu atque impreffione carminibus perfecutus hydrophobiam tacuerit, par eft arbitrari non aliunde eam filentio praeterijfle; nifi quia aetate ipfius nondum apparuerat. Neque Caclii Aurcliani auctoritas (fiue ipfe fit, fiue Soranus ab eo latinus redditus, qui in 


\section{$P_{R}$ I M V s.}

3.acut.de hac pasfione latisfime differit) me quică mouet, quandoquidem inepte fatis, ac indocte ex uno, vel altero Homeri, Menandri, Democriti, \& Hippocratis loco falfo, \& extra rem inducto Hydrophobiam veteres auktores nouiffe fe fe probare credit. Acced it quod Ouidius, qui paullo poft Afclepiadem vixit, Hydropho biae nullum effe remedium fribens hoc verfu,

Solueve nodofam nefcit medicina podagram,

Nec. formidatis ulla me detur aquis.

indicare videtur eum morbum nuperrime apparuiffe, quippe cuius medicina nondum inuenta effet; quin \& hac in re Plinij alioquin auctoris grauisfimi fententiam probare nequeo, qui vfque ad tépora fua aquae, \& aliarum rerum formidinem ex morfu canis, ortam incurabilem extitiffe, \& cafu quodam à milite Cynorhodi po tionem à matre fibi per-litteras ex infomnio indicatam huic malo inuentam effe medicinam fcribit; quum con ftet Cornelium Celfum, \& Scribonium Largum Plinio antiquiores eius remedia plurima frriptis mandaffe; vt filentio praeteream Diofcoridem, atque Caelium Aurelianum, fiue Arrianum, qui Themifonem medicum Afclepiadis fequacé à cane morsî huiufcemodi timoré incurriffe, '\& medicamentorum ope incolumé euafiffe fcribunt: mifi, Plinii auctoritate tuentes, dicam us vulne ratos à canis dente ante ip fius tempora curatos effe, $f_{1}$ in principio medicus accerfebatur; at fi neglectus longius procefferat morbus, \& timorem aquae pepererat, minime curari potuiffe, cui fententiae non parum Celfus fa uet, inquiens, aquac timore oppreffis in angufto fpem effe:Simili pacto Galenum à calumnia uindicare foleo, qui in 6. deloc.affectis, folos canes rabic tentari fcripfit, cui etiam Alexander ille probl.auctor affenfus eft. Nẩ Porphyrius, A pfyrtus, Hicrocles, \& Palladius, qui huiufmodi morbum in equis $\&$ aliis animalibus obfer- 


\section{I B E R}

uarunt Galeno pofteriores extiterunt, vnde facile conद tigit, vt illius tempeftate nondum in quopiam alio, quàm in cane rabies innotuerit, vel faltem id nomen tunc non obtinuerit, quod pofteriores in alijs animali-

$\zeta$ bus vfurparint, nifi dicamus Galenum haudquaquam Hippiatricem cxercuiffe, \& propterea, fi quicquam in ipla errauit, excufationem mereri. Quod uero Plutarchus fcribit Elephantiafim ab A rabum medicis lepram vocatam, Afclepiadis folum aetate fe fe manifeftaffe; id ita accipiendum puto, vt quemadmodü fcribit Plinius 26.lib: in I talia tunc apparere coeperit, quoniam eum morbum fub nomine Satyriafis A riftoteles in 4 . de gene.animal.cap.3.intellexit, ut Michael Ephefius in com mentario prudenter notauit. Adhuc in Aegypto antea vulgatum extitiffe declarat etiam Lucretius in 6.

ESt elephas morbus, qui $\mathrm{X}$ iliflumina propter

Gignitur Aegypto in a1edia, neque praeterea ufquaim:

$\mathcal{A}$ ttbide tentantur.greffus, oculiq. in $\mathcal{A}$ chaeis, Finibus

Elephătiafim autem licet in Italia ftatim reftinetam nar ret Plinius; in A egypto tamen frequens durauit vfque ad Galeni tempora, qui eum morbum Alexandriae familiarem in Germania, Scythia, My fia frigidis regionibus non graffatum, 2. libro ad Glauconem tradidit: Quod porro A egyptiorum reges ea lue capti fanguine humano in balinearum folijs fufo magna populi cede curarentur, vt non multum verofimile, fic ferini potius remedij habuiffe fpeciem opinor.

Restitutus Ga!eni locus de palmulis, o alter declaratus nonnulla de oliuis, Cap. 3.

15. Almulas \& vi quadam peculiari, \& quod magno labore coquantur, ac vaporibus fuperiora tentent, capitis dolorcm generare fcriptum eft à $\mathrm{Ga}$ Ieno 2. de compo. medic. s. l.vbi Apollonii ad dolores 
ex ebrietate fcripta recitat; necnón 2 , de alim. fac. \& in libello de facile parabilibus apud Solonem: quod an tea Xenophon apud A thenacum in 14 . dipnos. \& Diofcorides affirmant: Ceterum in 2. de comp.med.s.l.recenfens medicamenta procurandis capitis doloribus ex

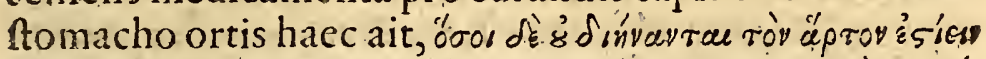

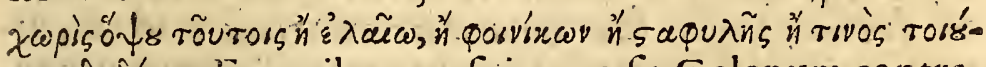
rou ds óvar. Ex quibus perfpicuum fit Galenum contrariafibi fentire: nifi dicamus hunc i pfum contextú depra uatum effe, \& loco posvircov legendum $\lambda \varepsilon u x \tilde{w} v$, vt iuncta

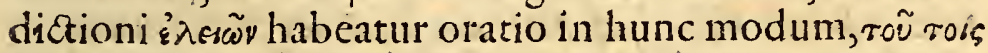

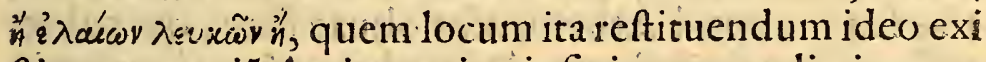
Atimo, quoniã Actius, qui vt in finita prope alia, ita eum contextum ad verbun in 6. lib. cap. 45 . induxit; fic \&

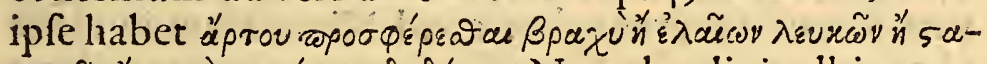

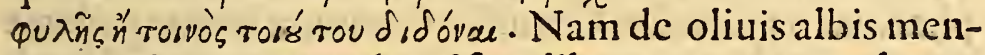
tionem inuenio a pud Celfum lib. 4. cap. 20. apud eundem Galenum 5.de comp.med.s.l. necnon apud Oriba fum lib.7 - qui omnes iis in ftomacho, atque in aliis partibus adfringendis vtuntur, ne quis miretur cur potius oliuas albas, quàm alias ibi legendum voluerim : porro oliuae albacillae dicuntur, quae mediae funt inter virides \& maturas : virides enim acerbae nimis funt, \& cruditatefua minime conueniunt ; maturae quae \& nigrae funt fua pinguitudineftomachum relaxant. Albaeautem viroque exceffu carent, cum neque incoctae prolfus fint, \& adfristoria facultate non priuentur. Quo ctiam Plinij accedit auctoritas, qui libri 2 3.cap.3.vliuas albas ftomacho vtiliores, ventri minus, fcriptum reliquit. Quomodoalbaeoliuac condirentur non eft mihi admodum compertum, inuenio tamen apud veteres plures eas condiendi modos extitiffe; Nam muria primo condiebantur, ipfisq. focniculum admifcebatur $x j^{2}$ $\lambda u ́ \mu b a \delta \varepsilon q$ à Graecis vocatae, à Romanis drupac. Cac- 


\section{L : $R$}

fius Aurelianus 4. chron. paff. cap. 3 . natantes vocauit ; Has aliquando albas vocatas putaui, quod Diphilus apud A thenaeum 2. dipnos.eas a nigris, quas $5 \varepsilon \mu \varphi u ́ d \lambda$ $\delta \alpha_{\varsigma}$ vocabant, diftinguat, \& ad firmandum ventriculum

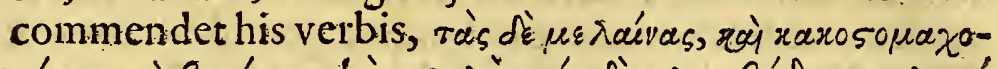

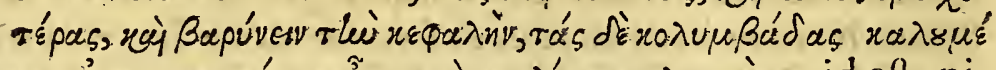

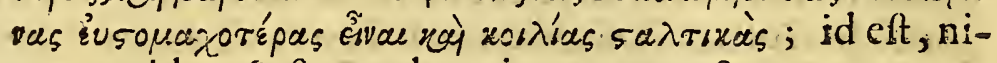
gras quidem \& ftomacho min us aptas, \& caput grauare: Colymbadas vero \& gratiores ftomacho, \& vêtrem retinere. Condiri etiam oleo confueuiffe inquit Arifto-

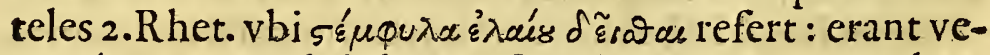

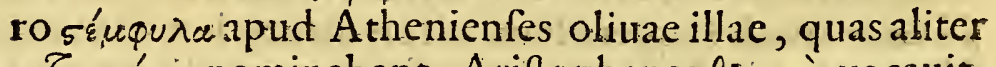

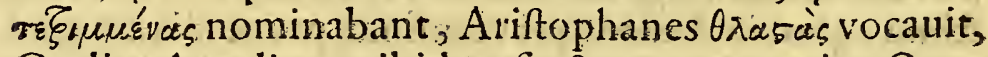
Caelius Aurelianus ibidem fractas nuncupauit. Quae vero fint oliuae premadiae apud Nicandrum in alexipharmacis aduerfus Ceruffae venenum commendatae nondum mihi quicquan certi compertum eft, nififit oli ua Paufia, quam ve Virgilius fimul cum. Orchade iungit hoc carmine,

\section{Orcbades, \& radï, \& amara Paufia bacca:}

Sic \& Nicander

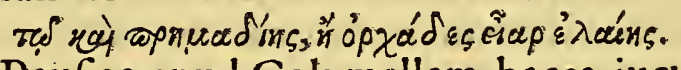

Eft cnim Paufiae apud Columellam bacca iucundiffma, ex qua oleum fit faporis egregii dum viride eft : vetuftum autem corrumpitur, vnde Seruium laudare non poffum, qui apud Virgilium pro amara bacca viridem exponit. Cum amaror Paufiae fit iucunditati cuidam iunctus, ut Plinius ait, cerafa laurea non ingratae amari tudinis effe. Cogitentquaefo eruditi, num aliquid lucis ci loco afferre valeant. A uctor eft Celfus lib.z:cap. 19. oliuas etiam ex defruto \& paffo códiri folitas: Qưoniam zutem de palmulis fermonem habui, locum alium Gale ni in medium proferre placet ; in quo interpretando omnes penè interpretes vel hallucinatos, vel obfcurio- 
res quàm par erat extitiffe video: is eft libro de locis pa tientibus 6. vbi difputans num vterus animal fit (quem admoduim Plato fcripfit) ait, quod fieffet, quando rebus.defideratis fruftratur, vtique triflitia afficeretur : \& forfan emaciaretur: exemplum deinde proponens, fubiungit ra dád quae verba ad Phoenices populos referre omnes videntur interpretes; cum minus diftet Caelum à terra, quàm vt id Galenus doetiffinus fignificare voluerit:Nam de vtero fecundum ipfum fenfibus orbato loqués. ineptus plane fuiffer, fi animali \& non plantae eum aequiparaffet: ad haec palmae plantae hiftoria adeo quadrat Galeni menti \& inftituto, vt nemo vel mediocri iudicio pracditusde alia re locutũ Galenum credere poffit: a uctor enim eft Philoftratus in Iconibus palmam marem atque foeminam ita fe amare, ve niff prope feran sur,ac fe contingant emacientur, exficcenturq.; ; quod Plinius quoque lib.1 3 . cap.4. non folum affirmauit, fed etiam addidit ipfas fterilefcere; cui fententiae non parum conucniunt, quae ante hos a Theophrafto fcriptis mandata funt 3 . de caufis plantarum cap. 20. palmam foemell am fructus nō retinere, nifi fupra eam flores $\mathrm{ma}$ ris palmae cum puluere iaciantur; quod nonnulli voluereidem operari acfemen mafculorum pifcium ouis foemellarum infperfun.

Galeni Locus emendatus in 12. Meth. of alter in 13. melius quaim d Linacro interpretatus. Cap. 4.

Alenus in medicos nonnullos inuectus, qui gene (2. 2. quodam praefidio interdum curafe, interdum necafle: modū vero illius curationis ita fuiffe tradit xpómpva $\tau \dot{\alpha}$

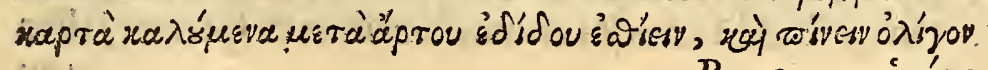




\section{I B B}

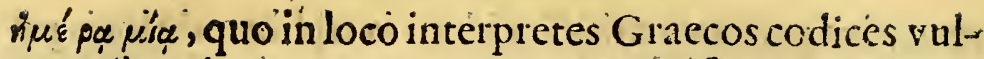
gatos lecuti,cepas cartas vocatas transferunt. Haruni cum apud nullos auctores genus vllum ita vocatum inuenerim, textum deprauatum effe, \& pro xápra vel $x v_{i}^{\prime}-$

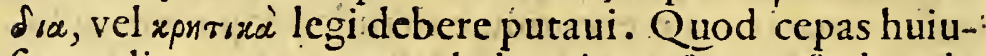
fccmodi vocatas veteres habuerint teftatus eft abunde Theophraftus, \& poft ipfum Plinius; qui etiam cepas coitas dy fentiricis vefcendas dare medicos confueuiffe cap.5.20. libritradit; Creticas in honore habitas dulciufculas fuiffe ex Theophrafti, \& Plinij verbis coniicitur, vt ea ratione fieri potuerit, quod medici illas tanquam palato gratiores elegerint, vel certe xpónua $\tau \dot{\alpha}$ xo

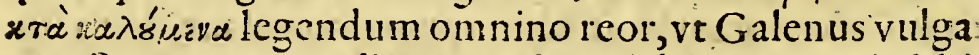
tum Romae nomen literis exarare voluerit, quod alibi identidem fecifenemini ignotum arbitior ; quae loci huius facile emendandiconiestura in memoriam mihi adducta eft a iuvene, cum primis \& erudito \& docto $\mathrm{Se}$ múelé Darderio Byzantio philofophiae; ac medicinae doftorc, \& noftri ftudiofifimo auditore.Sed quioniä me thodi locĩ explicui ; alterum lubet fubnectere in fine de cimi tertijlibri, quem interpretes forfan ob Romanae: vrbis ignorantiam male tranftulerunt : vbi .n. Gál.arté riarü incifionem inftituit, quae vincula in id opus eligéda fint, edocens Gaiuana ex Gallia Romã aduecta ceteris pracfert ac diligetiaffibi folita vfus, vbi quoq. in vrbe

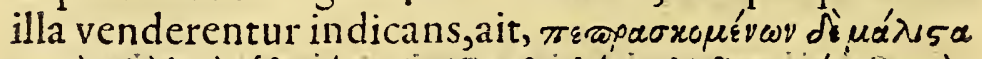

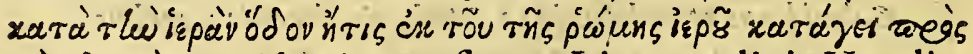

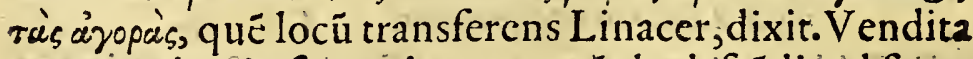
vero maxime in facra via, quac a têplo defcédit ad fora, cū trāsferre debuerit:quae a téplo Romae ad fora defcế dit: ita .n. mira Galeni diligentia in defcribendo appofi tiffrme loco ró occultatur. Erat.n.via facra non longe a templo Pacis, necnon a foro téplum Romae \& A ugufto (vt in quibufdá antiquis numifmatibus cófpicitur) dica 


\section{I. E}

tum, quod \& pulchritudine, \& facrificiorum magnificentia Veneris templo inferius nequaquam fuiffe his verfibus monftrat Aurelius.Prudentius.

Iamq. domoegrediens, ot.publica festa, diesq.

Et ludos fupuit, celfa \& capitolia ridit,

Ac facram refonare viam mugitibus, ante

Delubrum'Romae (colitur namisanguine, \& ips

More Deae,nomenq. Loci ceu numen habetur

Atque vrbis, Venerisq. parife culmine tollunt

Templa, Simul geminis adolentur tburi Deabus)

Eius Templi facies fere tota feruatur adhuc, Cofmaeq. ac Damiano hodie dicatum eft; ibi erant variae officinae, inter quas crant, qui vincula huiufcemodi venderent: illud quoque ex eodem loco colligendum eft $\mathrm{Ga}$ leni tempore fericum rariffmum fuiffe, quando id iple refert fub ditione Romana \& in magnis ciuitatibus penes folas mulieres opulentas inueniri potuiffe:

Arcbigenis locus cmendatus apud Galenum: ac de bulbis nonnulla non poenitenda contexuntur cap. 5.

The Renen medicus clariflimus; qui Hadriano im

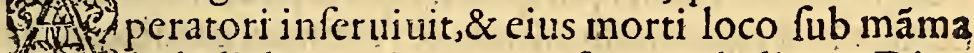
Cathali dem onftrato occafionem dedit, ut Dion Caffius fribit, apud qué pro Hermogene Archigenem legédum effe rcor, multa in re medica praeclariffima có mentaria cdidit, quae a Gale. paffim ceteris aliorum fui temporis medicolum fcriptis nó fine honore praeferan tur. Is cum illorum curationem inftitueret; qui prae fame in animi deliquia incidunt (ut fcribit Galenus)praecepit quamprimum viribus reficiendis incumbendum effe; \& ideo iam foluto deliquio ea illico exhibenda, quae belle nutrirét, qualia funt oua forbilia, panis cú vi no, cochleae, \& bulbi; Quo in loco vehementer fufpicor mendú aliquod latere, qm illa, q̃a $\alpha^{3}$ póm, fue aceruatim nutrire poffunt, oỉa multú \& cito in parua mole nutriūt; 


\section{$L A \& \&$}

cochleae vero, \& bulbi tametfinutrimenti multum cor poribus praeftare valcant, nihilominus tardiffime, \& fen fim alimentum fuum membris impertiunt, vt hac ratione Galenus 2.aphor. 18. apertiffime neget ea aceruatim nutrire : Accedit his quod Aetius haec omnia ad verbum transferens cochleas \& bulbos non habet, fed loco eorum halicam cum vino pofuit;quemadmodum etiam apud Galenum ipfe legendum puto : nec obftat quod paullo fupra Archigenes pro ftomachicis cochleas \& bulbos, ficit \& Diphilus apud Athenaeum probarit, quoniam ve illi ad corroborandum ventriculum, pro quo ibi laudantur, valent, fic ad reparandas ftatim vires minime congruunt. Neq. (dicet quis) Galenum in loco fupra citato halicam inter tarde nutrientia recenfere, propterea quod ibi de halica fola ab ipfo fermo habetur cui fe vinum mifceatur, aufcrtur fane ipfi vifciditas, atq. crafitities; \& ideo efficitur vt multũ nutrimentum, quod fecum habet, paruo tempore diftribuatur, qua ratione Galenus in primo ad Glauconem huiufcemodi mixtionem probauit in illis, in quibus fyncope timetur in aceeffionibus; quemadmodum \& Aetius in cardiacis, aliisq. plurimis: Quod porro de bulbisfcripfit Arift.20. probl. eos repofitos germinare, quoniam interna ac nu trititia humiditate abundant, id ita accipiendum eft, quemadmodum 5. de caufis plantarum Theophraftus prodidit, videlicet omnia bulbacealento quodam humore praedita effe, cuius ope tam diu natiuus calor con feruatur, quouff. is ab externo adiutus humiditatem illam explicat,praeparat, \& noua forma induit. Eos veneré excitare oftédit verficulus apud Athenaeú citatus,

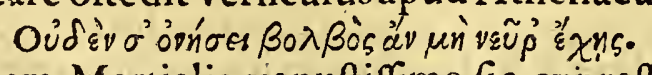

Quod etiam Martialis venuftiffime fic expreffit. cumfit anus coniux, chin fint tibi mortua membra, Quid bulbis aliud, quaim fatur effe potes? 


\section{P. I M P.}

Locus Galcni de foecundis correctus : of nonnulla ad id ex Lucretio or Paillo cap. 8.

Fin Anciuxta omnes impreffos codices fententiam (3) habet Galenus 5.aphor.63.quod tam mulieres, quàm virifi temperie quattuor qualitatum potiantur, generant, quamuis temperie illa priuatis commifceantur; intemperati vero nunquam generant nifi contraria intemperic pracditis iungantur, vtpote calidi frigidis, humidi ficcis, \& ita de fingulis : fic enim fua lin

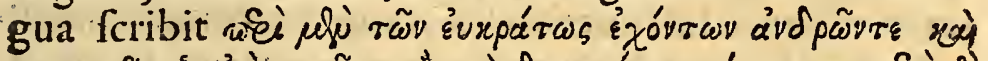

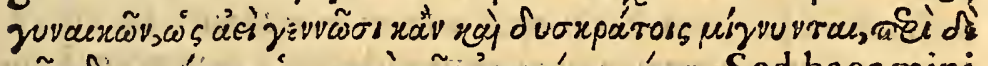

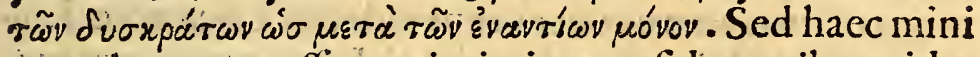
me cohaerere poff rem intimius confiderantibus videbuntur,quoniam fi intemperati folis intemperie corum contrariis naturis copulati gignunt, qui poterunt temperatis iuncti generare? neque dicendum eft temperatas naturas intemperat is quibufuis contrarias exiftere, quoniam Galenus infra fatis manifeftum facit fe de ea loqui contrarietate, quae inter vtraq.extrema, non inter alterum extremorum \& medium pofita eft . Itaque textum corruptum effe potius, atq.hoc pacto legi debere pu

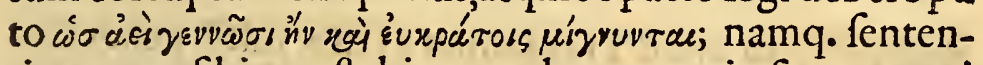
tia ve vera fibi conftabit, quod temperatis fi temperati mifceantur femper gignunt, intemperati vero tunc folum, quando contrariis fuae intemperiei copulantur. Haec omnia videtur Lucretius in 4 . de natura libro qua ff fomniaffe, vbi foecunditatis varias caufas exponens inter alias vnam fic ponit.

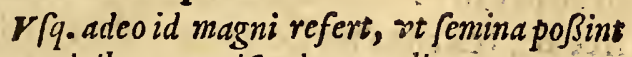

seminibus commifceri generaliter apta,

Craffaq. conueniant liquidis, o liquida craßis.

Quod vero paullo poft fribit ad concipiendum quoque magnopere conferre fi à tergo, beluarum more, vir 


\section{LE:}

cum muliere vtatur venere,

Et quibius ip a modis tractetur blanda voluptcis

Id quoq. per magni refert, nam more ferarum

Quadrupedurnq. magis ritu plerüque putantur

Concipere vxores, quoniam loca fumere poffunt

Pectoribus pofitis fublatis femina lumbis.

non eft ita explodendum, quin rationem magná fecum habeat, potiusq. diŝu turpe quàm factu videatur. Nam \& Paullus Aegineta non contemnendus auftor quicquid Lucretius ad hanc rem pluribus carminibus fcriptum reliquit, hifce verbis lib.3. cap. 74. complcxus eft

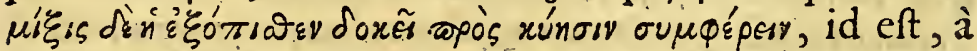
tergo coitus iuuare conceptum videtur. Loca vero Lucretij citata Q. Serenus Gordiani Imperatoris pracceptor indicare voluit, quando fcripfit;

Irrita coniugÿ sterilis fi munera languent

Dec fobolis pes eft multos iam zana per annos

Foemineo frat pitio res, nec ne filebo.

Hoc potcrit magni quartus inonstrare Lucreti.

Quid fit recentatum apud Alexandrum Trallanum; of quaeantiquorum propomata. Cap. 7 .

Hogitur apud Trallianum I r lib. fuife pénes RoII 1 manos propomatis genus, quod Romanirecen(1) tatú nuncupabant, vtq. in eo bibendo magis dele ctarentur, peculiari quadam arte refrigerabant : id nomen quid fignificaret, quodve potionis genus effet; mul tos dillambiguos tenuit : nec defuerunt qui Alexandri codicem corruptum effe crediderint. Ego vero fi coniectari mihi liceat, textuin nullo errore ibi effe infectum, recentatumq.R omanos vocafle puto vinum antiquum, mufto, vel lixiuio, vel tortiuo commixtum, quafiq. renouatum, quomodo plerosq. hodie factitare confpicimus : recentare enim apud veteres in vfu fuiffe pro re- 


\section{P R I M V S}

nouare auctor eft Noni us; vnde etiam quod a Varrone in libris de lingua latina vinum vetufnouum nuncupatum inuenitur, hocipfum recentatum fuiffe arbitror, quod caupones pro vetere interdum védere folitos me morat Galenus lib.de cib. bo. \& mali fucci. Quo pasto hoc Romani refrigerarent, cum nihil compertum habeam, id tamen diuinare audebo hanc potionem vtpote valetudinariis optatam aliquo diuerfo modo, ita vt e gelida potius, aut faltem modice frigida, quàm vere gelida fieret, non autem vel lamina, vel glarea, vel glacie, vel niue, vel alio ex ijs, quos infra exponam, modis refri gcrare confueuiffe: tot namq. modos vina \& aquam infigniter refrigerädi veteres habuiffe comperio: Et quo niam propomatum mentio incidit, quaenam illa forent non erit abfurdum fignificare. Scribit Paullus. Aegineta cap. 5 . lib.7 propomata mixtiones quafdam extitiffe factas ex mellis defpumati fextario vno \& vini quater nis; ve vero Alexander Trallianus lib. I. cap. Io. \& I I. \& alibi faepe meminit, propomata nulla alia erāt, quàm vina factitia diuerforum generum de quibus plura apud Columellam \& Plinium magnos Latinae linguae au-

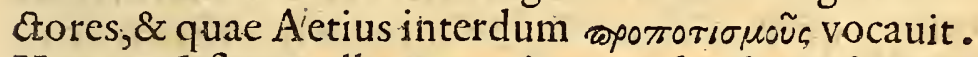
Haec auté fic appellata ea ratione credendum eft, quod ante reliquos potus atque cibus fumerentur; quam huiufcemodi vina bibendi confuetudinem fub Tiberio Claudio principe inuectam medicorum placitis nouita te aliqua fe fe commendantium feribit Plinius I 4: libro cap.20. Poft quem Plutarchus 8. fympofiacorum problemate 9. dum queritur tempore fuo propomatum vfum qui nouis morbis occafionem praeftaret, inductum, nil aliud intellexit quam quod Plinius antea deteftatus erat, haec fcilicet factitia vina bibendi morem. Quamuis कoтбóraros, vti antiquae cófuetudinis apud $A$ thenacû eft métio. Cur vero ita a medicis cómendatũ fit opinor,

C quòd 


\section{$L_{I} B_{R}$}

quòd vt principibus ac nobilibus viris largiore bibendi copiam facerent, ea vina excogitarint, quae varie affectos ftomachos curarent, confirmarent, \& ad bibendum impune magis excitarent, quando etiam non deerant, qui, vt coprofius potare atque edere poffent, vina praua quae ipfis excitarent vomitum, pracpotabant, de qua re dic Iuuenalis fatyr. 7 .

Tandem illa venit rubicundula totum

Oenophorum fitiens, plena quod tenditur prna

Ad motum pedibus, de quofextarius alter

Ducitur ante cibum rabidam facturus orexin,

Dumb redit o terram luteo ferit intestino.

De varÿs antiquorum refrigerandi vina, of aquam modis de decocta, \& quae fuerit calda. Cap.8.

A $A$ riis modis aquam refrigeratam veteres potaffe inuenio; quod enim niuibus antiquiffimis vfq. temporibus illud agerent, fatis Athenaeus ex Alexi, Dexicrate, Euthycle, $\&$ Xenophötc in 3.dipnos. probauit, vbi etiam niues potaffe, easq. in foffis magnis quibus quernos ramos fuperinijciebant, côferuare con fueuiffe memoriae mandauit: etfi Martialis dixerit

\section{Non potareniuem, fedaquam potare rigentem}

Deniue commenta eft ingeniofafitis.

Quòd Plutarchus in 6. fympof, fieri quoq. folitum fcri bit cum paleis \& rudibus pannis niuibus circunduetis, easq. ab acre tuentibus, \& frigiditate acquifita conferuantibus.Protagorides libro Comicarum hiftoriarum fecundo, quoddam militum A ntiochi regis refrigerandae aquae artificium memorat, quod fcilicet aquam die in aprico loco ponebant, \& quod craffum erat, nocte in cipiente excolantes reliquam nottis partem in hydrijs fictilibus fubdio in editioribus domus partibus expone bant 


\section{P $\quad$ R I $\quad$ M $v$ s.}

bant: per totam deinde notem duo pucri ipfa vafa $c x$ tcrius irrigabant, \& diluculo incipiente purgantes rurfus, faecemq. fubtrahentes $\&$ tenuem iplaim aquam maximeq. fanitati idoneam facientes inter paleas hydrias ipfas collocabant. ficq. demum illa vtebantur nullam niuis inopiam cognofcentes. Non admodum ab hoc diuerfus eratille refirigerandi aquam modus, quem Galenus in Alexandria, atq. vniuerfa A egypto feruatum fe vidiffe teftatur commen.4.6. epid. vbi occidente Sole prius calefastam aquam teftaceis vafis inijciebant, caq. vafa feneftris ven tos expolitis, vt tota nocte refrigerarentur, fufpenfa, deinde ante Solis exortum humi depofita frigida aqua confpergebant, ac interdum ipfis folia frigida, vitium, lactucae, \& fimilium circumponebant, ve firigus aquae noctu acquifitum interdiu conferuaretur. Semus Delius libro Nefiadis fecundo, in infula Ci molia loca refrigeratoria excauata fribit, in quibus acfatis tempore vafa fictilia tepida aqua plena deponebant; poftea aquam nulla re niuibus differentem cxpor tabant. Alium refrigerandi aquam modum fuiffe difpu tat Plutarchus ex A rifto. 6. fy mp.vbi cotibus \& filicibus necnon plumbeis laminis aquae inicctis eam refrigerari demonftrat. In puteis quoq. vinum refrigerandi ino rem habuiffe veteres teftantur. Strattis in refrigeratorijs \& Lyfippus in bacchis: Ceterum Neronis poftemum aquae refrigerädae inuentum nullo praedictorum igno bilius extitit, qui vt frigoris voluptate abfq. niuis vitijs frueretur, aquam decoqui fibi, vitroq. demiffam in niues refrigerari curabat : quem morem ita infecuta aetas Romae obferuauit, vt Neronis decosta fere in omnium ore verfaretur; De qua fermonem habens I uuenalis faty. 5. fic ait,

Cum stomacbus domini feruct, potuq. ciboq. Frigidior Geticis petitur decocta pruinis. 


\section{I B $R$}

\& Marcialis Spoletinabibis, pel Marfis conditacellis,

Quo tibi decoctae nobile frigus aquae.

De hac Galenus intellexir, quando 7.methodi libri me morat fe interdum fomachi, ac membrorum intemperics aqua niuibus refrigerata curaffe $\omega s$ है $\mathrm{P} \omega \mu$ (ait ille)

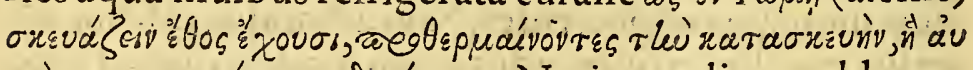
roi regrayopévour dérórtav. Ne in medium adducam Athenaeum, qui libro dipnos 3. clariffme demonftrat, quàm fiequens apud Romanos effet decoctae vfus; vbi notare licet eos conuiuas erraffe, qui penes eum auctorem probare nitebantur antiquiores Nerone decocta fuiffe vós. An vero calda vnquam in cóuiuijs fanorum vterentur antiqui in potu dubitatum fuit a multis; certe ex Philemone conftare potef aliquando eiufmodi potum vfurpatum effe, quãdo fcribit caldam chalco, quae fere eft quadrantis noftri menfura, vendi folitam, quae pufillitas non lotioni, fed potui inferuire poterat. Pofterioribus faeculis frequentior calidae potus fuiffe inuenitur, ita vt in conuiuijs aeque caldae atque frigidae minifter haberetur, quemadmodum fcribit Iuuenalis faty 7 .

\section{Quando vocatus adeft caldae, gelidaeq. minifter .}

Num autem calda quam medici frequenter fub vocabu lo $\theta$ epròv nominant, quam vt antiqui potabant aqua effet igne, fole vt calefacta, an aliter difputata quaeftio eft; Ego fane ita femper exiftimaui nunquam inter conuiuia Veteres aquam calefactam bibiffe, quòd ea potius concitet vomitum, quam aut voluptatem, aut commodum afferat, cum item Plinius potum calidum effe con tra naturam probet argumento brutorum; quae frigidum profequuntur, \& neque ipfe, neque Galenus vllum huiufce potionis nifi in aegrotis mentionem fecerint. Caldam autem fuiffe aquam illam, quam nulla 


\section{$P_{R} I \quad M \quad$ S.}

arte refrigerabant; fed quae qualis fuapte natura crat; potaturis porrigebatur,ideo opinor, quoniam Martialis ubi dicit

Iam defeciffet portantes calda ministros,

sinon potares Ceciliane merum.

๘

Frigida non defit, non deerit calda petenti,

Sed tu morofal ludere parce fiti.

Manifelte indicat fe de ea aqua fermonem facere, quae paffim in conuiuijs admifcebatur vino, \& eius magna co pia habebatur; cuiufmodi profecto extitit aqua nulla ar te calefacta, aut refrigerata: Nec aliter fenfit Philemon, qui uilitatem \& copiam caldae demonftrauit, fcribens eam quadrante vendi, cum verifimile fit aquam frigefactam, aut calefastam non ita vili pretio venditam fuiffe : nec obftat Platonis fententia nimirum qui eo loco fitim in exemplum adducat cupiditatis, \& non de ea ferio agat, quae frigidi, atque humidi appetitus ab omnibus definitur. Cur poftea fic appellarint communem potando aquam, puto vt eam a frigefacta niuibus, vel alio ingenio conuiuis inter petendum, \& miniftris inter feruiendum diftingue re liceret: Quod fi haec opinio aliquibus minus placeat, id faltem neceffario obtincbo, vel tantum aliqua valetudine affectos toto conuiuio, vel illos, qui vomere cupiebant, vt copiofius \& maiori fame ingurgitarent, ante cenam calefactae aquae potu vfos effe: quod \& Antiphanis in Omphale indicauit his verfibus.

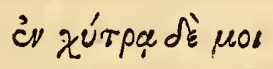

O"

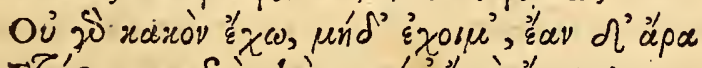

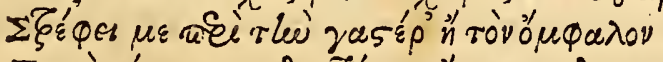
Парах ф́́ 


\section{I B E R}

Ad quod pertinere quoq. videtur ea difputatio, quae in eodem Athenaci libro tractatur, an poft ficus calida, an frigida bibenda.fit, \& medicorum Graecorum praeceptum, qui ad reprimendum renum feruorem caldae potum ante alios cibos fummopere cómendant. Quod vero ante cibum ad vomitum prouocandum nonnulli caldam praefumerent, ex Martialis epigrammate in Ce cilianum conftare poteft, qui cum tempeftiue nimis ad fecum cenandum iuiffet, ipfum incufar, quod ftatim nô dum accenfo in culina igne caldam petijflet.

Caldam pofcis aquam, fed nondum frigida venit, Alget adbuc nudo claufa culina foco.

Loci Aristotelis emendatiex $\ddot{i}$ beophrasto, \& locus Platonis cxaminatus. cap. 9 .

R. Riftoteles in 5. probl.primo,cauffam inquirens, 5. (1) qua ambulationes longae per inaequales vias fa 23. Etac maiorem laffitudinem, quam per inaequales inducant, iccirco contingere fcribit, quia multus, ac vehemens motus laffitudinem parit: fubiungit deinde

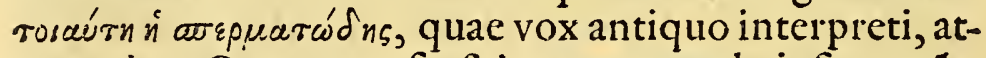
que etiam Gazae occafio fuit, vt non modo ipfi errarët, fed \& illi, qui in lexico componendo eos fecuti fcripferunt $\varpi s p \mu a \tau \omega^{\prime} \delta$ ns vocem motum per viam inaequalem fignificare, cum nec huiufcemodi fignificatio Arıfotelis loco quadret, nec vox alibi vfurpata reperiatur:Itaq. reftituendum locum effe puto, quemadmodum penes Theophraftum in libro reei xór brum ferc totũ ex A riftotelis problematibus conflatum effe quiuis iudicare poteft $:$ ibi.n. fic legitur "

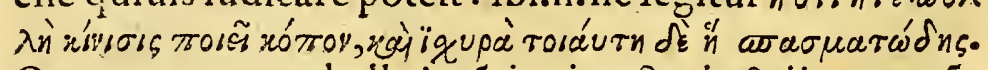
Quam vocem perbelle in tétioni au ctoris, \& litterae côuenire vnicuiq. perfpectum effe potert, eo nuagis quod 
fimili voce vfus eft Arito. in eadem probl. patti. probl. 8. ficuti quoq. Hippocrates in 2. de diaeta, vbi concuffionum, quae inter magnos motus collocantur, mentio nem fecit; non diffimiliter locutus reperitur, vbi dixit

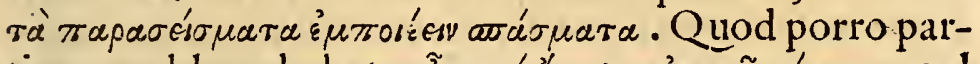

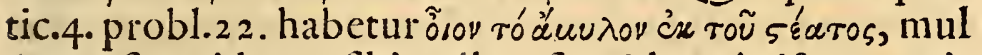
tos torfit quid nam fibi vellet : fi quidem Arifo. aequiparans ibifanguini id quod paucum ex multo nutrimen to efficitur, ficuti femen, exemplum afferens ea verba fubnestit, quae certe parum conuenire nemo nó videt : vnde opinor ego fic reftitui oportere oĩov ó $\mu v \varepsilon \lambda$ os ćs rov бе́єros. Nam ijs animalibus, quibus fanguis euadit feuo fus, ctiam medullam $5 \varepsilon a \tau \omega \delta \delta$ effici tradit Arifto. 2. de partibus animalium cap. 6 . vt fenfus effe poffit id valde praecipuum haberi, quod paucum ex multo fit nutrimento, veluti medulla ex feuo,nempe quae femper exigua ex plurimo feuo fuccrefcit : illud obiter hoc in loco adnotare volo, Platonem dum in Timaco fcriptum reliquit medullac morbum omnium periculofiffimum ef$\mathrm{fe}$, fub medullae nomine cerebrum intellexiffe, nempe quod ex genere medullarum exiftere fcripferit, Galenus fecundo de temper.\& 2.de vfu partium : fi enim me dullae nomine vel fpinalem ( $v t$ dicunt aliqui) vel alias medullas cóprehendere voluiffet, parum vera fane fuiffet illius fententia, quando non medullae fpinali, aut al teri, fed vni cerebro haec Platonis verba adaptari pof-

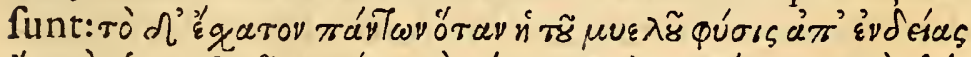

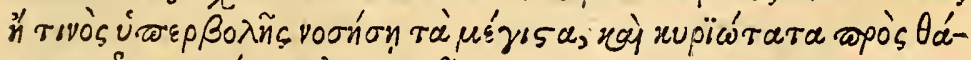

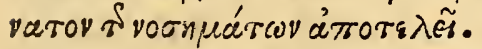

Locus Galeni, \& Caelij Aurelianiexpofita de Angina, \&

$$
\text { fomno forbili. Cap. } 10 .
$$

(5) Alenus in 2. eius, quam ad Glauconem foripfit, ( nem ex fitus partium indicatione captã demon Arans 


\section{I B E}

Atrans multorum affectuum exempla proponit ; inter ce tera de angina fecundum Latinorum interpretationem fcribit, tunc in ipfa venas fub lingua effe pertundendas, quando \& vniuerfum corpus iam exinanitum, \& paffo diuturna fit; ex quibus verbis nonnulli traxerunt anginam morbum alioquin acutiffimum a Galenc inter diu turnos aliquando reponi : quod tamen falfum effe quifque intelliget, modo Graecam litteram male ab omnibusfere interpretatam videre vellit ó $\tau \omega$ s ô

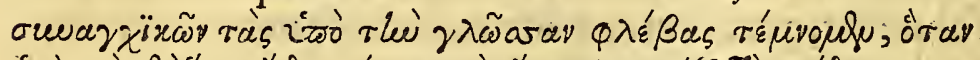

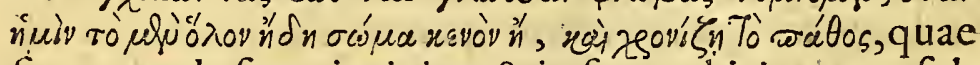
fic vertenda funt; ita igitur \& in fynanchicis venas fub. lingua pertundimus, quando iam vniuerfum corpus fit cxinanitum, paffioq. perfeucret. Quod enim zgovífety hoc in loco ficut alibi faepius perfeuerare fignificet, facile eft aequo Lectori concedere. Ceterum id praefidij genus ab Hippocrate primo omnium propofitum Caelius Aurelianus fiue potius Soranus a Caelio Latinus redditus in 3.acut. quattuor rationibus improbat : primo quod ex incifione carum venarum materia copiofior in affe đum locum tracta grauius malum reddat: fecundo quod ad hoc vt huiufcemodi adminiftratio belle fiat, laqueum collo, qui venas fubleuet, circundari opor tet, vinde fuffocationé augeri periculum eft:tertio quod fanguinem fluentem eo in loco reprimi, diuifa colligari fine manifefto periculo nequeant: quarto quod etiam. fi fanguinis fluxus inhibeatur, folent tamen loca tumida femel aperta leui qualibet de cauffa referari: Sed haec argumenta parum valent, quando corpus iam fit ita inanitum, vt aliunde materia confluere nequeat, $\mathrm{mi}$ niftrosq.optimos habeamus, qui incidere, colligare, \& fluoris periculum oinne vitare fciant. Et quoniam Caelij mentionem fcci, locum eius alterum fignare libet, qui cum libro acut.2.cap. 4.altercum bibentes opprimi 
grauatione forbili fopori fimili fcribat, aliqui non forbi li, fed terribili legendum, aut eam vocem abradendam volucrunt; ego vero neque tollendam eam, neque mutandam puto, fiquidem foporem eum elegantifime forbilem nuncupauit, in quo maximus ftertor efficitur, qui quod forbitionis clarifimam imaginem praebeat, practer fenfus fidem, etiam Plautinus ille Lucrio in Militis fabula manifeftum fecit, qui inter rogatus a Palaefrione, quid Sceledrus ageret, fic cum eo fermonem ha bet, Luc. forbet dormiens, Pal. quid forbet Lu . illud ftertit volui dicere, fed quia confimile eft, quod ftertas, quafi forbeas.

De Ificius Itrïs, \& Libis variae objeruationes explicationes cap. It.

2ay Vator is, qui problemata fub Aphrodifienfis Alexandri nomine vulgata edidit, libro corum

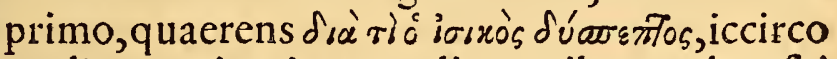
euenire tradit, quoniam in terendis carnibus multus fpi ritus immifcetur, qui eum cibum ita leuem facit, vt non in ventriculi fundo fubfiftere valeat, fed in altum effera tur femper, ficq. minus coquatur: Hoc in loco dubita-

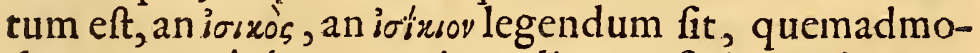
dum penes Athenaeum in 9. dipnos. fcriptum inuenitur. Ego certe textum Alexandri mendofum, \& io'insy legendum effe crederem, cum Latini quoq. noltri inficia dixerint ; fed dum cogito Alexandrum Trallianum libro 7. capit. primo, \& lib. vndecimo cap. I. eadem vo ce vfum, fit vt facile putem vocemiosxos in probl. mutari non debere, quae ratio vna cum multis aliis poterit quoque perfuadere, problemata illa auctorem habuife 


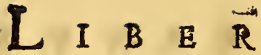

Alexandrum Trallianum, \& non A phrodifienfem, a quo omnia ea mutuauit Macrobius, quae 7.fatur.cap.8. de Ificijs difputauit. Infitia porro fiue ificia duplici mo do fiebant, vel ex varijs carnibus tritis \& pipere cô mix * tis, vt Athenaeus quoq. fcribit, vel ex pifcibus diuerfis, ficuti Alexander docet : ex illorum generibus funt falciciae noftrae non multum nomine differentes. Erat quoq. ijs fimile tetrapharmacum adeo imperatori $\mathrm{Ha}$ driano carum, quod ex fafiano, fumine, perna, \& cruftu lo compofitum fuiffe narrat $S$ partianus. Horum vero fi militudinem quandam referunt botargae, quorum inuëtorem extitifie Heliogabalum meminit Lampridius. Habuerunt quoq. veteres aliud edulii genus $3 / \tau$ piov vocatum, cuiusfaepenumero mentionem fecit Galenus, \& alii. id quomodo fieret,docuit Athenacus: apud quê

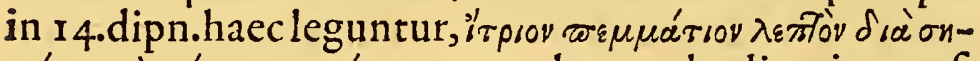

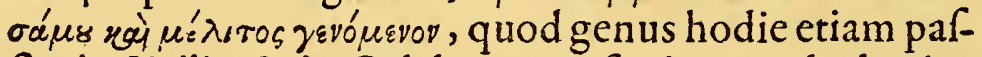
fim in Sicilia, \& in Calabria, praefertim apud Thurios populos conficitur,vbi olim Herodotus hiltoriam fuam condidit, \& vbi magna fefami, quam incolae giorgiolenam vocant, copia nafcitur, ita vt eo multis in cōdimen tis amygdalarum, quibus carent, loco vtantur; quo pacto Romae loco fefami amygdalae in vfu habentur ad conficienda itria, quae \& ibi, \& in Calabria, Siciliaq. coppettae nuncupantur. Quae vcro a Galeno itria faepius nominantur, hoc prorfus modo facta non credo, cum $\mathrm{ab}$ ipfo duplex genus tradatur, vnum $\rho^{\prime} n u \mu \alpha$, alterü $\lambda a^{\prime}$ zavov vocatum; quibus iam compactis papauer infper gi folitum fcribit in lib.de fimpl.med. puto tamen haud

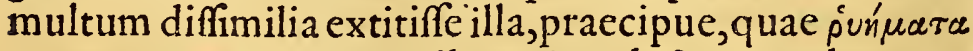
vocata memorat. Ex quibus, \& ex lacte cum placentas alias fieri confueffe fcribat, ea omnino intelligit, quae liba a Romanis nominata tradit Athenaeus; vnde qui

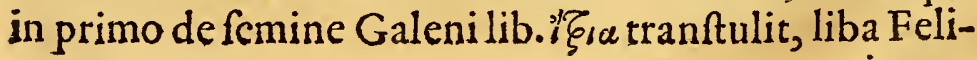

cianus, 


\section{P R P M $\$$.}

cianus, hanc rem ignorauit; quanquam \& liba diuerfimode $a b$ antiquis compofita fuiffe conijcere licet ex Catonis de re ruftica lib. quorum venditores libarios Senecam, apud quem pro libariis perperam librarii legebantur, vocaffe cum Caelio puto.

De panefurnaceo error in Galeni interpretatione explicatus, $\sigma$ alter de Myrtidano Plinï deteclus,

Quidfit tracta Plinio, or Atbenaeo Cap. 12.

Vicunque Latinis auctorum interpretationibus (1) contenti Graecos eorum contextus intelligere 4. non curant, quàm grauiter faepenumero errét, ex multis cognofcere licet; fed hoc quod nunc de pane furnaceo propofiturus fum, nequaquam minimum eft, tum quia panis, vt Alexander in primo probl.ex Home

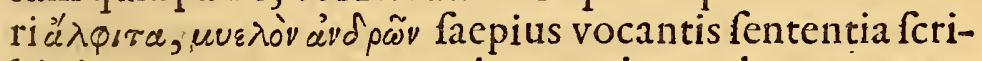
bit, inter ea, quae nos nutriunt, primum locum tenet, tum quia non parum ad valetudinis, \& vitae conferuationem eius coctura refert. Galenus itaq. in primo de alimentis varias panis cocturas referens haec ait; $x \alpha{ }^{\prime} \lambda$ -

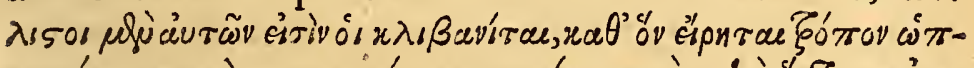

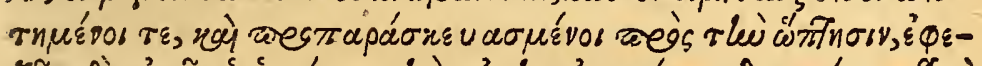

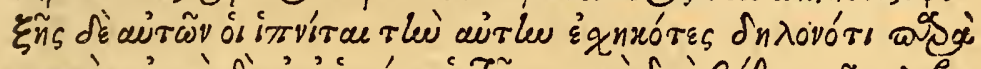

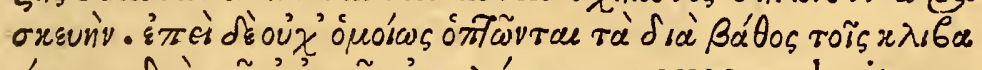

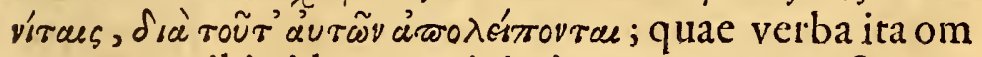
nes quos mihi videre contigit, interpretes transferunt, vt cenfuiffe videantur panes clibanitas Galeni cffe furnaceos noftros, imviras vero eos, qui in paruis coquuntur furnis, quam etiam fententiam multi deinceps nec proletarij authores diferte tenuerunt. Verum cnim uero rem contrario modo fe fe habere videlicet iтviras in furnis magnis, $x \lambda_{1}$ bavir $\alpha_{5}$ fub teftis, aut furnis portati libus coctos panes fuiffe Galeni verba demonftrant,

$$
\mathrm{D} 2 \text { quando }
$$




\section{I B E $\hat{R}$}

quando is panes ipnitas (fic mihi liceat loqui) iccirco inferiores clibanitis iudicat, quia illi non aeque extrinfecus, atque intrinfecus coquuntur, vt pani noftris furnis affato euenire ob immodcratum laterum feruorem quotidie obferuatur : hi vero nô minus intimas, quam extimas partes affatas habent, cum parui furni blandio rem quendam calorem ob eorum tenuitatem acquirät, cuilus merito exactior coctura panis perficitur; quam item fententiam expreffit Hippocrates, quădo fecundo de diaeta fcripfit, panes clibanitas ficcifimos effe ob teftae humiditatem vniuerfam exugentis calorem, ipnitas autem, quos recte furnaceos tranftulit Cornarius, magis nutrire, quam verubus, aut craticulis coctos, quod minus ab igne, quàm illi, vrantur. Quod porro

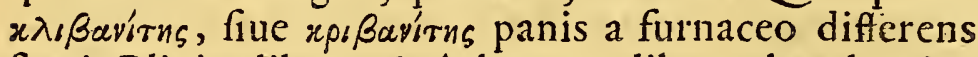
fuerit,Plinius lib. 1 8. \& A thenaeus lib.3.adeo clare indicarunt, vt amplius quicquam de hoc dicere minime opus habeam : illud addam non effe medicis ignorandum, panes noftros, quos vere iтrvitas Hippocratis \& Galeni facimus, non cfie prorfus innoxios: effe autem innocentiores illos, qui fub paruis teftis coquuntur eo pacto, quo apud nonnullos homines bifcocti parantur, quos fi clibanitas panes appellemus, neq. a veritate, nequea veterum appellationibus fortaffe recedemus. Inter panum genera fuerunt, qui tractam ab Athenaeo \&c Plinio voce (vt credo) Romana appellatam adnumerarint; fed ego ijs affentire nequeo, licet putem fuiffe quá dam pafae farinaceae fpeciem, quae pani adfimilabatur. Quod fi etiam noftra antiquis conferre par eft, tracta erat quaedam mixtura ex fermento \& farina confla ta, quam manibus faepius in formam longam \& planam trahebant, vnde nomen trastae emanauit, quod etiam hodie apud aliquos Italiae populos durat, qui huiufcemodi placentas ex fermento, \& farina compactas, ac 


\section{P R I M P}

deind e furnis coctas tiratas a trahendo populari vocabulo nominăt. Plinii verba loco fupra citato haec funt; Durat fua Piceno in panis inuentione gratia ex alicae materia. eum nouem diebus macerant, decimo ad fpeciem tractae fubigunt vuae paffae fucco: A thenaeus au

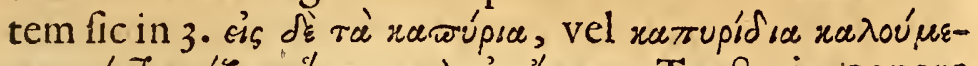

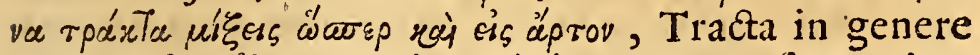
ncutro pluralis numeri, vt Athenaeus profert, etiam apud Catonem faepius nominata inueniuntur, \& (vt reor ) eafunt, quac hodie tortis fubtus, \& fupra coqui ponunt, foliaque fiue fpolia vocant. Et quoniam Plinii fatta eft mentio, eius ( ni fallor) errorem fubiiciam : is enim libro 15 . cap. 3 r. fcribit Veteres antequam piperis vfum haberent, loco eius baccas myrti vfurpanfe : quod cum neque apud alios auctores hactenus mihi eam rem diligentiffime perfcrutanti legere contigerit, neque admodum rationi confentaneum videatur, inde potuit faciliter Plinius errandi occafionem caepiffe, quod ( $v t$ auctor eft Galenus in expo. voc. Ant.) myrtidanum plurimi $\varpi_{\varepsilon}^{\prime} \pi \varepsilon p s$ nominarent, quemadmodum Hippocrates fructum myrti myrtidanum \& ipfe vocauit, ficque piper ab aliis vocatum fcripfit .

De aquis Veficarÿs \& Caeretanis Galenilocus de templo Pacis male a Giraldo intelleEtus. Cap. 13.

Vltas habuerunt maiores noftri balnearum a-

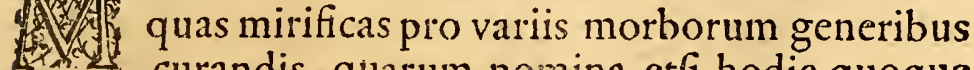
curandis, quarum nomina etfi hodie quoque apud autores conferuentur, ipfae tamen vel oblitae funt, vel ignotae, ficuti aquae Nepefinae a Caelio Aureliano inter Italiae nobiliores adnumeratae. Atg. etiam A uguriae, \& praeter has Veficariac ac Ferratae a Scri- 


\section{I B E $R$}

a Scribonio Largo, \& Marcello Burdegallenfi nomina cae, quae poftremae cum vbifuerint, a nemine adhuc notatum viderim, me operae pretium facturum fpero, fi quid fentiam, manifeftum fecero. Scriptum itaque apud praedistos inuenitur auctores, in Thufcia aquas extitiffe ferratas, quae mirifice veficae vitia emendabant, vnde veficariac vocabantur: locus vero Milonis Brochi, fiue Gracchi practoris hominis optimi ad quinquagefimum ab vrbelapidem erat: Has balneas olim Viterbienfes effe putaui, quod illae fint in Thufcia, vefi cae morbis adthibeantur, \& paullo minus, plusve quinquagefimo lapide $a b$ vrbe diftent; fed cum anno fuperiore Centum cellas, fiue ciuitatem veterem, Alexandrum Farnefum Cardinalem maximum fecutus, petijffem ; locum confpicatus ab co oppido duobus milliaribus diftantem, vbi veftigia antiquarum balnearum, \& amplifimi aedificij apparebant, volui diligentius omnia intueri, tandemq. reperi, ibi egregias aliquas balneas fuiffe extructas, ad quas ex propinquis montibus per fubterraneos cuniculos aqua ducebatur; vnde in eam coniccturam veni, poffe fieri, vt illae effent aquae ferratae a Scribonio \& Marcello nominatae; ad quod. credendum pluribus rationibus inductus fui. Primò quòd locus ille fit in Thufcia; Secundò, quod ab vrbe quinquagefimo lapide, fi via Caffia eo perueniamus, diftet; Tertiò, quòd montes illi, à quibus deriuabatur, fer rati etiam hifce temporibus vocentur, nempe quia ferrum ibi nafcatur, vt aquas fimiliter vi ferrea praeditas effe conueniat; $Q$ uartò, quòd incolae morbos veficae nterdu m earum aquarum beneficio curent : quáquam vfq. adeo deturpatae \& imminutae funt, vt pauci illis vti vclint: quod nullus alius locus vrbi hodie propinquus cognof catur, cui magis balnearum illarủ conditiones adaptari queant. Iam vero quales fuerint huiufmodi ba- 


\section{$P_{R}$ I $M \vee S$.}

lincae ex Iconographia cognofcetur, quam Pyrrhus Li gorius totius antiquitatis omnium noftri temporis hominum vir peritiffimus ex fitu acceptam apud fe habet. De caeretanis balneis Strabonis tempeftate ad curandas aegritudines varias maxime aeftimatis iam dubitaui, nunc certior factus Caere nobiliffimam olim vrbem prope eas aquas fuiffe fitam, quae fitilianae hodic vocantur ad credendü permotus fum huiufcemodi aquas antiquas quidem immo ipfa Caeretanea balnea a Strabone nominata effe; \& quanquam multis temporibus latuerint, ac fere nihil de illis ab auctoribus fcriptum inueniatur; hifce tamen temporibus non parum celebrantur ob mirificam opem, quam in curandis omnigenis fere cutaneis affectibus quotidie praeftant. His de templo Pacis Romae errorem Gregoriij Girarldi fubne etam, qui auctoritate quadă Galeni falfo intellecta permotus id ab aegrotis frequentari confueffe primo de Diis gentium libro fcriptum reliquit, cum nullibi legatur in illo, aut in alio templo eos vnquam verfatos, prae terquàm in infula Tiberina, vbi Aefculapij aedes fitae erant, \& quodam alio loco in id exftrueto, vt qui ad ludos Circenfes venirent $f$ f forte fortuna aegrotaffent, ha berent vbi commode curari poffent. Sed ne videar gratis Girarldum improbare, Galeni fentêtiam in medium ponam, qui in principio libri primi de differentijs pulfuum medicos fui temporis coarguens, quod de nominibus pulfuum futiliter contenderent, ait faepenumero inter eos excitatas effe contentiones fimiles illis, quae inter medicos in templo Pacis,vel fuper aegrotos difpu tantes oriri folebant; quod enim in templo Pacis conue nirent, omnium rationalium artium profeffores ad difputandum, ipfe met Galenus in fermone de libris propriis maniffftum fecit : quod etiam Romae medici non raro fuper aegrotos digladiarentur, videre eft in pluribus 


\section{I B E}

bus eiufdem commentariis : verba Galeni citata a Giraldo clara funt. De medicis enim eum, quem dixi fer-

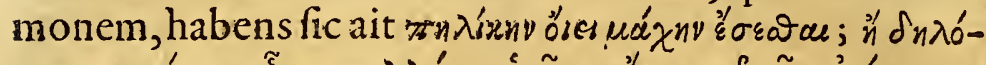

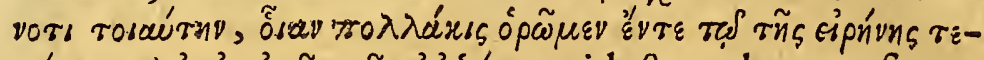

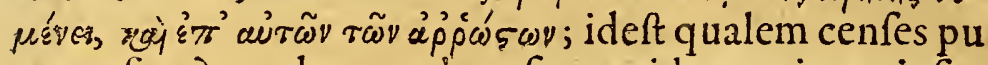
gnam fore?an talem qualem faepe videmus inter ipfos ortam in templo Pacis, atque etiam coram ipfis acgrotis? A ttamen id ignorari nolo alibi, quam Romae, languentes in templis quandog. detineri folitum fuiffe, vt curarentur, quod locupletiffime teftatus eft Strabo in 8. Geograph. lib. vbi memorat in Epidauro, Coa infula, \& T Tica Aefculapii fuiffe aedes, in quibus magna aegro tortim copia nutriebatur, tabellaeq. cun curationum inferiptionibus pédebant. An vero idem, vel quid fimi le fuerit valetudinariü, cuius loci habetur mentio apud Senecam lib. I.de ira, \& apud Columellam lib. I r. cap. I. I 6. \& lib. I 2. cap. 3.7. certe affirmare non audeo. pu to autem fuiffe peculiarem locum in vnaquaq. priuata domo, vbi ferui tantum infirmi curabantur, \& detinebantur, eo pacto quo hodie in monachorum coenobiis fimili muneri peculiaris locus dicatus confpicitur.

Error in Aetio correctus de Ficubus, of alia de ipfis: Columellae de Embammate locus emendatus. Cap. I4.

20 Bi remedia extinguendae fiti demonftrat Aetius . Iib.9. inter cetcra pro tollenda corum, qui ab 2. imbecillitate vires recuperant, fiti ficus ficcas fe cundum Cornarij translationem in cibo acceptas commendat; quae fententia cum femper mihi fufpecta fuif-

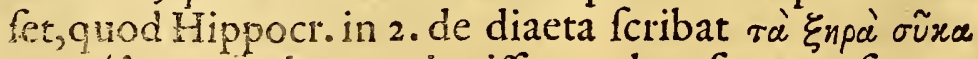
rosocídses, tandem antiquifimo vltra fexcentefimum annum codice mihi Meffanae, dum ibi cum Alexandro Farnefio patrono meo effem, cóparato, inueni loco ficcarum, legi debere, viridium : fic enim contextus meus habet 


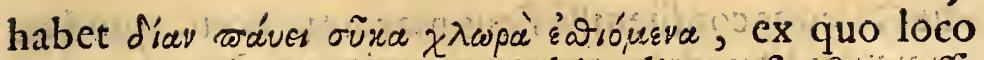
quènadmodum etiam ex multis aliis perfpectum effe potef, Cornarium habuiffe codices valde depratatos, id quod fi valecudo mihi concedet, intra paucos annos magna eruditor $\tilde{i}$ vtilitate \& in Hippocrate, \& in Aetio oftenfurim me polliceor. Ficus igitur virides fitim auferfe non folum medici dixerunt, \& praefertim Hippo.

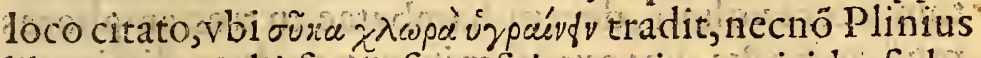
lib.2 3.cap.7.vbi ficcás ficus fitim excitare, virides fedare fcribit, verum etiä Martialis cognouit, quädo fcripfit Cbia fenifimilis Baccbo, quam setia mifit, Ipfa merum fécum portat, o ipja falem.

Poft ficus (vt Heraclides Tarentinus apud A theraeú dif ferit)alij calidam aquam, alij frigidam effe potãda $m$ voluerunt: qui calidam praetulerunt, his rationibus indu Eti funt, quòd ficut calida manus magis abftergic, quàm frigida, pariter citius eluit ventriculum, \& inteftina, ne ficus ibi diutius retineantur; addebant calidam aquam extra pofitas ficus magis diffoluere, frigidam nagis con ftringere, quod item ficubus intro acceptis euenire rationi congrum eft. Qui vero frigidam bibi debere putarunt, frigido dicebant poculo côfidentia in ftomacho \& grauia deorfum ferri ; \& iccirco ficus, quae ftomachü vexant, citius ab eo defcendere; Qua ratione alij fuper potabant merum, perfuafi nempe quod piompte, quae effent in ventre, deorfum propelleret; Oportere.n.aiebant polt ficus multo denfoq. vti poculo, ne illae in ven tre cômorentur, fed in inferiores inteftinorum partes ce leriter deferantur. Arifto. quoq. in probl.ficubus fuper potandun vinü credidit, quod vt ignis paruus a magno extinguitur, fic exiguus ficuú calor a vini maiore vincat;; idem ante ipfum cômendatum fưit ab Hipp. 3 . de diaeta lib. in iis, quibus ob frigiditate infirmus eft ftomachus. Non fuit abfq. vtilitate rufticorum infitutum, quos tra E dit 
dit Galenus, confueuiffe ficus macerare aceto, quod earum vifciditatem magnopere corrigeret. Non inconue nit ve hoc loco detegam errorem, qui hactenus in Colu mella a nemine, quem fciam, animaduerfus, \& emendatus fuit, praeterquam a Latino Latinio Viterbienf acris iudicij \& fingularis doctrinae ac probitatis viro;in lib. enim 12. cap.34. frc legitur, Qui fcilliticum acetum facere volunt, decem bambatae in tres amphoras mufti mitis \&c. vbi quid fignificent ce duae dictiones, [decem bambatae] nec Apollo fane intelligeret. Quare illa verba [Qui fcilliticum acetum facere volunt] extremis antecedentis capitis iungenda funt; deinde titulus fubfequentis Capitis apponendus feparatim [De Embammatc] poftremo incipiendum fequens, Caput In tres amphoras mufti : Hunc in modum clariffima erit Columellae oratio, qui eodem lib.cap.55. Sinapim faciendi rationes plurimas docens cuiufdam Sinapis ad Embammata idoneimentionem fecit: Quod porro fcri pfit VIpianus 1. fi quis Embamma fuiffe loco aceti, val de defriptioni embammatis Columellae quadrat; cui magna aceti poittio admifcetur. Sic etiam Latino intinetus nomine vfum Plinium reperio. Itaq. Turnebum alioquin doctiffimum probare nequeo, dum in.17. ad nerf. lib, cap. I 3. bambatae, vocem non mutandam leui bus quibufdam rationibus contendit .

Locus Tlutarchi de Pithoegüs emendatus : o De festo primae Augustidiei. 'Cap. I5.

(3) Omanos vina, quae annum faltem praeterijfent 19. vt plurimumbibere confueuiff, ita clare fcriL_ ptum habetur apud Galenum,aliosq.auctores, vt filperuacaneum iudiccm illud amplius demonftrare. Nam vinalia fefta deguftandis vinis inftituta XIII. Kal. Septem. 
Septemb. fiebant, vt Plinius fcribit, quae autem idem IX. Kal. Maij fieri folita tradit ab Aenea fuiffe inftituta meminit Ouidius 6. Faftorum. Graeci vero quod eadem noua necdúm fextum menfem adepta frequenter potarent, Galenus quoq. teftatus eft, qui in Com. fup. primum de Nat . hum. rationes varias exponens, quibus hieme pituita adeo copiofa in homin um ftomachis gignitur inter multas, quas recenfet, eam ponit, quod plurimi tunc noua vina bibant, quae aptiffima funt in pituitam conuerti : quare Plutarchi codicem in 8.fympo. Io. deprauatum effe puto, vbi haec in vulga-

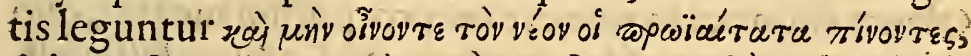

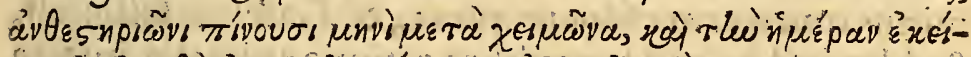

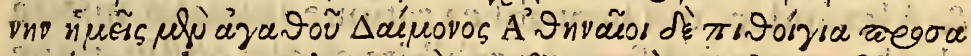

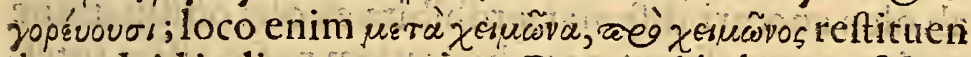
dum ob id iudico, quoniam Gaza, cui in hac re fidem maximam adhibeo, contra nōnullorum opiniones ảv รnpiôva Nouembrem menfem fuiffe contendit, raitoóziza vero quod menfe Nouembri celebrarentur, ficuti noftris temporibus in omni fere Europa vndecima Nouembris, qúae D. Martino dicata eft, die, multiauctores teftati funt, etfi Io. Grammaticus Ianuarij merife il lud factitatum fcribit. Quae fupra dixi vinalia XIII: $\mathrm{Kal}$ Septembris Romae fieri folita, ea puto, quae paffim hodie in Italia Kal. A ugufti celebrantur : vt enim feftailla in die, qua fidicula fydus oriri incipit, Autum nusque incohat ad tempeftates leniendas (quemadmodum fcribit Plinius libro is . cap. 29.)

inftituta erant, fic noftris tempo-

ribus prima Augufti ad excantandam

menfis prauitatem fieri videntur. 


\section{I B}

De oleo, \& butyro, aphrogeala, Daria Galeni \& aliorum explicata. Plinülocus correctus. ... Cap. 16.

7. Oquos antequam vel pifces, vel carnes affarent, (1) oleo inungere folitos refert Galenus 2. de fimpli. medic quod ideo ab ipfis factitatum credidit, ne exteriores partes vi ignis exuftae confumerentur, interiorumq. coctionem impedirent : ego vero potius ob id factum exiftimo, ne carnium \& pifcium inteftinus, atq. proprius humor extra flueret ; fed intus cohibitus, \& coctus iucundiorem cibum palato redderet: Oleum cnim occludere extimos corporum meatus, quo minus quicquam cffuere queat, \& Galenus faflus eft, \& Alexander, qui in probl.ea ratione animalia infecta ab oleo enecari difputat, prohibita ex olei obftipatione natiua eorum fpiratione : hoc autem pacto affata intellexiffe Ariftotelem verifimile eft, quando in 4 de mixto rum affectibus libro ea elixatis humidiora facit. Quod deinceps oleo cocta non ita vrantur, ve Archidamus cenfebat, in hoc iure a Diocle damnatus, Auerroes Ara bum omnium doctiflimus in 5 . collectaneorum lib.mon ftrauit; vbi conterraneos fuos oleo carnes omnes coquendi morem habuiffe, quia fic delicatiores \& meliores euaderent, pluribus demonftrat. Olei mentionem non incógrue butyri tractatio fequitur, nimirum, quod apud gentes, quibus oleum deerat, butyrum etiam in arngendis poft balnea corporibus pro ipfo fuppleret, ve notauit Galenus, nosq. in libris noftris Gymnafticae monftrauimus. Habuerunt quidem veteres varia butyri genera, fed pharmaci potius loco, praefertim apud nobiles, quam cibi illis in vfu erat, vt non immerico Pli nius butyrum gentium barbararum laudatiffimum cibum, quive diuites a plebe difcernerct, appellarit: hac namq. ratione fautum puto, vt A thenacus, qui in fuo 
conuiuio nullum cibi genus praeterijt, butyri nunquam mentionem fecerit. Non poffum certe mirari fatis, cur Galenus Diofcoridi impofuerit, quafi butyrum ex ouillo tantum \& caprillo lacte trahi fribat; cum fi eius litteram confiderare velimus, nunquam ipfum negaffe, quin \& ex, bouillo fieret, fed bonum ex ouium, atq. etiam caprarum lacte ficri cenfuiffe reperiemus; quae fententia vera putari debet, qucmadmodum verum eft,cafeum ouium, \& caprarum bonum effe; Diofcoridis mentem de butyro fortaffe explicans Plinius di xit, Plurimum e bubulo \& inde nomen: pinguiffimum ex ouibus fit, \& ex caprino, quo in loco"Plinij verba quaedam mihi fufpecta redduntur, quoniam de butyri effectibus fermonem habens, haec fcribit. Natura eius aftringere, mollire, replere, purgare. Nam practerquam quod duo ifta fibi aduerfantur, mollire 8 aftringere, a nullo quoque auctore butyro aftringendi facultatem attributam legi : neque id rationi \& eius temperaturae confonum videtur; quocirca pro aftringere, digerere, reftituendum duco, cum praccipua, quam butyro Galenus afcribit, facultas fit digerendi vis. Butyrum item ex equino lacte Scythas factitaffe memoriae mandauit Hippocrates, fiue Polybius quarto de morbis. Quod vero fcribit Plinius libro vndecimo,capit. 4r. barbaras gentes confueffe lac in iucundum acorem condenfare, \& butyrum pingue quod fpuma lactis effer, nil aliud intelligit, quàm oxygala, \& aphro gala apud Romanos maxime aeftimatum, \& nive re-

frigerari folitum, vt Galenus feptimo methodi narrat, idem enim hodie

apud multos inter fua-

uiffma edu -

lia fub nomine capitis la

ctis reputatur. 


\section{L $\mathbf{I}$ B $\mathbf{E}$ :}

De vino dulci, \& de confenfu Aristotelis, \& medicorum explicatiloci. Cap. 17.

are Inum dulce neq. inebriare, neq. a frigore denfa ri fcriptum reliquit Arifto.4. meteorolo . quod etiam confirmauit 3 . probl. fect. Hace tamen féntentia ab omnibus fere improbatur, quod certa experientia conftet innumera prope vinorum dulcium ge nera reperiri, quae infignem potoribus ebrictatem inNucant : Vnde melius cenfuiffe iudicant Hippocratem haec in 2 ad fentétias Gnidias libro fcribétem órfi $z \lambda v$

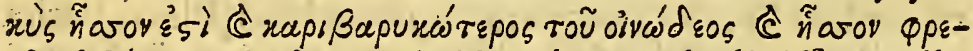

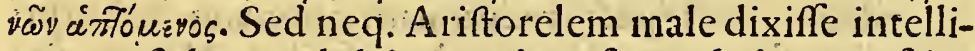
gemus, fi de quo dulci vino ab eo fermo habeatur, fcicmus : Inuenio apud Plinium \& Galenum protropum vinum, fiue prodromum quod ex Gnido, \& Lesbo Ro mam aduehcbatur, maximo in pretio habitum effe, non modo pro varijs medicamentorum compofitionibus, verum etiam pro divitum \& nobilium menfis ; cuius etiam meminit Vitruius lib.8.cap.3.vbi loco protyri, protropilegendum prudenter monftrauit Philander: Hoc autem crat mustum fponte defluens, antequam vuae calcarétur,quod protinus diffufum lagoenis fuis deferuere paff, poftea in fole quadraginta diebus torrebant aeftatis fecutae ipfo Canis ortu; Similiter factum inuenio olei genus qnoddam gleucinum, \& lixiuium a Latinis vocatum : Erat id vinum maxime dulce, vt videatur quandoq. inter dulcia primum locum tenuiffe; quemadmodum A thenaeus libro primo hifce teftatur,

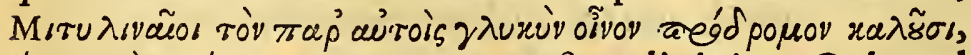

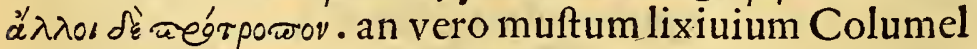
lae, fiue muftum lixiuium fucrit hoc protropum, confiderent alij:Itaq. cum in Graecia protropum vinum dul cenuncuparetur, ibiq. praeftantius, quàm alibi nafcere 


\section{$P$ R $I$ M}

tur, atq. tale minime inebriare perfpesum fit, credere cogor, Ariftotelem fub nomine vini dulcis, non quodli bet vinum dulcedine praeditum, fed hoc vnum genus Graecis quafi proprium duntaxat cóprehendiffe. Quid

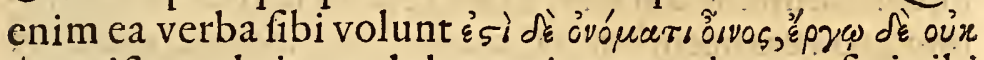
¿ $\tau$, nifi quod vinum dulce, cuius mentionem facit ibi Arift. erat naturae cuiufdam inter vinum verum \& mu fum mediae, cuiufmodi protropú fuiffe innuit Plinius, vt quemadmodũ mußtum haudquaquá ebrietatem parere in probl.monftrauit Arift. \& polt ipfum luculenter cóprobauit Plutar.in fymp.qué Macrobius fat.7. latine loquentem fecit, pariter in 4. meteorol.de vino dulci fi ue protropo idem enunciarit, nempcquod vt temperatura a mufto parum recedebat, fic etiam viribus ei fimile exifteret, nifi potius libeat pro dulci ab Ariftotele paf fum acceptum efle, non tantum quia Plinius illud inter dulcia collocat, fed quoniam Polybius in 6. auctor eft nec non Varro, \& Gellius Romanas mulieres vino interdiatas huiufcemodi paffum bibiffe, quafi ab eo nullum ipfis periculum ebrietatis immineret. Ex prob. Ari ftotclis aliud item mihi in mentem venit adnotare, a pud quem r.\& 4. fect. coitum morbos quofdam ex pituita

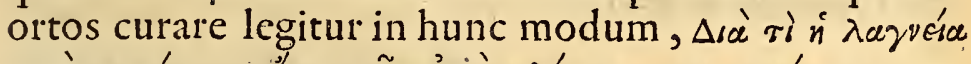

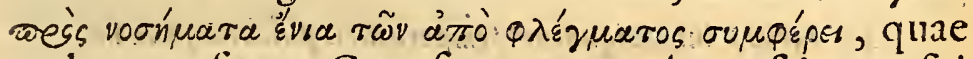
verba transferens Gaza femper $\lambda \propto \gamma$ víav, nefcio quo fpi ritu, immoderatum coitum eft interpretatus: et fi namq. ea vox $\lambda$ ayvés interdum Hippocrati femen fignificet, vt Galenus in expof. voc.ant. fcriptum reliquit, nünquam tamen ab ea coitus immoderantiam defignari certum

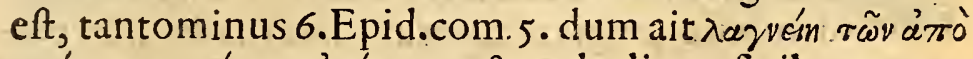

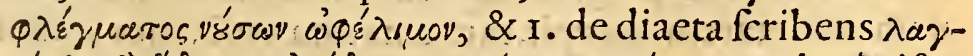

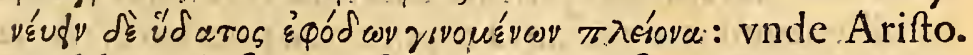
problematis fui occafionem accepiffe videri potet, \& vnde quoq. Dioclem ab Athenienfibus(vt fcribit Theo dorus 


\section{I B E R}

dorus Prifcianus) iuniorem Hippocratem vocatum fua mutuaffe puto, cum in epift. ad Antigonum Regem fcri pfit, folftitio hiemali, quando plurimum exuberat pitui ta,concumbendum effe. Hácc etenim fententia non folum pro vera accipitur a Galeno \& Auicenna, modo vi res fint firmae, immo etiam ab eodem Hippocrate duobus exemplis valde confirmatur : quorum alterum eft Thimocharis, quem in 5. Epid. refert, hieme a catharro in nares maxime defluente folicitatum, coitu omnem humorem exicaffe : álterum eft Hicippi, de quo refert in 4. Epid.quod nofturnam pollutionem febriens pluries paffus, nullum nocumentum fubiit, imo leuatus eft, ut male cenfuiffe uideatur Petrus Apponenfis, quando problema Ariftotelis exponens, coitum quemcunque in febribus femper obeffe fcribit, ficúti quoq. damnari meretur Clinias ille Pythagoricus, quem refert Plutarchus 3. fympo. interrogatum, quando mulieribus com mifceri expediret, tunc praefertim, refpondiffe, quando quis damnum aliquod pati uelit; quamquam idem Plu-

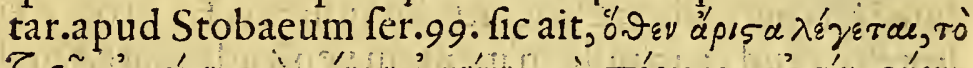

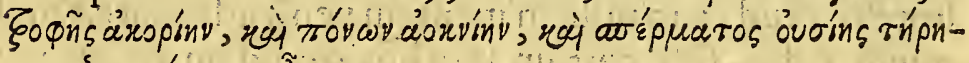

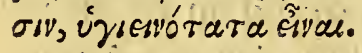

De varÿs Vini antiquorum temperaturis pulcbra quedam: locus Hippocra. illustratus, \& alius iAthenaei correctus, Hefiodiq. fententia interpretatur Cap. 18.

in In aquae primum mifcere coepit Staphylus Sitheni filius (ut fcribit Plinius) fed huiufcemoa di mixtio longis temporum interuallis non paruam varietatem accepit, tum à natura vini ; tum à natu ra bibentium; tum etiam à téporc quo potabatur: A na tura vini primum variata eft mixtio, quando Maroneú uicies tanto aquae addito ob cius vim mifcendum effe voluit 
voluit Homerus; cuius generis vini facultas, vigorq. indomitus etiam Mutiani ter Confulis tempore durabat, qui eius fextarios fingulos oftonis aqux mifceri comperit: fic.n.falcrnum indomitum vocauit Iuucnalis, quod vix \& ipfum multa aqua domaretur; ut Ga-

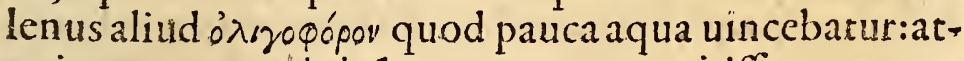
qui communes uini téperaturas tres extitiffe ex prouel

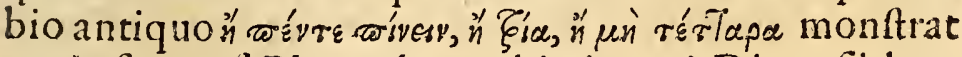
tertio fympol. Plutarchus, vbi ait; qui Dionyfii harmonias callebant, eos tres vini cum aqua confonantias afpexiffe, fefquialteram, diapafon, \& diateffaron: só́yte namq. hemioliam denotafle, quae efficiebatur tribus aquae partibus duas vini addendo, $\zeta_{\text {ice }}^{\prime}$ indicaffe diapafon, quae fiebat vni vini partiduas aquae immi-

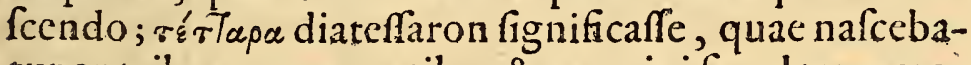
tur ex tribus aquae partibus $\&$ vna vini fimul temperatis : Additidem Plutarchus poftremam \& fequitertiam portionem tanquam remiffam $\&$ fobriam ijs in vfu fuif fe, qui in Prytaneo dominabantur, \& qui philofophiae aut contemplationibus incumbebant, nempe quos mente praeditos, atq : fobrios effe conueniebat; de qua etiam temperatura Ion Poeta apud Athenacum felmonem faciens dicebar.

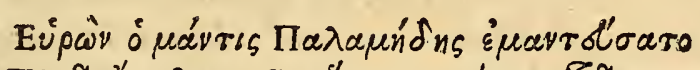

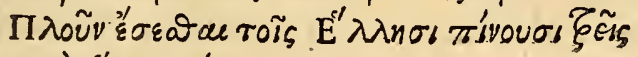

Mpóséva ruávous

Alios vero a praedictis eam mixtionem effugiffe, vnde Menander apud Athenaeum \& $\gamma^{\prime} \delta^{2} \alpha^{\prime}$

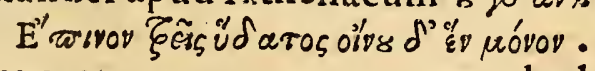

Temperaturam porro, quae ex duabus aquae partibus, \& vna vini mixtis conficiebatur, mentem turbare, \&leué quandam ebrietatem inducere creditã; cam aùt 
quae ex duabus vini partibus aquac tribus mixtis fub

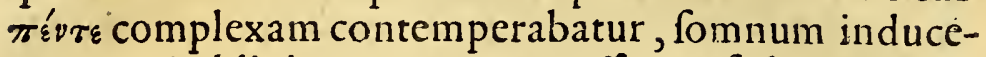
re, curarú obliuionem parere, paffiones fedare dictam: Sed illud mávre rívew fecus intelligi debere Athenaeus cenfuit, qui hanc mixtionem ex duabus vini partibus, \& quinque aquac factam fuiffe fripfit, atq. ad id comprobandum nonnullorum poetarum teftimonio vfus

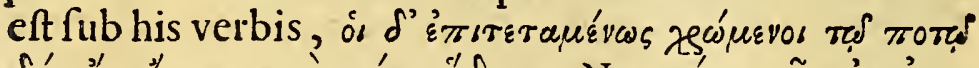

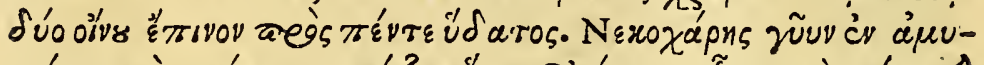

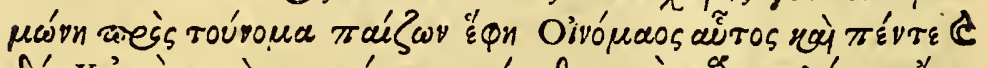

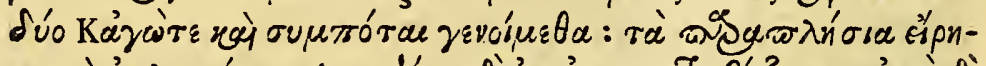

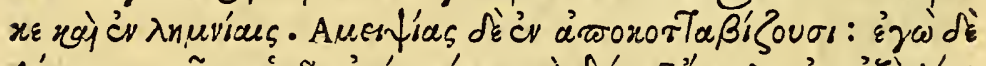

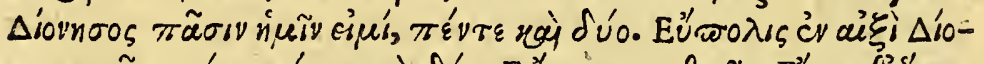

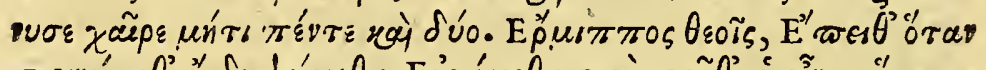

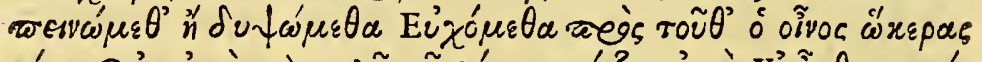

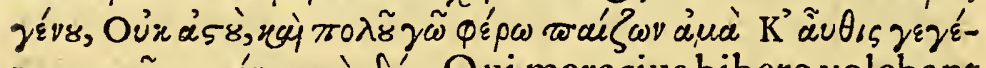

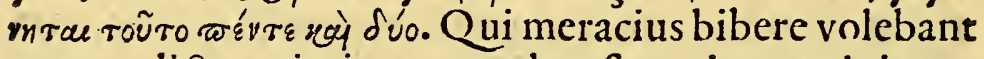
praeter dictas mixtiones ex aduerfo quinque vini partes duabus aquae mifcebant, id quod Athenaeus idem

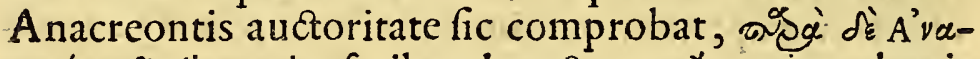

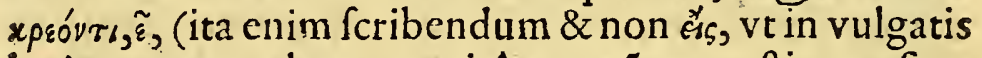
legitur, neq. vt legunt, qui Anacreōtem reftituere funt profeffi) ó,

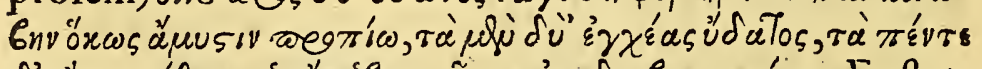

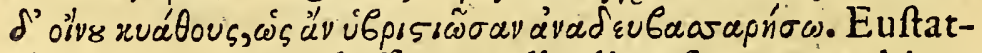
chius in $x$ com. Odyffeae paullo diuerfius prouerbium illud eft interpretatus, vbiait $\xi_{i a}$ fignificaffe vnius vini cyathi cum duobus aquae confufionem; øévre duorum

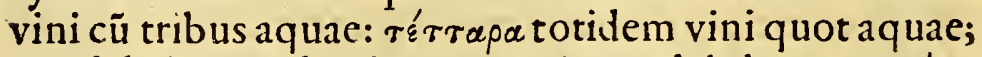
quod dicitur \& ab Hippocrate, \& apud A thenaeum / loov i $\%$. Ab his uero extitiffe \& quartam bibendi rationem,

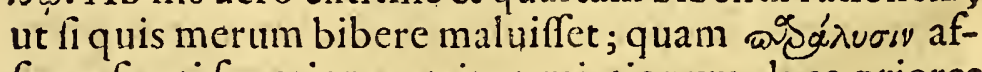
ferre, ficuti fuperiorum trium mixtionum duas priores hominum fanorum effe, \& tamen hilarorum, poftre-

mam 
mam infanorum fcripfit. Poteft alia fortaffc non inepta piouerbij й ferri; quod illo vetaretur quartum cyathum, fiue vltra quintum potari, fed vel tertium duntaxat, vel vfq. ad quintum. Scribit Plinius a Democrito conditum effe volumen, quare cyathi quaterni, \& fextarij non effent potandi. Eubulus quoq, apud A thenaeum quartú cyathum $u^{\prime} b \rho \omega s$, fextum $x \omega \mu \omega v, \&$ poft hunc alios aliorum vitiorum effe maiorum fecit; vt intelligere poffimus quartum cyathum nunquam laudatum. A natura bibentium quoq. variata fuit vini temperatura, quoniam fani \& natura calidi ac defides maiorem aquae menfuram adhibebant; ex aduerfo frigidi, debiles, \& exercita ti minorcm; \& propterea fenes(vt difputat Plutarchus) qui magis mero gaudent, meraciorem mixtionem femperfecuti inueniuntur : idq. A chilles a pud Homerum animaduertens, cum Phoenicem \& Vlyffem fenes effe, ac in armis tota die occupatos, ob idq. non aquofo, fed meraciore vino, quemadmodum ccteros fenes, gaudere fciret, vino paucum aquae mifceri iubet fub hifce ver-

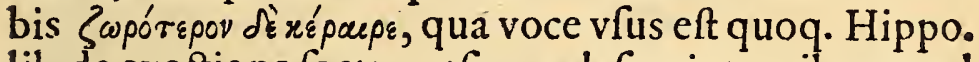
lib.de exectione foctus, etfi non defuerint, quibus apud Plutarchum hanc homericam fententiam in diuerfos trahere fenfus placuerit. In anxietudine, ofcitatione,

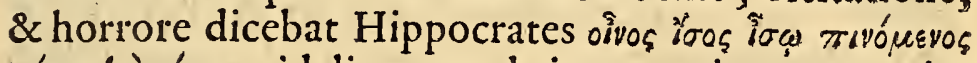
$\lambda u^{\prime}$ r $\tau$ lé v'śov, videlicet quod vinum pari aquae portione epotum foluit morbum: quam mixtionem appellans meraciorem Galenus fub his verbis, हैrasor ริ้ $\tau \tilde{\omega} y$ cipn-

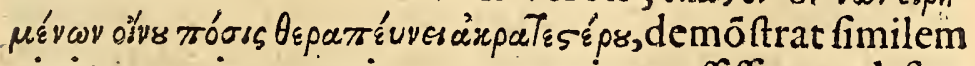
vini temperiem magis mero ceteris acceffffe, quod fere femper in ceteris mixtionibus aquae menfuram vinum fuperaret [ảnparésqpov] merum, vel mixtionem mero magis accedentem defignare etiam ex his apud Athe-

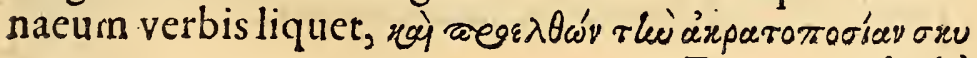
F 2 Oixlei 


\section{L}

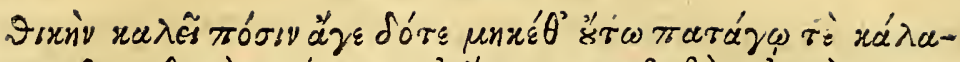

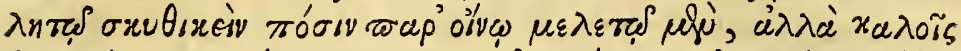

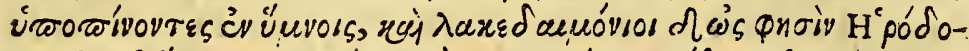

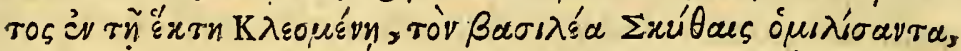

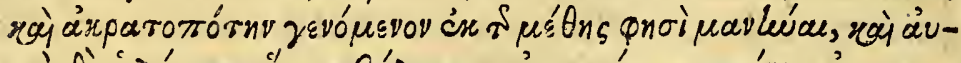

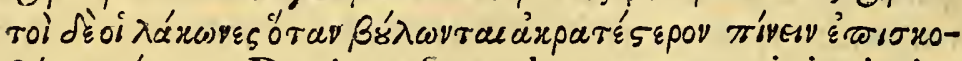

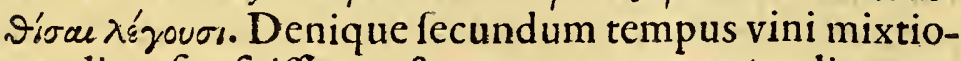
nes diuerfas fuiffe contat, cum praeter medicorum praecepta, qui dilutius aeftate meracius hieme bibendum voluerunt, etiam ueterum mores atteftentur. De liberis \& ingenuis loquor, quoniam me non latet $\mathrm{Ca}$ tonem praccepiffe, ut mancipia, \& vniuerfa ruris familia hieme aquofius \& parcius, vere $\&$ actate, quando magis laborarent, largius ac meracius potarent, quo modo Hcfiodi lententiam interpretandam puto, qui meracis potionibus per viginti dies ante Canis or tum, totidemq. poftea uti fuadet.

\section{De infibulatione, of quidfit apud Galcnum dicere pedem. Cap. XIX.}

Vod veteres fabulas tam tragicas, quam comi(2) cas non fermone, ut hodie fit; fed altis tiocibus cantibusq. recitarent, praeter Arift.in prob. atq. aliorum auctorum teftimonia, Galenus quoq. nofter affirmauit; vbi comoedos ac tragoedos ad conferuandam uocem frequentibus balneis \& laxantibus edulijs vfos narrat : quo in loco mirari foleo, cur illud artificij genus practerierit, quod anticui ad tuendas hiftrionum voces in vfu habebant, infibulationemq. nuncupabant; quae tametfi ualecudini quoq. inferuiret ( ut Celfus fcribit) virginesq. apud Lcnones a fer uis defenderent, quemadmodum hoc tempore eunucho- 


\section{P R I M V S}

nuchorum euiratio penes aliquas nationes, \& cquarum infibulatio apud Veterinarios, praccipuus tamen eius finis extitit, ne coitum exercere pollent, quem in mutandis, atq. corrumpendis vocibus quantum momenti habeat, nemo ignorat . Neque vero adolefientes tantum ( vt ait Celfus) infibulatos, verum etiam adultos, \& quod maiori admiratione dignum verpos ac recutitos credo; cum a luuenale fic fcri prum legatur Sati. 6.

Soluitur bis magno comoedi fibula:

si gaudet cantu, nullius fibula durat

Voceill vendentis Praetoribus.

Nec non a Martiale libro 7 .

Menopbili penem tam grandis fibula vestit,

$V t$ fit comoedis onnibus ona jatis. OH iterum

Dum ludit media populo pectante palaestra,

Hencecidit mifero fibula, Verpus erat.

His omnibus admoneor, vt locum Gateni a paucis intellectum in medium proponam, qui in finc fecund: libri de motu mufculorum : De exfufflatione fermo-

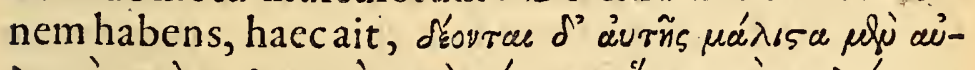

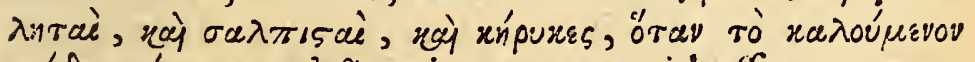

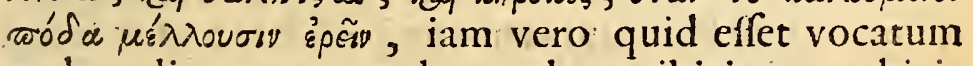
pedem dicere : quem decantabant tibicines, tubicines, ac praccones, nondum recte a quoquam explicatum obferuaui : Conijcio tamen fuiffe quoddam concitatiffmi fonitus, cantusq. genus, haud abfimile illi, quo noftri ad excitandas pugnas vtuntur : perinde ac dicere pedem, aliud nil foret, quam fono, vel cantu vehementiffimo ad pedes, uel in pugna, uel in curfu agendo mouendos infammare; qua in re non exigua exfufflatione opus effe animaduertunt illi,qui horum buccas diltentas, inflatas, ac rubentes infpiciunt.

Ramex 


\section{I B E R}

Ramex quid fit apud Plautum, hrfforia Domnini, nönulla de varicibus o de birudinibus. Cap. 20.

Amices apud medicos proprie venas tumidiores, atq. craffiores alio vocabulo varices nuncupatas, quae vel tunicis tefticulos veftiétibus, vel ipfi fcroto innafcuntur, fignificare neminem latere puto: Quid autem ramex apud Plautum fignificet, pau cisadhuc cognitum vidi . In mercatore namq. Acanthio feruus poft curfum ab fe fictum, fic Charinum alloquitur, Placide volo acquiefcere, Tua cauffa rupi ramices, iam dudum fputo fanguinem : In Poenulo quoque Agoraftocli tarditatem exprobranti refpondent ad uocati, Tua cauffa nemo noftrum eft fuos rupturus ramices. Vbi fi cui placeat pro ramicibus varices genitalium intelligere, quo modo fententiam fuam tueri queat, non facile video. Quis quaefo nefcit fputum fanguinis minime ramices froti confequi? quis item refinam ex melle Acgyptiam deuorare, quod Charinus ludens confuluit Acanthioni, earundem remedium effe fateatur? nempe quos fola chirurgica operatione curari magni medicinae auctores docent. Sunt itaque ramices apud Plautum venae pectoris latae, quas fortaf fe fic nominat, quòd populari ac ruftico vocabulo quaeq. venae amplae, vt varices nuncupatae, ctiam ramices vocarentur: quod vero in pectore, ac etiam in pul mone varices fiant, atq. interdum magno hominum pe riculo rumpantur, ita clare explicatum habetur ab Hip po.fitue Polybo in lib.r.de morbis, vbi de empymate tra Satur, ve nemini ea de re dubitare liceat. Hoc in loco Domnini philofophi Platonici Syri hiforiam a Suda relatam fubnectere placet, cui facpe fanguinem expuenti cum A efcuiapij Athenienfe oraculü refpondiffet, ut ob valetudine recuperandam carribus fullis ve- 


\section{P R I M V s}

fceretur frequéter, ille etfi patria lege prohibcretur fem per tamen vius eft, \& nunquã amplius expuit, nifi quan do vel vno dic ab earum carnium efu abftinuit. Varices ab Hippocrate i $\xi$ ias appellari auftor eft Galenus, in antiq.voc.exp.quam vocé non femel deinceps abA riftote le vfurpatã effe in uenitur, vt 4.par.probl.2 2.\& ro.par tic. prob.3 ). nec nó 3.de hifto.animal. cap. 19.8 I r.vbi dum a varicibus occupatos minus caluitio tentari, caluosq. a varicibus captos interdum capillos refumere fcribit,eam Hippocratis fententiam interpretari, aut po tius moderari videtur; quam Galenus 6 . aphor .34 . vt falfam iure merito damnat: An porro $\beta \delta_{\varepsilon}^{\prime} \lambda \lambda \alpha$ Hippocrati aliquando venan varicofam fignificarit, quemadmodum Diofcoridem cenfuiffe Galen us affirmat, nondum animaduerti . Certe locus ille prorrheticorum, in quo Hippocrates $\tau$ tw' $\beta \delta_{\varepsilon}^{\prime} \lambda \lambda \alpha \nu$ memorat, mulrum abent vt vel Diofcoridi, vel alicuialteri ipfum fequéti faueat, cum hirudinem ibi fignificari nullo modo dedeceat. He rodotus, cuius dialectos Hippocraticis omnino adlimilari omnes eruditi fciunt, de Crocodilo in Euterpefermonem habens, ciufdem vocis in fimili prope cafu men

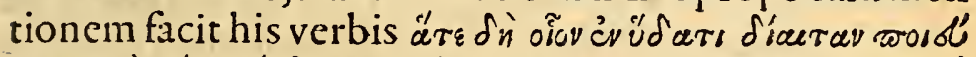

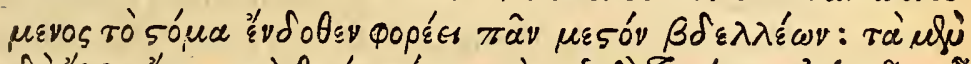

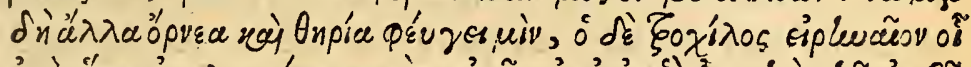

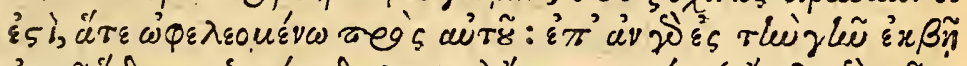

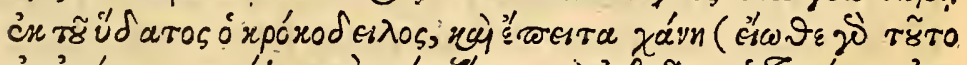

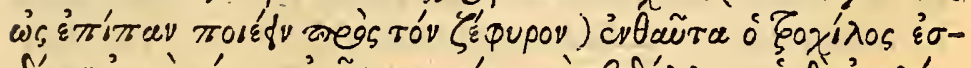

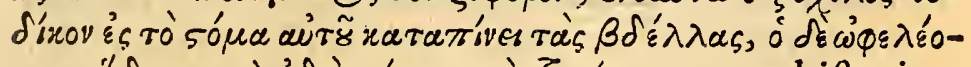

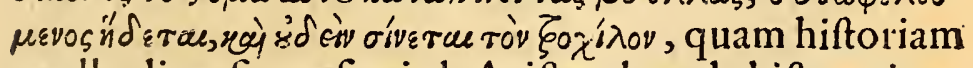
paullo diuerfius referri ab A riftotele 9. de hifto.anima. cap. 6. haud quaquam me latet: veruntamen $\beta \delta^{\prime} \varepsilon \lambda \lambda \alpha v$ Herodoto non venam varicofam faucibus inexiftentem, fed hirudinem ipfis infixam defignare nemo non dixerit. 


\section{I B E R}

Locus Atbenaci correctus ex Aristotele, ev nonnulla de canitie, \& de capitibus Aegyptiorum ex.

Herodoto.

Cap. 21 ,

Thenaeus lib. 15 . dipnos . vbi de vnguentis tractationem inftituit, Ariftotele citat, in quaeft. nat.quod dicat perfufos vnguentis citius cane fcere, quoniam aromata exiccant, ficcitate autem canities gignitur; unde etiam efficiatur, ut polia celcrem canitiem inducant : fic. n. in fragmento legitur, quod a Guliclino, Cauthero ex farnefiana bibliotheca, acce-

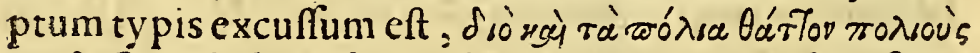
Troré. Quo in loco duo mihi nó parua animaduerfione digna cenfentur: Vnum eft, ea quae ex quaeft. natur. A rifturelis apud A thenaeum citantur, nec in prob.ciuf dem, nec alibi: neq. in libro Theophrafti aeio $\sigma \mu \tilde{\omega} v$ inueniri; ex quo conij cio perperam locum illum citari, eo magis, quod Diogenes Laertius in catalogo operum Ariftotclis quacfion um naturalium mentionem nullam facit; \& quod ibi ex eius fententia afferit A the nacus caniticm a ficcitate gigni, tantum abeft, ut illius placitis confentiat, vt 5 . de gen.animal.cap. v. ex profefio aduerfus eos difputet, qui a ficcitate caniticm ortum ducere putabant, quam non ab ea, fed a putredine fola produci pluribus argumentis monftrat; $v t$ facile fit iudicatu, quae in Athenaeo Ariftoteli adfcribuntur, minime ipfi conuenire. Alterum quod animaduerti uolo eft, an polia canitiem inducant. Nam aliquando credidi poffe eam fententiam defendi, tum quia polio canities, quac in fummo huiufccmodi plantae cacumine pendet; nomen fecit; tum quia polium non pauca ficcandi vi pollet, quãcanitiei cãm exiftere ibi difputatur. Verum enim vero Fuluius Vrfinus, vir dosisimus, oftenfo mihi antiquisfimo manufuipro Athe- 


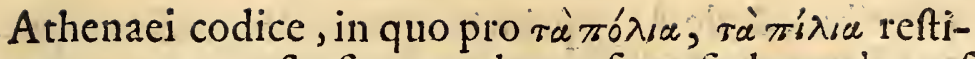
tutum erat, perfuafit vt crederem forte fic legendum ef fe, quando praefertim Ariftoteles 3. dic hifo . animal. cap. Ir. nec non 5. de gen. animal. cap. 5. pileos citius

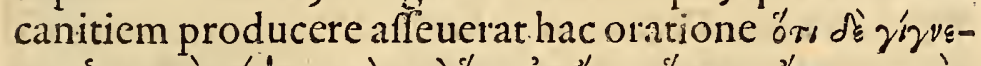

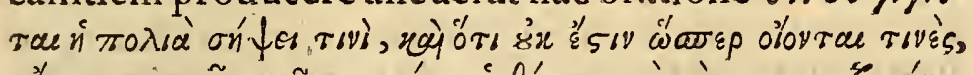

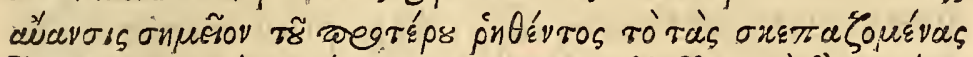

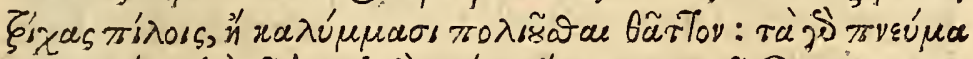

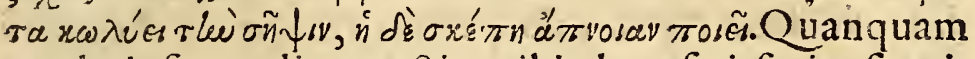
nec huiufcemodi correctio mihi plene fatisfacit, fi quidem Athenaci mens eit möftrare a ficcitate canitiem gigni, quomodo vero id argumento pileorum probare queat, non cognofco; nimirum quos non ficcando, fed prohibita tranfpiratione corrumpendo canitiem facere conftat: nifi hac quoq. in re dicamus, vt multa, fic $\&$ ea in Athenaeo probabiliter difputari. Pileorum effectus ad memoriam reuocant, quac ab Herodoto de Ae gyptiorum capitibus in Thalia referuntur hoc modo,

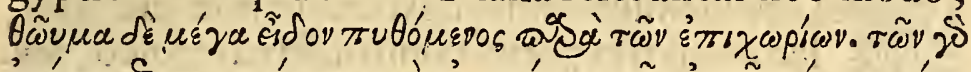

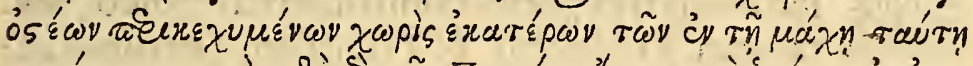

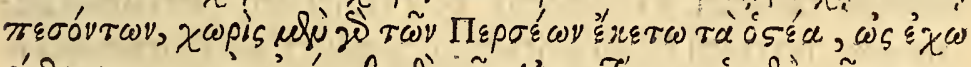

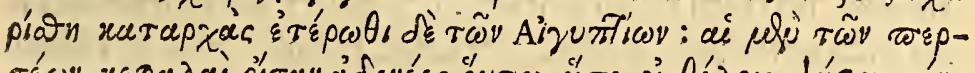

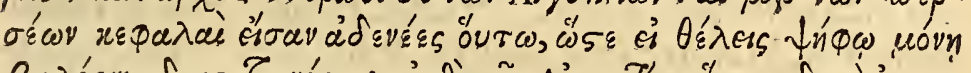

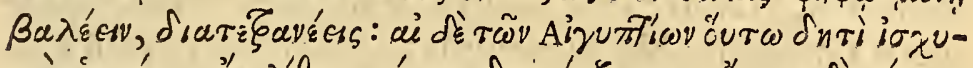

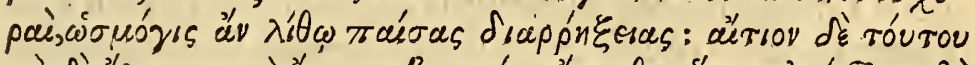

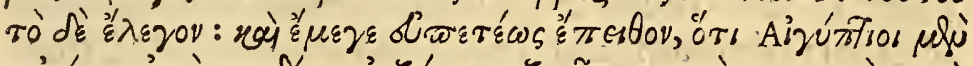

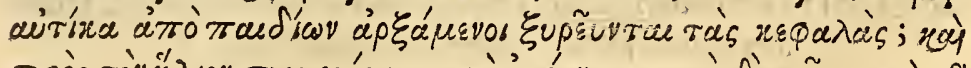

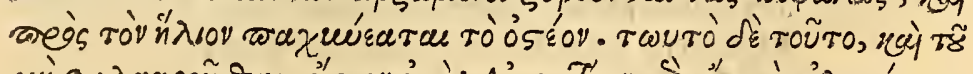

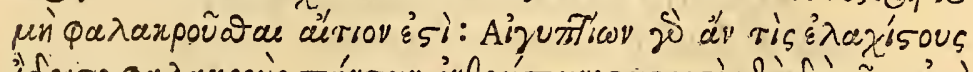

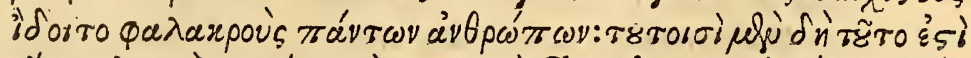

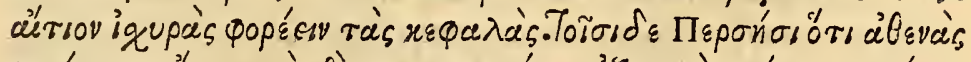

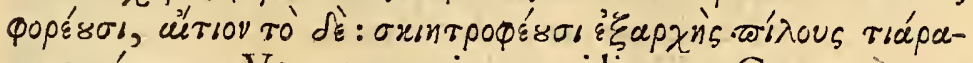

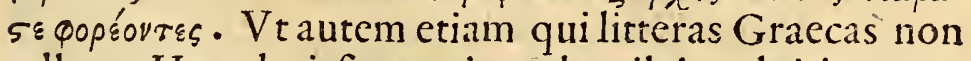
callent, Herodoti fententiam de pileis caluitiem pa$G$ rienti 


\section{I $B$ R}

fiue in trientes quatuor diuidebant; quanquam non ignoro interdum nullam effe in bibendo feruatam men furae rationem, quemadmodum inuitat Martialis Caium Proculum lib.i I.

$$
\begin{aligned}
& \text { Quincunces, \& fex cyatbos, beffemq. bibamus, } \\
& \text { Caius vt fiat, Lulius o Proculus. }
\end{aligned}
$$

Et quemadmodum in conuiuijs publicis factitatum rationi confentaneum eft, in quibus refert Alexander Trallianus libro probl. r. inftitutum effe, vt contrarijs poculis vterentur; in principio fcilicet minutis, in fine vero amplioribus : vt.n. epularum gratia ; in quibus frequentius bibere decebat, veteres crebrius potarent, $a$ paruis calicibus inchoabant, \& in capaciores definebant, quippe cum parua implere fatis ubi potare liberalisfime liberet, nequirent : quod $f_{1} a b$ amplioribus incepiffent, ocy us repleri neceffe erat, \& fubinde minus potare, fi quidem natura a largo protinus hauftu accepto veluti expleta copiam omnem fubfequentem contemnit; Ex aduerfo fi paruis poculis affueta paullatim ampliora exhibeantur, facile copiam quamcunq. fuftinet. Quod porro Nicandri fcholiaftes memoriae mandauit uetuftiores $x_{\varepsilon}^{\prime} p a \sigma i$, fiue cornibus potare folitos,atq. inde natum $x_{\varepsilon p a ́ \sigma \alpha}$, hoc eft merum temperare, verifimile quidem videtur tum ob rudes eorum mores, tum fortafle quod putarent inde potandi maiorem fecuritatem accedere. fic enim tradit Aelianus, Indorum reges afini indici cornu bibere voluiffe, fperantes a mor bo epileptico,\& venenisfe inde tutos euafuros.

Loca Hippocratis de aqua of bile explicata: de bile Anaxagorae of Aristotelisfententia cxaminata: aliag.ad idcm, Cap.23.

B Iliofis natura aquam in bilem verti friptum reliquit Hippocrates 3 . de acutis hoc pacto $x$ c. $\tilde{\delta} \delta \varepsilon \varsigma g^{\circ}$

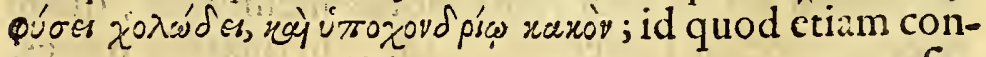


firmauit 3. de fracturis prope finem, quando biliofis aquam dari prohibet : vbi cum Galenus nil fere dicat, quod ad fcicndam dicti Hippocratis rationé pertineat, ego arbitror, haecomnia intelligenda de pauca aquae exhibitione: nam fi multa detur, potius extinguitur bilis : quomodo vero pauca aqua in bilem conuertatur cum tic frigida \& humida, bilis autem calida \& licca, inter quas nulla eft conuenientia, exiftimo ego ita fieri, quoniä pauca aqua in hy pochondrijs permanens, cùm nullam habeat contra bilis feruorem reastionem facile ab illa fuperatur; vnde bilis feruorem veluti pabuli copiam adepta augetur: Quin \& oleum rofatum corpori feruenti applicatum, licer aliquantifper refrigerare videatur, tamen poft modum magis calcfacit; \& hinc eft quod in eryfipelatibus, \& inflammationibus maximis iubet Galenus, ut faepisfime refrigerantia permutentur; alioquin magis ignirentur. Cur igitur Alexan der Trallianus, ubi pleuriticorum victú inftituit, ridicu Jũ effe dicat, fi aqua bilem augeri credatur, qúove ipfe Hippocratis fententiam interpretandamvoluerit, dum Hippocratem ab aliquibus hac in re falfo accufari fcribit, ignoro fane, illud tamen affero in ipfius Alexandri

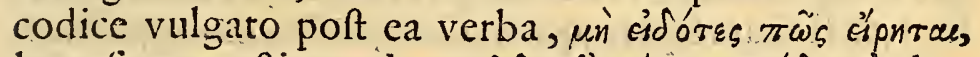

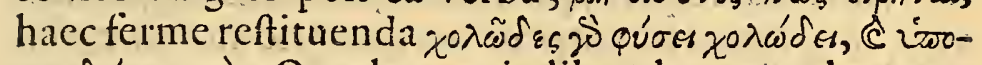
zor $\delta$ pís raxìy. Quod porro in libro de natura humana

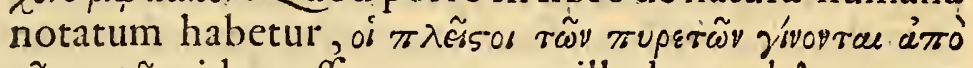

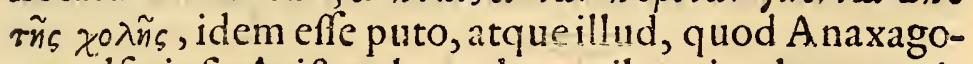
rae adfcripfit Ariftotcles 4. de partib. animal.cap.2. nimirum bilem, fiue bilis receptaculum acutorum morbo rum caufam exiftere; quam fententiam et fi damnaffe videatur, attamen fi quis morbos acutos ab humoribus feruidiffimis; fubtilifimis, ac mobilibus gigni confideret, quales biliofi omnes funt, animaduerratq. hanc vel cxtra proprium folliculum per venas illabentem, vel aliquo 


\section{I B E R}

aliquo alio pacto exuberantem corpora magnopere ve xare, inueniet profecto rationi minime repugnare, falfaq. \& fimplicis ingenij argumenta effe illa, quibus Ana xagorae placitũ deftruere conatur. Quomodo.n. id neget Ariftoteles, qui eodé in loco veteres fellis abfentiae diuturnitatis vitae in animalibus cauffam tribuentes có mendarit, finiliq. ratione iecoris bonā vel malam prae bile conftitutionem longitudinis, aut breuitatis vitae animalium, atq. etiam hominis cauffam effe confirmarit. Ad bilis autem prouentum compefcendum mirifice conferre ablinthium ponticum, traditur, quo quae pecora in Ponto frequenter pafcuntur ipfa carere, auctor eft Theophraftus in 9. de hifto. plant. \& A pollonius in admir.hift. Fella alioquin amariffima a Graecis $\gamma \lambda u x \varepsilon$ fiue dulcia contrariac interpretationis vocabulo nominata adnotauit Caelius Aurelianus diuturnorum morbo. lib.3 . cap. I. quod item Plinius obferuauit cap. IO. lib. 27. vbi herbam quandam duritiei penitus expertern holofteon a Graecis vocatam, ficut fcl dulce memo rat. Huic autem diffmilic non eft, quod Galenus fcribit

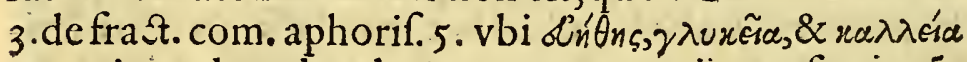
voces interdum de rebus prope contrarijs proferri móftrat, ea feruata figura, quam Graeci of $\varphi$ núav appellant, vtunturq. dum rem turpem non proprio nomine, fed. pulchro defignant:id quod ignorans Latinus interpres

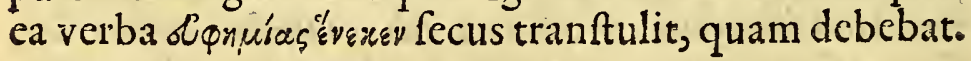

Deacre Romano; \& morbis eius: de Athenienfi Lucretïlocus, de moris, Serico, aliqua notatu digna. Cap. 24 .

Omanum aerem craffum atq. humidum admodum antiquitus etiam fuiffe morbi,quiolim in ea vrbe frequenter vagabantur, fatis teftari pof funt: Afclepiades apud Caelium Aurclianum lib.2. a- 
cut. cap. In. refert febres vna cum mentis, \& corporis oppreffione, necnon lethargicas Romae fiequenter có tingere folitas. Memorat Silimachus apud cundé lib.r. chro.cap.3. Hippocratis fectator cótagione quadá plurimos ex incubone veluti lue apud vibé Romam cófectos. A uitor eft Galenus I. de morbis vulga. com.2. femitertianas febres prauas Romae familiarifimas, atq. frequentiffmas extitiffe. Hemitritaeum vtlib.r.cap. 24. Sereni apud latinos nó habuiffe nomé, videt, cū fcribat

Mortiferum magis est, quod Graecis Hemitritaeon

Vulgatur verbis, boc noftra dicere lingua,

Non potuere vlli puto, nec voluere parentes.

Medici pofteriores femitertianã vocarūit, de quo Hemi tritaco crebra fit métio a Martiale, qui lib.2.

$V t i$ Tongillus male dicitur Hemitritaeo

Declamas aeger, declamas Hemitritaeos.

\&lib.I2.

Cui grauis \& feruens Hemitritaeos erat.

Idé Gal. lib.de té.mor.fcripfit Romac, \& in alijs fimiliter humidis locis phlegma a capite in ftomachum decú

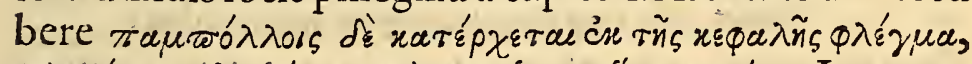

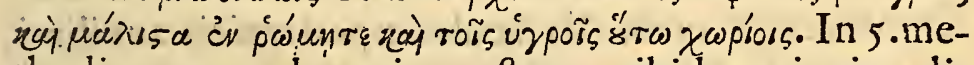
thodi non raro thoracis a poftemata ibidem gigni tradidit.Afclep.apud Caelium 2.acut.cap.2 2. Pleuriticos Athenis, \& Romae plebotomatos peius habuife : in $\mathrm{Hel}-$ lefponto \& Pario relematos effe fcribit, vt his omnibus iuremerito fcripferit Plutar. in probl. Rom. Templum A efculapij iccirco extra vrbem aedificatú fuiffe, quod ibi maior falubritas, quá in vrbe haberetur : quod vero inter cetera Rom. vibis loca V aticanus fitus peftilétior \& infalubrior effet,Symmachus cōful in epift.quadã, \& ante ipfum Cor. Tacit. memoriae prodiderunt, propte rea Vaticana vina velutioím peffima a Martiale, $\&$ aliis infamata fuiffe nulli fit mirũ. Addā huic quae de peculiari Athenarum podagrico morbo fcripfit Lucret.in 7. Atthide 


\section{I B B E R}

\section{Attbide centantur grefus, oculiq. in $\mathcal{A}$ chaeis \\ Finibus.}

Quacve de eadem ab Hegefandro ex Pythermo tradita apud Athenaeum inueniuntur, videlicet illius temporibus per viginti annos fructum nullum moros pro tuliffe, atq. tantam podagrae contagionem omnes inua fiffe, vt non homines folum, fed pueri, puellae, eunuchiq. \& mulieres eo morbo tentarentur; quae item caprarum greges ita grauis folicitauit, vt vix tertia earum pars libera extaret. An vero id euenerit, quia mororum fructus podagram arcere queant, in cótrouerfiam venire queat: ego certe apud Hippocratem, ac Galenum legi mora, quae fatis maturuerint, ventrem fubducere, ftomachumq. fqualidum, ac aefuofum confolari, praefertim fi frigida, nec cum ceteris cibis, fed paul lo anteffumantur, moxq. per pauimentum deambuletur: vndeHo ratius poeta non immerito cecinit

\section{ille Salubres}

Aestates peraget, qui nigris prandia moris

Finiet, ante grauem, quac legerit arbore Solem.

Quod vero priuata vlla facultate podagricis auxiliari, quo minus infeftenturilli, poffint, apud neminem ad: huc obfernaui : fieri tamen potuiffe crederem,vt mora frequenter Pythermi aetate ab omnibus fere efitata fto machis recreatis, aluisq. liquatis eorum humorum pro uentum interciperent, qui in articulos decumbentes podagram gignere confueuerunt; fed confideranti mihi capras, quae mororum fruotus non attingunt, ab ea lue non fuiffe immunes, potius aeris inclementiam, quae moris inimica extitit,etiam pedum morbos produxiffe exiftimo; quando varijs aeris conftitutionibus varias aegritudines peruagaffe non raro a maioribus noftris obferuatum fuit. Dixi mora ftomachos aeftuan tes rcficere,cum Diphilus medicus apud Athenaeum, 


\section{P: R: I:M: VIs}

\&. Galenus poft ipfum eadem ftomacho conferre feripferint : quanquam Diofcorides \& ipfum fccutus Aui-

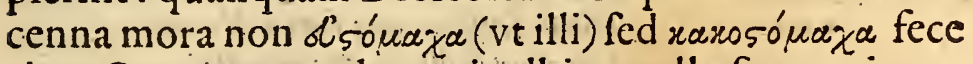
rint. Quare autem de moris albis a nullo fere antiquorum mentio facta habeatur, excepto Ouidio in fabula Pyrami \& Tisbes, vbieorum fanguine mora alba rubrum colorem contraxiffe canens, videtur potius vlla candida inueniri negaffe, facile eft illis intelligerc, qui fciunt, id arboris genus ex infitione fuper albam populum facta emanaffe: quae cum in Europa, acfub Romani Imperij ditione fero apparuerit, ficuti quamplures aliae infitiones; non eft mirum, fi palica de ipfis ab auctoribus memoriae tradita leguntur; quam etiam caufam extitiffe puto, vt fericum vfqucad Galeni tempora rarum effet, qui in 13 . methodi fcribie id in vrbibus Romanorum magnis tantum, atque ibi penes opulentas mulieres extitiffe : Ea enim animalcula, quae fericea fila nobis diuina quadam arte $\mathrm{fa}$ bricant, quod potiflimum foliis mori nutriantur, eisq. pinguefacta foecundiora euadant, omnes fciunt, ve hac vna ratione conijcere valeamus, quo tempore huiufcemodi arbores copiofae non crant, eodem nulIum, aut faltem pauciffimum illorum animalculorum, \& proinde quoque ferici fuiffe prouentum; auctor enim eft in vita Iuftiniani Zonara, eius Imperatoris tempeftate fericam telam a Romanis texi coeptam, quae prius a Perficis mercatoribus aduehebatur, \& quomodo ex vermium filis fieret ignorabatur. Nam duo monachi ex India Byzantium profecti originem illius declararunt, \& vt ex perexiguis ouis per fotum vermes illi educerentur, educti folijs mori alerentur, deinde ipfis natura magiftra filum redden tibus fericum texeretur, non fine multis muneribus edocuerunt.

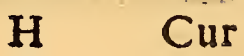




\section{L $I E R$}

Cur pifcesmedici antiqui facile concederent aegris: pifces tintin-

nabulo vendi folitum fuiffe: quis fuerit Hoedus, ex Ambracia apud Gellium, O nonnulla alia de Hoedo. Cap.25.

Vr mediciantiqui adeo in aegris fere quibufuis curandis pifces concederent, minime rationem puto, quod ipfi fuapte natura admodum conue niant: Sed quia pauci crant, qui in fanitate non potius pifcibus, quam carnibus vterentur, quemadmodum in fympofiacis docet Plutarchus. Vnde confuetudine, qua maxime refpiciendum iubet Hippocrates, impulfi id po tius, quam valida aliqua ratione factitarunt. Vnde neque hodie in aegritudinibus, facile debent pifces medici concedere, alioquin corruptioni obnoxios, nifi quis huiufmodi cibo frequenter uefci fit folitus, quéadmodum de Venetisferipfit Martialis.

InVenetis fint lauta licet conuiuia terris

Principium coenae gobius effe folet.

Pifces tintinnabuli foniru vendi folitum, non tantum apud Ariftophanem \& Demofthenem, fed ctiam apud Plutarchumauctorem granifimum obferuaui, qui in quarto fympofiac. problem. quarto, hunc fermonem à nobis Latinae linguae donatum habet: Ad haec ob: fophagos, fiue obfoniorum amatores minime eos, qui bubulis carnibus delectantur, effe dicimus, qualis fuit Hercules: neque ficuum a matorem, ut Plato, quem uirides ficus una cum carnibus ediffe (fic enim reftituo Plutarchi locum ) notatum eft; neque vuarum cupidum, ficuti fuit Archefilaus; fed eos, qui quotidie tabernas, ubi ueneunt pilces, circum ambulant, exquifite ve tintinnabulum audiunt; $Q$ uo ex loco tintinnabul um a pifcium uenditoribus ufurpatum, vt emptores 
a longe inuitarentur, etiam colligo; Quin, \& illos, qui magnis vocibus valerent, iis faepe pro tintinnabulis vos credo. Vnde Iuuenalis in 3. faty.

Iam princeps equitum magna qui voce folebat

$V$ endere municipes fracta de inerce filuros.

A pud cundem Plutarchum obferuatum eft, caupones confucuiffe carnes, atq. pifces non ab ipfis emptos, fed a b aliis fibi traditos inftar coquoru apparare:fcribit. $n$. quendam cum pifces cauponi, ve coqueret, tradidiffet, isq. piper \& alia quaedam pro condiendis illis popofcir fet, refpondiffe, fi haec mihi effent, profecto pifces non emiffem. Multa ad haec a pud Clementem Alex. fecun do paedag. cap.r. \& Gellium ex Varrone ciborum genera referuntur; quae ex longinquis regionibus Romä adue ta maximo in pretio erant : Inter cetera hoedum ex Ambracia nominat, quem nonnulli doctiffimi uiri pifcem rumpòv Athenaeo uocatum putarunc hifce Archeftrati uerfibus perfuafi.

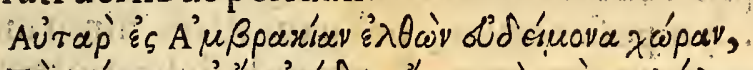

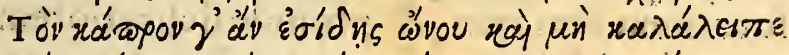

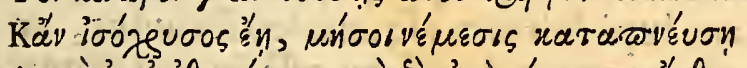

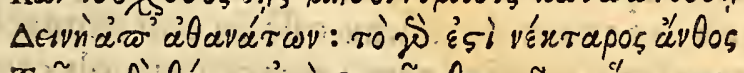

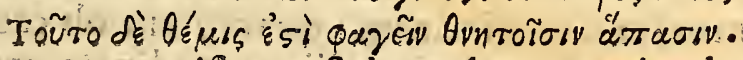
Ego vero non pifcem, fed quadrupes animal extitiffe potius exiftimo, ea perfuafione potiffimum adductus, quod fi pro hocdo pifcem intelligamus, fequetur veteres nulla Romam aliunde aduecta quadrupedia in pre tio habuiffe : quando a Gellio nullius alterius, fed auium, pifcium, \& pomorum tantummodo mentio fit; quod tamen ex co falfum probatur, quoniam Varro 2. de re ruft. fcribit multos Romac capras ex media Infula habuiffe, quod ibi maximos ac pulcherrimos hoedos ficri exiftimaretur; a Clemente quoq. Alex.2. paedag. cap. I. \& a Polluce hoedi melici omnibus aliis praefe- 


\section{I B E R}

runtur; vnde \& in Varrone non ex media, fed ex melica infula legendum cenfuiffem, nifi Columella cap. 2. lib. 8. auctor effet vulgares mutata littera medicos Melicos dixiffe. Iam vero hoedi Melici, tan quam celebris, meminit \& Clemens Alex. 2.paedag. Hoedos etiam ex Tybure valde aeftimatos videtur: Iuuenalis monftraffe fatyr. Ir.

\section{De Tyburtino veniet pinguißimus agro}

Hoedulus, es totogrege mollior, inficius berbae.

Sed quem gulofi omnium maxime quaerebant, erat hoedus lupi faucibus ereptus, dilaniatusq. de quo Horatius in Epodis.

Vel agna festis caefa terminalibuis,

Vel Hoedus ereptus lupo,

o Martialis lib.so

Paruus ony $x$ zna ponetur coenula menfa

Hocdus in humaani raptus ab ore lupi.

Cur autem huiufcemodi hoedorum caro ceteris iucunditate praecellere crederetur, affignat Plutarchus ratio nem 2. fympofiacorum, belluam illam nimirum fuo morfu carnem teneram, \& proinde delicatiorem efficere; nam lupi fpiritus vfque adeo feruidus, ac pene igneus eft; vt etiam duriffima offa in eius ftomacho emolliantur, atq. conficiantur; quam item ob cauffam a lupis commorfa, celerius alijs putredinem contrahurit: Ceterum de lanis, pellibusq. lupinos dentes expertis an pediculos gignant dubitatum fuit antiquitus, an potius caliditatis impreffae vi afperitatem quandam, ac pruritum gignant : Certe lupi morfus in totum pecudis corpus, vfque ad pilos, ac vngues vim quandam igneam mittere confat; neq. tantum hoc verum eft ; immo quamplurimum referre, an ea animalia quorum pellibus vti volumus, ferro iugulata, an fponte mortua fint. Homerus quoque intellexit dicens, ifmis Boòs iprntauévoro, ideft lorum bouis vi occifi ; pelles 


\section{P $\mathbf{I}$ M $\boldsymbol{v} 3$.}

namq. corum tenacior $\&$ fortior eft animalium, quae non morbo, aut fenectute, fed ferro iugulata obierint; ex aduerfo quae animalium morfu intercunt, illis vngues nigrefcunt, pili defluunt, \& coria flaccida effecta corrugantur, rumpunturve. Et quoniam fupra Ambraciae meminimus, hic adnotare placet, apud Athenaeum cephalos, \& lupos omnium optimos ex Ambra cia aduehi folitos; A puleius in oratione pro fe prima etiam pectunculos in Ambracia optimos nafci folitos fcribit, etfi mendofe. [Legatur Vmbraciae finis] pro Ambraciae; eos namq. Ennii verfus(fi tamé eius funt) ex Archeftrato apud Athenaeum tertio dipnos. aliquo modo acceptos, vel ab Archeftrato ex Ennio mutuatos vnicuique cognofcere licet, quos verfus, quoniam Turnebus reftituere conatus eft, nil de iis amplius dicam. Sunt vero Archeftrati carmina:

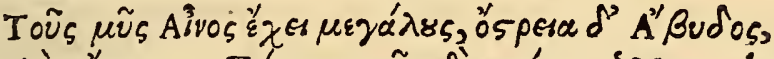

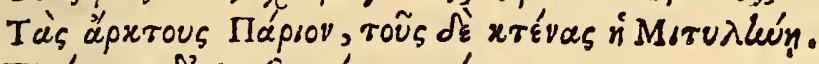

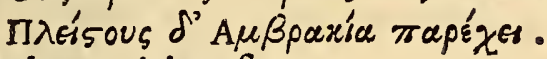

Sed $\&$ haec vitiata funt .

\section{FINIS LIBRI PRIMI。}




\section{$\begin{array}{ll}-411 & 83\end{array}$}

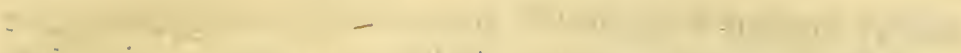

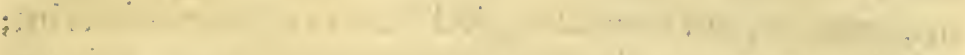
ז.

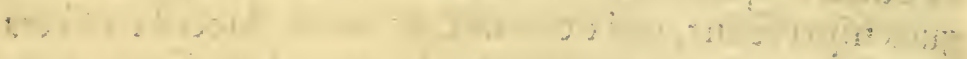

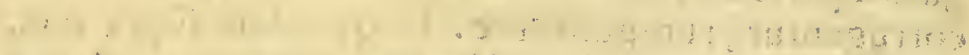

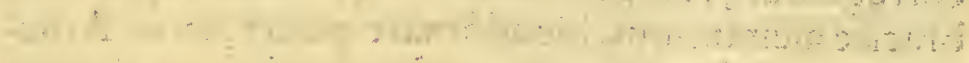

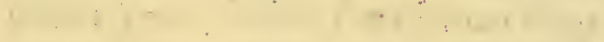

$\therefore ?$

i.

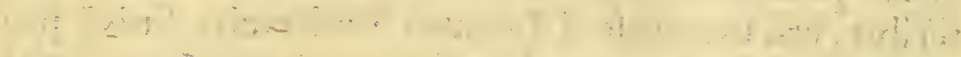

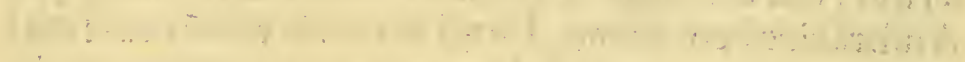

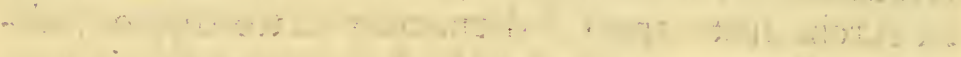

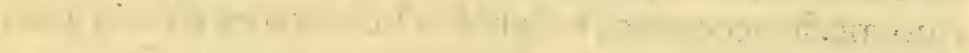

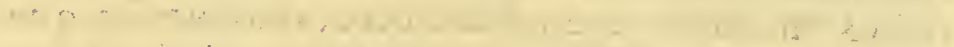

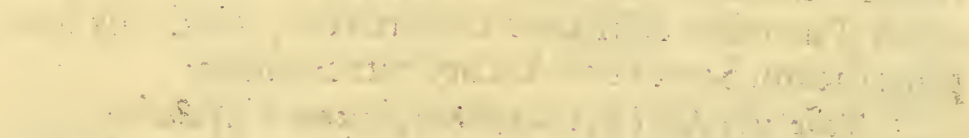

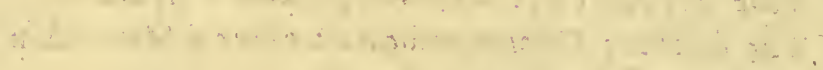
$+\cdots+\frac{1}{+}+\cdots$

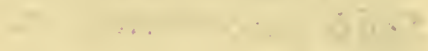

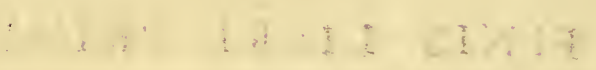




\section{A R I A R V M I $\mathrm{N}$ \\ $M \quad E \quad D \quad I \quad C \quad I \quad N \quad A E$}

AVCTORIBVS, ET ALIIS

\section{LE C TION V M. \\ Liber Secundus.}

Loca Galeni, \& Plinï emendata : Non nulla de Mangonibus. Cap. I.

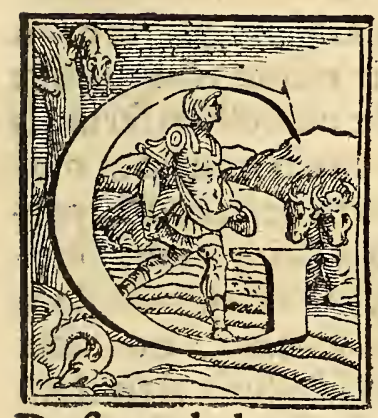

A LENVS in primo de articulis commentario aphor. $\mathrm{xxx}$. duo extenuatorum corporum genera in medium ponit; alterum quod feu fame, feu obfidio ne, feu luctu, feu moerore, feu aliquo alio cibi faftidio alimenti pa rum fumens fponte confumitur; alterum quod arte tale efficitur. Defecundo haec verba, vt funt in bafilienfi codice, ha-

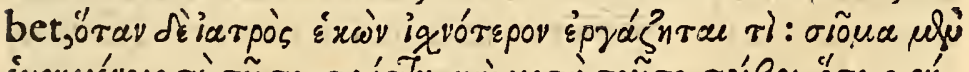

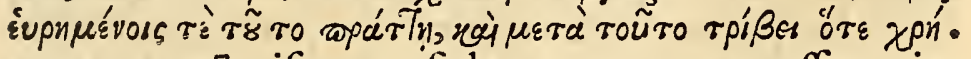
quae cum afterifco, quafi deprauata, notata effent, interpreti tamen fic conuertere placuit, fed vbi medicus de induftria corpus aliquod extenuat, per ea quae excogitauit, moliri id contendit; deinceps frictione vtitur : fed praeter qu quod uerbis interpretatione minime refpondet, etiam opus medici in extenuandis corporibus 


\section{I B E R}

poribus nequaquam appofite exprimit : Itaq. locum hunc mendofum effe, ficq. reftitui debere puto ötap

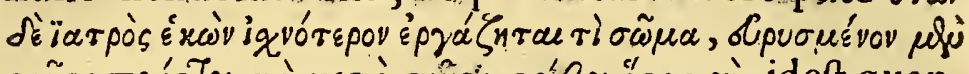

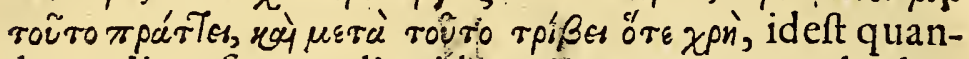
do medicus Sponte aliquid corpus extenuare vult, hoc quidem dilatat,aperitve:deinceps tempore opportuno frictiones adhibet, vocèm enim supurúvio vfitatam effe Hippocrati, \& Galeno, vbi corpola caloris ope rarefa cienda, ac aperienda funt, in multis corum commentariis, \& praefertim in 2.6.lib. epid animaduertere licet. Quod deinde Mangones \& Gymnaftac, dum corpora nimis craffa extenuare intendebant, prius neceffe erat denfata corpora calefactionibus, vel aliis adiutoriis rarefacerent, dilatarentq: ut poftmodum ita praeparata facilius frictionibus exiccarentur, nemini in medicina uerfato obfcurum eft; Non omnes tamen intelligunt: Qui praecipue effent Mangones a Galeno pluribus in locis nominati: Nam uetuftiffmis ufque temporibus cum nulla religio homines perinde ac belluas feruitiis teneri, atq. permutari uetaret, inueniebantur, qui nullam aliam artem exercebant, quàm in uendendis, permutandisq. infantibus, pueris, uiris, uirginibus, mulieribus, eunuchis, omnisq. tandem fortis hominibus; fed inter hos aliquod difcrimen obferuaui : quoniam qui pueros, puellas, \& mulieres in libidinis feruitium uenditabant, antiquo Romanorum tocabulo lenones uocabantur; qui uero infantes in caniftris, feruos, eunuchos, aliosq. homines alterius operis gratia uenales habeant, ávo pa

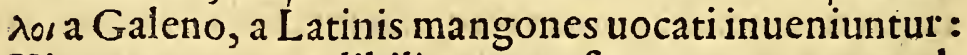
Hi autem quo uendibilior merx foret, corporum pulchritudini totis uiribus ftudebant; unde legitur apud Galenum eos confueuiffe facies puerorum fucco ptifanae, farina fabacea, nonnunquam nitro, quae deterge-

rent, 


\section{$S$ E C V N D $V$ S.}

gerent, \& lucidiores redderent, abluere; nonnunquam emaciatorum nates virgis percutere, atq: picare, quò habitiora \& craffiora corpora euaderent, aliquando puellarum coftas aretiffimis fafcijs conftringere, vt pectoris amplitudo, fimulq. coxarum altitudo, latitudove (qui folet effe mulierum decor)augerentur; quan doq. varijs modis pilos è genis, alijsq. partibus vellere, quò iuniores, \& venuftiores, qui erant vendendi,appa rerent. Scriptum eft a Vitrutio fecundolibro cap.8. corpora muliebria, dum grauida effent, a uenditoribus nunquam praeftari fana in more pofitum fuirfe; quod a conceptu ufque ad partum integra ualetudine non uterentur, quam fententiam nedum Hippocrates, ut ueram faepius protulit, uerum etiam Ariftoteles, qui quarto de generatione animalium cap. fexto feribit, bruta plurimam temporis partem corporc ualere, dum uterum gerunt, mulieres magna ex parte aegras degere, nempe quae uitam ociofam, $\&$ fellulariam agentes plus recrementi fibi contraherent. Inuenio quoque apud Plinium ob alopeciae turpitudinem feruorum pretia fuiffe diminuta; $\&$ iccirco ad eam corrigendam innumera prope remedia excogitata effe: \& quoniam mentio eius mentiti Plinij incidit, cuius libri de re medica circumferuntur; ex co monftrabo, quomodo Plinij maioris, ex cuius de natura opere toti fere minoris Plinij libri conflati funt, locum meliorem reddere poffimus : libro tertiodecimo, capire uigefimofecundo legitur, Neronem Caefarem dum nocturnis graffationibus conuerberatam faciem gereret, thap fia, thure, \& cera eam fibi illiniffe, \& fecuto die contra famam cutem finceram oftentaffe; fed in alterius citati Plinii libro de re med. 3 . cap. 47. loco cerae ceruffa habetur : cam cum ad fugilla tiones, uerberationesq.mirã operã quotidie praeftare; 


\section{$L$ I B \& : R}

ceram vero nihil plane adiumenti afferre experiamur, fit vt a principio librarios aliquos loco ceruffae in Pliniano codice, ceram exfcripfifle, ficq. errorem paullatim in cetcris fubinde irrepfiffe arbitremur, quãquam non negamus poffe quoq. ceram in eiufmodi medicamentis locum habere ad ceratum formandum, \& alia duo continenda.

\section{Morem Thufcorum vrendi pueros, fuife antiquum: Herodoti}

loc:s notatus, or quaedam de Scytbis ex Hippocrate, Cap. 2.

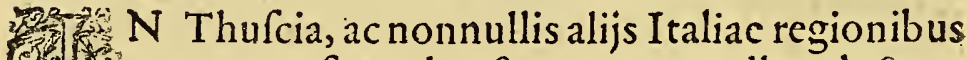
vetus confuetudo eft, vt pueros adhuc lactentes, vel paullo maiores in occipite ferris ignitis vrant, fperantes eo auxilio ipfos a pituitac malis, \& praefertim a puerili morbo stutos futuros; Hunc morem antiquiffimis vfque temporibus apud Lybiae populos fuiffe teftatur Herodotus in quarto, vbi haec le-

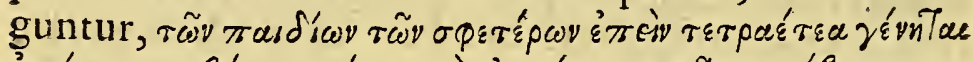

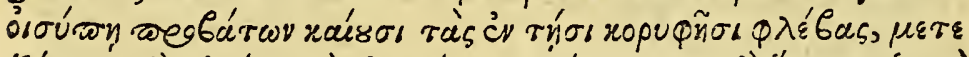

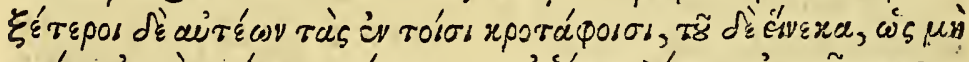

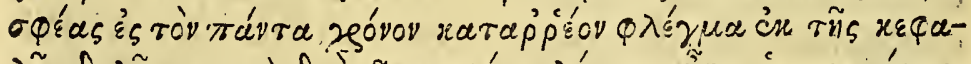

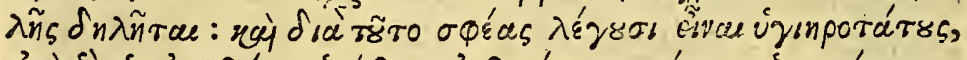

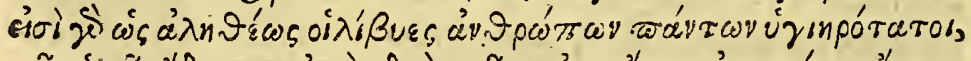

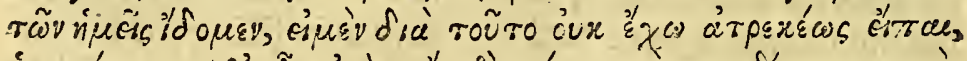

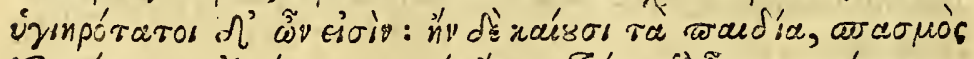
: p'ovтu oṕ̧as, id eft, puerorum fuorum cum annum quartum atrigerint oefypo ouillo venas verticis adurunt; alij vero ipforum temporales venas; quod ideo agunt, ne vllo tempore a capite defcendens pituita offendar, \& propter hoc feipfos fanifimos praedicant : \& certe Lybici omnium hominųm, quos viderimus, faniff 


\section{$S$ E C $\nabla N$ D V S}

mi exiftunt, an propter hanc cauffam, affirmare non au deo. Sunt igitur faniffimi, fed fi inter vrendum fuperueniat conuulfio, inuentum eft ipfis remedium . hirci nempe vrina afpergentes eos liberant. Quo in loco (vt Erotianus auctor elt accepifie Hippocratem ) pro ocfypo ftercus interpretandum puto, quod fanè vrendialiqua vi pollet, fed an fufficere fimili operationi illud po tuerit,anceps fum. At fcio, quod Theophraftus in libro de igne oirov, fiue viticem a pud medicos in vfu fuiffe ad viendum hifce verbis a Turnebo reftitutis teftatur $\delta 10$,

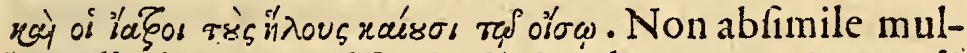
tum illud erat, quod fautitafle Scy thas memoriae prodi dic Hippocrates, in libro de aere, aquis, \& locis, qui cum ob frequentes equitationes coxis, atque cruribus valde offenderentur, incifione venarumpoftares fibi ipfis auxiliabātur, tanquam eo remedio capiti adhibito pituitae fluxum ad inferiora cohiberent ; quo fani quidem, fed infoecundi femper manebant. Haecomnia praefidia interdum magnopere ex vfu effe antiqui medici cognoucrunt, quando \& ipfi ad compefcendos humores a capite in partes inferiores delabentes modo fynciput, modo verticem, modo occiput, interdum oĩa haec, veligne, vel caufticis medicamentis vienda confulucrunt : quanquam in hoc vulgares faepenumero er rare confpiciuntur; qui contra Galeni praeceptum non raro ceruici, \& aliis partibus cucurbitulas ignitas admo uent, priufquam vniuerfum corpus exinanierint .

Sententia Galeni ex Herodoto comprobata: De Syrmea : Depar titione anni, fecundum Hippocratem: Error Jacerdotum Ammonis. Cap. 3.

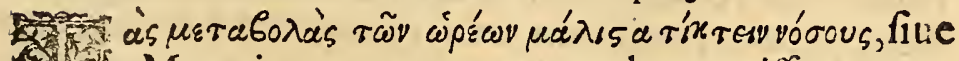
Mutationes temporum morbos potiffimum pa rere, dum fcripfit Hippocrates, fuerunt, qui pu

$$
\text { I } 2 \text { tarent }
$$




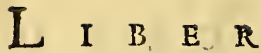

tarent cum fuccefliones temporum nempe Autumni, Hicmis, Veris, \& Aeftatis intellexiffe, quos Galenus et fi grauiffimis rationibus refellat, deq. peculiaribus temporis conftitutionibus ipfum locutum effe monftet, placet tamen cius fententiam Herodoti teftimonio con firmare; qui cum eadem aetate vixerit , fimiliq. dialeeto, quo Hip pocrates vfus fit, haud ab re fueritillius teftimonio, ad augendam Galeni fidem, in eadem prorfus re vti. Itaq. in Euterpe de Aegy ptiorum moribus fer-

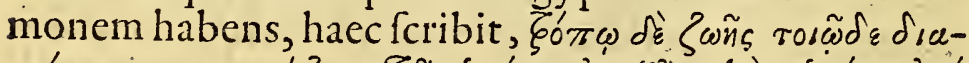

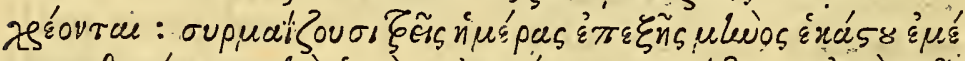

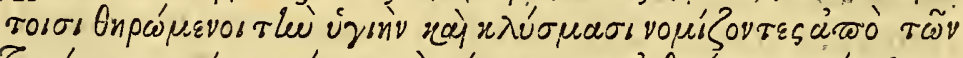

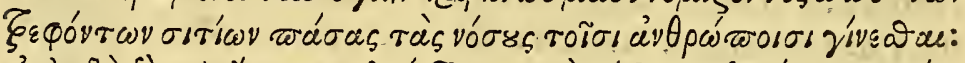

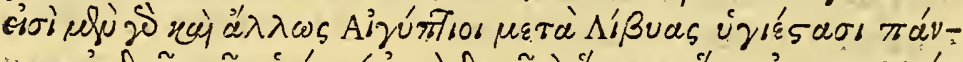

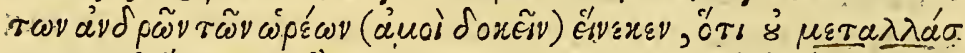

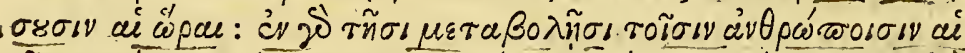

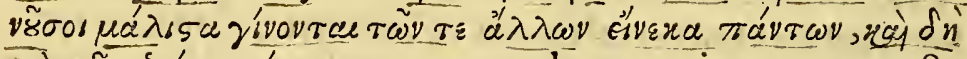

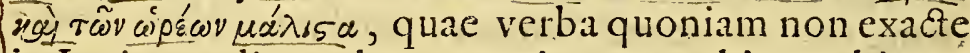
in Latino codice uulgato exprimuntur, hic a nobis, vt debent, conuerfa fubnectam. Hoc autem vitae genere vtuntur fingulis menfibus, per tres dies continuos potione corpus purgant, clyfteribusq. ac vomitibus fanitatem conferuant, putantes nimirum quofcunq. morbos a nutrientibus cibis hominibus euenire: Nan Aegyptijalioquin funt omnium, polt Lybias, virorum faEnifimi ob temporum(vt ego puto)conftitutiones, quae ibi non variantur; Nam in mutationibus quarumcunque rerum, \& praefertim temporis conftitutionum homines a morbis maxime tétari conftat. Quid autem anti

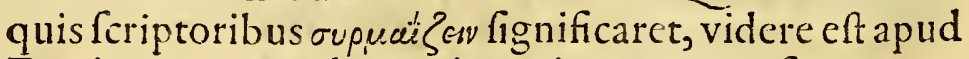
Erotianum, \& Galenum in antiq. ver. expofr. quorum ille purgationem factam, ex raphanide cum muria oup-

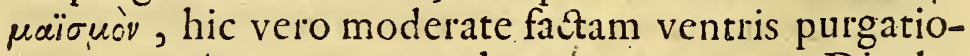
nem rupratav vocatam tradunt : praeter quos Diocles 


\section{$S$ E C V N D V S.}

in epift. ad Antigonum Regem vomitus ieiuno ftoma-

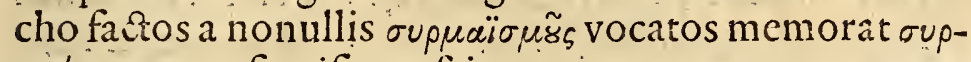
maiby. tamen fignificare fcimus quoque potum ex aqua \& hordeo, necron opfonium, vt apud Diodorum Sicu lum, \& apud nautas facere fyrmaiam eft comparare opfonia $\mu \varepsilon \lambda$ avooupuacios $\lambda \varepsilon \tilde{\omega} s$ apud Ariftophancm in Thefmoph. tefte Suida Aegyptii funt : nam auetor eft Plinius, Aegyptios hoc genere potus ufos. His adiicere pla cet, quae a Galeno de anni fecundum Hippocratem partitione fcriptis tradita funt in principio Epid. commentariorum, quod ideo lubens ago, quoniã futurum fpero, vt quampluribus Hefiodi, ac Homeri locis ex Galeni verbis quandoq. maior lux afferatur, quos cum Hippocratem quadrigentis annis praeceffiffe ex Herodoto fciamus, ab illis veluti auctoribus maximis multa ipfum mutuaffe, quamuis nunquam citet, vero fimile

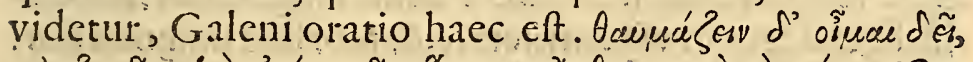

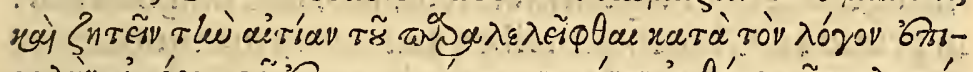

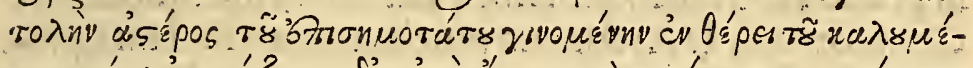

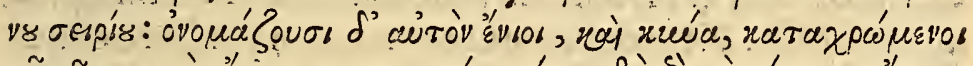

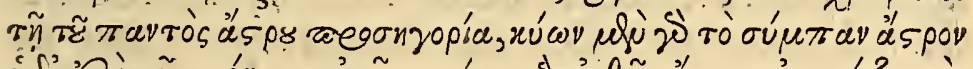

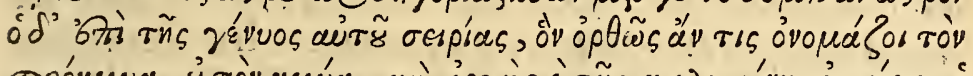

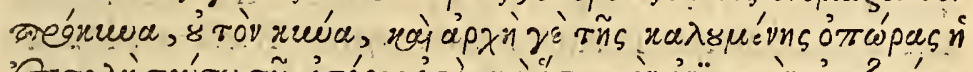

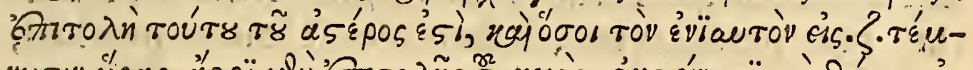

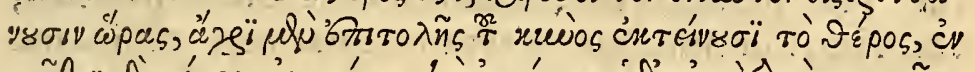

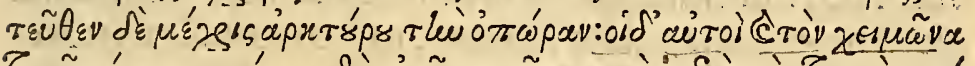

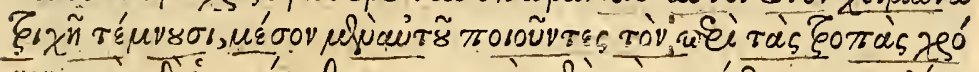

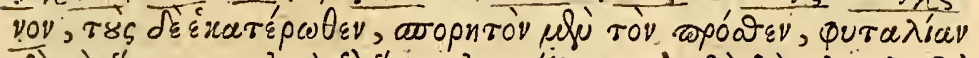

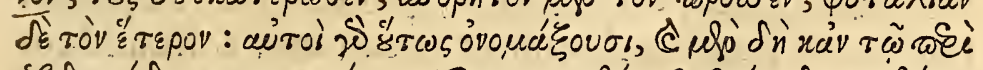

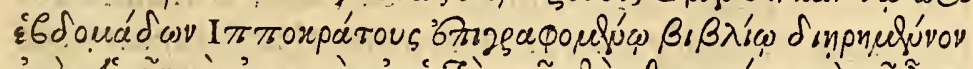

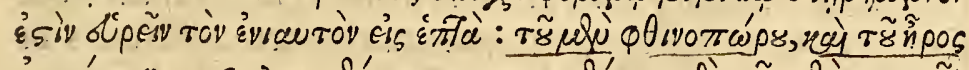

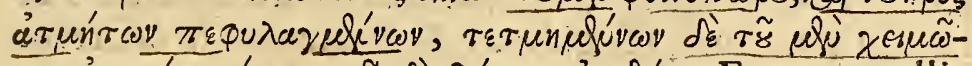

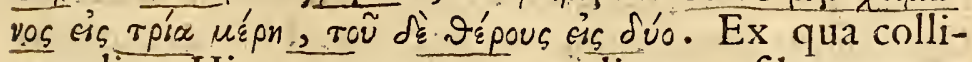
gere licet Hippocratem, atque alios quofdam totum 
sonum in feptem partes diuififfe, Ver, Aeftatem; Oporam, A utumnum, Sementarium, Hiemem, \& Plan tarium. Verinchoabar ab Aequinoctio, vfq. ad Pleiadum exortum : $a b$ hoc A eftas erat ad Canis ortum : a cane Opora vfq. ad Arcturi cxortum durabat: A utum nus vero ab Arituro vfq. ad Pleiadum occafum extendebatur : reliquum temporis tractum in tres partes par tiebantur, quarum primam Autumno continuam Sementarium, quafi feminibus iaciendis aptam; mediam Hiemem; poftremam \& Veri adiacentem, Plantarium, quafi tunc plantae colerentur, vocarunt. Oporam de qua Plutarchus etiam meminit 8. fympo. probl. I0.m1a xime omnium calidam, atq. ficcani ; \& proinde hominum virium confumptricem fecerunt medici; \& iccirco Galcnus, qui in 4. de acutorum victu com. fcripferat hifce temporibus non effe è vena fanguinem mittendú, licet aeger in vigenti actate, \& morbus magnius fint, in primo ad Glauconem libro narrauit, quotquot inter Canis ortum, \& A Ariturum phlcbotomati fuerunt, plane interiiffe : Non defuerunt tamen,qui probare conati fint, hoc tempore ( \& is fuit Theophraftus primo de cauffis plantarum)corpora plantarum \& hominum humefcere, addu fti his rationibus, quòd fruetus plantarum tunc perficiantur, \& homines febribus putridis, ven trisq. folutionibus tententur; quae certe nihilo ma gis id monftrant, quàm fudores, qui copiofiffimi in $\mathrm{Ac}$ ftate è corporibus feruntur : fed alias refelli opportunius poterit tam grauis auťtor; quê defendere acquius poffumus, quando Autumnum calidum \& humidum fecit : quoniam fi principium Autumni aeftimemus, \& forfan etiam medium, argumenta maiora caliditatis \& humidiratis, quàm frigiditatis \& ficcitatis fe fe offerent. Quod facerdores Ammonis(vt eft apud Plutarchum in: lib. de defectu oraculorum) annorum inaequalitatem 


\section{$S: C \vee N D \sim S$.}

probar'ent ex eo, quod Lucerna cius templi inextingui bilis, vnoquoq. anno olei minus côfumeret, infirmum fane argumentum erat, quoniam poterat multis rationibus tum ex parte olei, tum ex parte acris id euenire, quanquam etiam erat porius confentaneum ab eiufmo di euentu annorum imminutionem, \& nundi corruptionem, quàm inaequalitatem colligere.

Theophrafil loca ex Athenaeo, \& Plutarcbo correcta, de fida, de le guminibus, de pedicults: Theophraftie Gale nicontr.adictio de forpionibus cap. 4 .

Varto de hift. plant. cap. II. Theophraftus narrans in Orchomenio lacu multas arbores nafci, velutioleagnum, fidam, \& fimilia : de fida in

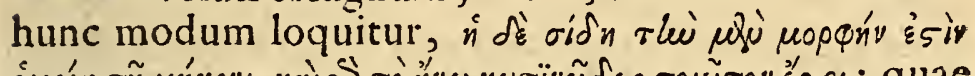

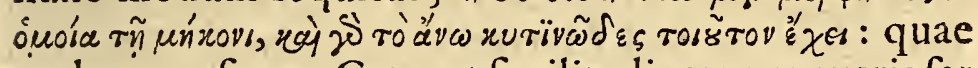
verba transferens $\mathrm{Gaza}$, vt fimilitudinem papaucris fer uaret, vocem illam $\tau_{\tau} v \omega \tilde{\omega} \delta \varepsilon \varsigma$ omifit, ficq. errorem erro ri addidit. Quis autem non videat fidam arborem cum papauere nullam fimilitudinem gerere poffe? Itaque textum Theophrafti corruptum effe faciliter, qui vis intelliget, en magis quod Athenaeus I 4 . lib. dipnos. citans hunc Theophrafti locum, fidam ex ipfius fententia non papaucri, fed punicae malo fimilem facit, vt rationi magnopere confentit, ita fuiffe appellatam ob fimilitudinem punicae, quam veteres fidam nominaffe prae ter A thenacum; Plutarchus quoq. 5. fympof. probl. 8. teftatus eft, vbi Empedoclis verfum exponens,

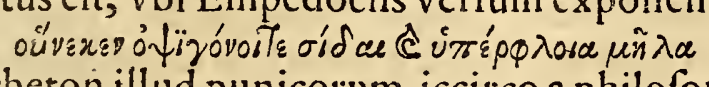

Epitheton illud punicorum iccirco a philofopho excogitatum fribit, quoniam illae Autumno deficiente, acftuq. iam extincto, frustum perficiunt; fiquidem aefti no tempore debilem ipfarum, ac minime vifcidam hu- 


\section{I B $R$}

miditatem haud quanquam concrefcere finit, nifi aer frigidior euaferit : propter quod Theophraftus 2. lib. de caufis plant . cap. 9. fcribit hanc folam arborem in umbra melius, atq. citius fructum concoquere, fubiungam his a Ruellio male Diofcoridis ea uerba de aci

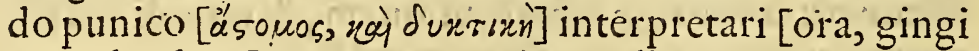
uasq. lacdunt]nempe quac a Marcello Serapionem imi tante melius fic uertantur, [eademq. ori ingrata, adftrin gunt, ] quis ignorat, (quaefo) acida punica multum abeffe, ut laedant, cum gingiuas laxas, \& ora in fammata mirifice confirment, \& iuuent, quae tamen'ori aufteritatc fua , \& aciditate difplicent. Eft \& alter Theophrafti locus quarto de caufis planta. cap. 14. qui in graeco codice corruptus, nec a Gaza cognitus eft : De fabis namq. Philipporum fermonem habens, ita inquit, g $^{2} \mathrm{~d} v$

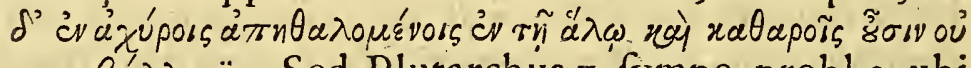
$\mu \varepsilon \tau u \beta u ́ \lambda \lambda \lambda$ ӝiv. Sed Plutarchus 7. fympo. probl.2.ubi multa ad uerbum ex Theophrafto adducit, pro $c^{2} \pi r \theta \alpha-$

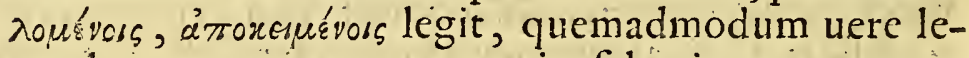
gendum puto; non tantum enim fabas in arcacum paleis fuisfepofitas, uerum etiam triticũ omniaq. ferelegumina conferuari inoffenfa in iifdem libris palam móftrauit Theophraftus. unde quid torrefautae palcae (ut convertit $\mathrm{Gaza}$ ) ibi apte defignare ualeant, non fatis in telligo. Addam his Theophraftum 2. de cauffis plantarum cap. 22. noltiffe ex fanguine corrupto pediculos gigni, quos ipfius pracceptor A riftoteles ex carne corrupta nafci, quinto de hifto.animal.cap.32. maluit; fed neutrum fefelliffe omnibus illis putare licet, qui utroque modo animalcula illa produci, \& carné ipfiffimum fanguinem effe cogitarint. Illud non praetereundū, fcri ptum effe ab A pollonio in hifto.mirab. quod Ariftoteles uoluerit pediculos in morituris capita corum deferere, atq. in puluinaribus in ueniri; cuius eucntus cam Alexander 


\section{$S$ E C V N D $v 3$.}

Alexander in 2. prob. lib.30. affignauit cauffam, quod pediculi nutrimento atq. têpore ex fanguine opus habeant, quorü vtroq.in morientib.deficiéte, cos defcrüt meliorem locū fibiipfis quaerentes. Quomodo vero nố omnino contraria Theophraftus \& Galenus fentiant, dum alter 4. de caufis plantarum cap.10.hominé a fcorpione ictum non interire, alter interire faepius fcribit, $2 \mathrm{~d}$ huc ignoro, nifi dixerimus, Theophraftũ de Italicis fcorpionibus, ac nonullis alijs meminiffe, quos innocuos enle affirmat Plinius.

De varijs antiquorum edulïs criftotelis locus examinatus, de carne Camelina, de fumine, de turte nomine. Cap." $V$.

Atulorum latentium carnes procibo veteribus (S⿰亻⿱丶⿻工二木 La. lib. 29.cap.4. fribentis, Catulos lacentes adeo puros exiftimabant ad cibum, vt etiam placandis numi nibus hoftiarum vice vecrentur, las Hippocrates quoq. grauiffmus autor pluribus in locis mon trauit, vbi eas in varijs aegritudinibus ab ipfo non parum commenda ri clarum eft, quemadmodum eriam Oribafius in primo Collect. ex fententia Mnefithei A thenienfis laudauit. At Camelinae quomodo vfq. in vfu effe potuerint, vehementer dubito, Galeno praefertim in lib. I. dcalimé

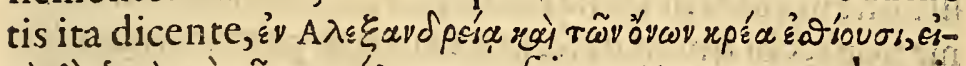

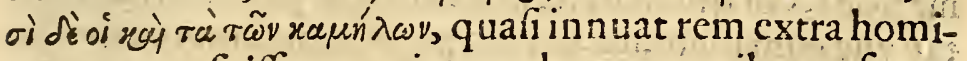
num mores fuife, vt quis camclorum carnibus vefceretur, nempe quas in 3.lib.ve malas valde damnat; Vnde quae Ariftoteles.6. de hift. animalium fcripta reliquir, carnes fcilicet \& lac camelarum vfquequo conceperint, omnium fuauiffuma effe mihi femper fufpecta fucrunt, credidiq. $\tau \dot{\alpha} x p \varepsilon ́ a$ ab aliquo ex marginibus interfcrta, quando Plinius lib.8. folum lac, \& non carries camela- 


\section{I B E R}

rum ab hominum lacte dulciffimum facit: quod fi vulgatis philofophi,codicibus fidem placeat adhibete, neceffe eft fateamur illa ex aliorum relationibus ipfum di xiffe; ex quibus maiorem librorum de animalibus, partem conflatam putant eruditi omnes: Id quoq. a me fae pius notatum eft, ranarum carnes, quod cderent pro cibis maiorcs, a nemine fuiffe proditum, eas tame hac tépeftate veluti delicatiffimas deguftant multae nationes, \& praefertim Itali, quos hac rationea Graecis aliquando BuTpaxocágous vocari animaduerti. Quod enim ranae ventrem Archeftratus apud Athenaeum laudet, illiud de rana pifce intelligendum eft. tempore Plutarchi cerebra animaliū manducari coeperunt, quae antiquos vti abominatos proieciffe affirmat 8.fymp.probl.9.quo in loco vuluas quoq. quas Horatius \& Plinius mirum in modum praedicarunt, pro iucundiffmo edulio tunc habitas lcribit; at eas qui noftra tempeftate in fuas men fas recipiant, nulli, aut fare pauci inueniuntur, ficuti nullus fere eft, cuius palato grues hodie admodum arri deant, cum \& Galenus fibrofamac duram cat'nem habe: re dicat, quas tamen tanti fecerunt interdum maiores vt ex Melo infula eas (quod refert Gellius ex Varrone) maximis impenfis Romam vehendas curarent; quinim mo eis pinguibus reddendis magnum ftudium adhibuifle oftendit idem Plutarchus in 2 de carnium efu decla matione, vbi quem defcribit ventrem porcae nuper foe rae vna cum mammis baculo percutiendi morem, vefan guis, lac, \& caro fimul mixta iucũdioia gulae euaderét; is eft, quo noftra tempeftate fumatas populari vocabulo appellatas faciunt, haud multum ab antiquo fuminis nomine dcfleftentes, quod etenimi vetuftiores abdomen vocabant Publius minorum poeta fumen primus vocauit, vt fcribit Plinius lib.8.cap.5 I \& lib. I I.cap.37. vbi cum dicat antiquos non confueuiffe fcientes occide 


\section{$S$ E C.V N D V S.}

re priufquăabdomen calleret, id innuit, quod damnatüs eft à Plutarcho in 2. de carnibus declamatione, videlicet fuo tempore homines iam partui vicinas fues occidere folitos, atq; ventres percutere, quò mortuo foetu, lac fimul, \& fanguis in carne commixta edi polfent, ve Turnebi correctionem non contemnendam omnino putem, quilib. 23. aduer. cap. 20. loco [id fcientes] infcientes reftituendum voluit, quamquam Hermolaum Barbarum, \& Gefnerum aliter fentire non me lateat. Sumen inter delicatiores cibos, non infimum locum tenuiffe omnes Latini poetae atteftantur, quafi vno verbo dicere liceat, de cibis quod Horatius de vocabulis cecinit.

\section{Multa renafcentur, quac iam cecidere, cadentq.}

Quae nunc funt in honore.

Auctor eft in Onomaftico Erotianus äp Atticis appellatum effe panem ex pinguibus palmulis farina, \& aqua confeetum, nec non in calido cinere costum. quem etian roúprav uocatã dicit. Quo in loco fa cile affentirem dostiffimo, \& de medicinae ftudiis optime merito Bartholomeo Euftachio, noftrum tortae po pulare nomen veteres Romanos habuiffe, fi quemg. alium corum temporum fcriptorem monftraffet; qui id nomen vfurpaffet, vt verifimile videtur, alios etiam \&e praefertim Plinium, Athenaeum, Pollucem debuiffe if lius mentionem facere, fi nomen fimile habuiffent, quo circa fortaffe vox ea apud Erotianum deprauata eft, aut $a b$ aliquo recétiore in margine haec claufula notata ồ

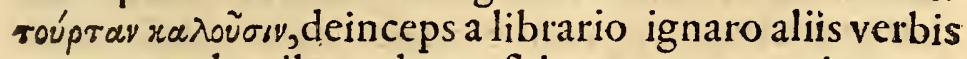
antecedentibus adnexa fuit: quanquam etiam

non me lateat facrae Bibliae interpretes, áprov żz rupuqiav tortam pa-.

nis tranftuliffe.

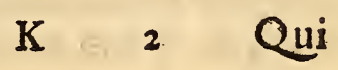




\section{L:I:B $\mathbf{R}$}

Quifint apud Platonem ficus, ơ puae generofae ex Galcno, De pane fabaceo, ó faba. Legyptia: locus.ingefithei
de ficulus.
cap.
VI.

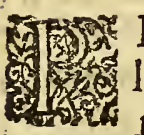

Lato 8. de legibus dialogo fruetuum Tñs óøópá legescondens vuarum, \& ficuum gruvácov mentionem facit, vbi mitius eos puniri iubet, qui huiufmodi fructus praedantur, quam qui alios. propterea -quaefitum eft a pud A thenaeum in 14 . quae nam a Platone generofae vuae, ¿ ficus appellataefint. Mafurius

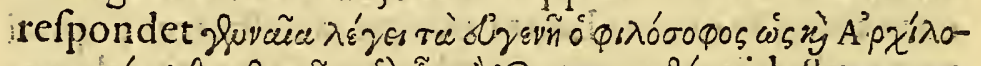

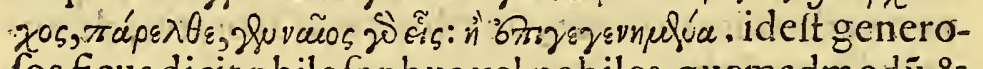
fos ficus dicit philofophus vel nobiles, quemadmodū $\&$ Archilochus, Accede,es.n. nobilisivel poft genitos:Sed qui fint nobiliores ficus, ac vuac, quas multis alijs portponere videtur Plato nondū ex his Mafurii.verbis certe côftat; attamé rationi confentaneũ videtủ , fic effe appellatos ficus, qui poft primos; \& praecoces, frue in ijfdem, fiue in diuerfis arboribus nafcuntur, ceterofó; ple rumq. fuauitate antecedüt. Quae vero dicerêtur vuae generofae, fiue nobiles omnium clarifime explicuit

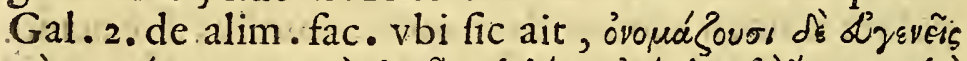

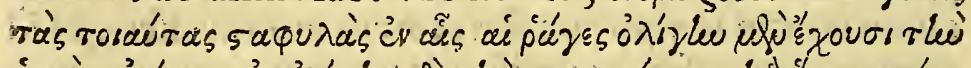

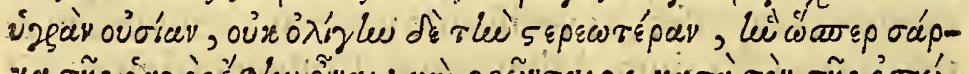

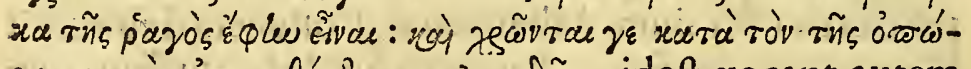

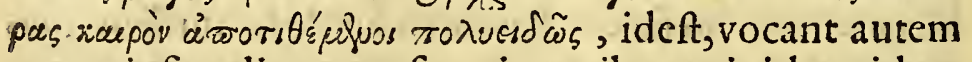
vuas eiufmodi generofas, in quibus acini humidam quidem fubftantiam habent exiguam, folidiorem autem non paucam; quamve carnem acini effe diximus: Atq. iis vtuntureas variis modis in fine actatis repo-

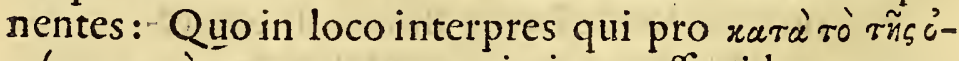
mópas rupòv autumnum vertit, ignorafle videtur, quae proprie fuerit apud veteres opora, cuius Plato meminit, \& quam nos alias ex Hippocrate monftrauimus 


\section{$S$ E C V N D V S.}

efle dies illos, qui inter can is or tum \& ar A urum nume rantur:itaq. ficus vocauit Plato generofos qui nobiles, \& poftaliosorti funt: at vuas generofas appellauit nobiles quidé, fedquac parú humidaefubrătiae, durioris pluîculü habét: quaeve edédo funt; neq. vinis faciédis idoneac habetur, fed ve ceteri fructus autumnales, lỏ go tépore cöferuari poffunt; vt nô inique egerit, fi mitius in cos animaduertédũ fat ueric, qui vuas, facièdis vinis minus idoneas, licet côferuationi aptas furarétur. De vtris generofis loquitur Ouid. 2. de remed. amoris. Est tibi rure bono generafae fertilis puate Vinca, ne nafcens pua fit ufla time.

Quod de ficubus fcribitur a Plutarcho,eft fane cognitu dignum, qui in cauffis naturalibus tradit Mnefitheum medicum a Galeno in prohemiolib.ad Glauconem.có mendatum narraffe, quod qui in principio pulmonariae morbicaepas ap petunt feruantur, qui uero ficusin tereunt,eo quia ap petitus temperaturas, temperaturae autem morbos confequuntur. Galenus interlegumina \& frumenta illud difrimen ponit, quod ex his panes confieiantur, ex illis non : Fabam deinde cum inter legumina recéfeat, manifefto videtur indicaffe; antiquos eo pane fabaceo minus uititafle, quo hodie apudvaroos populos mànã rufticorũ parté uefci cófpicitur:fed forfan id de Graecis dumtaxat intelligere dixerit aliquis; quãdoquídé Plinius lib. I 8. cap̣. I 2. fcribit etiāa ex fabis pané effe tentatũ ; vbi monftrat quoq. fua tempetate plerafq. gentes frumento fabam mifcuiffe in panis vfum, quemadmodum hodiefit. Quod porro effet fabae Aegy ptiac pondus, cuius frequentifima mentio a Galeno, atq: aliis Graecorum medicis habetur, docuit Soranus Ephefius 24. cap. fuae ifagoges; ubi eam cótinuife fcrupulos duos tradit; quod ideo verifimile puto, quoniam ex Dlinii loco nuper citato granum A egy-

ptiae 


\section{I B E R}

ptiae fabae ceteris valde maius fuiffe maniferto colligitur; vt his rationibus nullă fidem habeam libro de pôd. \& ment. Galeno falfo adfcripto, in quo legitur fabam Acgy ptiam pependiffe obolum \& femis.

De pulmonis carne Galeni contradiltio ex Letio Jublata de carne

Leporina, \& Vulpina o tenera carne locus Galeni

$$
\text { refitutus. Cap. VII. }
$$

T. VImonem iccore faciliorem effe coctu, minus nu1. trire, magifq. pituitofum fuccum facere ait Galenus 3. de alim. fac. cap. 2 2. At idem lib.6. de vfu partium cap. I o. tradit, pulmonem tenui, leui, ac vaporolo fanguine nutriri, iecur autem limofo, \& craflo, vnde fi tale eft nutrimentum, qualis eft fubftantia nutrientis, uidetur fubftantia pulmonis vt eft tenuior iecore, fic fuccum tenuiorem, \& non pituitofiorem parere. A tqui Aetius lib. 2. cap. r 27. hanc dubitationé tol lit, dicens pulmonis nutrimentū effe magis pituitofum

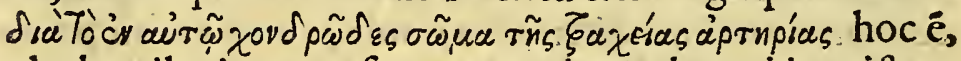
ob chartilagineum afperae arteriae pulmoni inexiftenti corpus : quae verba fortaffe codici Galeni effent addenda, cum Actius omnia illa ad verbum ex Galeno fumat, potiufq. minuat, quàm addat. Mirantur porro multi cur Martialis inter quadrupedes lepori primas dederit, qui fane mirari defincnt, modo confiderare ve lint quae a Galeno de fanguine leporino in 3. de alim. facultatibus fcriptis tradita funt, eum nimirum tanquả omnium fuauiffimum in magno pretio habitum: carné cnim talem effe, qualis fanguis, ex quo tota conftat, nó modo omnes medicinae auctores, verum ctiam ipfa ra tio declarat; unde fanguine leporis fuauiffimo exiftéte, quomodo cius caro magna fuauitate non polleat uiro erudito creditu difficile erit. Maiori fortaffe admiratio 


\section{$S$ \& $\vee$ N D $\checkmark$}

"ne dignum videatui, quod Galenus in 4.de victu acut: commentario, \& 3. de alim. fac. fcribit, autumno carnes vilpium, quâdouuis nutriuntur, palato gratinimas habeifi \& iccirco uenatores apud Graecos tunc ipfas efita reconfreuiffe: Hic admoneor, ve errorem quorundam detegam, qui carnes quomodolibet teneras recentibus. femper praeferunt, haud quaquam cogitantes teneritu dinem eam veluti putredinem quandam, aut faltem ad, putredinem pracparationem effe, quae cibum détibus quidem faciliorem \& gratiorem reddat, fed qui poftea in venis deteriores fuccos, \& longo tempore prauas affestiones progignere queat: Vnde Hippocrate aut Pobybü laudare foleo, quòd dixerit in 2 de diaeta, Ta apó $\sigma$

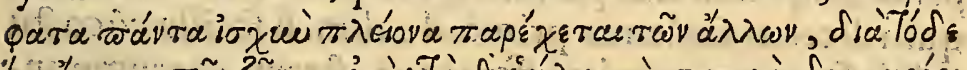

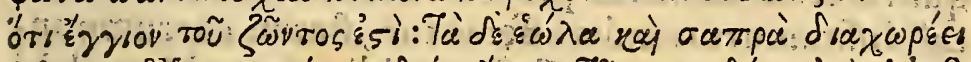

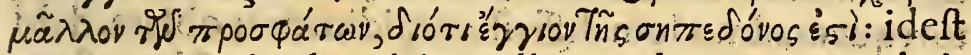
recentia omnia plus virium alijs praebent, eo, quod viuentifint proximiora, hefterna uero, \& marcida recétibus excernunturmagis, quòd ad putredinem propius accedant. Nam recentes carnes plus roboris inferre cor: poribus, praeter Hippocratistationem, bruta quoq.om nia carniuora demonftrant, quac carnes recentifimas ino tho calentes; \& quali viuentes comedentia, omnium aliorum robuttifsima funt: haud inficior tamen aliqua hac in re effe rationem habendam tum hominum tum. carnium edendarum: Dehominibus dixit Hipp. in lib.

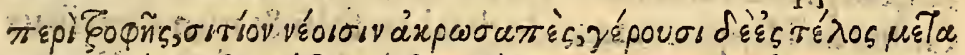

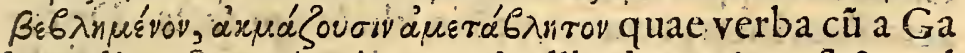
leno diuerfo modo citentur in lib. de optima fecta ad

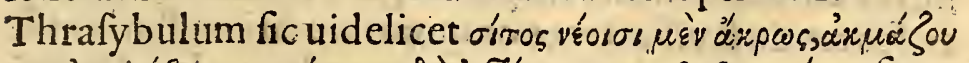

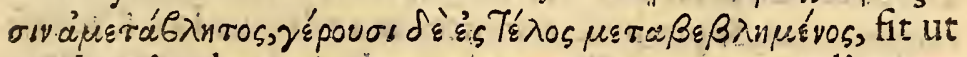
credanı in altero corumc ontextuum errorem aliquem latere;potiufq. Hippocratis codici quam Galeni, fidem adhibendam, immo co modo Galeni textum reftituen- 


\section{I R}

dum, ficut in Hippocrate legitur; ut haec fit fententia, ci bos iuuenum debere eire parum mutatos. (In expos.n.

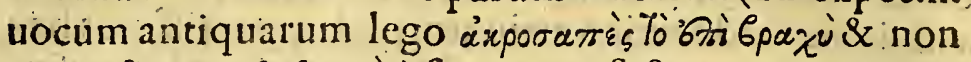

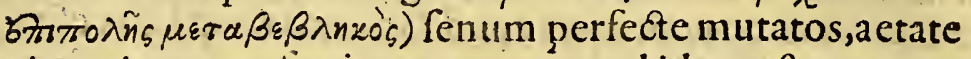
uigentium prorlus immutatos; quod idem eft quoq. ac fi dicamus(vt Antonius Fracãtianus praeccptor meus; \& nemini fuorum temporum in medicina facienda, ac docenda fecundus, luculétiflíme explicuir) carnes quas fenes funt efitaturi, debere teneras effe, quas aetate vigentes recentiffimas; quas uero adolefcentes medias quodammodo inter has \& illas: pio vt namq.calor, qui: concoquere debet, maior vel minor eft, fic etiam edulia paratiora, vel minus parata concostioni effe decct;alioquin dicebat Galenus primo de alim. fi facilia cócoetu calidiffrmis uentriculis offerantur, ftatim corrumpun-. turi; quemadinodum difficilia tepidioribus oblata, debi tam concoitionem nunquam affequuntur. Non eft tamen ignorandum, Rabim Moyfem 19.aphor: Galenü ex 4.com.n lib.de alim.citare, vbi cum haec verba barbaro fuo more ex Galeno defcribat: Singula animalia ex quibus cibandi funt fenes, $\&$ domini corporum defe Etorum per diem, \& noctem ea dimitte, \& poft modum coquina carnes ipforũ , \& fac ex eis cibaria bene couta, $\&$ minittra eis. Et iuuenibus, \& dominis cò̀rporum fortium \& opcrantibus fortia opera coquina carnes recen tes, coquens cas bene uel affatas, uel elixatas. Videtur Galenus Hippocratem de duabus folū \& non de tribus aetatibus interpretatus, ut e in lib.de opt.feuta. De car nibus aninalium edédis praecepit Oribafius 4. collêt. ex fententia $R$ uffi, carnes omnium agr eftium ftatim effe coquendas, \& proinde recentes manducandas; Cicurü uero ouillas \& caprillas recentes, bubulas autem uetuftas;fimiliter ex auibus magnas atq.paluftres; item galli nàs, palumbos, perdices, pauones, atq.attagenes noo effe 


\section{$S$ S $\vee N D$ S.}

recentes coquendas; fed turtures, columbas, \& turdos: pifces vero omnes quamprimum coquédos.ex quo Ori bafij delectu potelt fubinde quilibet iudicare non effe femper, nec a quibusuis recentes, neq. femper tencros quoslibet cdendos cibos.

Locus Hippo. emendatus, Galenilocus defenfus de opio . Flinip loci emendati, alter Herodoti de medicis $\mathcal{A}$ egyptiorum examinatus of correttus. Cap. VIII.

. N libro Hippocratis de locis in homine, vbi de

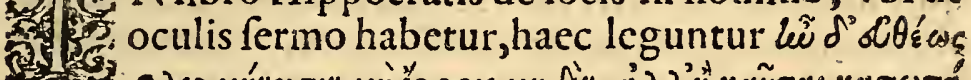

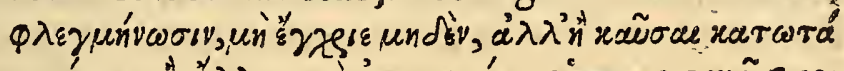

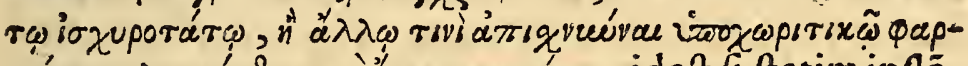

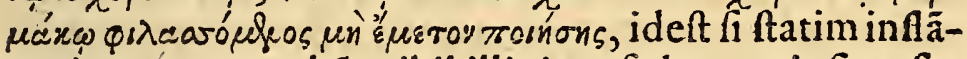
mationem contrahãt nihil illinias, fed quam infime for tifimo uras,aut alio quopiam aluum fubducente inedicamento attenues, cauens ne uomitum facias. Quoniá uero uftio in inflammationibus, praefertim in initio, pe riculofa eft, ea propter locum corruptũ fic reltitui.(ut e

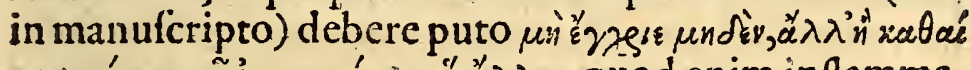

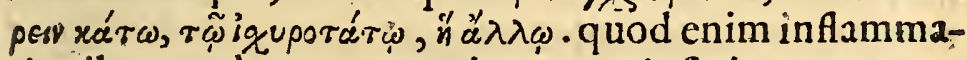
tionibus oculorum purgationes per inferiora, magnopere profint teftatum fecerüt Hippocrates, \& Galenus

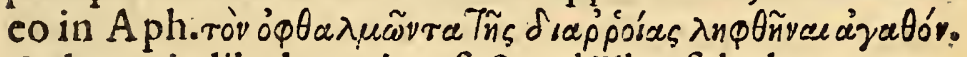
Galenus in lib.de optima fecta ad Thrafybulum contra Methodicos difputans, eisq. indicationes côferentium nó femper ab effeetibus accipi demonftrans, haec ferip-

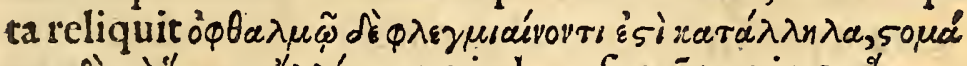

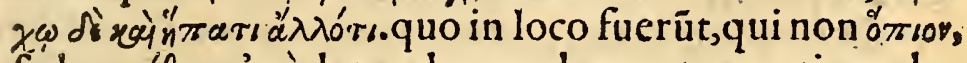

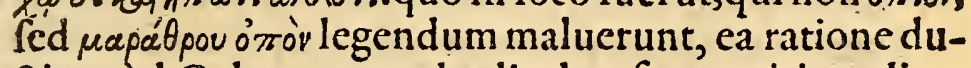
eti, quod Galenus 3.methodi aduerfus empiricos dicat medicamenta opiata magnam oculorum perniciem exi ftere, ve etiam ante ipfum Plinius lib.20. cap. I 8. ex Era 


\section{I B E R}

fitrạti, \& Diagoraefentètia fatuerat, fed ipfos falli, nec mutari debere contextum ex eo faciliter probatur, quo niam nullum fere ex tot relatis a Galeno in 3.de comp. med.s.l. praeclarifimorum medicorum ad oculos com pofitis medicamentis innenies, in quod opium iufto mo do non ingrediatur : id tamen ueriffimum puto,opium vehementer ob effe nifi recte caftigetur, \& debita menfura adhibeatur, quemadmodum quofdam ophtalmicos medicos giffe videtur, quosibi damnat Galenus, quafi nullo adhibito delectu in omnibus paffim opiatis quibufuis uterentur. Hanc fententiam eo libentius am plector; quod Rafarius acerrimi iudicij, \& fummae doetrinae vir in fir translatione ita legendum cenfuerit . Legitur a pud Plinium lib.24.cap.5.glandis fagineae ci nerem calculis illiniri, quod quomodo fieri queat, \& vt prodeffe poffit non uideo quando praefertim Galenus. fagũ vehemétius robore adftingere fribit. 6 de fimpl.: med: \& frustus eiufdé femper acerbos effe dicir 4. eiufdem tractationis uolumine, $v t$ his facultatibus nullo modo calculis illitu mederi valeat.ideo legendum puto non calculis, fed oculis: Guillandino eruditifimo videtur poffe legi callis, cuius iudicium non improbo.Quod autem apud eũdem Plinium lib.27.cap.7. friptum eft; in regio morbo crudum abfinthium bibi cum opio, aut adianto, reftituendum eft,cum apio, opium enim multum abeft, vt in hoc morbo vllam opem ferat. Habebát Romani \& Graeci medicos, qui nudis quibufdam experimentis peculiares corporum humanorum partes curare proficcbantur, veluti aures, teftes, detes, fed major illorum copia atq. aucforitas erat qui oculis meden dis operam naubant; qui ve coeca experientia tantum confifi, non raro magnum detrimentum afferebant; vt de quodarn medico notauit Martialis, qui oculos erue bat it? ficquenter hominibus, vt eam profeffionem relinquere 
linquere coactus, ad hoplomachiam exercendam fe cá tulerit, in qua ctiam paria damna infercbat.

Hoplomacbus nunc es, fueras optalmicus ante,

Fecifti med icus, quod facis Hoplomaclous

Quomodo vero ea varijs medicis varias corporum partes curare confuetudo inuecta fuerit, exiftimo A egyptios, vt multa alia, fic \& hos mores in Graecos inuexiffe, ab his deinde emanaffe ad Romanos, quos vniuerfam medicinam ex Graecia recepiffe Cato \& Plinius teftati funt. Quod autem Acyyptij medicos eiufmodi haberent, affirmat Herodotus fub hifce verbis in 2.lib. n d'in ל̧

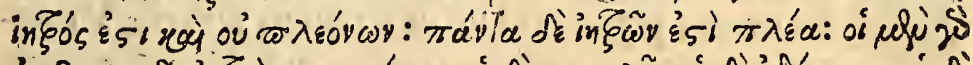

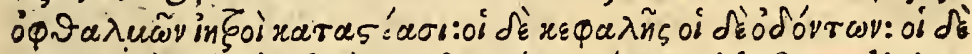

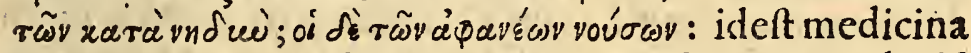
apud ipfos fic diftributa eft: vnius morbi, \& non pluriú vnufquifq.medicus eft; omnia vero plena medicis funt, alij enim medendis oculis, alij capiti, alij dentibus: alij ventri, alij occultis morbis curandis funt deftinati:vbi vltima illa verba mihi fufpecta femper fuerunt, quando quidem Hippocrates, qui ea voce, undù, faepius pro vé tre, \& cauitate vtitur, (quemadmodum fribit A erotianus) \& quemadmodum non raro vfus inuenitur Herodotus, eofdem poene facit in lib. de arte morbos ocul$t_{0}, \&$ morbos ventris aut cauitatis; cum de ocultis lo-

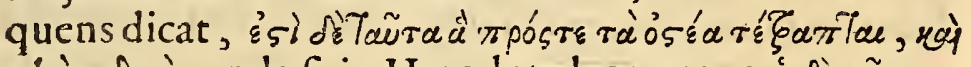
$\tau$ twind wi, vnde fi in Herodotolegeremus oi dह่ $\tau \tilde{\omega} y x a-$

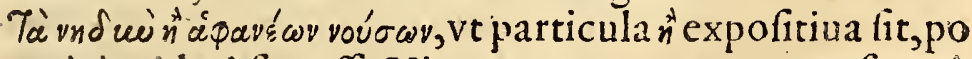
terit is videri fortante Hippocratem coaetaneum fuum?, cademq. lingua vfum imitatus, dicens nimirum dios fu iffe medicos ventris morbormm, qui oculti funt, neq.am plius dubitandi occafio dabitur, qui effent oculcorum morborum medici, \& quarum aegritudinum : neq. ité vlla apparebit in verbis Herodoti cótradictio, quae ae- 


\section{I E $\mathrm{R}$}

gre profecto vitari poteft, $f$, cum paullo fupra dixerit vnius partis morbi, \& nó plurium medicuın vnĩ fuiffe; ftatim dicat, vniuerfim medicum vnum quofq. ocultos morbos, \& non ventris quae ocultae funt aegretudines, curare folitum. Haec dico \& fi non me lateat ctiarn ita, vt legitur, Herodoti orationem fanam effe.

\section{De aqua um per piumbum duCtarum prauitate, \& quod Romae $e x$} fontibus potarent, locus Paterculi emendatus. Cap. VIIII.

Vantum ad falubritatem conferat per quos du(. Etus aqua potui efui ve deferuiens feratur; VitruAius auctor nó cótemnendus in 8.lib.cap.7.lucu létiflime monftrauit, cuius verba tamquã medicis omni bus valde vfui futura hic fubfcribere placet. Habent au tem tubulorum ductiones ea cōmoda: Primum in opere, quod fi quod vitium factum fuerit ${ }_{2}$ quilibet id poteft reficere; etiamq.multo falubrior é ex tubulis aqua, $q u a \bar{a}$ per fiftulas; quod per plumbum videtur effe ideo vitio$f a, q u o d$ ex eo ceruffa nafcitur; haec autem dicitur effe nocens corporibus humanis; ita fi quod ex eo procreatur, id eft vitiofum, non eft dubium, quin ipfum quoq. non fit folubre: Exemplar autcm ab artificibus plumbarijs poffumus accipere, quod palloribus occupatos ha bent corporis colores : Namq. cum fundendo plumbü flatur, va por ex eo infidens corporis artus, $\&$ indies exu rens eripit ex membris eorum fanguinis virtutes . Itaq. minime fiftulis plumbeis aqua duci videtur; fi volumus eam habere falubrem; faporem quoq. meliorem ex $t \mathrm{u}-$ bulis effe quotidianus poteft indicare victus, quod omnes extrustas cum habeant vaforum argenteorum men fas, tamen propter faporis integ ritatem fivtilibus vtuntur. Columella.quoq. rei medicae non inexpers dü pro gallinarum 


\section{$S$ E $C \vee N D \vee S$.}

gallinarum potu \& cibo vaforum fabricandorum rationem tradit, lignea aut fictilia plumbeis praefert, quod viliora effe compertum fit:poft hos vero Galenus in 7. de med. comp.s.l. cum in componendo ex papauerum capitibus medicaméto aquã pluuiā puram, \& omni mix

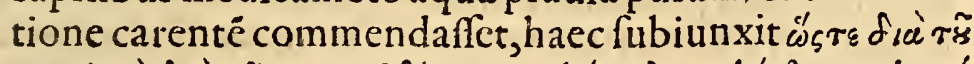

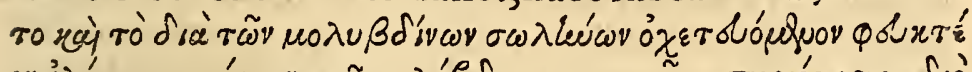

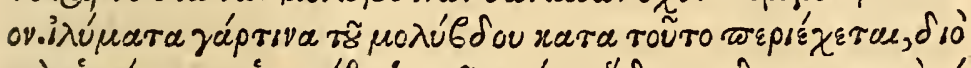

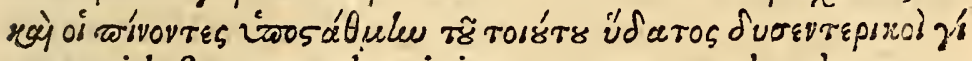
vovfac: ideft propter hoc igitur aquam per plumbeos canales duotam fugiendum eft, quoniam recreméta quae dam plumbi huic immitūtur, unde poftmodum huiufce aquae fedimentum potantes dyfenterijs tentantur. Ex quibus omnibus perfpectum fieri poteft aquas per plü bum ductas non immerito femper tamquam per niciofas effe damnatas, \& ideo medicos quoq.illos perperam facere, qui aquas, fuccos \& olea ui ignis per plumbum extracta medicamétis per os affumendis inimifcere nô verentur; fi enim Galenus in primo de antidotis libro pro medicamentorum conferuatione vafa ftănea fugie bat,quod fciret ftānum plumbo adulterari,ab eoq.vim aliquam perniciofam immitti formidaret, cur etiam me dicinon valde timeât plumbum in vllum eorum vfum vocare, quae ab ipfis pro fanitatis conferuatione, aut re paratione acgrotis exibenda funt? Ex ijs etenim quae fuperfunt Romae vetuftorum aquaeductuum veftigijs apparet,maiores quantum fieri poter at, fiftulas plübeas effugiffe, in illis praefertim ducendis aquis, quae nô tan tum lotionibus, fed potibus, cibifq.inferuire debebant; quamquam haud facilecredo eas, quae ex Tyburti nis montibus Romam ducebantur, multum pro cibo potu ue in vfu fuiff; ; propterea quod Galenus omnium Romae conditionũ diligêtiffimus obferuator in 4.6. Epid. 


\section{I 5 :}

commentario illas omnes crudas, \& coquendis edulijs inepcas extitifie affeucrat, addens eam vrbem, vt alias excellentifimas dotes, fic \& plurimos ac pulcherrimos habuiffe fontes, ex quibus aegri nedum fani potarent. Vr enim alios plurimos omittam, auctor eft in hiftoria Roinana Velleius Paterculus Syllá aquas falubritate, medendifq. corporibus nobiles ad agros omnes duxiffe, fer quonia Paterculi verba in vulgatis codicibus vit!ica funt, non abfurdum erit ea a Claudio Puteano $\mathrm{Pa}$ riffen li iuuene doctifimo reftituta proponere:?unt vero haec. Grates Dianae cuius numini regio illa facrata ef foluit: aquas falubritate, medendifq. corporibus nobilesagros omnes ad duxit . deq. huius gratae religionis meinoria \& inferiptio templi adfixa pofti, hodieq. \& tabula teitatur aerea incra aedem.

De Cicutalocus Lucretÿ explicatus. Ariftotelis, \& Varronis de Caprisloca examinata, nonnulla de anatome.

$$
\text { cap. } x \text {. }
$$

6ry I cuta furnos nutriri apud austores, \& praeferTht tim apud Galcnum faepius notatum obfcruaui; cuius euétus cauffă illā, is 3 :de fimp.med.attulit, quòd aues huiufcemodi anguítos corporis meatus habétes, haud finũt cicutae fuccú ad cor penetrare, fed eú in ventriculo tädiu retinét, quoad natiuo calore fupera tus in nutrimentú cốciertatur ; cú hominibus fecus eueniat, quibus nimirum ob uenarum amplitudinem cicuta in cor celerrime perdusta, natiuum caloré extinguat. Iraq.illud admi or, quomodo Lucretius hunc effêtum non in fturnis, fed in capris apparerc atteftetur in $5.1 \mathrm{lib}$.

Quippe videre licei pinguejcere faepe cicuta

Barbigeras pecudes, homini quae eft acre renenums

Quod quando verum elfe experientia cóftaret,cauffam hane 


\section{$S E C V N$ S}

hanc affignarem, capras quas mirum in modum ficcas effe, \& perpetuo febrire Varro a tq. Plinius tradiderüt, cicutis feruorem, ac fquallore temperare, quo poftriodum tempcrato nutrimentum melius conficitur, $\&:$ in pinguedinem concrefcit : De capris fcripfit Arifoteles primo de hift animalium cap. I I. Alcmeonem falí pro didiffe eas non naribus, ut cetcra animalia, fed auribus fpiritum ducere, quam fententian deinceps Varro in 2.de re. rult. \& Plinius lib. 8. rctulerunt; fed ambo hi Archelao, \& non Alcmaeoni attribuerunt; vade fit ve vel Ariftotelis vel Varronis a quo Plinius fua accepit., mendofum effe contextum exilimem. Fuerunt quide Alcmaeon \& Archelaus austores vecuftifimi, alter phi lofophus, alter medicus \& philofophus, vt eorum vterc. fententiam huiufcemodi fcriplffe potuerit, \& maxime Archclaus, qui etiam homines \& animalia ex limo nata prodidit. Alcmaeum primum anatomen monftrafe Chalcidius in com. fuper Platonis Timaeum affirmat, quam deinceps eius pofteri per manus accipientes, pueros non folum qui medici, fed \& qui philofophi erät fijturi,edocebát: ita enim Democritun , aliofq. plürimos in anatomica difciplina eruditos fuiffe legitur: quam $\&$ fi a nullo veterum vfq. ad Dioclis aetatem fcriptis man datam referat Galenus in 2. dc anat. admin. melius tamen fic conferuatam, \& amplificatam inde intelligere poffumus, quod tunc homines a primis annis anatome (vt ceteras artes) nô ex fcriptis, fed ex parentum fermonibus ipfiq. exercitatione addifcebant; fico, melius eâ comparantes non modo tenacius in animisferuabane, verum etiam affiduis ftudijs augebant: At A riftotelem neq. fic anatomen didiciffe, fed folum quae feriplitad eam pertinentia ex aliorum relationibus tradidife, $f \mathrm{em}$ per putaui, quando quidem non femel id libris de an:malibus annuat, \& praefertim in primo de hift. anima-

lium 


\section{I B 8}

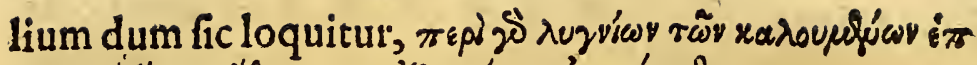

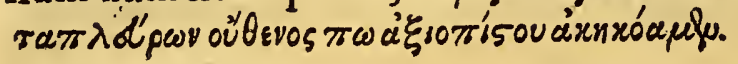

Hippocratis locus emendatus, locus Diog. Laertï ex Galeno mutatus. Galeni de vrinae fedimentorum nigredine of de lapide veficae error. Cap. XI.

Agnus Hippocrates in lib. de foetatione, \& $\mathrm{fu}$ - perfoetatione (fic enim \& nó de fuperfoetatione 2olum infcribendum puto, cum ibi de vtraq. copiofe traßtetur')docens quid ad generãdū marem obfer

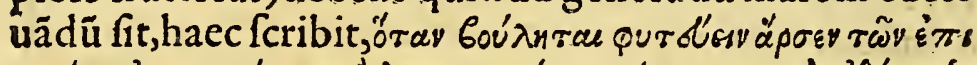

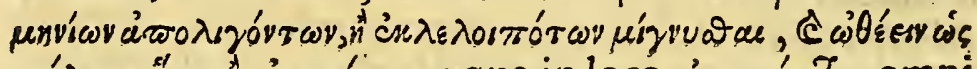

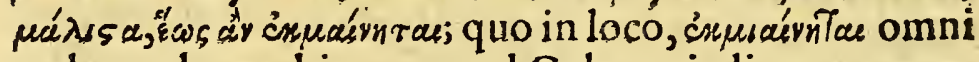
no legendum atbitror, quod Galenus in linguarum ex. pofit hanc vocem feminis emiffionem fignificare feribit; quantum autem rationabilius fit dicere,impellendum quam maxime, quoufq. femen emittatur, quả, quo ufq. faeuiat, vt interpretes transferunt, cuiuis perfpectum effe poteft. Diogenes Laertius in vita Xenocratis auctor eft eum, philofophum ad quendam, qui neq. mufica, neq. geometria neq. aftronomia intrustus ludum fuum frequentare cupicbat, refpondiffe wap'seol ou тórss xyám Tsтa, quae verba alioquin ab interprete latino male translata, \& fi recte accommodari poffent, mihi tamen placeret magis fi non, 'xvá T $T_{\varepsilon}$ ras fed zra $\varphi \mathscr{L}^{\prime}$ ras legeretur; atq. ad id opinandum ea ratio me impel lit, quod Xenocrates co refponfo innuere voluifle vide tur, difciplinas ordine quodam cffe apprehendendas, neq. adeundum philofephiam, nifi mathematicae dif $\mathrm{c}^{\mathrm{i}}$ plinae teneantur, ficut nemolanam nondum vellicatā, ac politam ad fullonis officinam, vt tingatur, ferat. Sic

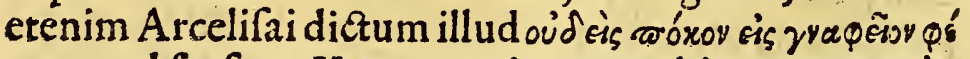
per, quod forfan a Xenocrate in prouerbium emanauit, intelligendum 


\section{$S$ E $C: N D V s$.}

intelligendum effe longa hac, atq. eleganti oratione fignificat Galenus in 2. de differentijs pulfuum. To 20 rô

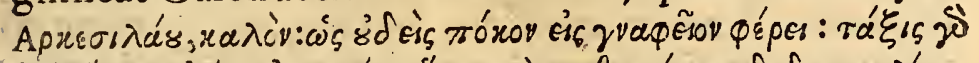

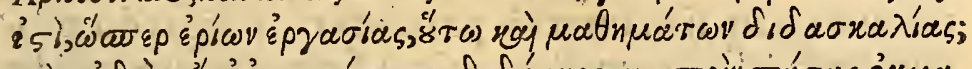

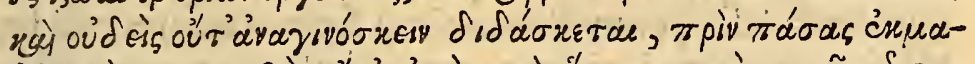

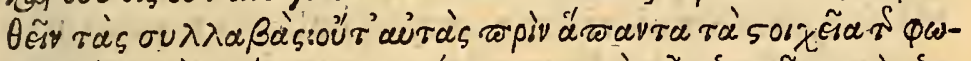

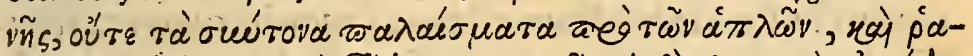

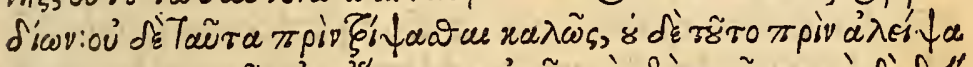

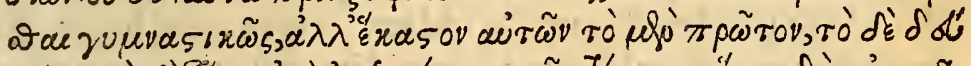

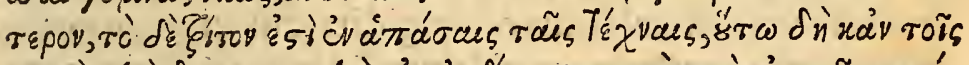

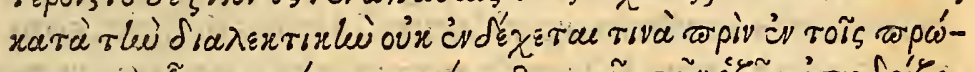

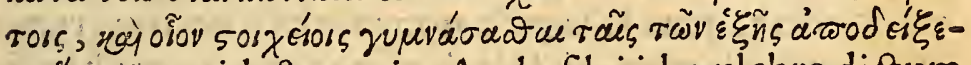

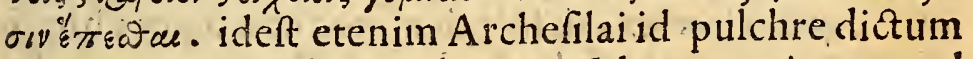
celebiratui, quód nemo lanam nỏdum carminatam ad fullonis officinam portat, Nam ve lanificij fic \& difcipli narum addifcendarú ordo habetur; A tq. nullus legere difcit, nifi prius fyllabasteneat, neq. has, nifi prius oía vocis eleméra : Neq. validas palaeftrae exercitationes, ante fimplices, $\&$ faciles obeũt:ncq.haec, priufquã reçe fricentur, neq. hoc priufq. vngātur gymnaftico modo. Sed fingulorum hoc quidem primum, hoc fecundum, illud tertium in cũctis artibus repcritur. Pariter quoq. in dialectica minime contingir, ve quis demoftrationes confequentes comparet, nifi in primis, \& veluti clemen tis exerceatur. In omnibus quidé Galeni vnde quaq. admirabilis auctoritate magni facerc foleo, at in ipfius quoq. commentarijs interdum inuenio, quod iure reprehendi queat, ficuti eft quando in primo wepi xpiosesy libro nigras vrinarum fubfidentias ex mortificatione a vehementi frigore induata proficifei fribit:quod enim in corpore viuo tanta poffit confiftere frigiditas, quâta fedimentis vrinae nigris reddendis fufficiar, captu diffi cile admodum ef: fi quidem habitus hydropicorum fri gidifimus multum abeft vt huiufcemodi quicquá pro$M$ ducat: 


\section{I B E $\mathbf{R}$}

putem : in altero namq. citato libro multa inueniưtur, quac mihi illum ualde fufpectum reddant; inter alia ibi plurima ex Arifotele referuntur, quae in ipfius philofo phi codicibus plane diuerfa leguntur : quamquam etiá fcio Galenum impium fane, \& irrcligiofum in ea haere In fuiffe, quod anima noftra mortalis foret, ac tempcratu ram corporis fequeretur; quemadmodum alij uctuftiffimi philofophi céfuerunt, ex quorum numero Parmenides \& Empedocles extiterũt, quorum alterum haec.

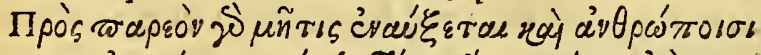

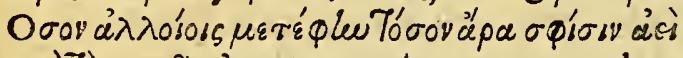

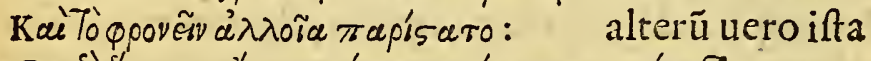

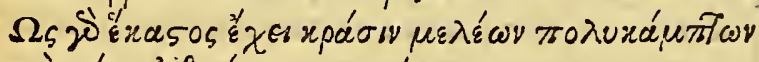

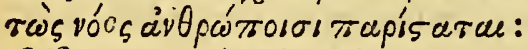

Scripfiffe narrat Arifoteles in 3. metaphys. quae tamé omnia grauiffimis, \& plurimis argumentis a Nemefio, fi ue Gregorio theologo in lib.de nat. hum.refutata funt. Ad arteriarum pulfus redeo, quos Hippocratem nouiffe remo fanus inficiaretur; \& fi neq. villam corum curā geffiffe, neq:ad artem, vt alia multa, redegiffe conftet : Nam \& Ariftoteles, quiannis fexaginta tantum poft ip fum floruit, quod de pulfibus nihil poene reliquerit, in dicium clare eft tempore fuo vix notum tale nomen fuif fe; neq. quis libellum de fpiritu Ariftoteli falfò adfcriptum inducat, vbi cum pulfuum multa fiat mentio, id fo lum praeter alia Arifotelis genuinum non effe librum apud eruditos probaret. Qui primus omnium, quos viderimus, pulfuum exactam tractationem pofteris raliquit, fuit Herophilus Archigeni in hac re a Galeno. praelatus: Hunc fribit Plinius lib. Io. cap. 37. medici nae arté miranda arte pulfus defcripfiffe, fed ob nimiá fubtilitatem fuiffe defertum: quod fortaffe in Galenú ardentius exclamaffet, fi libros ipfius ad cam trautationem fpectantes non minus profufa oratione, quam in compre 


\section{$S$ E C V N D V S}

comprehenfibili fere arte compofitos intueri potuiffet: Haud tamen de Herophilo credenda effe omnia Plinio arbitror, quoniam Strabo, qui fub Augufto vixit, in fine lib. I 2. fcribit, aetate fua inter Laodiceam \& Carurả fuiffe fcholam per celebrem medicorum, qui Herophilum fectabantur, qualis erat tempore patrum fuorum Smyrnae medicorü Erafiftrati fequacium; led eius ver ba nec graeco in codice recte notata, nec ab inter prete

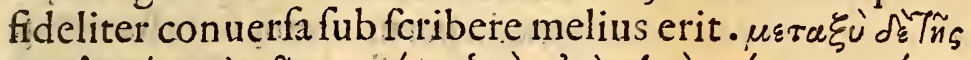

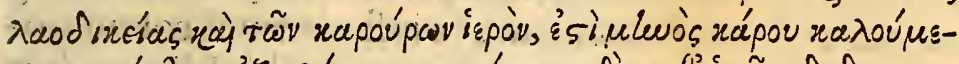

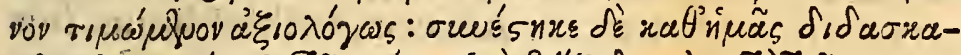

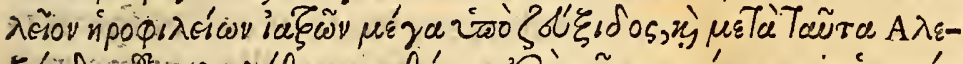

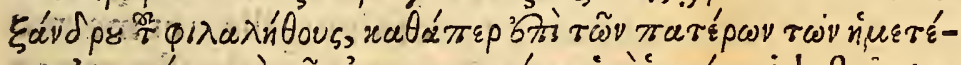

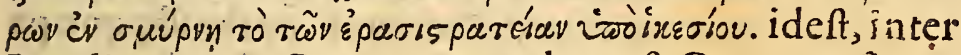
Laodicem atq. Caruram templum cft Caro menfi magna veneratione dicatum, vbi etiam aetate noftra fchola Herophiliorü medicorū magna a Zeuxide, \& poft ab Álex. Philalethe cóftructa perdurat:quemadmodú tépore patrú noftrorũ Erafîtrataeorủ medicorum fchola Smyrnae ab laefio. Pulfúu arté, vt fuperuacaneã, \& dif ficilé damnauit Afclepiades Prufiêfis aetate Pópeij ex oratore medicus effectus, qué Plinius cú ceteros medi cos improbaffe dicat, non fine ratione Galenus in 3.de

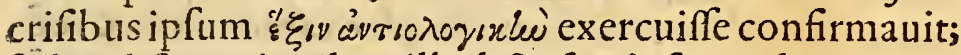
fed in difputationibus illud forfan ipfi condonari potuifiet, nifi Caelius Aurelianus, vel potius Soranus a Caclio latinitate donatus in lib. de acut paffionibus fcriberet, ipfum femper in curandis aegris ambitione quadam aliorum medicorum praefidia, quaecunq. fuiffent fiue bona, fiue mala, rcijcere confucuiffe; quae detcrima confuetudo vtinam tempeftate quoq. noftra in ter faftuofos quofdam \& humano generi infenfiffimos medicos non vigeret. 


\section{L $I$ B $\mathbf{R}$}

De condituris vinorum, de vino picante, de vino Massilienfi; locus Galeni emerdatus. "Cáp. XIII.

Vod vina antiqui varijs modis condirent factitia ab hoc genere feparo) ita clarum eft ex aucto rum feriptis, vt id demonftrandi vanus fit futurus omnis labor. Cauffas vero. quibus illud agerét, tres praecipuas inuenio, V nam ad leniendam ipforum afpe ritatem; alteram ad augendā paruitatem, vctuftatemq. accelerandam; poftemam, vt ipfa ab omni corruptionis genere conferuarent. Africam, fcribit Plinius, fuis vinis gypfo, \& in aliquibus regionibus calce afperitatem dempfiffe; $G$ raeciam autem fuis argilla, aut mairmo re,aut fale, aut marina aqua lenitatem excitaffe, quo pa croctiam hodie a Cretenfibus vinum maluaticum nun cuparum parari audio. Refert Plutarchus 5. fympor. prob. 3. cx Graecis Euboios, \& ex Italis eos qui circa Padum incolebant, confucuiffe vafa pice oblinire, refinamq. ipfam vino commifcere, quod talia vafa non mo do gratum quendam odorem impertirêt, verum etiam vinum generofum redderent, celeriterq. ab eo aquoftatem, nouitatemve caloris ope remouerent; de quibus loquebatur Plinius, cum feripfit, in Italiac prouincijs nonnullis vulgare fuiffe, muita pice rabulana atq. refina condiri: Et ne quis miretur, quomodo a pice acrefina graueolentibus potucrit vinis odorem gratum dona ri,firi velim eas locionibus alijsq. modis (ve docet Columella)a graui odore fpoliari cófucuiffe, \& propterca refinata vina, ac picata apud aliquos in prectio extitifle. An vero quod hodie, picans, \& recens vinum populari vocabulo dicitur, veteribus notum fucrit, qui de huiufmodi fapore nihil meminifie videntur, multi dubitarunt. Ego autem puto primum a Plavto ipfum fuife fignificatum, quando in Penulo dixit, vetuftare vino edé 


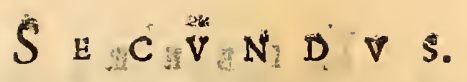

tulo aetatem irriges, quafi edentulum vocarit vinum, ad illius differentiā, quod dentatum, atq. mordax crat. Plinius fimiliter lib. I 4. cap. 20. fcribens picis afperfu odorem uino contingere, $\&$ fapot is quaedarn acumina. duo me commoniefacit, unum, quod vinum picans cognouerit, alterum, quod facile potuerit picãs I talorum a picato vetcium effe deductum ; quamquam fcio non deeffe, qui velint, picans uocem ex media Gallia fuifle productam. Auerroes quoq. 7. Colle 3. Cap. I 6. eum faporé mihi videtur his verbis indicaffe. Et vinû, quod melius reperitur, eft aromaticum: cuius caliditas penetrare poteit per totum corpus, quod fit fine amaritidine, \& ftipticitatc, \& eft illud vinum quod é vinolum pũ gitiuum in principio \& poft deleđtabile fine aliqua ama ritudine, \& póticitate. Cur autem maiores nihil de hoc fapore explicatius nobis reliquerint, puto eâ fuife cauf faim, qua etiam plurimas alias res tunc temporis vulgatiffinas nobis relinquere deftiterunt. Ad inducendam vinis vetuftatem erant qui uafa in locis calidis, aut fumo exponerent, ut is continuo quodam; \& blando calo re penetrans aqueas partes abfumeret; quod parentem fuum factitaffe affirmat Galenus primo de antid. \& de quo locutus eft Horatius 3. lib. carmi ode. 8.

Hic dics anno redeunte festus

Corticem asistictuan pice dimouebit

Ampborae fumum bibere insitutae, Confule Tullo. Narbonenfes, ac Maffilienfes paffim uina fumo maturaf fe praeter Plinij teftimonium, Martialis abunde demöAtrat, libro 3 .

Vel cocta fumis musia Massilanis, कlib.x.

Improba Massiliae quicquid fumaria cogunt,

Accipit actatem quisquis ab igne cadus \&lib.xiii.

Cum tuacentenos expugnet $\int$ portula ciues,

Fumea Massiliae ponere nina potes: E lib.xiï. 


\section{I B B}

Mafsiliae fumos mifcere niualibus vndis

Parce puer, pluris ne tibi conftèt aqua.

Ex quibus non folum vina Mafsilienfium parum aeftimata, verum etiam infaluberrima(quod Plinius lib. 23. cap. I. tribuit omnibus vinis fumo in ueteratis, quae Galenus capitis dolorem inducere primo de Antidotis inquit)extitiffe faciliter colligi poteft; \& iccirco Galeni locum in 2.ad Glauconem mendofum effe fufpicor", vbi pro eliquandis ad Herpetas medicamentis accommodata vina recenfens, inter tenuia, alba, \& fub adftrin gentia Mafsiliêfe adnumerat, quod tamen Athenaeus ex ipfius fententia craffum, \& carn ofum fuiffe, quemad modũ eft verifimile; afferit: cũ igitur A thenaeusaté. ét

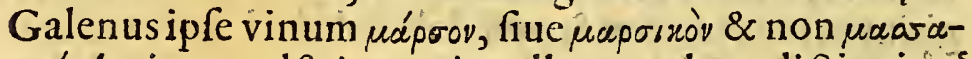
$\lambda s \omega$ t $\mathrm{W}$ inter adftringentia collocent, loco dictionis, 0

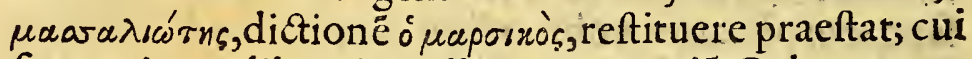
fententiae eolibentius adhaereo, quoniă Galenus nun quam alibi, aut rariflime faltem vini Maffilienfis mentionem facit: in 4 . aute de comp. med.per genera Mar fico tanquam albo, \& adftringenti in componendis vlcera exicantibus, fine mordicatione medicamentis vna cum Falerno, ficut in 2. ad Glauc. vitui:; Ad tuenda vero ab omni corruptione vina in primis ea nonnullas nationes igne coxiffe inuenio, quemadmodú de Spartanis A thenaeus, \& de alijs Plinius atq. Columella refe runt. Alij defrutum immifcebāt;quod hodie aliqui populi Romae vicini faciunt; Non deerät praefertim a pud Graecos (vt fcribit Columella) quifalfa aqua, aut fale ipfo componerent, tum gratia cuiufdam fuauitatis maioris, tum quia mare, vt cetera multa, fic vinum incorru pium feruare compertum erat; atq. huiufcemodi vina ab Afclepiade Tethalaffomena vocara ée prodidit Cae lius Aurelianus acut. lib. ij. quāquam puto fic etiam nũ cupata interdum fuifle omnia ea, quac ex alijs in alias

igreones 


\section{$S=C V N$ D $V$ s.}

regiones per mare transferebantur;quae ue fimili tranf ueitione non parum in bonitate, ac fuauitate proficere experimur omnes. Quibus vero marina aqua non mifcebatul", oivous ámsapa jútrous a Lesbiis vocatos. Scribit Galenus 12. meth.

Defenditur Plinius in traifatione argenti viui, \& bydrargyri. Locus Theopbrafti restitutus. Cap. XIIII.

1. I qui Plinium auctorcm inter latinos grauifsiW. Tum paffim reprehendere delectãtur, ij aequio20. rent ea, quae damnant, faepe laudari potius debere, ut euenit de hydrargyro, quod quia ab argento viuo fepa rat,ftatim in ipfum tãquam linguae Graecac ignarum debacchantur, cum potius hac in re non exigua commendatione dignus fit, quoniam Graeci Diofcoride po fteriores, ut uno nomine tam natiuum quam factitium hydrargyrum appellant, fic Plinius latinae linguae locupletandae gratia(quemadmodum non raro facit) natiuum argentum viuum; factitium vero hydrargyrum vocare maluit: Neq. puto vllum vfq. adeo coccum inueniri atq. hebetem, qui non videat Plinium hydrargyri fiue factitij argenti viui naturam defcribentem eadem prorfus Diofcoridis verba tranftuliffe, in quibus \& is de factititio fermonem habet; Ex quo capite cum etiam Pliniusilla, quae austor tribuit hydrargyro nati uo, defumpferit, atq. argéto viuo fuo clariffime adfcrip ferit, quis nif Plinianae gloriac nimium infenfus non cognofcit eam mentem habuiffe, vt genera vtraq. duobus nominibus defcriberet, non autem qued linguae Graecae imperitus effet ? quaudo fermonem Diofcoridis, vel faltem eius austoris a quo etiam Diofcorides de fumpfit non minus accurate quàm eloquenter in lati- 


\section{L $I$ B E : R}

num conuertit: Immo rationi magnopere côfentaneü mihi uidetur prifos Graecos, qui factitum argentum viuum non cognouerunt, nempe quod minio, ex quo fiebat, 249. Vrbis conditae anno reperto, pofterius fa.. Etitari coeptum fit, natiuum alio nomine vocafic quam ifpáprupov; fi quidem Ariftoteles 4. Metheorol.illud. áp jupor zurov, quemadmodum etiam Philippus Comitus apud eundem libro de anima $I$. \& non úpáprupor nonclipauit : neq. fortaffe apud quemquam Graecum Ariftotele feniorem, aut Latinum Plinio vetuftiorem id pópzupov, argentum viuum natiuum vocatum obferues, fed apud Diofcoridem, quem linguae graecae poli tioris rudem admodum, atq. imperitum pofteriores tá giaecos, quam latinos fecutos efle, \& in eundem erroré impegiffe exceptis Plinio \& Galeno forfam aliquis non abfq. ratione tueatur. Atq. hoc tunc magis pro certo habere cogor, quando Nicandrum poetam vetuftiffmum in fuis alexipharmacis lithargyri, \& non hydrargyri( de quo potius, fi cognouiffet,aliquid edocere debebat) mentioncm fecifie cófidero. Nam Galenus, qui tantummodo factitium nouit in 9. de fimpl. med. non eft mirum fi hydrargyrum, ficut Plinius, vocauit; Quinimmo cum dixerit hydrargyrum non effe ex fponte nafcentibus, videtur Plinij ftudium imitatus, qui foli factitio id nomen tribuendum voluit : Nec ex eo loco cogimur putare Galenum natium argentum vinum fi

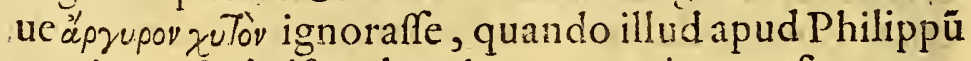
comicum, \& A riftotelem, in quo maxime verfatus elat, legifle potuerat; fed fortaffe non viderat oculis, \& proinde nihil de ipfofcriptum reliquit: Vitruuius quoq. Diofcoride \& Plinio antiquior, in 7. lib. vbi argenti viui mentionem facit, hydrargyrum nunquam nominat, folius natiui tractationem habet, quafi Auguli etiam aetate argentum viuum natiuum folummodo dicere- 


\section{S E C V N V V S.}

tur ; in qua re Fallopium virum doctiffmũ \& alios hal-: lucinatos effe cuicuun q Vitruuium non ofcitanter legenti perfpectum effe poteft : Quomodo autem Verba Theophrafti, ex quibus multa accepit Plinius, \& ex qui bus factitium etiam á zupoy zurò ab ipfo vocatum videtur fint interpraetanda dicam vbi prius ipfiffima verba refiftuta in medium adduxero quae in lib. $\pi \varepsilon p i \lambda i \theta \omega$

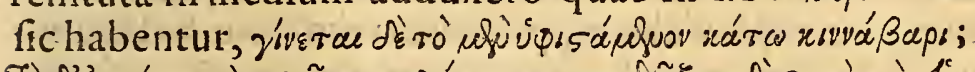

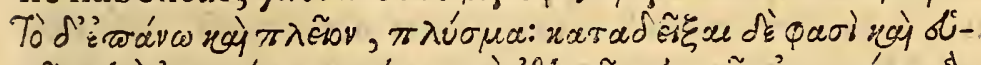

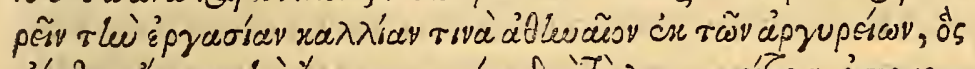

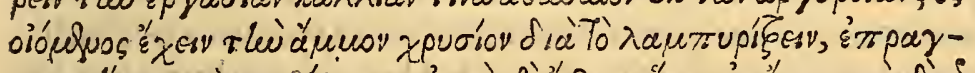

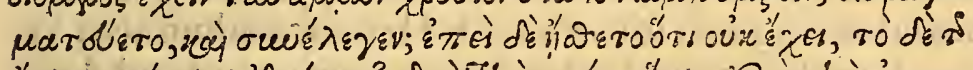

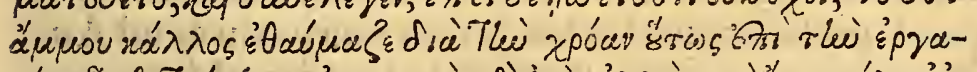

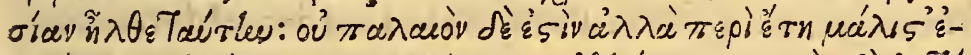

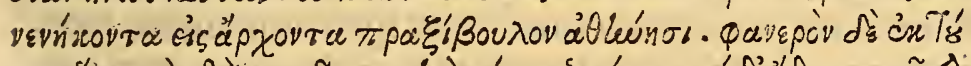

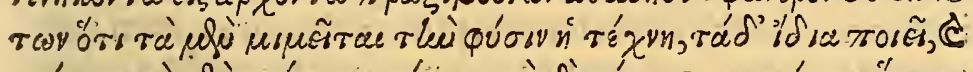

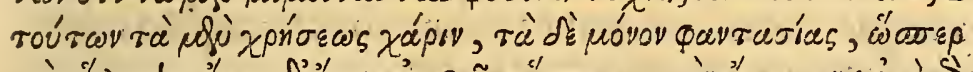

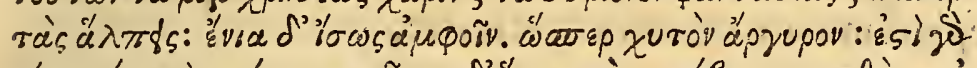

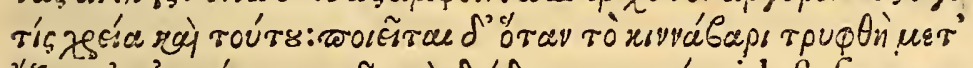

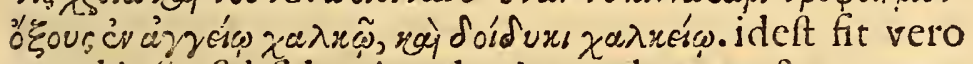
quod infra fubfidet cinnabari, quod autem fupra natat lot'ra eft, huius opificium aiunt colliam quenda A thenienfem cx argenti fodinis inueniffe. atq. monftraffe, qui cum puafet harenam auream, ob fplendorem fe te nere multa follicitudine collegit, fed poftquam fe eam nố habere intellexit, harenaeq. pulchritudinem ob colorem admiratus fuit, adhuifcemodi operam cóuerfus eft. Neq. hoc admodum antiquum eft, fed circa nonaginta annos tancum imperäte A thenis Praxibulo.Atq. ex his perfpicuum fit, quod ars in aliquibus naturã imitatur, in aliquibus vero propria facit, \& horũ alia vfus, alia apparentiae gratia. quemadmodum al pes; alia forfan ob utraq. ficur fufile argentum. Eft enim \& huius aliquis vfus. Efficitur autem, quãdo cinnabari in aenco

$$
\mathrm{N} 2 \text { vafe, }
$$




\section{$L: B \in R$}

vafe, aeneo, piftillo cum aceto tritum fit. Itaq. ex his facile conftare arbitror a Theophrafto ápyúpau xutou nomen vfurpatum plane inueniri etiam in factitio, quod ita eueniffe conijcio, quoniam nonagefimo anno ante ipfum minio demonftrato fastitium argentum viuum. aetate ipfius componi coeperat, \& propterea nondum aliud nomen illi indiderant, fed eodemmet, quo natiuum, tunc appellabant; pofterius vero dum fautitium magis innotefceret. hydrargyrum nominarút . vfquequo Diofcorides parum fermonis puri obferuator vo-

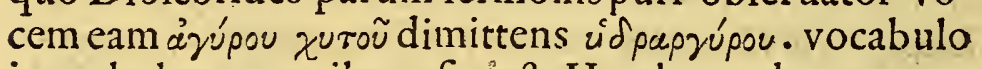
in ambobus generibus vfuseft, Hoc loco admoneor vt. quod apud medicos havtenus non obferuaui apud Aufonium poetam, fed Aufonij filium medici obferuatum in medium proponam nimirum argentum viuum toxici venenum debellare, fi poft ipfum bibatur; quam rem exemplo vxoris maritum veneno tollere cupiętis. hoc epigrammate monftrat poeta ille.

Toxica Zelotypo dedit vxor mocch a marito,

Nec Satis ad mortem credidit effe datum,

Mifcuit argentilaetbalia pondera viui,

Cogeret vt celerem vis geminata nccem;

Diuidat baecfi quis faciunt difcreta Denenum,

Antidotim fimet qui fociat a bibct.

Ergo inter fefe dum noxia pocula certant

Cefsit laethalis noxa falutiferae,

Protinus, of vacuos alui petiere receffus,

Lubrica deieitis qua via nota cibis:

Quàm pia cura Deumb, prodest crudelior Dxor,

Et cum fata volunt, bina venena iuuant.

Detempore 


\section{SEC N D s.}

De tempore coitus Plutarchilocus refttutus. Hippocrates, of Ariftoteles collatus. Errorgazae deteritus. De fitu corporis in fomino. Error Alexandri contra Hippoc. . Cap. XV.

Thes Oitum exerceri debere poft fomnú fecundü $\mathrm{Ga}$ 15. J leni interpractationé mandauit Hippócrates 6 . 2. Epid. fub hilce verbis labor; cibus; fomnus, venus oĩa moderata; quã tamen féntentiä haud omnes po Aeriores medici prorfus fecuti funt. Aetius quide lib. I ferm. 3: cap. 8. voluit a prandio coeundum effe, vbi cibus delcenderit, a coena autem; vbi paululum dormieris: At Paulus lib. 1 . cap. 35 . maluit concumbendum effe fecundum cibum, antequam fomnus irrepat : qua in re conceptioni potius, quam valetudiniftuduiffe vi detur; \& fineq. hoc a veteribus admodum probatum inuenitur, cum in lib. de foetatione, \& fuperfoetatione (fic en im in fribi debet) Hippocrati adfcripto legatur mulierem con cepturam coitu ieiunam; \& virum fobriú modice paftum vti debere, ex quo locofententiä illä in probl. mutuaffe A riftoteles videtur, quando fcripfit an tiquorū nónullos praecepiffe, vt cốcubituri parce coe narêt, quod fic meatibus magis patétibus facilius, \& lōgius femé propelleretur:Haec quaeftio apud Plutarchú in 3. fympof. 6. prob. latiflime difpurata eft, vbi poft multas rationes hinc inde deductas tandem decernitur venere in noite poft coenam modice acceptam vtendũ effe, quod fomnus deinde fuccedens laffitudines omnes tollat, ac purgatiora corpora efficiat, ubi etiam duo hac in re ueluti-praecepta traduntur; unum poft coitum bal neum calidum ne quis ingrediatur; ita namq. corruptũ graecum codicem reftituendum ceneo : भi $\mu$ iे

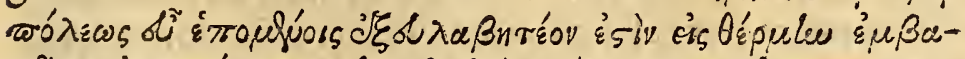

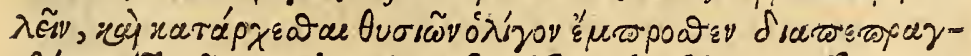

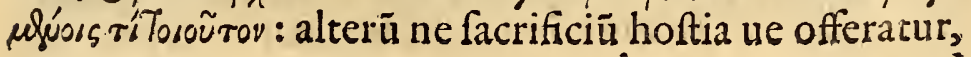




\section{I B E R}

quod etiam Tibullus hoc carmine docuit in 2. Vos quoq. abeffe procul inbeo: difcedat ab aris Cui tulit extcrna gavdia notte Venus

Hippoc. 2. de acur. tex. 16.6. Epid. com.5. aphor.15. fcribit coitum in ijs morbis prodefle qui a pituita oriun tur, \&5. Epid. Timocharem a deftillatione per coitum effe liberatum narrat quam Hippoc. fententiam A rifto teles eius aemulatcr 1. fét. prob. 5 I. \& 4 . fest. prob. I 7 explicans docuit id fieri, quia pituitae multum una cum

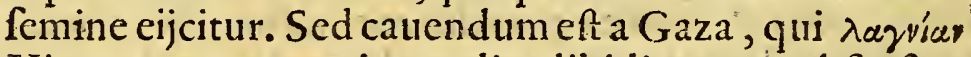
Hippoc. uocem pro immodica libidine non abfq. fum mo periculo interpretatus fuit cum ea ipf uel coitu, uel femen fignificet, ut in linguis monftrat Galenus. Hanc eandem fententiam habuit Hipp. in $\mathrm{I}$.de diaeta, fed ae-

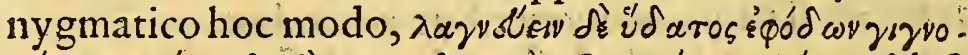

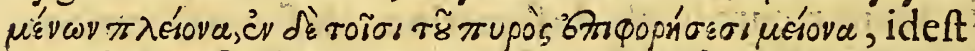
utendum effe pluri coitu in aquae acceffibus, pauciore in ignis impreffionibus. Iam uero me fomnus admonet, ut communem omnium fere er rorem detegam, qui fi altiore capite dormiant a deftillationibus minus tentari fperant,cum contrarium potius euenire praeter ru fticorum omnium experientiam, qui ut plurimum capi te toti corpori aequo fitu pofitum dormientes urbanis minus catharris uexari clare confpiciuntur, ratio etiam atq. autoritas Ariftote. in ro. prob. euidentifime demonftrant:ibi enim quaerens philofophus cur untis hô mo ccterorum animalium maxime $\&$ fternuat, $\&$ confe quenter deftillationibus laboret, inde euenire determi nat, quoniam in alijs brutis neq. calor, neq. ipfum confequentes humores reta (ut eft eius naturalis prompt tudo) ferri ad caput queunt, fed in armos, ceruicé, atq. alia membra per refractionem difiecti diffipantur, quo minus caput pertentent, fed in homine erectae figurae ratione calor, \& fubinde humores faciliter in caput $\mathrm{cffe}$ 


\section{S E. C V N D V S}

runtur, ubi is rarefaciens mentus, calefaciensq. hi uero fubeuntes, \& poftmodum craflefacti varias deftillationes gignunt; quod item contingere ijs, qui alriore capite dormiunt, nemo fan us non videt; quemadmodú per fpicuum eft, fi humilior $\&$ roti corpori aequali capitis fi tu dormiatur, idem euenire, quod in brutis, calorem .f. \& humores non poffe resta fecundum naturalem inclinationem in caputattolli, fed in cetera membra partitos neceffario diffari, interrumpiq. Atq. hanc dormiendiconfuetudinem fortaffe approbariab Actio quis putet, quâdo fublimiorem capitis fitum in ijs folú commendauit, qui ventriculi imbecillitatelaborant, quod ijs opus fit huifcemodi erectiore figura cibum in ventri culi fundo continere, Addam his magnum medicinae auötom Hipp non abfq. fumma ratione $I$ Aphor. I 5 . fcriptife fomnos, fierilongifimos hyeme, tum ob notium longitudinem, tum ob pituitae copiam, \& iccirco Alexädrū A phrodifienfem erraffe, qui 2. quaeft. nat. cap 20 nos aeftate, quam hyeme fieri fomnolentiores tribus de cauffis putauit vna quod a deftillationi bus hyeme natiuus calor minus uincatur, citiufq. ob magnitudincm fuam vapores diffoluat:altera quod aeftares plus dormire uideamur ob nodium breuitatem, nempe cum aliquam diei partem fomno tranfigamus: poftrema quod tunc ob calorem extrinfecum fenforia fint debiliora, \& iccirco operari nequeuntia fomnum $\mathrm{fa}$ ciliorem, \& maiorem efficiant.

De DuaTaminia \& lambrufca Plinü, locus examinatus,

$$
\text { o emendatus. Cap. XVI. }
$$

Dam taminiam apud Cornelium Celfum naphi fagriam vocatam effe puto dubitare neminem; quae vero illa fit penes Plinium nonnulli in có- 


\section{I B}

trouerfiă vertunt; Nam qui fub nomine taminiàe vuae Plinium lib. 23. vitem filueftrem, \& non labrufcam explicaffe exiftinant, id neceflario fentire videntur, quod Plinius duplicis agreftis vitis fermonem habeat, eo ferme patto, quo a Diofcoride duobus diuerfis capitibus

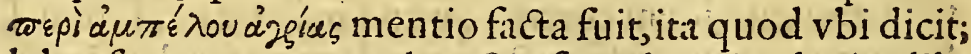
labrufca quoq. oenanthen fert fatis dictam, de vite lib. 5. cap. 2. a Diofc explicata loquatur; ybi vero fubiungit, quae a graecis ampclos agria \& reliqua eam vitem planc ad verbum explanet, quam in 4lib. fúfius Diofe. declarauit : Hanc fententiam tribus potiffimis rationibus confirmare nituntur; quarum prima eft quod quä do Plinius inquit, labrufca quoq. oenanthen fert fatis distam, de oenāthe fructu fiue flore labiufcae nil fe ampliús dicturum infinuat, nempe cum in prohemio eiüfdélibri \& in i6.cap. lib. I5. ac vltimo i 2 . de illa abüde tractauerit, \& ob id fequentià verba, in quibus taminia memorat, de labrufca nullo modo effe intelligenda; $\mathrm{Se}$ cunda ratio eft oenanthen florem cffe \& non vuam, qué admodú teftatur ipfemet Plinius cap. vltimo I 2. libri : vnde verba häec polt labrufcam prodita, fert vuas rubentes cocci modo ei conuenire minime poffe. Tertia ratio eft quod ea verba, quae a graecis ampclos, vfq . ad eum locum eft huius fimilis, omnia ex Diofcoridis capi te de prompta funt; in quo is auctor de uite filueftri, \& non de labrufca latinorum fermonem fecit Ego vero, qui Plitiium fub taminia vua labrufcam edocuiffe potius credo, primae illi rationi refpondere foleo, verba illa, fatis dictam, alio fine ab ipfo prolata fuiffe, nimirum qui alios auctorum fermones in fuum uolumen transferre affuetus, in hac quoq. re Diofcoridis uerba aucta diminuta \& transformata pro more fuo trăftulerit; $D$ io fcorides etenim de labrufca Jatinorum loquens ait $\alpha$ $\alpha-$

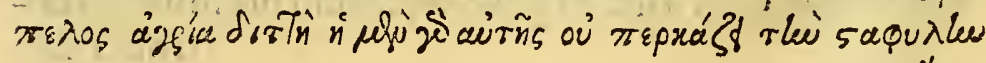
ăzs! 


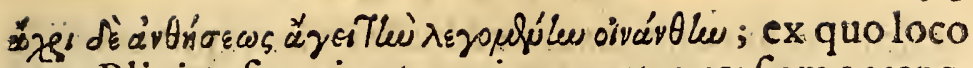
cum Plinius fua citra omnium contsoucrfiam acceperit, facile eruditus lector cognofcere poteft Plinianum noftri temporis codicem mendofum, \& particulam illá fatis vel abundare, vel eius vice particulam, fic, legi debere $v t$ haec fit genuina lestio (oenanthen fic dictam)

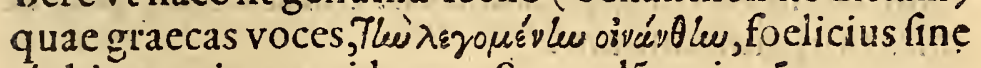
dubio exprimere videatur. Secundã rationé propterea nihil valere affero, quoniā nifi Plinij verba extorquedmus, tantum abeft ipfum oenanthen vuam effe negare, vt potius ore pleno affirmet hifce verbis, code \& oenan the pertinet, eft autem vitis labrufcae vua, colligitur cü flöe cū optime olet, idem affeucrit columella, quilib. 8. cap. 5. labrufcam ipfam vuam núcupauit: Quod por ro tertio loco fubiügitur, vltima illa verba (quae a grae cis ampelos) vfq. ad illud, eft huius fimilis, labrufcae nó effe attribuenda; proptcrea quod tota illa feries cx Dio fcoridis cap. defilueftri vite translata fuerit; ficut \& eyo fateor, opinioni eorum nequaquam fauere opinor; quä doquidem fi Plinius \& illis \& anrecedétibus verbis nó de labrufca fola, fed primo de labrufca, deinceps de filuefte vite fermonem faceret, dum ait, quae a $G r$ i ecis ampelos agria, demonftraret vtiq. labrufcam etiam a graecis ampelon agriam non fuife vocitatam, quod tamen falfifimum eft, cum labrufca non minus, quam vitis filueftris illud nomen obtinuerit; Relinquitur ergo Plinium loco citato de labrufca, quam vulgo taminiam dițam arbitratur, métionem facere, atq. poenes ipfum quando nullo alio loco(quod recorder) de filueftrialia

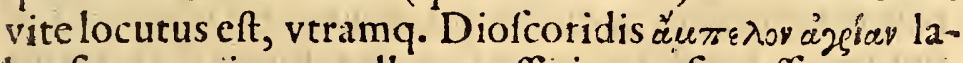
brufcae nomine appellatam effe, immo fortafl pro vna atq. cadem habitam, quemadmodum cenfuife quoq. ab aliquib. creditur Galenum, Paullum, \& A uicennam diligentiffimos Diofcoridis obferuatores, \& interpre- 
tes, qui vnum dumtaxat de filueftri vite caput condide runt; ficut pariter eueniffe poteft, vt ex vno Diof coridis capite vel ineruditi librarij vel fcioli aliqui duo fecerint; eo magis quod in labrufcae cap. pauciffima haben tur, quae fere viti filueftri non conueniant, taminiam hanc vuam verrio appcllatam effe tradic féftus, quae tã mira fit, quam minium.

De vua theriacae: de mulfo quaedam, et $P$ lutarchi error, de vino mafsico; 0 cur vinumpercolaretur Plinü locus resti

tutus. Theodori error. Cap. XVII.

Ib. 23.cap. I.nominatur a Plinio vua theriacae;

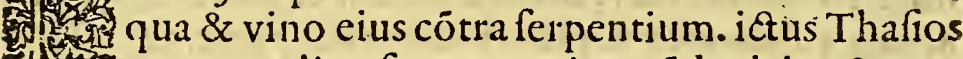
pro remedio vfos memoriae mädauit in I 8. cap. libri 1 4. vini huius potionem theriacam appellatam nó infulfe aliquis exiftimarit; atq. eam fortaffe $M$. Varro: nem intellixiffe apud Nonium, quando ait, vel maxime illic didici \& fitienti theriacam mulfum, efurienti pane cibarium filigineum, \& exercitato fuaue fomnü. Quod autem vinum vitis theriacae biberetur, atq. in varios hominum vfus veniret locupletiflima teftimonia habë rur apud Palladio infebr. vario cap. 28 . \& apud Geopo nicos feriptores lib. 2.cap. 46. \& lib.4. cap. 8. vbi, \& quomodo fieret, \&.in quem vfum, tam ipfum vinum, quam acetum, vua, cinifq.adhiberentur, faris vnicuiq. clarum efficitur. Ceterum quòd Petrus Viatorius doctiffimus in primo Variarum. arrepta inde occafione du bitat an theriaca olim biberetur, nempe quae tempefta te noftra craffior, ac durior quam ut potui idonea fit, té pererctur, haud quaquam fane quaeftione dignum mihi uidetur, quoniam nullus eft in antiquorum medicorủ , \& praefertim Galenilectione verfatus, qui nefciat. Theriacam, quamuis craffam modo uino, modo alijs liquoribus 


\section{$S$ S V D P s.}

quoribus diffolutam propinari folitum; quam fiue mul fo hac ratione Varro compararit, fiue theriacac vuae (vt dixi) uinum, non multum laboro;quod magis miror: eft M. Antonium Muretum multae lectionis, atq. egre gij iudicij virum aduerfus Victoriū ita egiffe quafi theriacam potari inauditú fuerit, fi enin medicos quos habuit plurimos amicos percunctari interdum voluiffet, fcio mutaffet, fententiam, atq. theriacam licet amaram obfuam valetudinem quandoq. bibiffet. At nec illud facile Mureto concedo theriacam noftram eãdem effe, quam tempore Varronis, \& antea habuerunt veteres: vt enim non inficior ca tempeftate fuiffe in vfu medicamenta Anp.axa, quòd aduerfus ferarum venena valerét appellata, de quibus copiofe fcripfit Nicãder,certe theriaca noftra minime excogitata fuerat: fed Andromachus primus Neronisprincipatu eam cópofuit, vt monet Galenus in principio lib. de antidotis. Quas uero antiquiores habuerūt theriacas etiam ipfos potaffe docet Plinius, qui lib. 20. cap. ultimo fcribit theriacam illam incifam lapide uerfibus in liminc aedis A efculapij. qua magnus antiochus rex utebatur, uino mixto diffolutam bibi folitam, ne quamplures alias à Galeno nominatas adducam. M. Varro apud Noniü, fic ait. Qưid medico mihi eft opus? nempe tuo abfinthium uti biba a grauem \& caftoreum, leuemq. robur: Iam uero caftoreum quale fit, folidiufculum quam ut fit potando, omnes norunt: \& tamen Varro bibi folitum móftrat, quod idem de theriaca cogitandum. Id praeterire nolo mulfurn hodie $a b$ omnibus fere neglectum, antiquitus in maximo honore fuiffe; quod Varro praeter citatum locủ etiä. in .2. de re. ruft. Virgilius in Georgicis Celfus, qui quédă toto anno a uino, mulfo uenere fibi temperă tem a podagra tota uita incolumen uixiffe fribit \& alij multi fcriptum reliquerunt; Vnde mirari foleo Plutar-

$\mathrm{O} 2$ chus 


\section{L $1: B$}

chus auctor grauiflimus 8. fympor. prob. in 9 . Cripferit

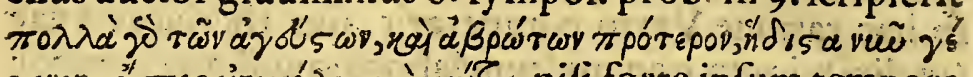

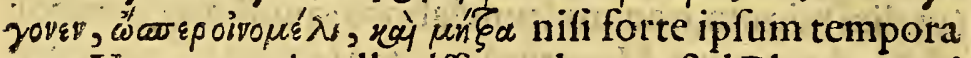
ante Varronem intellexiffe credam us; fed Plautus, qui faepius mulfi cerebrem mentionem facit, nos hac in re facile conuincet ; ne Hippocratem uetuftifim un foriptorem in medium proferam : quem fi quis in libris ad gnidias fententias; \& alibilectitare uoluerit, certus fict Plutarchum uel er raffe, uel eius codicem deprauatum haberi, ubi legitur ueteres mulfum nó guftaffe, ne praererea Plinium, qui Ariftacum Thracium huiufmodi po tionem primum inueniffe tradit. Idem quoq. de uulua fufpicandum eft in Plutarcho:quam ueteres. in delicijs habuiffe hoc uerfu, quid melius turdo, quid uulua $8 *$ Plinius, fufe monftrat; lib. i 1. cap. 37. Sed Plutarchi mentio admonet me, vt non nulla de mulfo ex ipfomet proferam, quac in 4. probl. fympof. prob. 5 . fic latine fonant; Praeterea in facrificijs iudaei mel non adhibét; co quod vino contemperatum illud corrumpere videatur, quam uis antequam vites effent inuectae, niclle libarent, ac inebriarétur, ficuri etiam hac tempeftate bar barorum quam plures, qui vino carent, multum bibút, dulcedinem mellis uinofis quibufdam, \& aufteris radicibus temperantes. Ex adueifo graeci abfemii ob hace mulfum, in libationibus facrificiorum offerunt, quafi mel natura vino oppofita donatum fit: quod autem vinum hebraci magna in exiftimatione teneant illud nö paruum argumentum eft, a pud ipfos cum multae pocnae fint, unam omnium maxime ignominiofam haberi, quando illi, qui puniuntur, tanto tempore, quantum il le, cui eft puniendi poteftas ftatuerit a vini potu inhibé tur. Fiebat optimum mulfum vt docet Diofcorides ex vino auftero, \& melle proptereaq. ex maffico vino, \& melle attico factum commendabatur, ficuti.Martialis 


\section{$S E \subset \sim \vee v$}

atteltatur hifce verfibus.

Tambene rara fio mifcentur cinnama nardo,

Mafsica Thejaeis tam bene vina fauis:

Ob quod iure damnatur ab Horatio Aufidius qui mul fum ex falerno, \& inelle factitabat.

Aufidius forti mifcebat vina falerno

Mendofe quoniam raculs committere venis

Nil nifitene decet, leni praecordia mulfo

b) Troluerismélius, fi dura morabituraluus

Mafficum autem vinum, fiue marficum ( $r$ Galcnus \& Athenaeus dicunt ) nafcebatur in monte Gaurano in Puteolorú, baiarumq. prôfpectu, quod licet apud fere omnes latinos poetas maxime celebratū extet, craffum tamen, ac turbidum aliquando fuiffe ex his Horatij ver bis colligitur:

Madsicafi celo fuppoitas vina fereno,

Nocturnifi quid crafsieft tenuabitur aura,

Et decedet odor neruiuis inimicus; at illa

Integrum perdunt linovitiata faporem

Nain vina craffiufcula facco lineo percolare côfueuiffe maiores praeter Lucretij, Horatij, Martialis, \& aliorum reftimonia; Platarchus probl. in id inftituto abüdc mó ftrauit: Cur vero id agerent explanaffe videtur Plinius cap. vltitio libri. 1 fo vbi dixit, quod vinorum vires fac co frangebantur, vt potores plus bibere poffent. Vina etenim diffufa, perfrigerata, \& excolata tenuiora ficri, atq. debiliora etiam in libello $\approx \rho$ i $\pi \alpha \theta \hat{\omega} \%$, fub Hippocratis nomine vügato notatū inuenitur vt iure Plinius. Vina inueterari, faccisq. caftrari dixerit lib. 19. cap. 40 zpud quem etiam faccis anifum, \& amaras nuces ad cōmendanda vina addi folitum legitur. fic enim lib. 20. cap. 17. vulgatos contextus reftituendos puto. Saccis quoq. additum cum amaris nucibus vina commendat: Cum autem Scribonius cap. I22. Falerni non faccari 


\section{?. Lor}

mentionem faciat, id intelligendum eft quod ualentius erat, \& cuius uires faccis non erant caltigatae, huius vini percolati mentio quoq. eft apud Theophraftú 6. de cauffis Plan. cap. 24. vbi Thcodorus mire hallucinatus

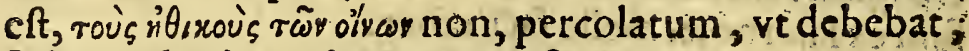
fed morale vinum inepte transferens.

Medicinam eiufq. regulas ab Aegypto manaffe; locus et Hip pecrat is Herodoti, Aristotclis Plutarchi o Celfi, in id de purgatione; Leliani improbatio de ling gua

Hippocratis, es de Acrone medico.:

Cap. XVIII.

Edicinam ficut \& omnes fere artes apud A egyp tos ortum habuiffe probatiffmi auctores fcriijs quoq. manaffe rationi confentit ; qualis eft illa a maximo Hippocrate omnium primum monitrata. Пśtrova

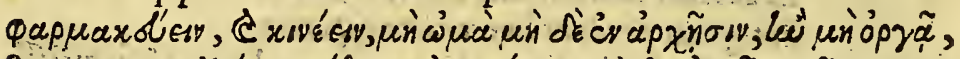

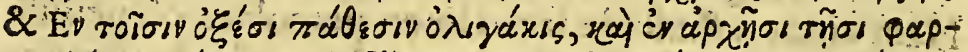

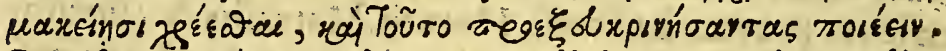
Quod enim Aegyptiolum medici purgantia medicamenta in principijs morborum uitarent abunde teftatur Ariftoteles, qui, ubi haec in 3.polit. cap. 1 1. Cribit,

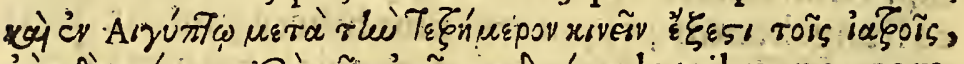

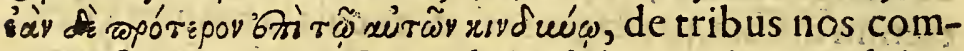
monefacit; V num eft quod apud Aegyptios uetabātur in principio purgationis, alterum uocam illam uretr, an tirjuitus pro purgare (ut Hippocrates ) ufurpari confue uiffe; poftremum quod in morbis quarta dies tanquam iudicialis fere femper, \& ubiq. obferuata inuenitur: Höc idem elegantifimum Celfum. intellexiffe puto, quando-lib. 3.cap. 4. ait antiquos medicanicutrs qnibuf $\mathrm{am}$ datis concoktionem moliri folitos, eo quoa crn ditatem 


\section{$S$ E Y N D V S.}

ditarem maxime horrerent;deinde cam materiam quae laedere uidebatur ducendo faepius aluum fubtrahere; Afclepiadem uero medicamenta fuftuliffe, aluum non toties,fed fere tamen in omni morbo fubducendo: Ad uerfari tamen hifce uidentur, quae de Aegyptijs ab He rodoto in 2. lib. memoriae mandata funt, eos fanitati tuendae ftuduiffe tum quibufdam purgationibus, quas fingulo menfe per triduum faciebant, tum uomitibus, atq. clyfterijs; quafi nullam quattridui ante dicti rationem habendam, uellent; fed illud in morbis curandis, hoc uero in ualitudine conferuanda lenioribus medici nis ab ipfis commendatum non inconuenit, ut pariter non abfurde factum appareat, dum Aegyptios omnes medicos cffe prouerbio dicébatur: nam ciborum abftinentiam, fuccorum herbarumq. non incuriofam cogni tionem, clyfterij frequentem ufum ab ibide aue commoftratum cum paffim omnes in Aegypto affectarent, quid aliud nifi medicinam profitebantur? ueluti fignifi carum ab Ifocrate puto in Bufiride dum hunc in modu

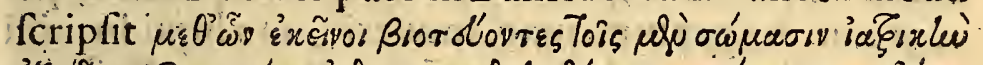

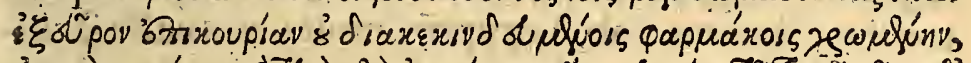

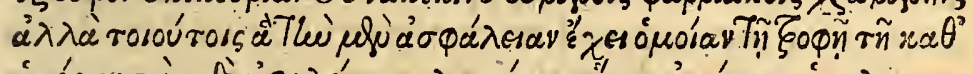

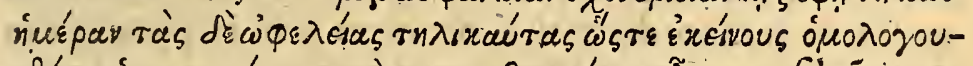

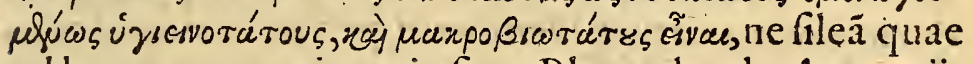
ad hanc rem pertinentia fic a Plutarcho de Aegyptijs

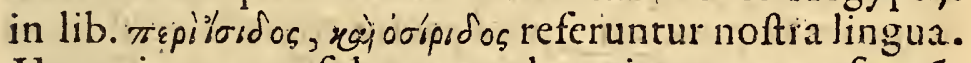
Hoc primum confideres, quod maxima cura profequãtur iffi hominesea inftituta, quae ad faniratem pertinêt, $\&$ eft fanc in facrificijs. luftrationibus, \& uietu non infe rior fanctitate fanitas, neq. enim rectum putabăt ut cor poribus fubputidis, \& morbofis colerêt id, quod purū, fincerum, \& immaculatum eft, quoniam iraq. $2 e r$, quo plurimum utimur,'\& in quo maxime uerfamur, non eãdem femper temperiem habet, fed noctu condêfantur, \& offendit 


\section{I}

offendit caput, \& animum contrahit in anxietates $\&$ eu ras, dum quafi nubilofus redditur, ac grauis, furgunt fatim, \& refina fuffitum faciunt, \& fanát, purgantq. diffipationibus, aeiem, \& innatum corpori fpiritum iam marcidum refocillant, cum hic odor uchemés quiddā; \& incitatilum habeat. Iterum cum circa meridiem fen tiunt a fole copiofas, ac graues exhalationes ui ex terra fubtrahi myrrham incendunt quam aeri immifcent, refoluit enim calor, \& diffipat id quod concretum in aere, \& turbulentum, \& limofum eft, fiquidem \& medici aduerfus peftilentes morbos ita fuccurrere uidentur, \&c flammam ingentem accendunt, quae aerem attenuet; attenuantautem reitius fi odorata ligna urant; qualia funt cypariffi, iuniperi, \& piceae, Acronem itaq. medicum A then is ex co fuiffe celebrem memorät quod magnae peftis tempore ignem accendere iuxta aegrotos iuferit unde non paucosiuuit. An Hippocrates, qui difcendae medicinae gratia Delum Lybiam, atq. Scythiam (ut is in Progn. \& in lib. de acre. atq. innuit) peragiauit, Aegy ptum quoq. inuiferit, non liquido mihi conftat; Attatmen ab A egyptijs multa mutuaffe faciliter credo, quemadmodum exaltera parte nullam A elia no fidem habeo dicenti 4 . de varia hift. Hippocratem dorica lingua natum Democriti perfuafionibus induAtum Ionice fcripliffe; neq. uero inficias eo Doricam linguam Hippocrati (quod paetus etiam in epiftola ad A rtaxerxem fatetur ) natiuam extitiffe, quam Siculos, Calabros, Anconitanos, aliofq. innumeros populos ob lafciuam quandam eius dulcedinem amplexos fuiffe fci mus; at Ionica potius monuméta fua pofteris relinque re uoluit, quòd ipfa poft Atticam alias elegantia \& faci litate fuperaret,ipfaq. Attica hoc maius commodũ haberct; lit cum facilitate iunctam quädam gratiam in explicandis rebus maiorem feruare poffet. Atquoniam 


\section{$S$ E V N D 3.}

in citatis Plutarchi uerbis Acronis medici fit mentio, fciendum uolo eum Acronem fuiffe agrigentinum Em piricac fectae, ut ait Plinius, auforem ab Empedocle commendatum, atq. Hippocrate antiquiorem, cuius $\mathrm{fa}$ cti A ctius quoq. tetra. 2. lib. x. cap. 94.8 Paulus lib.2. cap. 35. meminerunt, quod igitur feciffe Hippocratem conftat, cum graeciam prope uniuerfam pefte uexatam crebris ignibus accenfis liberauit, ab Acrone didiciffe facile credi poteft.

De Vnguentis, of quid Hippocrati fignificet vnguentum Legyptiuut; de Metopio locus Hippocratis emendatus quae damex zlutarcho de onguentis, o myrrbs. cap. XIX.

Afres tam potibus, quam cibis unguenta admi 6. riae mandarunt; ratio autem erat, quod ut muficis fonis, cantibufq. aures; fpectaculis uifum ; edulijs:pa latum, fic \& uarijs unguentorum atq. florum odoribus nares in conuiuijs delectare fudebant: Quem tamen ufum non primis illis faeculis (quando nondum in creuerancluxus, inuestum credimus, fed multo poft Hippocratis tempora; apud quem de unguentis uarijs faepius quidem faeta mentio inuenitur; at medicinae potius, quam ullius libidinis loco: Acgyptii quippe omnium primi ob myrrhaecopiam inter alia medicamentorum genera unguentorum mixtiones excogitarunt, \& tamdiu ceterae nationcs ab illis per uniuerfum orbe tranfportare durarunt, quarndiu in diucrfis regionibus illa parare homines \& mulieres edocti funt : Quocirca mirari debet nemo, fi pencs celebriores ueterum aucto res maior unguentorum atq. oleorum pars Aegyptiorum cognomina fibi uendicauit: Hippocrates enim(ut P Galenus 


\section{I B E R}

Galenus in eius vocum expof. (fribit) quattior corum geneta memorat vnum oleum Aegýptium alterü oleủ A egyptium a album; tertium unguentum Acgyptium album; quartum unguentum A egyptium hoc poftre-

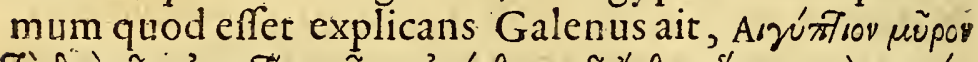

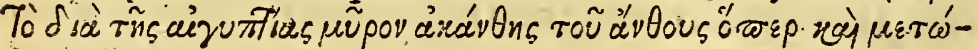
rov covónascu. Verumtamen fuerunt qui Hermolaum, \& R uelliúm fecuti hac in re Galenú damnare aufifint, propterea quod Dydimus apud A theneum vnguentú Acgyptiū ftactem faciat; metopiumq. \& a Diofcoride, \&a Paulo valde ab Aegyptio diuerfum ponatur : Cete rum facile ij redarguentur; fi quae a Theophrafto, ac Athenaeo memoriae prodita leguntur, in medium afferamus: ille enim in libello, $\pi \varepsilon p$ i o $\sigma \mu \tilde{\omega} v$, hunc in modum

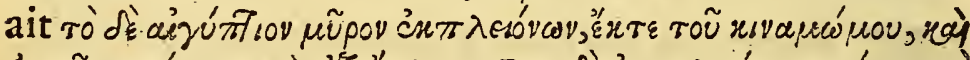

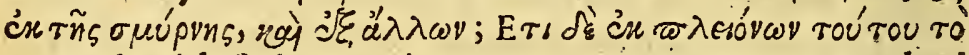
$\mu \varepsilon \gamma a \lambda \tilde{\varepsilon} \sigma$, idelt Aegyptium autem vnguentum ex pluri bus ex cinnamomof. myrrha, atq.alijs. Ad huc ex pluribus quam iftud componitur Megaleum, et paulopoft

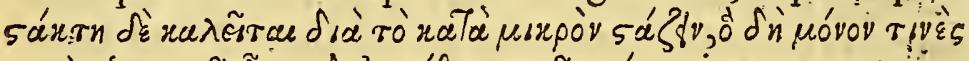

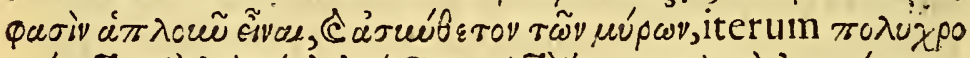

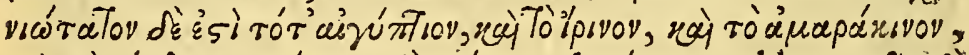

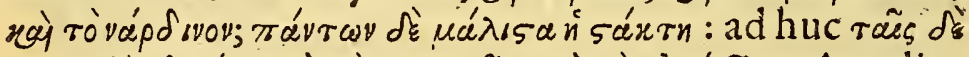

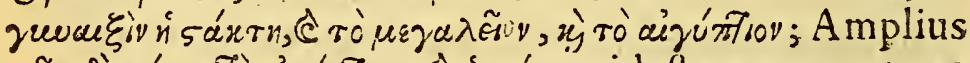

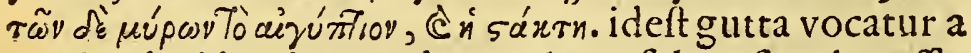
guttim decidendo, quod vnguétum folum fimplex effe, \& alicuis minimae commixtum quidam aiunt. Diutius autem manet Áegyptium, \& irinum, \& amaracinum \& nardinum, omnium autem maxime gutta mulieribus gutta, \& megalaeum, \& A egyptium. Vnguentorum ve ro A egyptium \& gutta ex quibus om nibus luce clarius apparetaliud aegyptium vnguentum ex pluribus phar macis commixtum; aliud ftactem extitiffe, nempe quam vnguenti genus fimpliciffmum fuiffe omnium Theophraltus 


\section{$S$ E $C, N D, V$ S.}

phraftus; ex fola myrrha conftitife Athenaeus cap. I5. lib. I5. ipfius myrrhae pinguitudinem fuiffe Diofcorides fcribit: fed hic obijciant fortaffe vnguentum aegyp tium Theophrafti id effe, quod ab Hippocrate aegyptium album nuncupatur, \& propterea ex verbis a nobis propofitis nil aliud colligi, quàm aegyptium vnguentum album, \& ftactem, non autem aegyptium fimpliciter differre : quam obiectionem minime arduum é

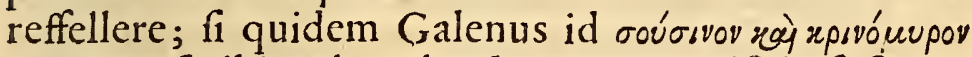
vocatum fcribit; Theophraftus vero manifefte fufinum vnguentum ab aegyptio feparauit, vbi ait unguétorum alia a florıbus nomen mutuaffe, vt rofaceum, liliaccum,

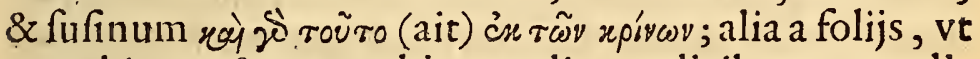
my rhinum, \& ocnanthinum, alia a radicibus, vt nardinum; alia a ligno, ut phoenex; alia a fructu, vt mclinum, myrtheum, \& laurinum; A egyptium vero ex pluribus, ex cin namomo, ex myrrha, atq. aliis: neq. illud verum puto, quod Theophrafto adfcriburit nimirum in aegyp tio vnguento albedinem commendatam, quoniam is, dum myrroplaftas alia vnguéta vtpote viliora certis co loribus inficere; alia yt preciofiora nullis refert, propterea aegyptium tamquam preciofum albú hoc eft nulIn colore cxtraneo faturatum; fed ćsewrátısov eos voluiffe innuit; quamquam fcio Pollucem nigri quoq. aegyptii \& alterius quod fagdas ab ipfo, \& ab Hefychio

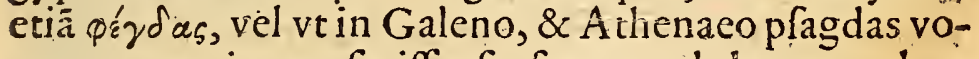
catur, mentionem feciffe, forfam quod alterum colore nigro infectum componeretur, cuius ab alio nullả men tionem factam adhucobferuarim. His omnibus addo, quod fi Theophraftus diucrfum agnof cit megaleum ab aegyptio; Galenus vero ambo hace, \& mendofium unü atq. idem facit, quomodo aegyptium album Hippocra tis fub nomine Mendosij \& Megalei fignificatum pro acgyptio Theophrafti, quod a Megaleo diftinguitur, ac $\mathrm{P}^{-} \mathbf{2}$ cipi 


\section{$\mathrm{L} I \mathrm{~B} \mathrm{R}$}

cipi queat intelligere non poffum, nifi forfam contendant Mcgaleum Theophrafti aliud fuiffe a Megaleo Ga leni; quam rem fi ipfis conceffero, illud tantum confe: quentur verum Megaleum Galeni aetate fuiffe defideratum, nomenq. in aliud tranfiffe : Diofcorides enim fcribenstempore fuo Megalci mixturam fieri defiiffe, id ait quod Galeni tempettate extitiffe verifimile eft, quädo Megaleum quidem illud vetuftum non amplius cóficiebatur, fed eius nomen dumtaxat in aegyptio albo conferuabatur, vt non fine ratione is dixerit aegyptium album ab aliquibus Megaleum \& Mendefium effe vocatum, atq. in hac fententia ideo magis confirmor, quoniam Plinius. Mendefio colorem nigrum tribuere vide tur; vnde patere poteft aegyptium album non fuife verüm Mendefium, aut megaleum, fed ipfo deficiente folum nomem obtinuiffe, \& iccirco ex Theophrafto ftaStem ac vnguentum acgyptium fimpliciter ita dictum, non parum inter fe diftare. Nunc Athenaeum videamus cuius verba in 15 . dipnos. haec funt ex vetuftiffmo codice Alexandri Farnefii Cardinalis maximi ex ce

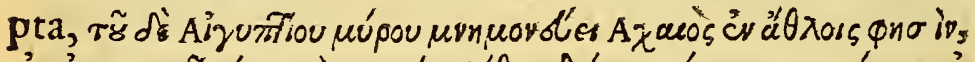

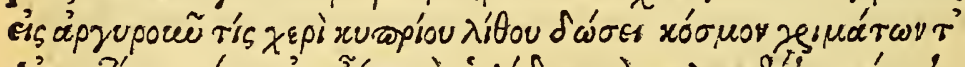
Aizuntil

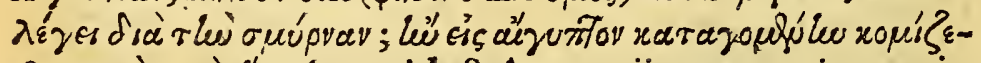
oas mpòs roùs ¿ $\lambda \lambda$ lwas. ideft Aegyptij unguenti mentio nem facit. A chaeus, inquit enim in certaminibus, in argenteum quis manucyprij lapidis vnguentorum aegyp tiorum dabit ornamentum ? Nunquid (ait Didymus) guttam vocatã dicit ob myrrham, quam fcimus in Aegypto natam ad graecos portari? ex quibus nomini ob fcurum eft Didymum minime aferere de aegyptio vn guento fimpliciter fic appellato, quod ab Achaeo pro facte comprehenfum fit; at potius interrogantis inftar de illo ambigere videtur, quam dubitationem omnino 
leucm putare debemus, quoniam Achaeuscuius verba is interpretari ftudet, de aegyptijs vnguentis, non autem de vno folo mentionem facit : Metopij vero nomen cum oleo amygdalino \& alijs multis tributum reperiatur, nihil inconuenit quin etiam vnguento aegyp tio, vt fcribit Galenus fuerit traditum; propterea locum

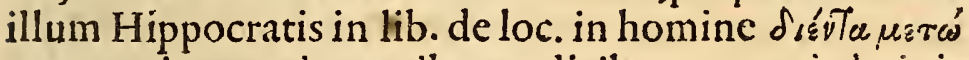
$\pi \omega$, tam in graecis omnibus codicibus, quam in latinis corruptum \& $\mu \varepsilon \tau \omega \pi$ tí reftituendum arbitror, vel enim pro oleo amygdalino, vel pro vnguento Aegyptio capiamus, melius fanead explicandam Hippocratis mentem confultum erit. His addam Plutarchum in lib. de Ifide, \& Ofiride ex Arifotelis fententia dicere vnguen torum, florum, pratorum odoriferas refpirationes non minus ad fanitatem, quam ad voluptatem conferre, cū cercbrum natura frigidum \& concretum fenfim calore \& leuitate rcfoluant; Myrram infuper apud Aegyptios Bal vocari, quod translatum delirij expurgationem ma xime fignificat.

Morborum rara quaedam genera ex Hippocrate, $\mathcal{A}$ gatarchide Plutarcho, \& Galeno, locus Hipp. resititutus, \& alter

Platonisindicatus. Cap. XX.

7od Galenus in r. \& 6. de locis affectis negauie 1. - de, ac in veficis lapides gignantur, id minime mi randum putari debet, quando \& nos $\&$ alij rophaceas materias ex inteftinis,atq. alijs corporis partibus non fi ne fupore extractas infpeximus : immo verufinimus auctor Hipp. in 5. Epidemiorum famulae Dyferidis in macrice lapidem enatum refert: quod neq. admiratione ulla dignum uidebitur, fi quibus cauris renes \& uef ca humores in lapideam compagem uertunt, alunt, \& augent, 


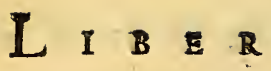

augent, ijfdem alias quoq. partes illud efficere poffe co̊ fideremus. Negauit quoq. ibidem Galenus fe animalia in cruribus hnmanis apud Arabas genita, dracunculos appellata confpexiffe; quae tamen Auicenna 3.4.t. 2. cap. 2 I . a fe uifa innuit: \& fi, quod effent animalia, palä affirmare minus uideatur: Haec eadé fuiffe femper exiftimaui, quae Plutarchus aetate Galeno non multú fuperior in 8. fympol. 9. hunc in modum defcripfit . oi dè

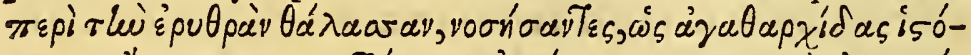

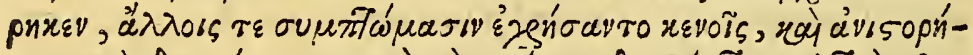

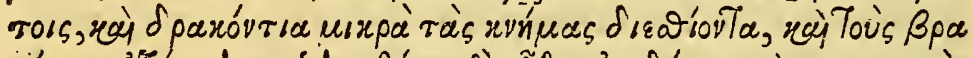

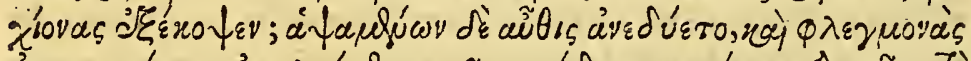

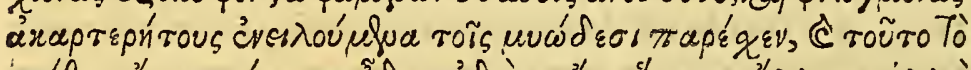

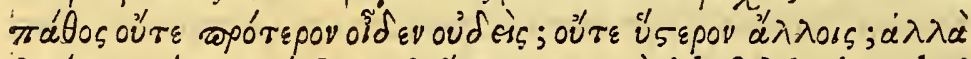

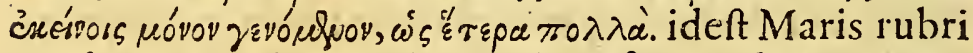
incolae, vt retulit Agatharchides affectionibus nouis, et nunquam auditis tentati funt. Nam dracunculis quidá parui crura, \& brachia e dentes eruperunt, qui fi tange bantur, ftatim emergebant, atq.'mufculis infixi minime tolerabiles inflammationes pariebant ; Hoc morbi genus prius nemo vidit vnquam. neq. pofteriusalijs, nifi his folis contigiffe vt alia multa. An is morbus ab aere, an a regione, an à viotu nafceretur, fortaffe dubitandū effet; fed me certum faciunt, victum potius fimili mor-

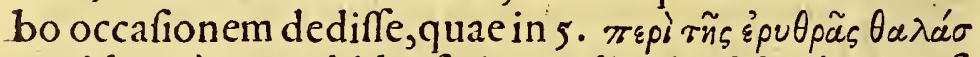
ons idem Agatarchides fcripta reliquit, Nimirú quofdam populos ob frequentem locuftarum efum non no do breuiori ceteris vita effe, verum etiā faeuifimo quodam, nec admodum dracúculis praedictis diffimili mor bos confumptos interire; vnde vehementer mirari foleo, quomodo Parthi, ac Iudaei potuerint(vt leuitici 2. narratur) locuftis viotitare, nifi Dci immortalis beneficio id perinde factum eft in ipfis, ac in Ioanne Baptifta obferuatum legitur apud Mattheum; alioquin, vt Gale 


\section{$S$ E C V D D S}

nus 5 . de loc. affinec nion Suidas tradunt, Sel eucidos aues in Afia locuftis vefcentes, Itatim ipfas excernere, $\&$ proinde nil fere nutriri, fic par erat homines eo vnico cibo haud quaquam diu fupereffe poffe: Hiftoriam ab Agatarchide relatam quoniam medicos iuuare ac delectare deberefpero, eam latino fermone expofitam hic fubiungam. A praedictis non multum differunt lo cuftarum efores, gens quidem ftaturae alijs breuioris afpectu macilens, ac fupra modum nigra; fub aequinoEtium vernum, quãdo apud ipfos Aphrici \&zephiri fpi rant; ex loco quodam incognito in effabilis magnarum locuftar um multitudo vna cum illis ventis ipfos peruehitui, quae ab auibus uolandi facultate parum, at corpore longe differunt ; ab hoc animalium genere toto te pore nurriuntur, ijs falitis atq. alio modo paratis uefcen tes; venantur a titem ipfas fumo ex aere in terram deijci entes; A tq. hi agilitate quidem \& pedum velocitate pol tere dicuntur; fed cum valde ficcum nutrimentum capi ant, vltra quadragefimum annum minime vitam produ cunt; irmo vita miferiorem fane mortem obeút, fi qui dem appropinquante fenectute eorum corporibus alata quaedam pediculorum genera innafcütur figura qui dem caninis mufcis fimilium, fed alioquin minorum: Incipiunt a pectore, ac ventre, breuiq. vniuerfam faciei cutem depafcuntur: Atq. horum alij primum fcabioforum inftar afficiuntur, deinde fe ipfos grauiter dilacerant, tandemq. morbo confiftente nec non cum beftiolarum exortu tenuibus effifis humoribus intollerabiles cruciatus fubire miferi coguntur; ficq. vel ob fuccos vel ob alimentum, vel ob aeris prauitatem intereunt. In lib. de medico Hippocrati adfcripto, Haec legútur,

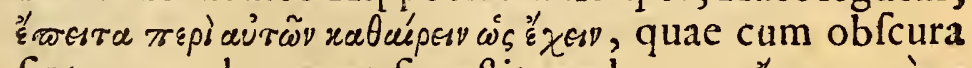
fint, neq. cohaereant, fic reftituenda puto, है $\pi$ erre $\tau \alpha$. $\pi$

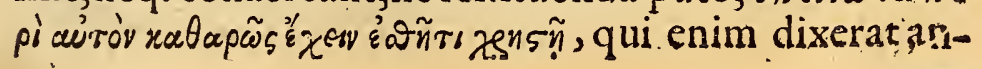




\section{I :}

tea de corpore medici vt effe debeat mox iure de ijs, quae funt circa corpus, loqui poteft. Quod autem dixit ibi Hipp. medicum carnofum \& optimi caloris effe debere, quoniam male difpofiti alijs minus auxiliari poffe putantur, diuerfum eft ab eo, quod in 3.de Rep. fcriptū eft apud Platonem. $[$, medicos fieri excellentifímos fi 2 pueritia artem difcere aufpicati, cú plurimis aegris verfati fint ipfiq. omnes morbos experti, natura quoq. vaIetudinarijfint.

De ̈̈s qui femel in die cibos capiunt. Cap. XXI.

Aiorem antiquorum partem femel tantũ in die cibis faturari folitã multi varijs rationibus atq. autoritatibus comprobarunt: Non defuiffe tamen \& praefertim feniores, qui valetudinis gratia bis, ter ue manducarent, \& Ariftoteles, \& Galenus memoriae prodiderunt : V tri melius fibi ipfis cófulerent huic loco non conuenit, vt difputetur; Id folum dicam ab au ctoribus varia in ijs, qui femel manducarent vitia fuiffe notata: Ariftoteles in phyficis quaeft. quemadmodum refert A ppollonius in mirab. hiftorijs fcribit rous rovo-

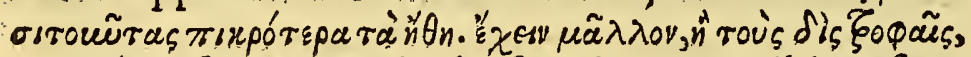
xpespépous; fiue cos qui in die femel tantum cibis uefcun eur, amarulentioribus effe moribus, quam cos qui bis, quoniam austa in ipfas vtraq. bilis animum magnopere perturbar, eofq, iracundos $\&$ melancholicos facit, un de auctor ille in fine primi libri de dieta, qui calido tem peramento funt, mádat vt polt?umptos cibos, actiones obeant, quoniam fic calor cibis temperatus cos fabilio res, ac agedis rebus aptiores facit Plinius quoq. lib. 28. cap.5. ex fententia Hippocratis tradienon prandentiü exta celerius fenefeere: Ante hunc dixerat Cellus affue tis bis in die comedere, fi femel folum cibis impleãtur, aluum 


\section{E C V N D $V$}

aluum adfringi. ambos vero ex 2 de dieta Hippocra-

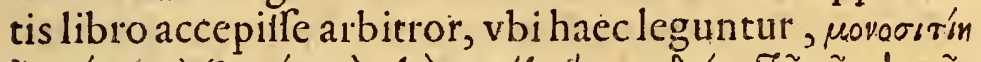

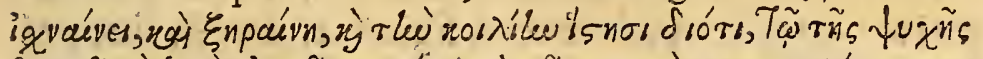

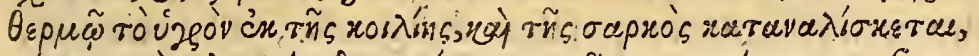

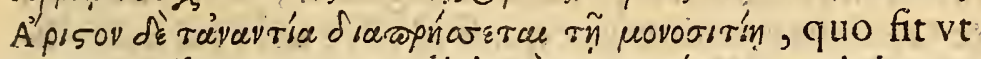
non omnibus tuto a medicis rò povorıté esv praecipi credam: Quemadmodú inutile omnibus puto fi cibis quo tidie repleri. (Quod Plato in Syracufanis notauit) bis velint: Certe alimentum in plures vices difpertitum fa cilius concoqui nemo negat. At fi modus qualitatis,ac menfurae non habeatur, quanto copiofius quis alatur, tanto detcriora pcricula fubire conftat: atq. his locutû̉ puto Hippocratem, quando in lib. de aer. atq. \& locis, aprśrics edaces appellauit, quafi illi ab ipfo, vtintemperati damnentur, qui tam in prandio, quã in cena efcis impleri volunt. INeq; enim Cornelij Celfi fententiam probare queo;vbi, modo concoquas nullum in cibis difrimen haberi neceffarium ducit, quod etiam ante $\mathrm{Lu}$ cletius dixerat hifce carminibus .

Nec refert quicquam, quò viEtu corpus alatur Dum modo quod capias concoctum didere pofsis Artubus, \& ftomachi bumectum.eruare tenorem.

Si quidem athletae peffimis cibis, \& avajuo фaj'sa illa ab Ariftotele in politi. \& Clemente Alexandrino decantata vtentes fortaffe ob exercitationes, \& cottiones minus offendebantur'; fed Galenus, quii illud probè no-

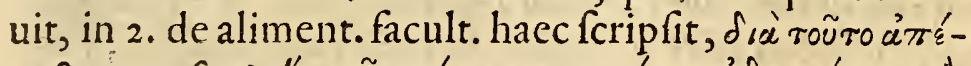

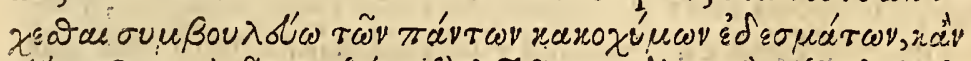

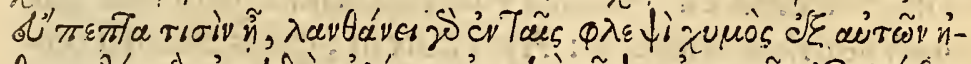

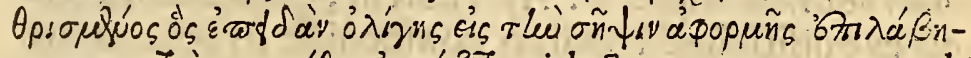

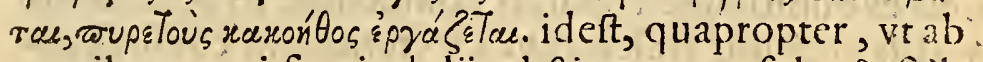
omnibus praui fucci edulijs abtineant confulo, \& fi illa cotu facilia fint. Latet enim in venis prauus humor ex ipfis coaceruatus, qui cum vel paruam ad putredine

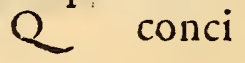




\section{$L$ I B E R}

concipiendam fit nattus occafionem febres mali moris inducit. Hoc tamen obferuandum $\delta \tilde{e} \pi v_{v} v$, quod \& $\mathrm{Ga}-$ leni \& noftra tempeftate cenā fignificat, üpıs sov, fiue prä diü vetuftiffimis temporibus defignaffe, vt Erotianus,

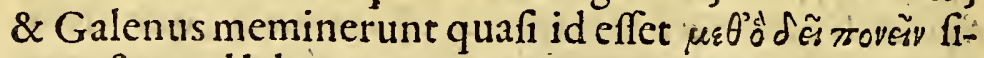
ue poft quod laborare oportet.

De Caryce, o Carycia; de Aproe Lumbo. Cap. XXII.

Hv rapúrles edulium, fiue intritum fuiffe lydium in ex fanguine, atq. aromatib. có pacto quo in pluon ribus Italiae locis conficiuntur, commixtum \& Suidas, \& ante ipfum Philocrates Samius, Erotianus, ac Galenus memoriae mandarunt; cuius item mentionem fecit Plutarchus 4. fympof.prob. I. vbi dum hace fcri-

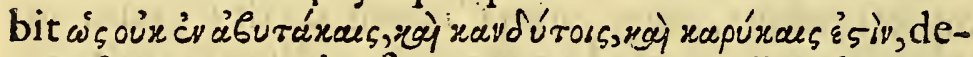
monftrat ea omnia efcarum genera ex varijs rebus apparata fuifle: Ad Caryces vero immitationem. aliud non illi difrmile condimétú pofteriorib. feculis côponi folitum puto, quod a multis, \& praefertim a Galeno in 4. de fanitate tuenda rapuré́ce vocatum eft; cuius ue apparatú maximam artem requifiuiffe ex hifce ipfus met

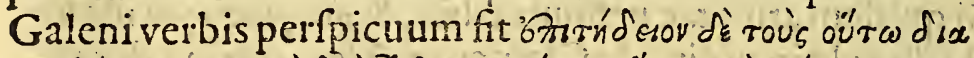

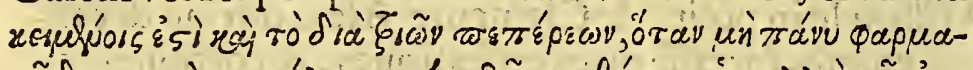

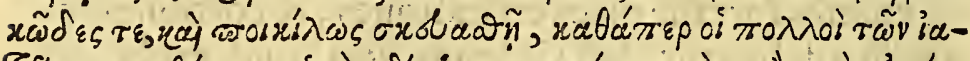

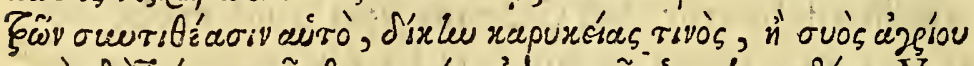

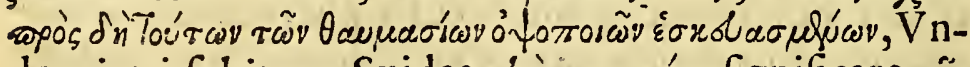
de mirari fubit cur Suidas $\tau$ \&u iapuxéav fignificare $\tau \tilde{\omega}$

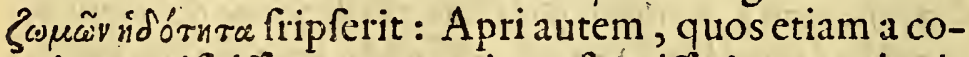
quis exquifitifime apparari confuéuife in praecitatis verbis meminit Galenus, vt a V cteribus in côuiuijs aeItimarentur, Iuuenalis hoc verfu teftatur.

Quant a est gula, quae fibi totos

Ponit apros, animal propter conuiuia natum 
Ne Martialcm proferam, qui vix vnquam.cenas, aut nobiles efcas memorat, quin inter ipfas apro nobiliore prope locum tradat; quem ficut hodie varijs iuribus, ac delicatis liquoribus condiunt coqui, vt cius filueftrem odorem occultent, ita quoq. Maiores noftros non minus gulae ftudiofos factitaffe intelliget, quicunq. A picij illius opfodaedali varias apri condituras cxaminauerit, Apri lumbus omnibus alijs partibus, eius praepone batur, hunc Plautus \& Cato aprugnum vocauere, cuius tenera durities commendata ipfi ctiam callinomen dedit; propter quod etiam Horatius longa oua extollens callofa nuncupauit, tam quam compasta illa teneritudo in omnibus ciborum generibus $\&$ dentibus, \& palato valde grata fit: Quin \& hodie in Italiae nónullis regionibus ac Venetorum praefertim fuum domefticorum lumbos inter fuauia actimari fcimus.

$$
\begin{aligned}
& \text { Quid fit wrún } \lambda v \sigma \varsigma, \text {, De farre factitio Aetï locus emaculatus, } \\
& \text { \& quod far Hordei, de Hordeo quaedam ex Arist. } \\
& \text { ospollonio. Cap. XXIII. }
\end{aligned}
$$

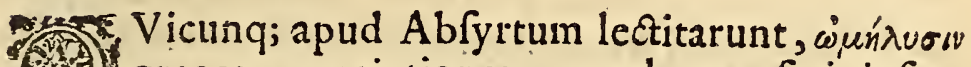
(1) graecorum mixtionem quandam ex farinis foe1. A nugraeci,feminis lini, \& hordei aequali pondere confarctis extitiffe, iure dubitát quomodo Caelius Aurelianus acutorum 2. cap. $24 . \& 37$. interdum fimplicis pollinis cataplafma, interdum pollines aqua folutos a

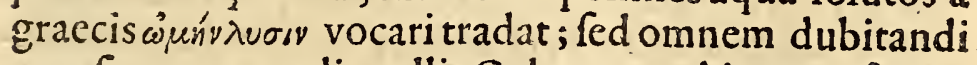
occafionem e medio tollit Galcnus, qui in expof. voc. antiq. co nomine a veteribus appellari tam tenuiores, quam crafliores et nó torrefactas hordei farinas fcribit,

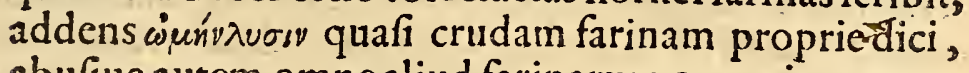
abufiue autem omnealiud farinarum genus ita nuncupari: Et quoniam farinarum mentionem feci hic locus

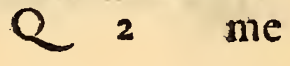




\section{I B $\mathrm{B}: \mathrm{R}$}

me admonet vt errorem quorundam recentiorum detegam, qui apud antiquos far etiam rem factitiam extitiffe duabus rationibus probare credunt, quarum prima eft quod Archigenes apud Aetium lib.9. cap.45. manifefte montrat Romanos far ex frumento madefato,ficcato, \& in partes craffiores diffracto paraffe: Alte ra eft quod Palladius farris hordei mentionem faciens clarc innuit far illud facicium fuiffe; Ego vero qui nec Plinium Archigeni fere coetaneum nec quemquam, alium (quod recorder) far aliud praeter natiuum adoreum vocatü nominaffe vidi, facile puto eos in magno errore verfatos effe: \& quod primo de A rchigene in me dium afferunt, fciant velim ea omnia ex margine, ab ali quo inf cio librario contextui fuiffe perperam interpoli ta; nam praeterquam, quod nemo mediocris iudicij inueniretur, qui verba illa in latinis codicibus pofita nec inter fe, nec cum praecedentibus fubfequentibus ve, co hoerere non adnerteret; accedit quoq. codicis vetuftiffimi, qui apud me reperitur, teftimonium in quo tota il la pars fine farris fatitij mentione hunc in modum legi

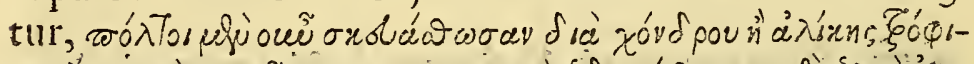

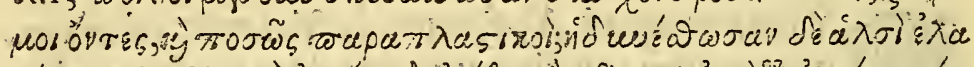
占

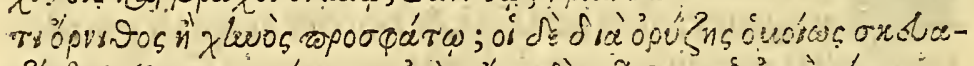

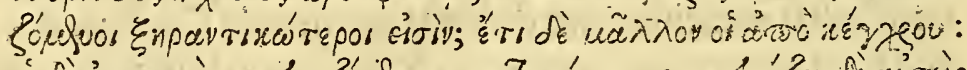

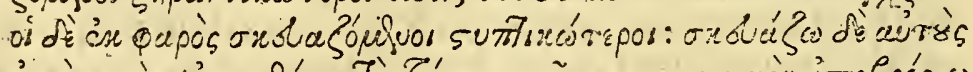

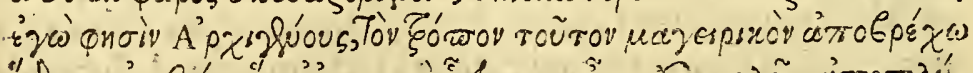

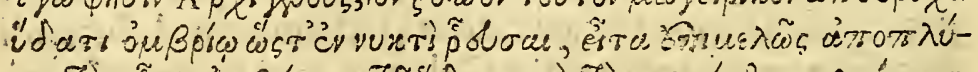

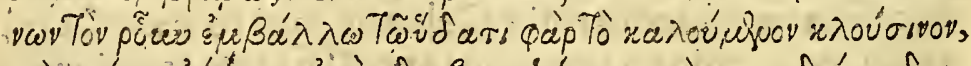

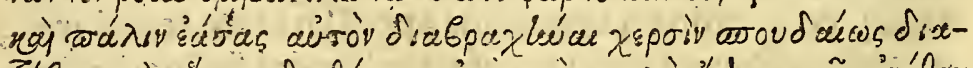

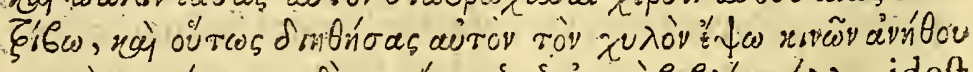

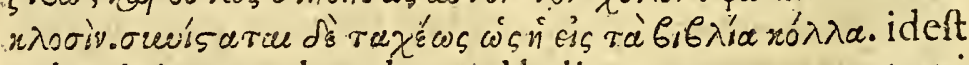
pultes igitur ex chondro, vel halica apparentur, vt qui valde nutriant, \& aliquo pacto obducant, códiantur ve 


\section{S E C V N D V S.}

ro minimo falis, oleo, \& anctho vel potius olei loco recenti gallinae, aut auferis pinguedine; quae uero exory ra eodem modo parácur magis exficcant, \& quae ex mi lioadhuc magis; \& quac fiunt ex farre magis adtringunt, ipfas autem paro(ait Archigenes) hoc coquorum modo, Aqua plutia tota note rohem macero, deinde deligenter exprimens, aquae inijcio far clufinum vocatum, rurfufq. ipfum macerari finens, manibus diligenter tero,ficq. percolatum ipfum fuccum coquo, anethi ramis agitans, confiftit autem celeriter infar gluzini librorum, quae verba vei inter fe mirifice confonant, fic latinis germani interpretis comparata nó modo ea corrupta ene, verum etiam quicquid plus in ipfis legitur, fu peruacaneum fore monftrant: cum enim aliquis recen tior in margine ediction is far reginne adnotaffet farris illius ap paratun, forte vel interp res ipfe, vel librarius alter id totum textui interferendum exiftimauit; vnde poftmodum alia exemplaria tranfcripta fimili errore in numera infecerunt, multos etenim errores in antiquos libros fimili ratione irrep fiffe apud omnes eruditos cóftat : de Palladio autem quod dicunt ita fentio far hordei apud ipfum idé effe quod apud Columellam a quo omnia illa accepit, Columellam porro farris nomine faepiffimie pro craffiore farina v ti fcice poffunt, qui octa ui eius libri cap.4.5. \& I I. attente legerunt, quo padto Varro etiam ufus faepius inuenitur, \& pracfertim quan do pro turdorú cibis offas modo ex craffiore, modo ex fubtiliore farre componi mandat, nam \& farinam a farre quo tercentum annis veteres Romani victitarunt, di ctam fuiffe teftatus eft ex Verrio Plinius lib. I8 . poft quem \& iuuenalis fimili,vocabulo propane ex farina. vfus in uenitur fatyr: 5 .

cumpnfsis boneftiusillic

Et tremere fordes farris mo rdere canimi

Addam 


\section{I : $E$}

Addam his in hiftorijs mirabilibus A pollonij notatum inueniri Ariftotelem in phyficis quaeftionibus docuiffe eos qui hordeo ferendo incumbunt pallidioribus cor poribus effe quam qui tritico; cum tamen in $2 \mathrm{I}$. prob. fec. prob.24.id paullo diuerfius legatur,eos fcilicet qui cibos ex hordeo factitant decoloratiores, \& deftillationibus magis obnoxios effe, cos uero qui ex tritico, meliorem habitum referre, quod ficut triticum hordeo facilius coquitur pariter etiam effluxus ab illo in corpus illabentes melitis conficiantur, \& propterea nec in crudos humores conuertant, nec fanguinem corrumpant, quemadmodum uapores ab hordeo effluentes efficere uerifimile eft .

\section{Locus Arifotelis de melle correltus \& expofitus, quod mel conferuet mortua corpora ér alia qiacdam. Cap. XXIIII.}

VIgarium quorundam iam diu fuit opinio mellis prouentum maxime praemonftrari, quando fiequentiores arcus celeftes apparent, quod pro bant nonnulli ex hifce uerbis Aritotelis in lib. 5. de hi

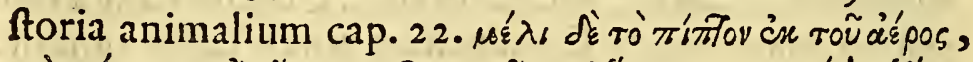

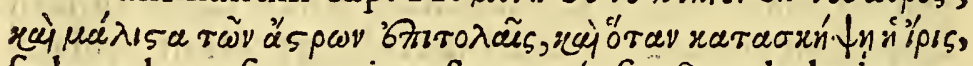
fed ego hanc fententiam femper fufpectam habui, prop terea quod Ariftoteles codem in loco ita frribens $a^{3} \lambda \lambda^{\circ}$

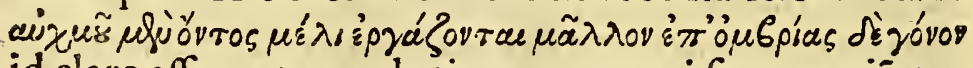
id clare affirmat, quod etiam communi fere omniũ experimento conftat, nimirum in fummis ficcitatibus ma iorem mellis fuper herbas quas depafuntur apes, copiả abundare, iccirco quin A riftotelis codicibus impreffis error aliquis lateat, nemini dubitandum puto, co magis quod in metuftiffimo Scipionis Carteromachi codi ce, quem mihi opera eruditifimi Fuluij Vrfini uidere contingit, 


\section{$S$ \& $C$ N D V S.}

contingit, in hunc modum fcriptum inueni wà $\mu a ́ \lambda, 5 a$

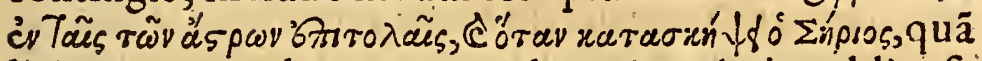
lectionem vt vehementer probem, in primis publica fe re experientia admonet, deinde Plinij friptoris inter latinos grauiffimi autoritas, qui cum omnia ab Arifto tele acceperit, fenfiffe videtur lib. I I. cap. I 4. optimum mel Sirio ex oriente produci; apparente vero arcu coelefti,fi imber non fequatur, medicamenta oculis $\&$ non nulla fieri : Quid porro aftrorum exortus A riftoteli fignificent fcio alios diuerfa fentire, mihi vero probatur magis,vt canem \& procyonem interpretemur, quando quidem Theophraftus I. de cauffis plantarum cap. 6.82 alibi canem ròás pov per excellêtiam vocaffe inuenitur: cum cnim(vt Hipparchus ac Hyginus declarant)Sidus canis plures ftellas contineat, quarum vna Sirius vel ca nicula nuncupatur, Ariftotelem id fignificaffe arbitror, quod mel tunc maxime ab aere cadit, quando aftra, videlicet procyon, canis, \& piaefertim Sirius, qui canis ftella eft, exoriütur : eo namq. tempore ardere terram, \& ficcitates maiores inftare, vnde roris mellei vbertas nafcatur, nemo nefcit: Illud vcro admiratione dignum eft, quod Eudoxus Cnidius apud A pollonium refert in Aphrica quandam gentem effe, quae fupra Syrtes \& Chartaginem incolat Gyzanteres vocata, hancq. exerceat artem quod fores iftis in locis colligat, melq. copia \& qualitate ex ijs cóficiat, vt apum aequet mellificium : Multas autem atq. omni ex parte homini vtiliffimas vires a natura obtinuit mel: fed illa reliquarum praeftantiffima putanda, quod vitia coerceat, nec ferpere ea patiatur; qua ex cauffa ctiam exanimum (ficut Columella lib. I 2. tsadit ) corpus hominis per annos plurimos innoxium conferuat: nam Plinius refert principatu Clau dij fe vidiffe hippocêtaurum in Theffalia natum ex Aegyptio ad Imperatorem in melle allatum ante Plinium 


\section{$L I: B, E$}

vero Xenophon. in 5 graecarum rerum, morem quandoq. fepelien di mortuos in melle vt conferuarentur ex. titiffe tradith, quod in 3. Lucretium intellexiffe puto cü fcriplit.

Aut in melle fitun fuffocari, at q. rigere

Frigore, cum in fummo gelidi cubat aequore faxi

$V$ thac ratione valeant medici in vfu mellis effe audicio res, vbi praefertim corruptionibus occurrere, atq. putredinem compefcere neceffarium eft; alioqui fi cú ficci tate contendatur, detrimentum potius quam commodú mellis vfui fuccedere merito innuit Galenus, dü biliofis, vt pote ficcis, magno ftudio eũ cauẽdũ praecepit.

Locus Theopbrafti Apollonio collatus; de Hclleboro quaedam alter Theopbrasti locus, non integre a Plinio exprefus. Cap. $X X V$.

Heophraftus 18. cap. lib. 9. de hifo. plant. quã (4. clarans, aliquot hominu exempla proponit, qui magna hellcbori copia affumpta ob confuctudiné, neq. fuperius, neq. inferius purgabantur: inter alia Eudemú Chiü refert 22. hellebori poriones in foro vna die haufiffe, nec quicquã purgatũ effe, quamquã hoc ab ipfo fa ctú fubiungit, cũ pont feptimã pótioné pumicis pulueré aceto fubactum ad comprimendum hellebori vim bibiffet: Haec hiftoria ex iplomet Theophrafto non parú diucrfa ab A pollonio in lib. de mirab. hift. refert hoc

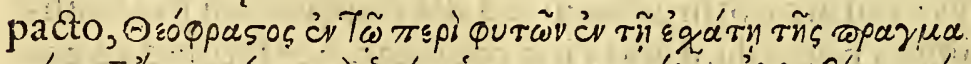

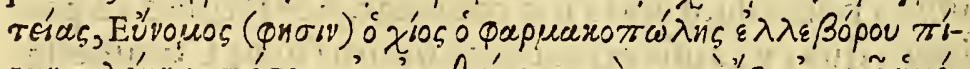

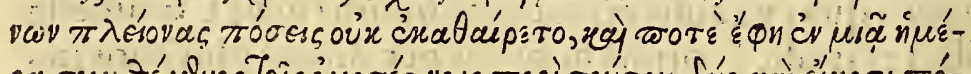

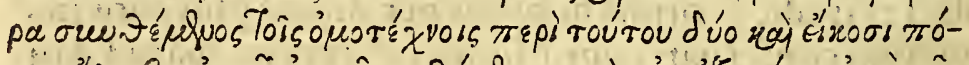

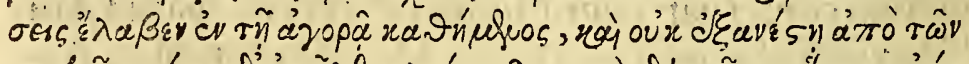

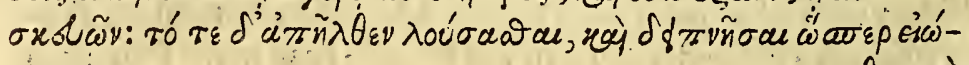
$\theta \in$, rà 


\section{$S$ E C V N D V S.}

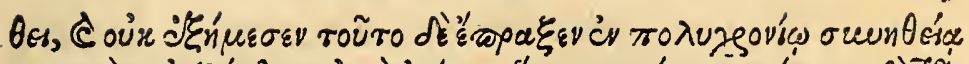

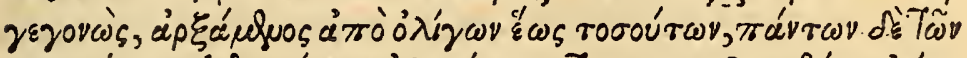

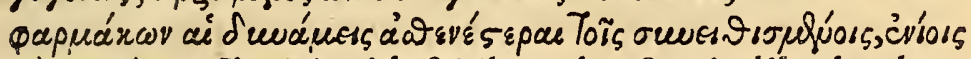
fì, Yà čmpartor cisiv, id eft Theophraftus in lib. de plantis, in poftrema trastatione Eunomus (ait) Chius pharmacopola multas ellebori potiones hauriens non purgabatur, \& nonnunquam vna die cum eiufdem profeforibus re compofita in foro fedens vigintiduas potiones accepit, neq. tamen a fuis vafis furrexit : tum vero abijt lotum atq. cenatum, vti cōfueuerat, neq.euomuit. Hoc autem fecir longa côfuetudine ita paratus.f. a paulcis principio accepto, ficq. ad tot potiones progrediente. Sunt enim omnium medicamentorum vires in confuetis infirmiores, in aliquibus etiam prorfus inefficaces. Quae verba libenter propofui, vt queant eruditi iudicare Theophrafti ne vulgatis codicibus, an A pollonij fcriptis potior fides haberi debeat: Cum enim Theophrafti mens in eo capite exiftat confuetudinis potentiam demonftrare, videtur potius fi fuam fententiam ta li exemplo confirmare quaerit, voluiffe Eunomüchium tot hellebori potionis impune accepiffe ob confuctudi nem (vt legitur apud Apollonium) quam quod pumicem aceto fubactum potaffet. Cur veteres hellebcro, elaterio fimilibufq. vehementiffimis medicamétis adeo frequenter, atq. audacter vterentur, inopiam leuiorum pharmacorum, qua laborabant, in cauffa extitiffe putarunt multi : Ego vero non tam eorum confilium huic adfcribo, quam quod (vt Galenus in libris de artic. mcmorat) huiufcemodi pharmacorum praeparationes varias ac tutas habebant, quas pofteros edocere neglexerunt nifi potius eorum commentarijs careamus ve contigit de lib. Hellebori Hippocr. cuius principium dum taxat habetur. Praeterea linimentis balneis, alijfy. extrinfecis (vt notat Oribafius) remedijs admifcebant, 


$$
\text { L I B E R }
$$

quae vt fine noxa hominũ corpora purgabät, fic quoq. jucunditatem maiorem vel faltem moleftiam minorem afferebant: His autem temporibus nihil pene huiufce generis notum eft, \& iccirco non eft mirum, fi dum medicamenta leuiora fectari ftudemus, valentiora dimitte tes in curandis aegris ab antiquioribus tum in celerita te, tum etiam in fecuritate non raro fuperamur: Ita fane interpietor Plinij fententiam, qui helleborum fcribit quondam terribile, poftea tam promifcuum effectum, vt plerique ftudiorum gratia ad peruidenda acrius, quae commentabantur, fumptitarent; An venenis edê disita quoq. poffint homines affuefieri, vt ab illis non ledantur dubium eft. Multi grauiffimi auctores id fieri poffe exiftimarunt, fed Auerroes auctor in perfcrutandis rerum cauffis acutiffimus in lib. fuo de theriaca tale fententiam acriter confutauit : Hic fubiungendus alter Theophrafti locus a Plinio non integre expreffus.Is.n. libro de lapid. in hunc modum fcribit, ávaxẽ wa na co

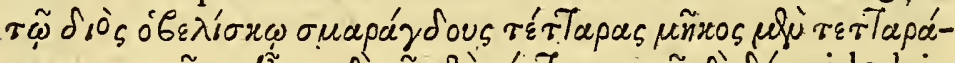

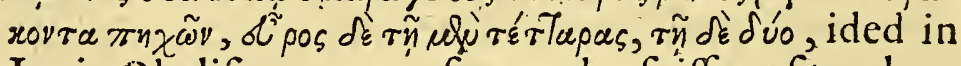
Iouis Obelifco, quatuor fmaragdos fuiffe pofitos, longitudinis quadraginta cubitorum, latitudinis vero in vna parte quatuor, in altera duorum. Hacc Theophra ftus at Plinius ipfum citans fic ait 37 . lib. cap. 5 . \& fuif

fe apudens in Iouis delubro obelifcum cap : 4 . fmaragdis 40. cubitorum longitudine, latitudine vero in vna parte quatuor, in altera duorum. Mihi fane rationabi

lius videtur in obelifco fuiffe fmaragdosarte infixos, quam totum obelif cũ ex finaragdis cōftru ctủe êe. 


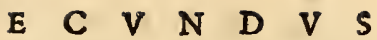

Locus Hippocratis de Hippace Herodoto collatus : de lactis coagulatione; Ctefiae locus de radice vinum coagu.

lante: muria dura, é marinae 2 fus.

cap. XXVI.

Etuftifimús auitor Hippocrates in lib. de aer (1) Equa,\& lo. fcytharum mores varios enarrans, in . taffe refert; quomodo autem Hippacem eae gentes con ficerent, in 4. de morbis hac oratione edocet, हैor

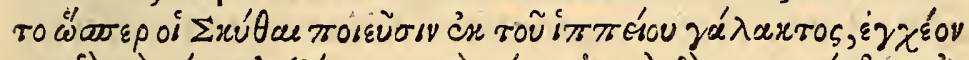

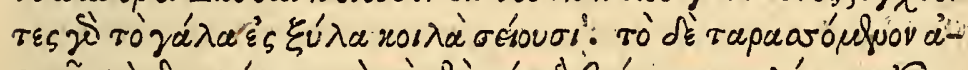

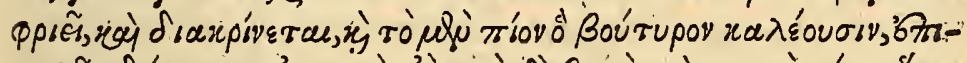

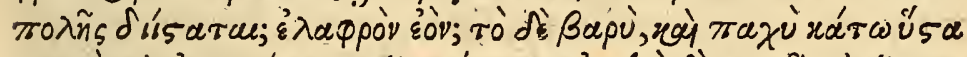

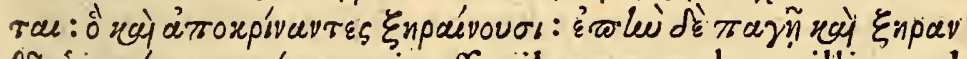
$\theta \tilde{n}$, itrtráruv ra réovow, i. affimilatur vero hoc, illi quod Scythae ex equino lacte parant. Nam lac vafis ligneis inijcientes conquaffant: quaffatum fpumefcit atq. diffe paratur, \& id quod fuperficiei fupernatat butyrum appellant veluti leue quoddam: quod autem infra fubfidet graue fegregantes exiccant, \& poftquam concrewerit Hippacem vocant. Hanc eandem rem quoniam Herodotus Hippocratis coaetaneus in 4. diuerfo quodam, \& latiori modo exponit, cius quoq. verba fubne-

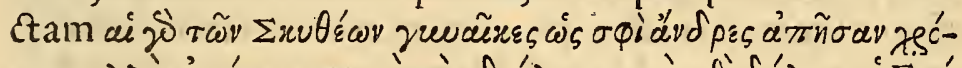

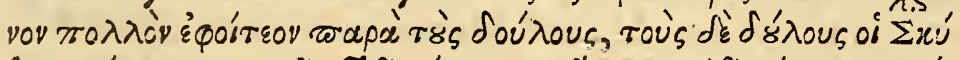

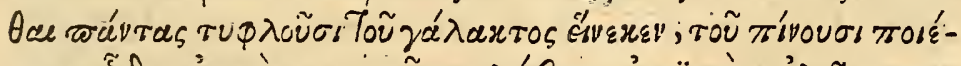

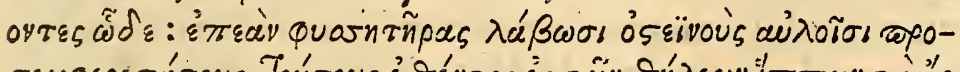

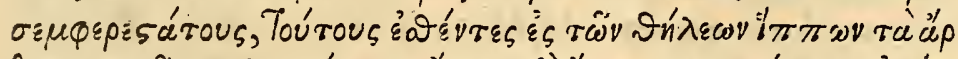

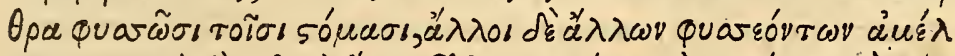

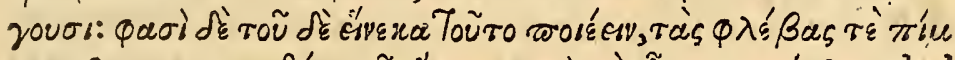

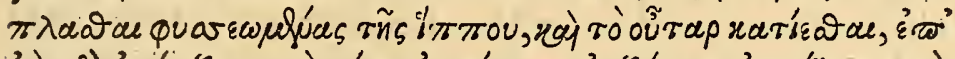

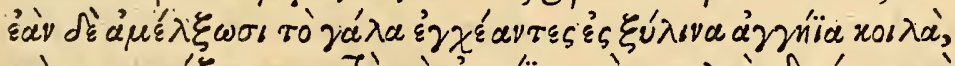

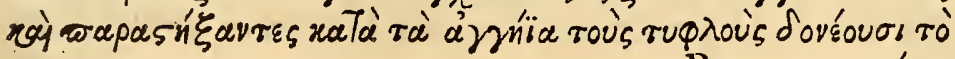
$\mathrm{R} 2$ rára 


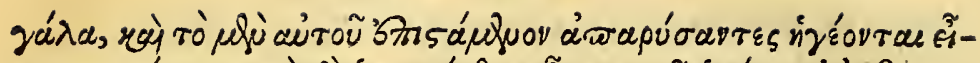

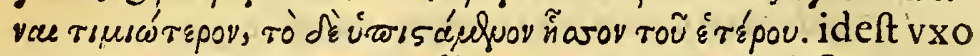
res namque eorum in diuturna virorum abfentia ad feruos accefferant vifu orbatos. Orbant autem Scythae feruos omnes lastis gratia quod potant, ita id facientes: fufflatoria oflea fiftulis fimillima fumuntur, eaq. genitalibus equarum impofita ore in flantur, hoc alijs facientibus, alij equas emulgét. Hoc ideo fe facere aiũt,quod venae equarum fuflatae implentur, \& mammae defcen dunt. Pofteaquam emulxere lac, in cócaua vafalignea diffundunt. His circumpofiti caeci lac agitant, cuius, quod fummum eft delibatur, preciofiufq. habetur : vilius autem, quod fubfidit. Ratio autem qua feruos occoecarét Scythac nulla alia fuit,quam ne fugam capere poffent, fiquidem cum in hunc vnú faciendi lactis vfum eos adhiberent, foculi ipforum non erant neceffarij, vt ideo poffent fine detrimento ne fugitarent feipfos exoculatione fecuros reddere, itaq. ex praedictis perfpectú habetur praeter coagulum, \& fuccos diuerfos nobis experientia notos quendam alium condenfandi cafei modum antiquos cognouiffe; medicos autem folos fuiffe, vt 4. Meteorol. cap. 3. fribit Arift qui coaguli opera lac in cafeum condenfarent, forfan quod fic purior cafeus, \& valetudini accómodatior euadat, cum qui alijs rebus commixtis efficitur, earum qualitates imbibcre neceffe videatur; $\mathrm{Nam} \&$ Hippocrates loco citato A ri ftotelis fententiam ratam faccre videtur, cum ipfe medi

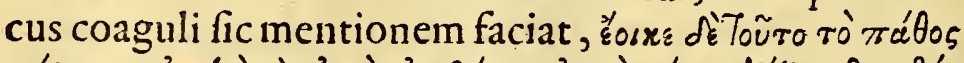

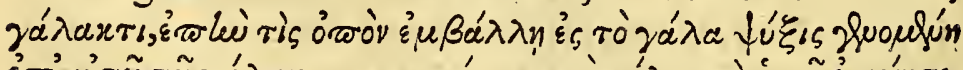

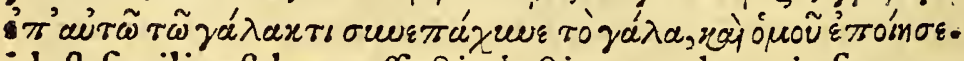
ideft fimilis eft haec affectio lacti, quando quis fuccum lasti inijcerit frigiditas ipfi lacti inducta id códêfat, atq. vnit ; quamquam poffer aliquis fufpicari nomine óroú intellexiffe Hippocratem fuccum ficulnum, vt faepe no 
tatum eft apud auctorcs, \& praefertim poetas graecos. Hippicem quoq. herbam, defcribit Plinius lib. 25 - cap. 8. quam in ore habentes famem, fitimq. non fentirc, \& ob id Scythas illa etiã in duodenos dies durare in fame fitiq. An vero fir herba Hipprce Plinij, cuius meminit Theophraftus 9. de hift. plant. I 3. his verbis d10 raúrn

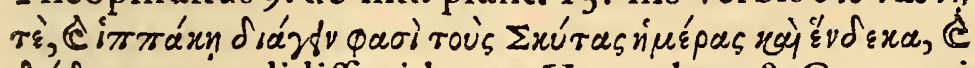
$\delta \omega ́ \delta \varepsilon x a$, vt credidiffe videntur Hermolaus, \& Gaza, qui iтráxy vocem tranfulit equeftri, an vero cafeus equinus, ficut Turnebus in an notationibus in lib. Theophr. de odoribus, in hoc Plinium reprehendens, exiftimauit; nō ita faciliter aufim affirmare ; certe Theophraftus aliquid miri de Scythis diccĩ voluiffe videtur;atqui eos duodecim dies ea radice, \& cafeo equino viuere confue uiffe nullam admirationem habet, quando ferunt Zoroaftrem intcrdú fololacte fex menfes träfegiffe, quod de quodam alio narrat A thenaeus, immo ipfemet Hippocrates, atq. Herodotus videntur innuiffe, quod plurimam temporis partem folo cafeo equino Scythae veEtitarent, igitur quin Turncbo difcors fim hactenus facere nequeo. An vero ope caloris, an frigoris femper lacti coagulatio accedat, dubitari merito poffet; fed cú à rebus diuerfis facultatibus praeditis hanc operatione nafci conftet,ab vtraq. cauffa proficifci autumo, calore ferofum humorcm exfuggête, frigore terrenum condé fante, atq. ab aqueis partibus fegregante; fic namq. Cy nara;gallinae guttur: cnicus (quod tradit Alexander probl. autor) coagulare confpiciuntur. Illud mirum, quod a Ctefia fcriptis mandatum eft radicem quandam apud Indos haberi, quae aquae, aut vino parua menfu. ra immiffa ita condenfat, $v$ t manu veluti cera teneri, ac tractari queant, quemadmodum item de aquifoliae arboris flore aquam glaciante, \& coriaccfia, calliciaq. idé operantibus ex Pythagorae auctoritate tradit Plinius 


\section{I B B R}

lib. 24. cap. I 3. \& I 7. id autem efficere vim radicis mirifice exficcatoriä, ac frigidam propterea exiftimo, quo niam Ariftoteles fcriptor grauiffimus, in 4. Meteorol. lib. aquam ferum, \& vrinam folo frigido ficco concrefeere prodit, vbi etiam fcribit Arcadici quoddam uini genuseffe, quod a fumo in utribus ficcatum adeo conpiffatur, tit gladijs abraium bibatur. Cur itaq. apud Scribonium largum, aliofq. fcriptores pro muria dura non eam intelligamus, quae ui folis ufq. adeo craffefaSta fit, ut alterins liquidioris refpectu dura quodammo do appareat? Certe Turnebus alioquin oculatifimus fi Columellam in lib. I 2. ubi muriae durae conficiendae rationem edocet, attente lestitaffet, non ipfi neceffe fuif fet cilus ety mologiã nimis fubtiliter in ueftigare, fed fta tim intell exifet inaiores noftros plures murias habuiffe, \& inter aliąs vnam, quam \& copia falis, \& calore folis confpiffatam ut à reliquis feperarent, duram nuncupare uoluerunt, quave etiam oliuas albas condiriconfueuiffe innuit Celfus in 2.lib. Nam Columella idé lib. 7. cap. 4. coeleftis aquae fubdio falibus duratae ad peco ris fcabritiem curandam meminit; mentionem quoq. facit Celfus lib. 2. cap. 30 . aquae durae, quam difficiliter putrefcentem exponit. Ad hacc marinam aquam ad profligandos uarios morbos in ufum receptam ab antiquis inuenio; qua facerdotes aegyptios Euripidem, illuc cũ Platone appulfum \& morbo correptum curaffe memorat Lacrtius, unde is quafi remediogratiam redditurus verficulū decantatũ omnibus fecit, $\theta a ́ \lambda a \omega \sigma a ~ x \lambda v^{\prime}$

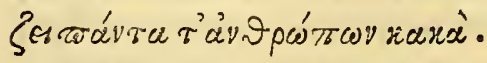

Scntentia Plinï defenditur de lino viuo, Er ex alüs comprobatur quid fit Scribonio foeniciusn. Cap. XXVII. 7. X X Cyprio lapide, quem amiantum alij nominăt, 19. - quae ignibus iniêta arderentquidem, fed flam- 


\section{$S E^{x} \mathrm{~V} N \mathrm{~N} V \mathrm{~S}$.}

mis inuicta \& fplendidiora exirent; Diofcorides fcrip. fit : Hunc quod Plinius crediderit ac appellarit linum uiuum, \& inextinguibile non erat a quibufdam recentioribus damnandus, quandoquidem Paufanias ante ipfum Carpafium linum, Strabo Caryftium nocarant, quem Solinus Carbafum, Zoroafter Boftrychitem, qui dam Corfoydem,alij Poliam;alij Spartopoliam, uulga res pulueres Salamandrae aut alumen fcifsile falfò dixe re: Ex huiufce generis lino mappas etia factitatas quae igni immiffae, ut aliae ăqua lotac a fordibus mundabãtur,practer Plinium A pollonius quoq.auctoritate Taci

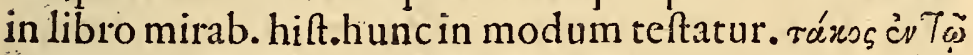

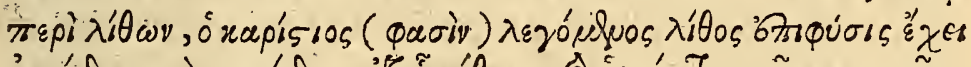

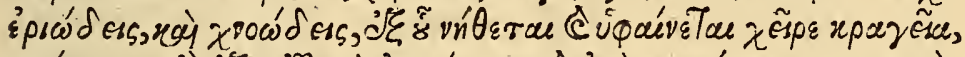

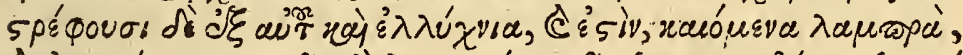

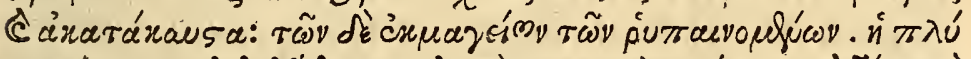

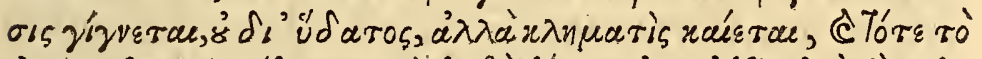

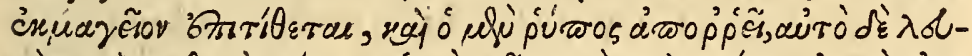

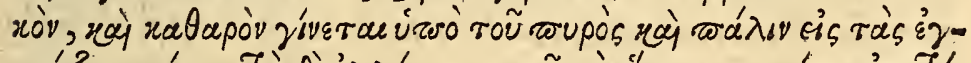

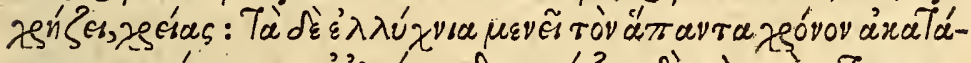

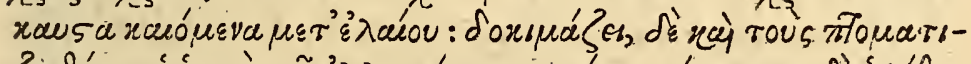

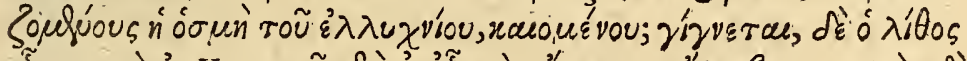

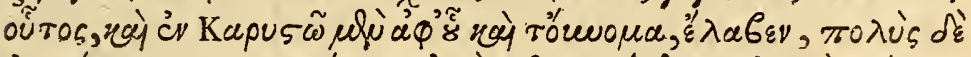

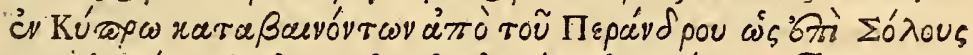

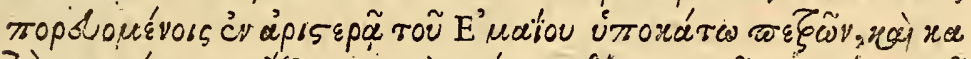

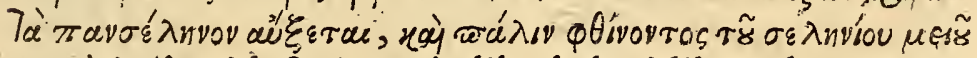
$\tau a, y_{j} 0^{\circ} \lambda^{\prime}$ Os. ideft Tacus in lib. de lapidibus, lapis (ait) Caryftius dictus habet adnata quacdam linea, 8 colo. rata, ex qua materia nentur, ac texuntur mantilia; ex ea dem \& fila pro lucernis torquentur, funtq. dum vruntur, fplendida atq. incremabilia. Porrò fordes mantilium non aqua eluútur, fed clematis vritur, atq. ei map pa imponitur, vinde fordes omnis effluit, ipfaq. mappa igne alba, atq ue pura redditur, rurfumq. in vfum adhi-

betur: 


\section{I : R}

betur. Funiculi autem lucernarum ex ipfo facti vfti cú oleo nullo vnquam tempore confum untur, atq. harum lucernarum odore deprehenduntur, qui morbo caduco vexantur; gignitur vero huifcemodi lapis tum in $\mathrm{Ca}$ ryfto, a quo nomen fumplit; tum copiofius in Cypro, qua a Gerandro Solos verfus iter deorfum ducit, ad lae uam Elmaei infi'a rupes;augefcit circa plenilunium; rur fumque luna decrefcente minuitur. Ex quibus manifefte colligitur lapidem fiue linum cyprium, non tantü fpêtaculi gratia, verūetiam ad mappas, ac mantilia cóficienda, vt quoq. Plinius meminit, vfurpatum effe; que vfum Diofcoridem fanè latuiffe nemo dubitet; fortaffe quod illius tempeftate, vel potius in regionibus fuis $\mathrm{mi}$ nime amiantum in id adhiberetur. Ad hunc locum faciunt \& illa', quae Plutarchus feripfit in lib. de defectu oraculi : vbi flumina, fontes, metalla, alialq. plurimas terrae vires, aliquando deficere oftendens, idem euenif fe fcribit lapidi Caryftio fub hifce verbis,

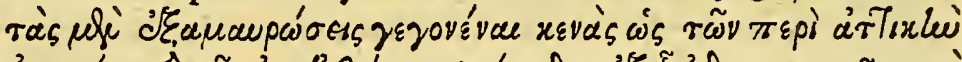

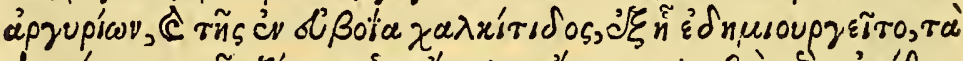

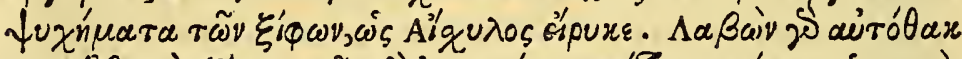

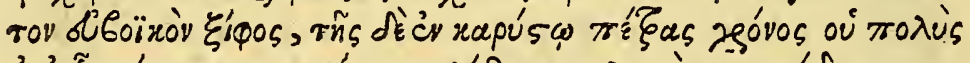

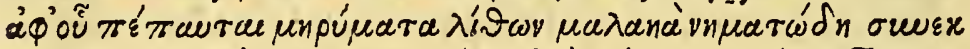

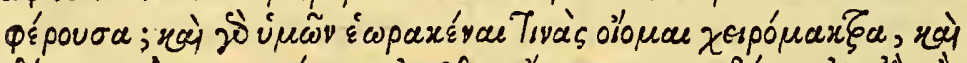

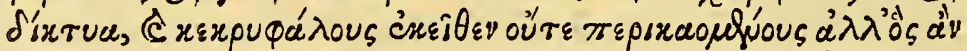

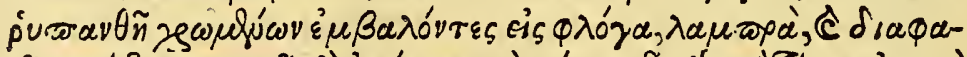

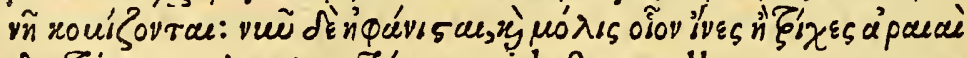

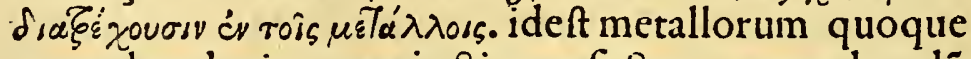
nouas haud mirum extinctiones factas, quemadmodũ argenti apud Atticam regionem, atq. chalcitidis, in Eu boea, ex qua aquae frigore tinctos enfes fieri folitum te ftatur Aefchylus his verbis(cupiens enim Euboicum enfem acie rigentem) petrae autem in Cary fto iam diu eft, quod vena defijt glomos lapideos molles ferre, ex 


\section{$S$ E C V N D V S.}

quibus fila nebantur. Nonnullos enim veftrum mantilia, plagulas, retia ex illa materia contexta afpexiffe pu to, quae non comburuntur, fed vfu fordida effecta in flam mä conijciunt, atque inde lucida, \& fplendida affe runt. Nuncautem cuanuit, vixq. in metallis rarae veluti fibrae ac pili intercurrunt. Laborauit Turnebus, vt quid Scribonio Foenicium fignificarit, apertum faceret, fed quis non videt ea verba in 267 . fic legi debe$i c$ ? fecundum quae adijcitur crocum tritum ex aceto, deinde my rra trita per fe afpergitur, vltimum nitrum, \& afí lapis: Phoenicio inducitur; Marcellus enim qui Scribonium tranfcripfitcap. 35. idem malagma defcribens, fic ea verba refert; fecundum quae adijcitur crocum tritum ex aceto, deinde my rrha trita afpergitur, vltimum nitrum, \& afius lapis additur : Ea vero vltima duo verba, Phoenicio ind ucitur, arbitror fic intelligen $\mathrm{d} a$, quod malagma fuper pannum vel coriũ purpurcú, dum poftulat vfus, duci debeat, atq. ita loco patienti ap poni ; Nam, \& Marcellus \& Scribonius alia huiufcemodi emplafmata memorant, quae pannis fuper inducta aegrotantibus membris applicabantur ; in 37 . capite Marcelli: de lapide Sarcophago vnciam I. tundes, \& cribrabis, \& ex aqua tepida permifcebis atque in pannum inductũ impones pe dibus \& alligabis.

FINIS SECVNDI LIBRI. 



\section{$V A R$ I A R V M I $\mathrm{N}$

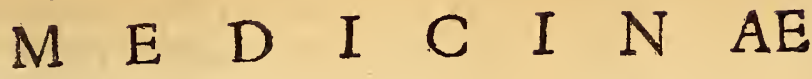 AVCTORIBVS, ET ALIIS

\author{
E C T I O N V M, \\ LiberTertius.
}

Eoca Oribasï ex stobaco refituta. Cap. I.

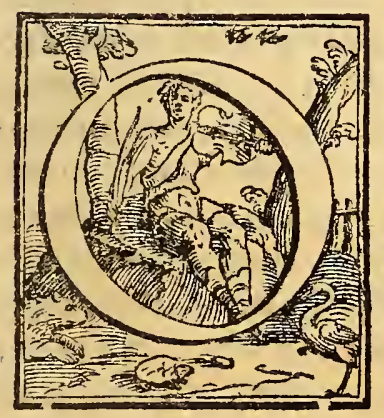

R I B A S IVS qui multa veterum medicorum fcripta collegit, cuive, ob hanc cauflam medici omnes magnopere debent, in 9. collect. fuorum libro nónulla ex Antyllo de aere profert, quae, quoniam apud Stobaeum diuerfo fatis modo leguntur, hic lectoribus proponere volui. Ea igitur quae in cap. 4 . Oribafij feripta ha bentur, fic apud Stobaeum fer.99. leguntur niépar $\lambda$ xußávo

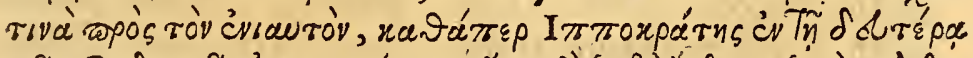

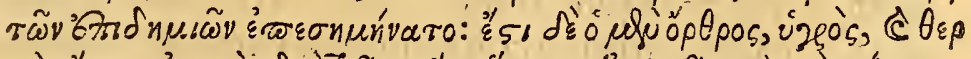

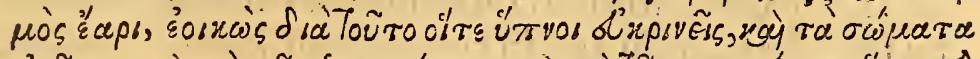

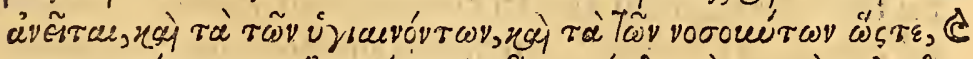

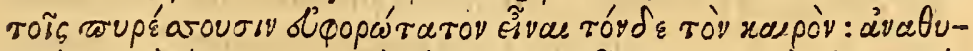

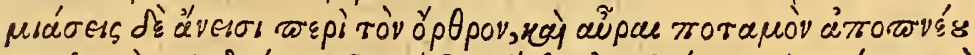

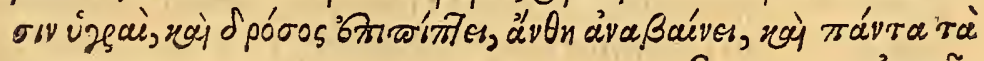

$\mathrm{S} 2$ वि $\pi$ तुद 


\section{I}

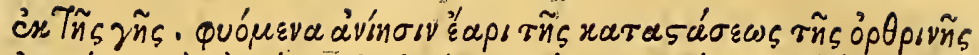

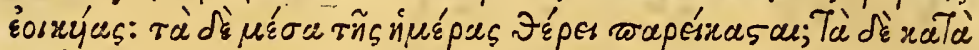

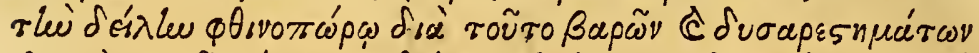

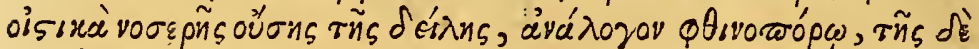

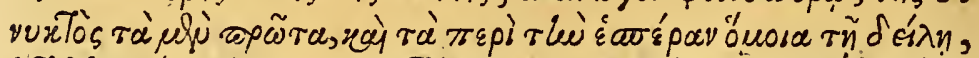

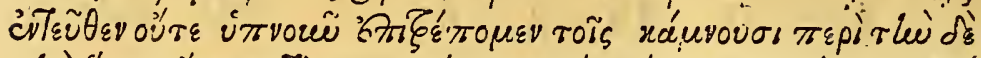

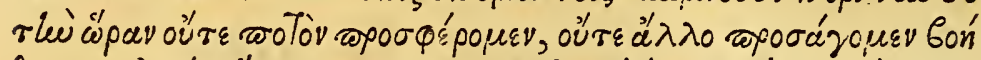

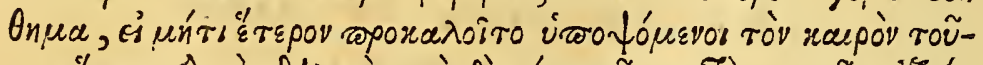

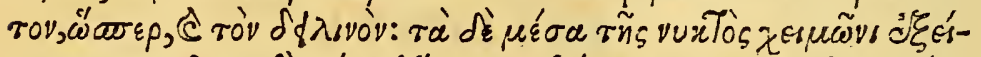

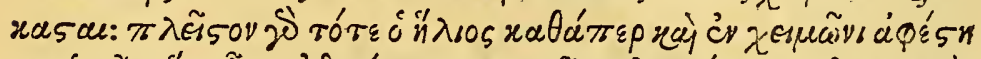

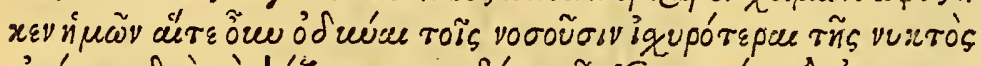

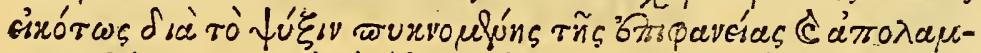

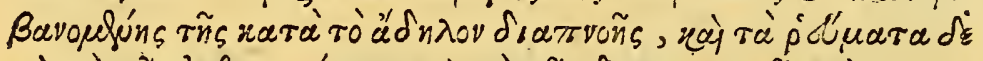

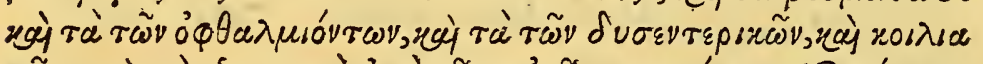

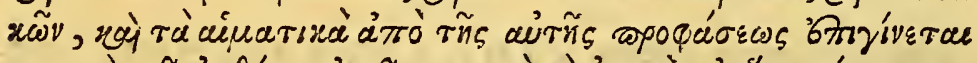

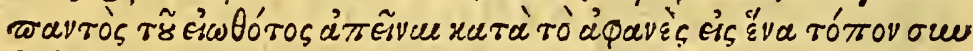

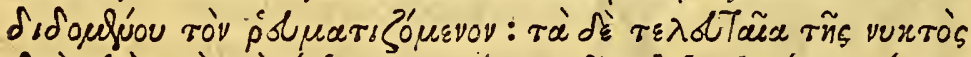

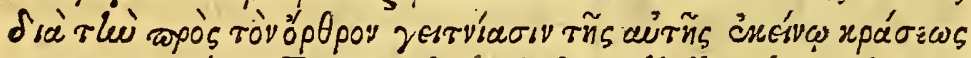

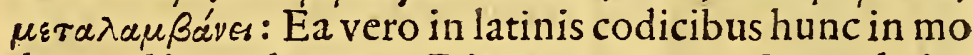
dum reftituenda erunt, Diem vna cum nocte modo intelligimus eumq. anno fimilé effe pronunciamus, quëadmodum Hippocrates in 2. Epid. fignificauit; matuti num enim tempus humidũ , calidumq. eft, veri fimile; quamobrem fomni puri, \& corpora tam fanorum, quã aegrotantium recreantur; ex quo fit vt febricitätes hac hora placidiffime degant; nam exhalationes mane diffoluuntur, \& humidae fluminum aurac refipirant, \& ros cadit, flores exurgunt, omniaq. e terra orientia attolútur: nimirum matutina conftitutione veri fimili exiften te: meridies autem aeftati comparatur, par's vero quae ad occafum pertinet, autumno propter hoc grauitates ac faftidia infert, quippe cum occafus morbofus fit : noEtis vero pars prima, \& quae circa vefperam eft occafui fimilis eft; eo tempore neq. fomnū aegrotis fuademus, 
neque potum damus, neq. vilum ailiưu âxilium adhibemus, nifi quid aliud admoneat, quod facimus veluti illud tempus aequo, ac tempus occafus vereamur mediae nottis tempus hyemi comparatum eft, fiquidem tum fol plurimum a nobis, vt hybernis dicbus, diftat: ergo dolores notturno tempore vehementiores funt, idq. merito, cum nox fuo frigore extremam cutim denfet $\&$ perfpirationem, quae clam in corporibus fit, inter cipiat; \& defluxiones tum corum qui lippitudine labnrant, tum eorum, quos tormina inteftinorum exercent, tum eorum qui coeliaci nominantur, tum eorum quibus fanguis fluit, ab hac eadem cauffa promouentur,cú ij, qui defluxionibus correpti funt, id totum quod clam ferri confueuit, vnum in locum amandent: Vltima no ctis pars propterea quod matutino tempori propinqua eft,eiufdem cum eo temperamenti eft particeps. In eo dem fimiliter lib. cap. I r.quae fcribuntur, ita Stobaeus

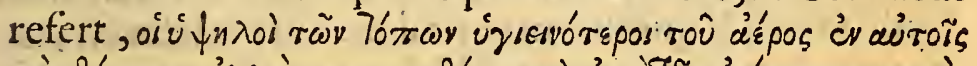

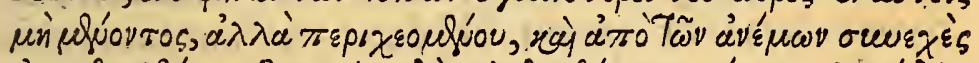
a’

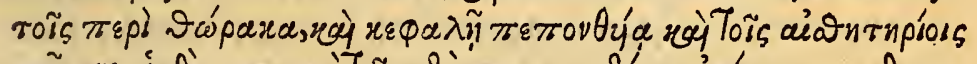

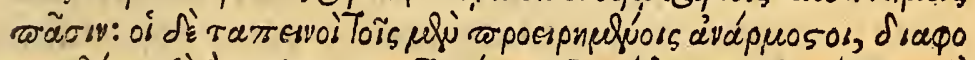

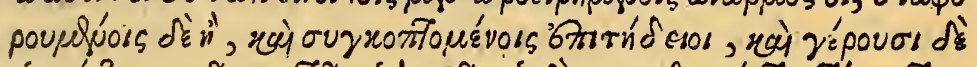

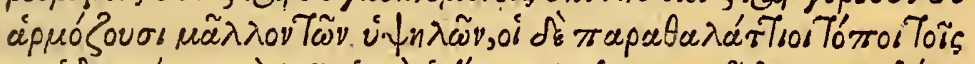

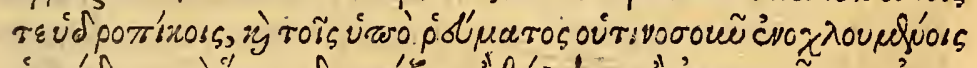
cipró d 1os, rà ó

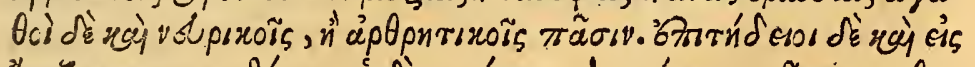

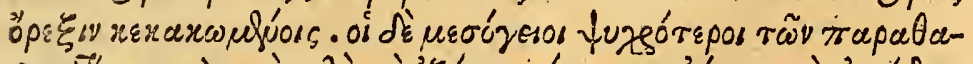

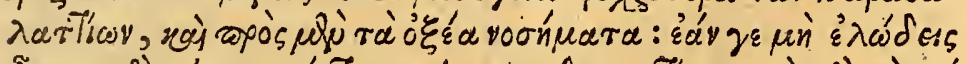

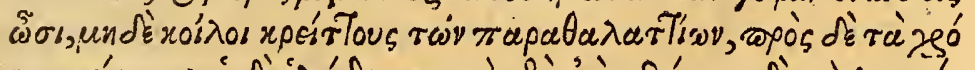

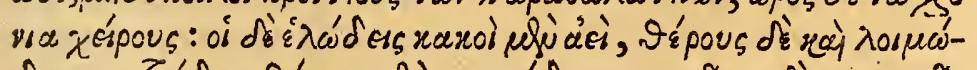

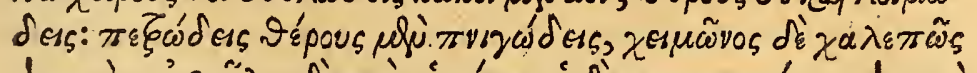

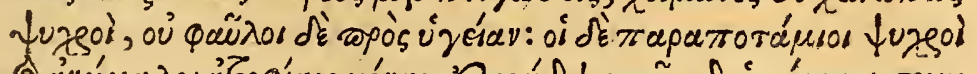
¿âvwua sapévars 


\section{I B R}

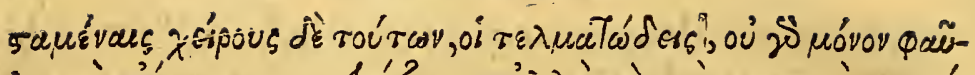

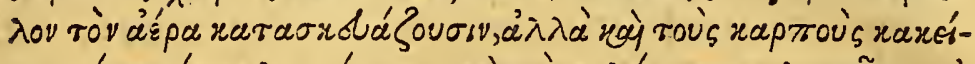

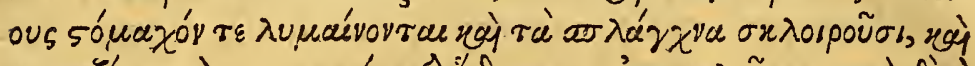

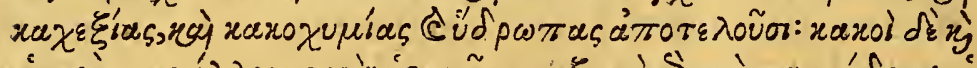

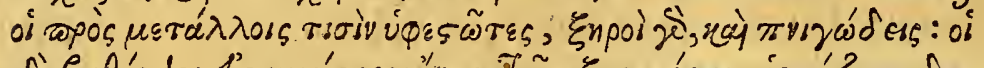

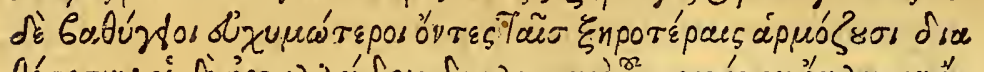
Oद́

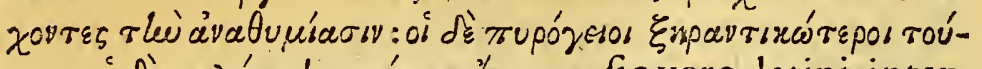

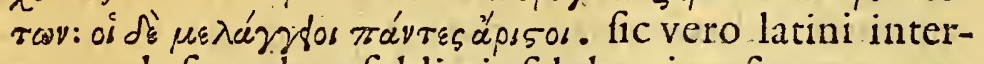
pretanda funt: loca fublimia faluberrima funt, cum aer in eis non fit permanens, fed perfundatur; \& a ventis có tinenter exagitetur, cumq.reete perfpirentur omnibus thoracis affectionibus erunt accommodata \& capiri laboranti, \& omnibus fenfuum inftrumentis conuenient: at loca humilia antedictis non funt idonea : ijs vero qui per halitum digeruntur, qui in fyncopas cadant, \& feni bus magis quam fublimia apta funt: loca vero maritima hydropicis, \& quibus quaenis defluxio moleftaeft, accommodata funt, itemq. vbi detcrgendum, aut calfaciendum, aut aperiendum eft conveniunt; fed profunt etiam omnibus ijs, qui neruorum, \& articulorum doloribus torquencur; Iam deprauatis quoq. appetitibus profunt : Mediterranea vero funt maritimis frigidiora, ceterum ad morbos acutos fi neq. paluftria, neq. caua fuerint, funt maritimis accommodatiora, fed ad morbos diuturnos ineptiora : ftagnantia cum femper funt in vitio, tum vero etiam aeftate funt peftilentia: petraea aeftate quidem fuffocant, hyeme vero molefta frigora faciunt, neq. tamen fanitati incommodant: Q uac vero funt prope flumina frigida ac inaequalia exiftunt folis atrophia ob humiditatem laborantibus accommodata: Hifce peiora habentur lutulenta, quoniam non folum aerem prauum, fed \& fructus deteriores reddunt, ftomachum corrumpunt, vifcera indurant, malos habitus cacochy- 


\section{$T$ E R T I V.}

cacochymias, \& Hydropas pariunt; praeterea quae me tallis propinqua funt, mala itidem exftimantur; fiquidem ficca funt, \& fuffocantia; quae vero fub terra funt, fi bonifucci fuerint, ficcioribus affertionibus apta cenfentur: argillofa vero robur diffoluunt, cum exhalationem habeant, in qua exfoluendi vis ineft; ruffa maiore exficcandi vi, quam quac nunc diximus funt praedita: nigra vero omnibus bonitate longe praeftant.

De Cyphoide of Cypbi Galeni, Plutarchi, \& Herodoti loca collata, emendata; ex explicata de verbo rapux bues in condiendis corporibus mortuis 2 furpato. $\quad$ Cap. 2.

X praeclariflimis quas ad varia morborum gene 4. ra reliquit Andromachus compofitionibus, vna de fuit pro hepaticis curandis Cy phoides appellata, cuius Galenus 8. de comp. med. fecundum lo. men. tionem faciens, fic ab ipfo vocatam fribit ob fimilitudinem illius Cypheos, quod Acgyptij omnium primi inuenere, ac in honorem Deorum quotidic accendere, eiufq. vapore templa fuffumigare confueucrunt : $\mathrm{Cy}-$ pheos vero compofitionem, etfi Damocrates ex Rufo, in 2. antidotorum Galeni libro clarifime explicaffe videatur, nihilomin us \& a Plutarcho traditam defcriptio. nem proponere gratũ futurum putaui, vt vtrifq. fímul conlatis Galeni hiftoriac fplendor \& gratia maior adda tur. Plutarchus itaq. in libello de Ifide \& Ofiride prope finem fic lingua noftra loquitur, Cyphi autem temperamentum cit ex decem \& fex rebus compofitum cypero, melle, \& vino, \& vua paffa, \& refina, \& myrra, \& afpa latho, \& fefeli, \& iunco odorato, \& bitumine, \& mufco, \&lacaptho; nam vbi Graecè $\theta$ púou legendum Gpúou, \&

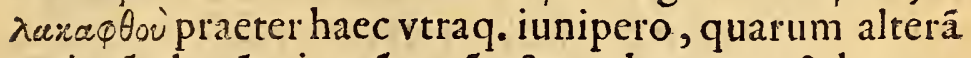
maioré,alterā minoré vocãt, \& cardamomo, \& harundine; 


\section{I B E R}

dine; cốponunt aŭt nổ temere fed recitatis interim, dü feplafiarij temperant, fcripturis lacris; numerus vero ta metfi maxime videtur quadratus, ex quadrato, \& folus habere acqualem aequaliter numerum, eo quod loco acqualem anbitum decenter inducat, minimc eft nomi nandus : In hoc autem cooperari oportet in ter fe fimul plurima quae coniun cta funt. Cum odoriferas habeât facultates; Dulcem enim fpiritum \& vtilem emittunt exhalationem, per quam \& mutatur aer , \& corpus etiă fpiritu commots: $\mathrm{m}$ conftringit, vt \& erga nos accommo detur, \& tempcramentum blandum habeat, \& continuas grauefq. curas diuturnas fine ebrietate rélaxat, ac foluit, \& vim imaginatiuam \& infomniorum capacem veluti foccul um leuigat, ac puriorem reddit, nihilo deterius quam lyrae pullus, quibus ante fomnum vteban tur- Pytagorici: odorata enim fenfum deficientem reuo cant faepe, rurfus obtund unt; \& auferunt diffuris prae tenuuitate per corpus humoribus, ficut \& medici nonnulli fomnum fieri dicunt, cum cibi exhalatio leniter circa uifcera ferpens, \& blande attreetans pruritũ quédam facit: Cyphi autem tum potione, tum maffa utuntur; potum enim interiora purgare uidetur, maffa uero emollit \& praeter hacc refina folis opus eft, \& myrrha, earum plantarum quae ad Lunam lachrimas emittunt, at inter ea quae Cyphi conftituñt funt; quae noste gau dent magis, ut funt quaecung. uétis frigidis, \& umbris, \& rore, \& humoribus nutriri folent, quando folis quidem lumen unum eft, ac fimplex; $\mid \&$ folem Pindarus nul lo contradicente dicit per Aetherem cerni, fed nocturnus aer commixtio eft, ac temperamentum multorum luminum, multarumq. virtutum ueluti feminũ ex omnibus in unum Sydus confluentium : merito itaq. illa cum fimplicia fint,\&ex fole originem trahăt, interdiu, haec uero cum mixta fint,\& uaria qualitatibus, incipié-

te noete 


$$
\text { T E } R \text { R } T \text { I } v \text { s. }
$$

te nocte fufficiunt. Qunemadmodum enim Plutarchus Cypheos potionem interiora purgare fcribit, fimiliter

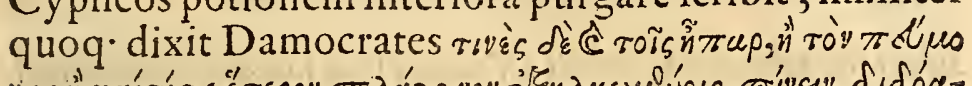

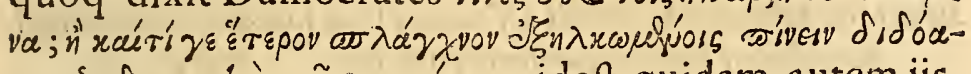

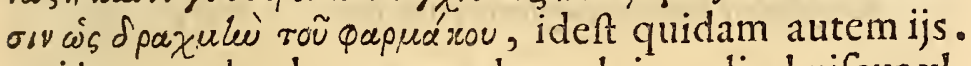
qui iccur, vel pulmonem, vel quodpiam aliud vifcus vlceratum habent drachmam pharmaci bibendã tradüt, vt inter ipfos conueniat non folum luffitu, fed etiam po tu pro medicamento in vfu extitiffe id mixturae genus: Quod porro memoriac mandauit Galenus 3. de loc. affec. Cypheos odorem capitis dolorem inducere, id in telligendũ eft de quibufdã, qui leui qualibet de caufa eius partis dolore occupátur, quando praefertim caput cảlidum a natura habent, alioquin fcriptum eft ab eodem Plutarcho in libro citato Ariftotelem voluiffe cere brum ab odoribus maxime recreari, quin \& ipfemet $G$ a lenus $\mathbf{2}$. de comp. medi. . l. vbi in febribus humores fri gidi dolorem capitis faciunt, fronti illini Cyphi praefentaneum remedium putat; quod cum tradat Damocrates Aegyptijos Dijs quibufdam in facrificio fuccendere confueuiffe, fit vt credam de illo Herodotum fermonem facere, quando in 2. libro eius gentis in facrifi cando ritus enarräs ait, His actis reliquum bouis corpus ftipant panibus puris, \& melle, \& vua paffa, \& ficis, \& thure, \& myrrha, atq. alijs odoribus; vbi haec infar ferunt, adolent, multum vini,oleiq. infundétes : Et quo niam de Aegyptijs fermonem hactenus habui non ommittam notare apud Herodotum hoc verbum Taprx búdv iccirco vfurpari faepiffime, in corporum mortuorum cô dituris, propterea quod cú plures gens illa haberet modos, quibus mortuos a putredine feruarent, primus om nium atq. etiam frequentius a populo vfurpatus fuit, qui ex folo conftabat fale, vnde iure condire corpora, diccbatur falire, \& condita rerapix suefúa; Nam fimpli $\mathrm{T}$ ciora 


\section{I B E R}

ciora $\&$ cuinis promptiora primo cognita, \& in vfu pofita fuiffe rationi valde confentaneum eft.

De turdis Horatÿ et Martialis defendituriudiciumet Galeni Sententia improbatur; moduscoquendiphafianos. Cap. 3 .

Quod Horatius Flanus fcripferit

Nil melius turdo, nil vuluadulcius ampla,

Idq. Martialis confirmauit dicens

Inter aues turdus ( $(i$ quis me indice certet)

Inter quadrupedes gloria primalepus,

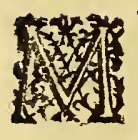

Vlti miratifunt, in eamq. venerunt fententiam, vt vetercs tamquam gulae indoctos damnarent: fed fi rem hāc exactius confiderare velimus, pro fecto apparebit haud quamquam male cos iudicaffe: Nam quantam nutriendis, pinguefaciendifque turdis maiorem operam impenderent, $M$. Varro in 3. de re ruft. lib. \& Columella pofteris teftarum fecerunt, vbi praeter alia inumera circa turdos ftudia, in cibum illis quotidian um offas ex ficis \& farina alias craffiore, alias fubtiliore confarctas, nec non milium cum aqua copio fa \& clara pracbuiffe monftrat; vt hac rarione perfuafum cuiq. effe poffit aues fimilibus cibis, alijfque curis enutritas iucundiffimas euaffife, adeo quod finguli tur di ternis denarijs iure emptitari potuerint, quemadmo dum interdum tempore fuo Varro, quotidie aetate fua factú fcribit Columella. Atque temporibus noftris tur dorum faginandorum cum nullus ueram gerat quales ve capiuntur in coquinas mittantur, necefle cft eam in ipfis manducandis fuauitatem minus percipi illud fane de turdis non parua admiratione me afficit quomodo Galenus cos \&z pafferculos duriores effe concoctu perdicibus, attagenis, columbis, gallis, fafianis, \& Gallinis fcripferit 3. de alim. fac. quem locum aliquo médo fca-

ter'e 


\section{$S$ E C V N D V S.}

tere poffet quis fufpicari, nifi eadem verba apud Oriba fium \& Aetium notata haberentur; Cur autem hoc ad mirer potiffim um in cauffa eft quod \& 7. metho. \& alibi ex Galeno colligitur quaecunq. magis nutriunt debere difficilius (datis ceteris paribus) a calore naturali confici; vnde fi turdis, \& pafferibus magis perdices, gallinae, \& phafiani nutriunt funtq. (veloquitur Celfus) materiae firmioris, par eft quoq. difficilius concoqui : Iam vero phafianos quos quantum ad coetionem, ac nu

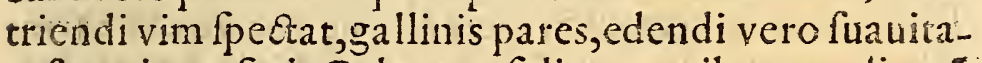
te fuperiores facit Galenus, folis vaporibus a culinarũ magiftris ob maiorem gulae iucundiratem coqui confueuiffe apud D. Hicronymum obfcruaui: Is enim in Epift.ad Oceanum 83. Facerdotis munera ty pice enarrans, fic eum depingit debere effe domum fuam bene regentem, non vt opes augeat; non vt regias paret epulas; non ut caelatas patinas fruat; non vt phafidas aues lentis vaporibus coquat, qui ad offa perueniant, \& fuperficiem carnis non diffoluant artifici temperamento, Hocetiam pacto folitum fructus coqui pro valetudinarijs meminit Galenus 2. de comp. med. vbi examinat fcripta A pollonij ad capitis doloré ex ebrietate, \& Alexander Trallianus lib. I 2. cap. de tertiana.

De Aconiti nomine ex Antigono : de eodem Athenaei,locus emendatus, item alter Theopbrasti melius quam a Gaqa interpretatus: de cicuta quaedam, error Macrobï. Cap. 4.

Iu inter austores difputatum fuit, a quo nam aco (3) niti nomen acceptũ cffet; tandemq. potior pars Theophrafto adhaefit, qui in 9 . de plátarum hiftoria fic ipfum vocatum fribitab Aconis Periandyno rum fiuae Mariandynorum (vt quidam corfigendum volunt) pago ad Heracleam Ponti: Theophrafti fentê-

$$
\text { T } 2 \text { tiam }
$$




\section{I B E R}

tiam ex Theopompo comprobauit. Primo Aelius promotus cuius verba haec funt, ex lib. $\pi$ spi iobó $\lambda \omega v$, rey $\delta n \rightarrow$

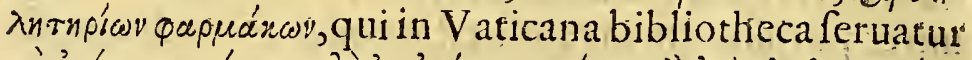

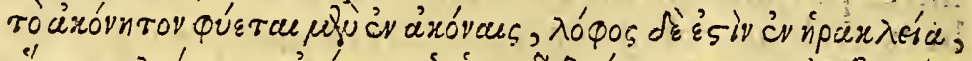

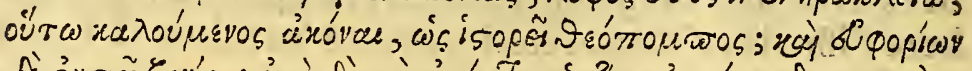

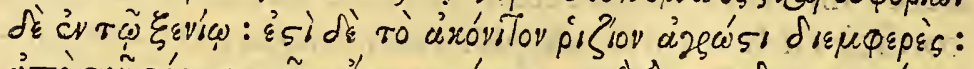

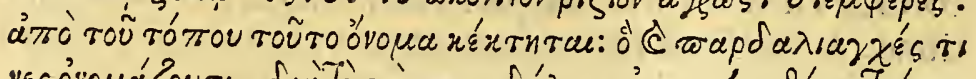

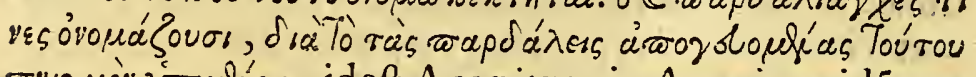
Trv'quòv íâfúesv, ideft A conitum in Aconis quidé nafcitur,mons autem eft in Heraclea fic vocatus, vt narrat Thcopompus. Vt uero Euphoriô feribit in Xenio, aconitum radicula eft gramini fimilis a loco huiufmodi no men fortita, quam nonnulli pardalianchem uocát, pro pterea quod pardali fi eam guftauerint, fuffocantur. Deinde Antigon us in collectaneis paradoxis vbi haec

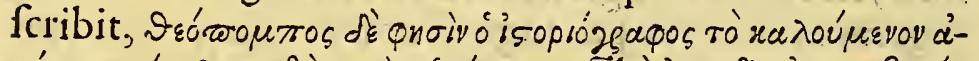

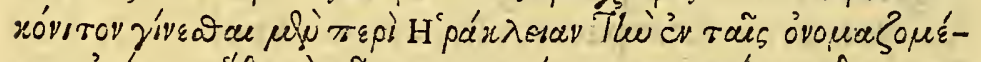

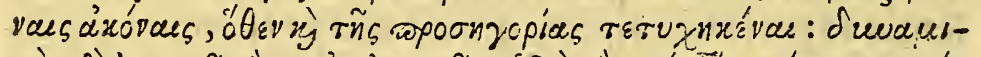

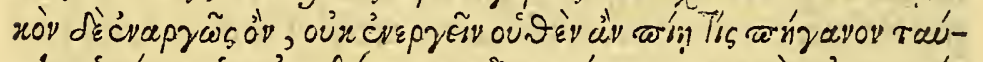

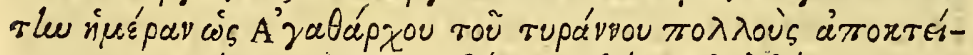
valvтоs фарна́r

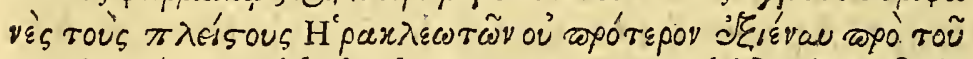

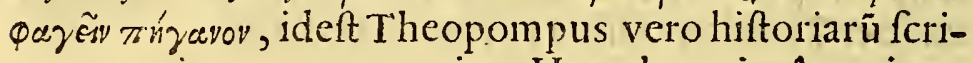
ptor aconitum uocitum circa Heracleam in Aconis vo catis nafciate. iride nomen habuife narrat, Cum auté magnas vires pofficar, quicquam non operari, fi quis eadem die rutam poter, vinde A gatharco tyranno multos eo pharmaco tollcre atq. latere cupiente : vt primú res detecka ef, plurimi heracleotarum non exibant domo priufquan rutam comedifent, quomodo uero Aga tarchus Heracleotas aconito interfictet, Theopompus apud Antigonum clare non expreffit : conijci tamen po teft occultum aliquem modum habuife, quando ipfe tanto tempore latuir ${ }_{2}$ arg. Heracleotae, ut ihlaefi euade- 


\section{$T E R$ T I $\vee S$.}

rent,antequam e domibus proprijs exirent, rutam bibe bant; quafi nulla ui, aut arte alia fe fe tueri ualerēt, quo in cafu id uenenum etiam extimarum partium contactu forte iugulare potuiffe crederem, poftquam Heracleotae ftatim extra domos uenenum formidabant, ac Theophraftus, \& Plinius retulerunt aconitū $\theta u \lambda$ ń $\varphi$ ovov, genitalibus quadrupedum feminarum folummodo inditum eo die enecare : alijq. foripferunt aconitum, tam extrinfecus, quam intrinfecus homini nocere; nifi verifimilius effet Agatharchum eo fecreto componédi aconiti modo ad interimendos Heracleotas ufum, cuius Theophraftus 9. de hift. plant. cap. 16. meminit; ubife cundum interpretationem noftram fic loquitur de aco nito. Petracis locis maxime gaudet; co nec oues, nec aliud animalis genus pafcitur; ad hoc autem vt operetur, quodam modo componi dicunt, nec cuiufuis effe fimilem compofitionem parare; \& propterea, cum medici eam ignoret, pro putrefactorio uti; quinimmo nec in uino, nec in mulfo ad quaecunq. alia propinatũ ulla tenus fentiri : Ita uero componi, ut quibufám ftatis té poribus ueluti duorum aut trium, fex ue menfrum, aut unius anni uel duorum fpatio fuftollat: Atq. cos infeli ciffime mori, quibus pluri tem pore corpus confumitur; felicius auteni quibus citius : Nec ullam eius antidotú fponte nafcentem (ut audimus) inueniri, fed quaedam auxilia illis, qui acceperunt, effe reperta; Si quidem incolae nonnullos melle, \& uino, \& fimilibus, fed raro, \& cum labore a morte reuocant. Haec Theophraftus in quibus quot graues errores commiferit Gaza, cognofcet quicunq. fua \& noftra graecis cóferre uoluerit. Id quod ex Antigono rettuli apud Athenaeum quoq. 3 ; dipnos paullo diuerfius legitur hoc pacto. Eliss roú

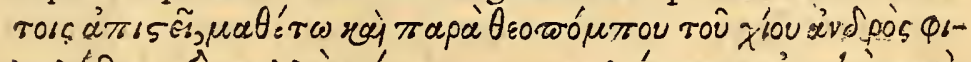

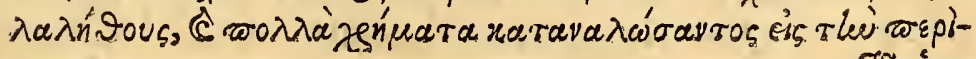




\section{L $\begin{array}{lllll} & \mathbf{B} & \mathbf{L} & \mathbf{R}\end{array}$}

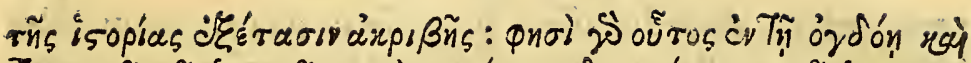

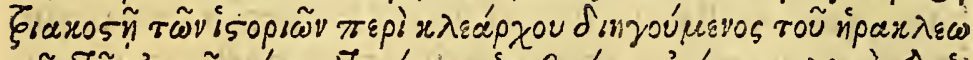

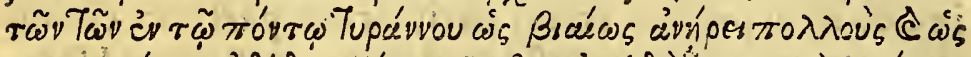

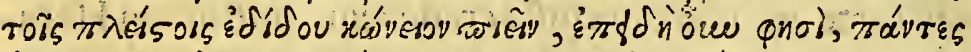

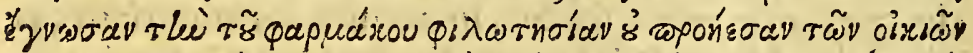
कoiv

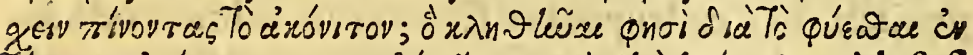

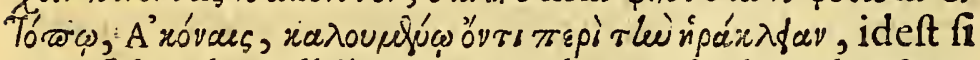
quis fidem his adhibere non vult, apud Theophraftum Chium difcat, hominem veritatis amantiffimum, quiue in exafa hiftoriarum cognitione comparanda multum pecuniarum confumpfit. Hic enim in 38 . hiftoriarum libro fermonem faciens de Clearcho Heracleotarum in Ponto ty ranno, vt ui multos fuftulit, \& vt plurimis aconitum potu dedit, poftquam, ait, omnes pharmaci in po tu faciendam a rege inuitationem cognouerunt, haud prius domo exierunt quàm rutam comederent eo quod nil ab aconito laedantur illi, qui prius hanc potarint, Aconitum vocari fcribit a loco circa Heracleam Aconis appellato, fed vbi apud hunc habetur, ¿̇ंídou róvyor

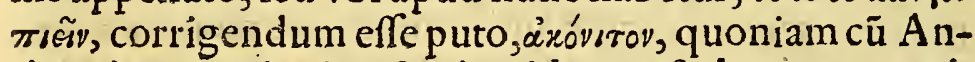
tigoni nuper citati auctoritas id ex poftulat, tum maxime ipfiusmet Athenaei poftrema verba requirunt: vt interim quoq. non omittam cicutam valde aconito lenius effe venenum, \& iccirco eam maiori menfura propinari, atq. interdum fallere; nifi malumus Athenaeo xćvesov, \& áróvstov, idem perperam extitiffe; quemadmo dum Stephanus in lib. de vrbibus eum citans in voce a'xóvac atteftari videtur; quo pacto Arabum errorem tegere quoq. poffemus, qui xwy putantes turdos, fiue fturnos aconito uefci tradiderunt, cum non aconito fed cicuta eos notriri Galenus, \& alij verius tradant. Exijs quoq. Athenaei verbis clarum effe poteft apud Antigonum Agatarchum, fed Clear- 


\section{T E R. T 1 V 5 .}

chum cffe legëdum, atq. illum ea die, in qua olim reges pocula praegultata porrigebant populo, vt hac propina tionefuam erga ipfum beneuolentiam teftarentur, ipfa pocula aconito inficere, atq. hoc pacto ilios interficere decreuiffe, Porro cicutam vino hauftam irremediabile malum inducere, $\&$ fi poft ipfam vinü bibatur, eius prauitatem atq. illum caftigare Plinius feripfit; cuius cuen tus eam rationem afferre foleo, quod cicuta pauco vino haufta citius ad vitalia penetrat, nec ab illo fui uis hebe tatur; at fi vinum large bibatur, poltquam ipfi per aliquod tempus cum natiuo calore pugna fuit, uim eius in pugna iam retufam ab illo vt pote calido penitus extin gui neceffe eft, \& iccirco apud Platonem in Phaedone voluerunt Satellites vt Socrates haufta cicuta non moueretur, timentes ne calore motus ueneficium cicutae firgus nimium retufum foret, ficq. mors vel impedita vel faltem prorogata effet, Itaq. Macrobium erraffe facile hinc patet, yuando lib. $7 \cdot$ cap. 6. fcripfit aconito po to fuperhauftum vinum effe remedio, ficut vinum cum aconito tritum, \& potu hauftum irremediabile malum facit; praeterquam enim quod de aconiton id nullus probatac fidei auctor tradidit. Plutarchus etiam a quo omnia illa accepit 3. Sympor. 5 . monftrat non de aconito, fed $\pi \varepsilon p i$ rcuvéou, fiue de cicuta ea vera effe, vt Macrobius hallucinatus fit róvov, ideft cicutam aconit um effe putans. Eft apud eundem Pluta! chum in lib. $\pi \varepsilon p$ i

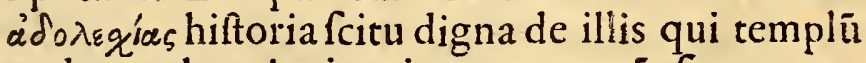
depeculaturi prius cicutam potarāt fecumq. lagoe nam vino plenam artulerant,

$v t$ fi capti fuiffent ueneno interirent, fin minus ui

ni poru fefe a ue nenolibe-

rarent. 


\section{I B E R}

Macrobü error ob imperitian medicinae: quod potus ad pulmo_ nempertingat non lunum $\mathrm{Platonem} \mathrm{dixiffe} \mathrm{:} \mathrm{Plutarchi}$ locus ex Macrobio emendatus. Cap. 5 .

1. Acrobius qui totum faturnalium fuorum feptiM num librum ex Sympoliacis Plutarchi verbote If $x$ nus furatus, illius uunquamımentionem fecit, 1 a nobis interdum damnabitur, ingratitudinis fuae debi tas luere poenas aequi iudices clamabant; quemadmodum hoc loco vbi Plutarchi, quem latinum eius nomine occultato faciebat, veftigia defercre \& medicorum harenas ingredi non veritus, calumnijs locum fatis amplum parauit: Dum enim eius lib. cap. 4. quattuor vir tutes, quas medici naturae in perficiendis nutrimentis fubminiftrare fciunt, exprimere conatur, quafi in primolimine maximo errori impegit, fi quidem nullus eft vel in medicinae auctorum lectione minimũ verfatus, qui ignoret eas facultates appellari $\varepsilon \lambda x \tau i x l s i$ fiue attra-

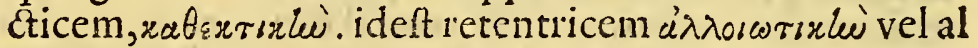
teratricem, \& a'тоxpsтьxlej five expultricem: quam uero

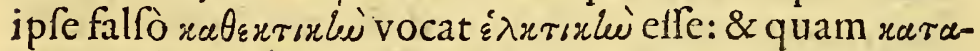

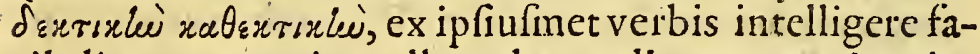
cile licet : neq. etiam vllus adeo rudis grammaticus in-

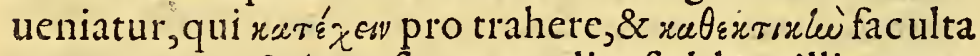
tem pro attractrice vfurpare velit: fed hoc illius proprium crratum fit; Aliud autem cum multis fibi commune, \& forfan cum Plutarcho \& Galeno, qui Platoni adfripferüt, tamquam primus $\&$ folus potum per afperam arteriam ad pulmones defcendere fenferit, cum an te ipfum fucrint celebres medici idem fentientes; aduer fus quos Hippocrates fiue Polybus in 2. de morbis difputauit, \& quos potiufquam Platonem ab Ariftotele in libris de animalibus damnari crediderim: Hifce adij ciam aliquas quoq. gratias Macrobio habendas effe, né 
pe qui plures in Plutarchi problematibus lacunas ex plendi, \& errores corrigendi foriptis fuis poteftatem faciat; ficuti ex loco citato hos verfus Eupolidis apud Plu tarchum corruptos reftitucre poterit quiuis.

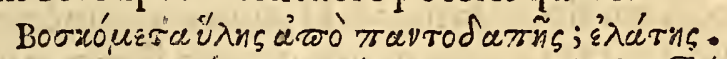

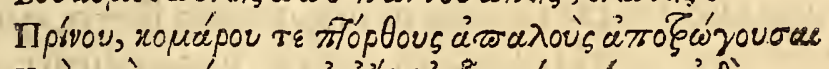

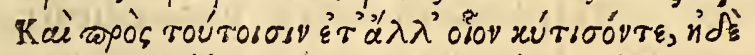

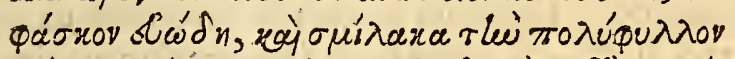
Kót

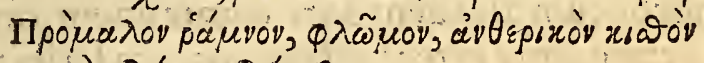

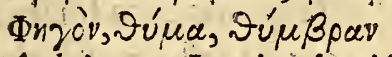

Quos fi Adrianus Iunius legiffet noo traduxiffet, $\varphi a ́ \sigma x o$ D ob $\delta$, $n$, leguinina odora, fed aut alio quodam modo legiffer, aut фuनxò intellexiffet faltem apud Hefichium, $f$.

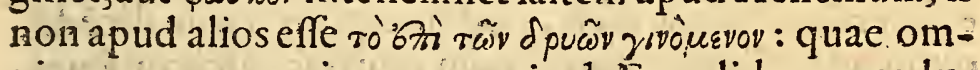
nia vna cum ceteris en umeratis ab Eupolide capras lubentius, quàm legumina pafci nunquam negarent $\mathrm{pa}-$ ftores; quamquam illius poetae fententiam nequaquá opinione èrum fauerc putem, qui multiplices cibos $f a$ cilius concoqui fimplicibus afferunt; propterea quod ex Eupolide non conuincitur capras frmul tor eduliorum genera mäducare; fed quod, cum maior pars aliarum pecudum duobus, tribusve tantum cibis vtantur, ipfae vno vel altero deficiente adhuc multas habét, qui bus vefci queant, plantas, vel herbas.

Lacretï locus de peste Hippocrati collatus es eius defenfio. Cap. 6.

Vlti fuere ex veteribus, qui pentis rationem ex-
plicare, \& polteris tradere tentarunt, fed vnum 14. plicare, \& pofteris tradere tentarunt, fed vnum fe inter medicos conftat, non modo in ijs quos Epidemi cos infcripfit libris, verum etiam alibi, \& praefertim in 


\section{I B E R}

illo vbi volumine vbi œéi $\varphi$ ow̃ fiue de fpiritibus difer tiffime tractat; quod cum ab Erotiano, Galeno, Grego rio Nazianzeno, S tobaeo, \& ab alijs fide dignis fcripto ribus vt Hippocraticum citetur, quin magnae apud me dicos exiftimationis tamquã Hippocratis doctrina plenum effe debeat neminem negaturum fpero, quemadmodum etiam latiffime in noftris, quas edituri aliquan do fumus fuper Hippocratem adnotationibus, probabi tur: Itaq. in lib. de fpiritibus fapientiffmus fenex omnium morborum aliquem dari communem originem

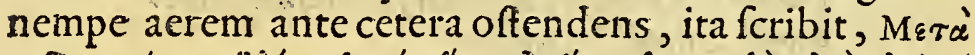

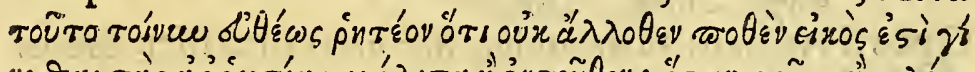

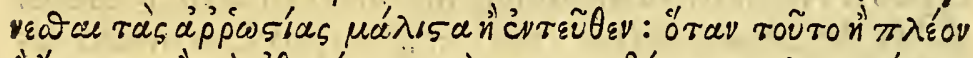

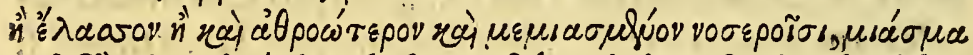

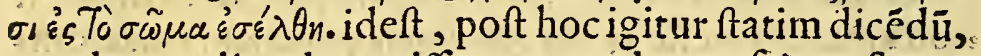
quod non aliunde potiffimum morbos nafci confentaneum eft, quam hinc, quando. f. hic (de aere loquebatur fiue (piritu) vel copiofior, uel paucior, uel cumulatior atq. morbofis in quinamentis infectus corpus ingrediatur. Ex quibus liquet eum fenfife, quod licet aliunde quoq. morbos nafci côtingat, nihilominus tủc maxime contingunt, quando aer morbofis contagijs af: fectus corpus intrat: Paullo poft febres in duogenera partiens, alterum commune omnibus peftem vocat; alterum ijs, qui mala uiuendi confiretudine vtuntur, $\mathrm{ob}$ vifum proprium facit; vtrumq. tamen $\mathrm{ab}$ aere ortum capere fcribit de primo fiue de pefte hunc in modum lo

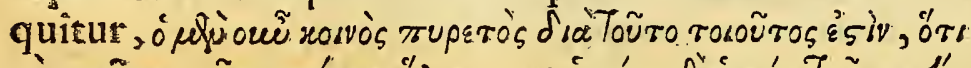

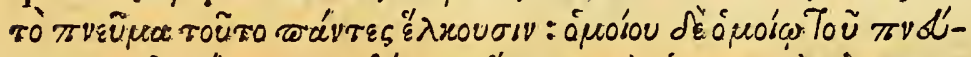

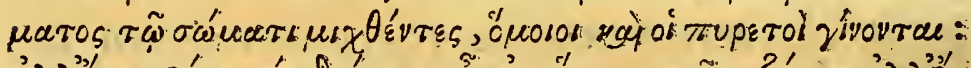

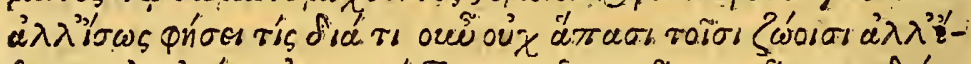

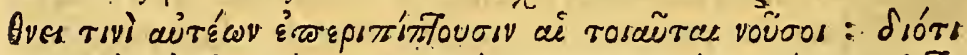

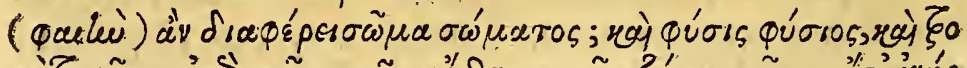

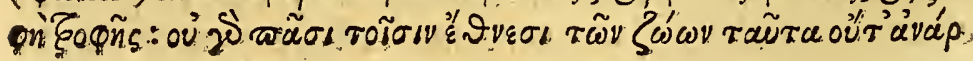




\section{$T E R T$ T}

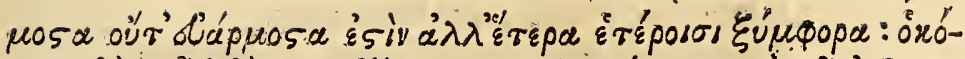

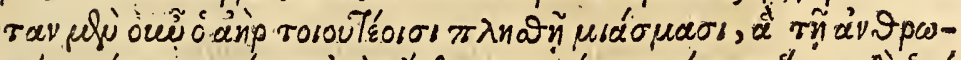

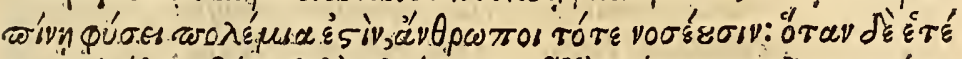

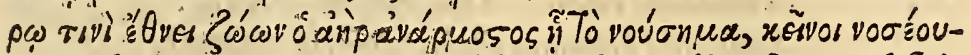
ow. ideft communis itaq. febris ideo talis eft, quod fpiritum huiufcemodi omnes attrahant. fimili vero fpiritu fimiliter corpori commixto fimiles quoq. morbi efficiuntur: At fortaffe dicet quifpiam, cur igitur non cun Ctisanimalibus, fed alicui ipforum generi contingunt tales morbi? cauffa eft (inquam) propterea quod corpus a corpore, natura a natura, nutrimentum a nutrimento differunt:non enim omnibus animalium generi bus incongrua eadem vel congrua funt; fed alia alijs conueniunt, quando itaq. aer huiufcemodi contagijs, quae hominum aduerfantur naturae repletus fuerit: tunc hómines aegrotăt; quando autem alicui alteriani malium generi aer incongruus extiterit, illa fimiliter aegrotant. Quam lententiam Lucretius in 6. de natura adeo eloquenter ac oppofite expreffit, ut non aliüde, quam ex hoc Hippocratis libro ea omnia excerpliffe, \& quae breuiter hic docentur, ibi fufius \& luculentius de claraffe uideatur. Verfus ipfiushife fubijcere placuit.

Nunc ratio quase fit morbis, aut undc repente

Mortiferam pofsit cladem conflare coasta

Morbida vis hominum generi, peciudumq. cateruis :

Expediam; primum multarum femina rerum

Effe fupra docui, quae fint Vitalia nobis

Et contra quae fint morbo, mortique neceffe est

Multa volare, ea cumcafiu funt forte coorta,

Et perturbarunt coelum; fit morbidus aer, Atq.ea vis omnis morborum, peftilitasque Aut extrinfecus, Vt nubes, nebulaeque fuperne Per coelum veniunt; aut ip Ja faepecoorta De terrafurgunt, Vbiputorembumidanalta est 


\section{I 8 \&}

Itempestinis pinuijsq. \& Solibus ifta. - Tonne vides etiam coeli nouitate, \& aquarun Tentari procul a patria quicunque domoq́ue Adueniunt ? ideo quia longe dijcrepitat res. Nam quid Britannis coelum differre putamus, Et quod in Aegyptoest, qua mundili clandicat axis;

Quid ve quod in Ponto eft differre a Gadibus, atq. $\checkmark$ Vque ad nigravirum, percoctaque faecla calore? Quae cum quattuor interfe dinerfa videmus Quattuor a ventis, \& coeli partibus effe, Tum calor, \& facies bominum diftare videntur Largiter, \& morbi generatim faecla tenere. Eft elephas morbus, qui propterflumina $\mathrm{N}^{\mathrm{i}} \mathrm{li}$ Gignitur Aegypto in Media, neque praeterea Pfquam. $\mathcal{A}$ ctbide ientantur greffus, oculique in $\mathcal{A c b a e}$ is Finibus; inde alijs alius locus est inimicus Partibus, ac membris, Varius concinnat id aer. Proinde vbife coelum quod nobis forte alienum Commonet, atque aer inimicus ferpere coepit; $V t$ nebulaac nubes paullatim repit, $\mathcal{G}$ omne Quagraditur, conturbat, of immutare coactat ; Fit quoque vt in nostrum cum venit denique coelum, Corrumpat, reddatque fui fimile, atque alienum. Haec igitur rubito clades nona, pestilitasque Aut in aquas cadit, aut in fruges perfidit in ipsas, Aut alios hominum paftus, pecudumque cibatus, Aut etram fun $\beta$ enfa manet vis aere in ipfo: Et cum pirantes mixtas binc dicimus auras : Illa quoque in corpus pariter forbere neceffe est. Confimilitratione venit bubus quoque Saepe Pestilitas, etiam pecubus balantibus aegror . Necrefert vtrum nos in loca deueniamus Nobis aduerfa, \& coeli mutemus amiztum: An coelum nobis vltro natura corruptum Deferat, aut aliquid quod non confueuimus rti ; Quod nos aduentu poofsit tentare recerti , 


\section{T E R T I V V s.}

Si igitur quis attento animo Lucretiana Hippocraticis conferat, fane cognofcet latinum fcriptorem non modo fententiam atq principia a Graeco accepiffe, immo \& facpc verba uerbis alterius correfpódere perfpicuo animaduerter: quod ego magis miror, quoniam cum Epicurus, \& Democritus cuius difcipulus fuit Hippocrates, eandem opinionem tenuerint, facile dici poflet Lucretium potius illos, quam Hippocratem fecutum effe: Vt uero cumq. frt manifefte paret peftis originem apud illos omnes pene candem haberi, atq. in hoc duntaxat varietatem aliquam apparere, quod Democritus ato-

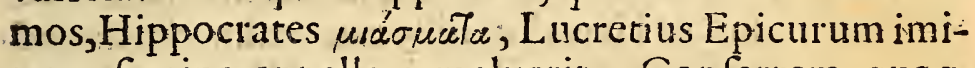
tatus femina appellare maluerit : Conferrem quoq. Thucydidis de Athenienfium pefte narrationé Lucre tianae, quando praefertim Galenus faepenumero Thu cydidis mentionem facit; fed quia id a multis eleganter factú inuenio, quos Fuluius Vrfinus fingularis probitatis, \& eruditionis vir in fua Virgilij collatione non parum anteceffit, libentiffime abttinebo; itaq. illud vn ũ admonebo nonnullos inique profe to agere, qui Lucre tio vertunt uitio, quod interdum a Thucydidis oratio. ne ac mente deflestat; quandoquidem non ipfe Thucydidis ucrba ad unguem exprimere inftituerat; fed tătum modo hiftoriam latinis carminibus complecti; quả ut feliciffime affecutus eft, ita magnam laudem meretur, ubi praeter fentétias uerba quoq. Graeca(id enim faepiffime facit) latino (ermone reddit.

Hippocratis of Herodoti loca de morbo Scytharum foemineo collata de amaronibus. Cap. 7 .

- Erodotus in Thalia auctor eft Scythas praelio

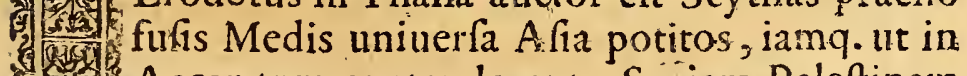
Aegyptum contenderent, Syriam Paletinam ingreffos 


\section{I B E R}

ingreflos Apfammiticho rege precibus \& muneribus fuiffe perfuafos, vt ca regione intacta relista in loca fua renerterentur, cumq. in Afcalonem Paleftinae vrbem perueniffent, multipor form uetufiffimum V raniac Ve neris templum depecularunt; ob quod facinus Dea illa templi fpoliatoribus, corumq. pofteris omnibus morbo rum fensineum immifit; quo quicunq. laborabanta reliquis Scythis évápers fiue évápres hoc eft euirati uocaban tur: Ceterū qui nam fucrit is morbus cũ Herodotus nô docuerit, Hippocratem qui \& morbum, \& originem ue ram, ciufq. nominis rationem explanat, in medium ad. ducemus, cum ut Herodoti hiftoriae maior claritas addatur, tū maxime ut per Herodotum Hippocratis verba ac fententias facilius intelligamus: fic ergo in lib. de

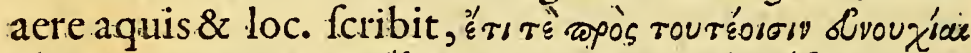

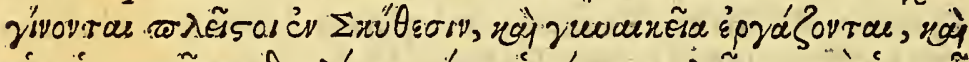

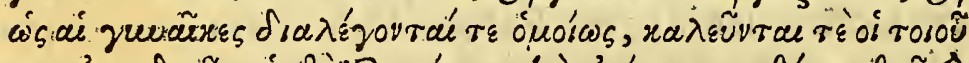

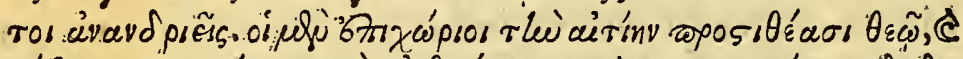

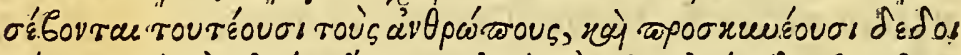

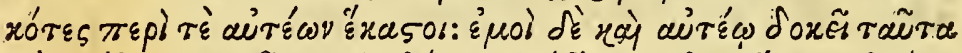

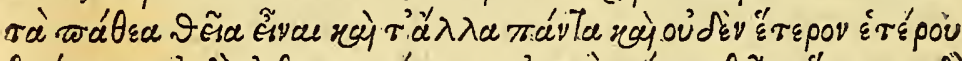

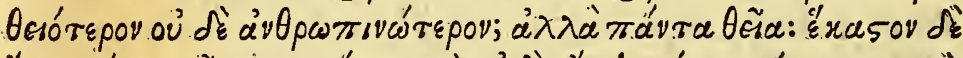

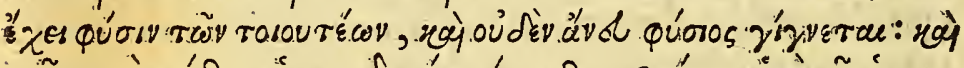

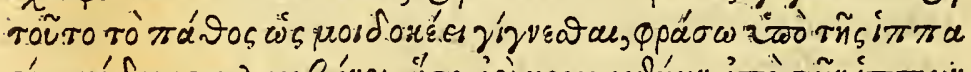

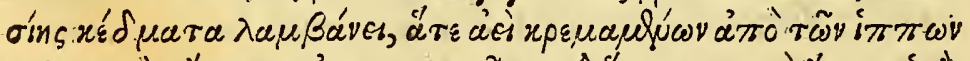

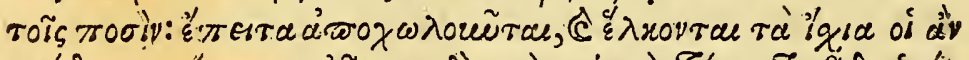

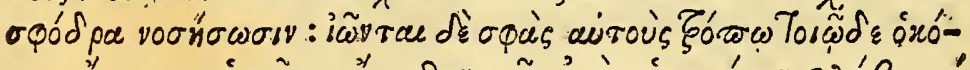

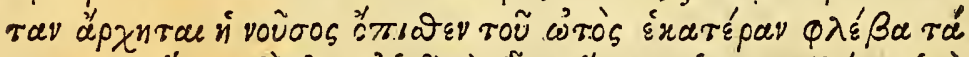

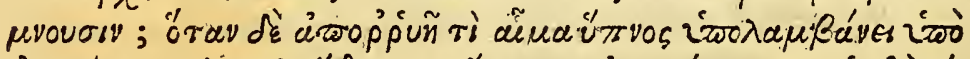

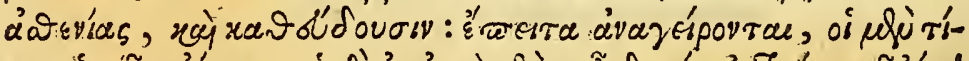

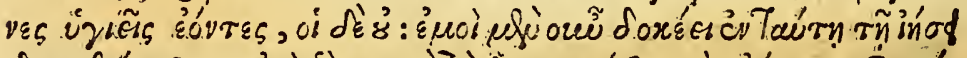

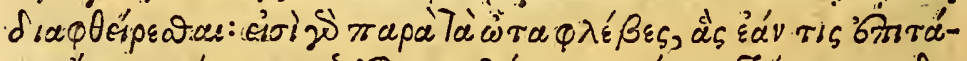

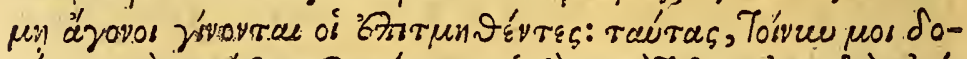

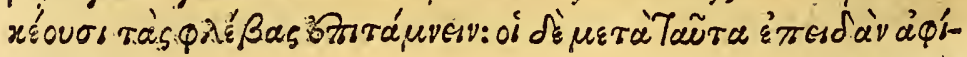




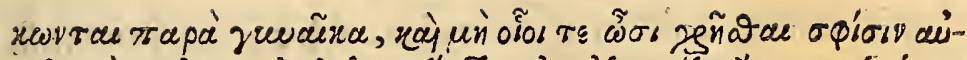

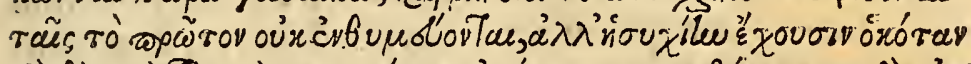

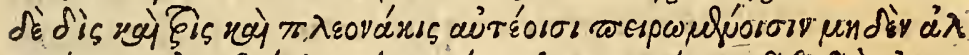

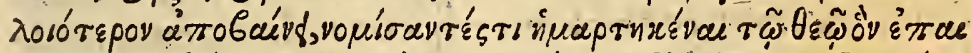

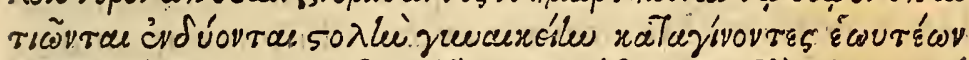

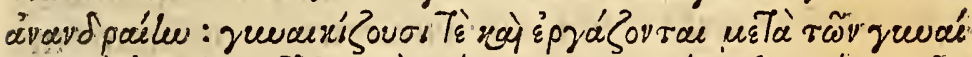

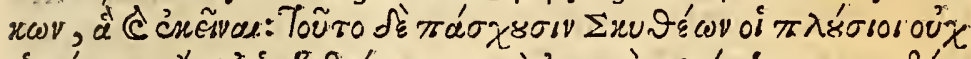

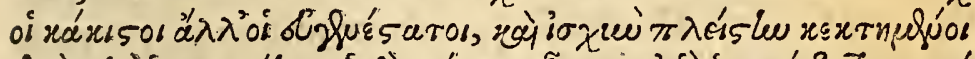

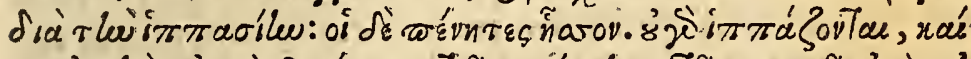

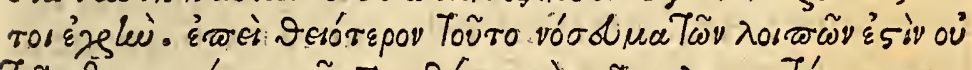

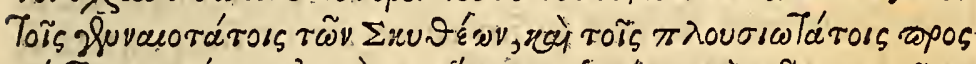

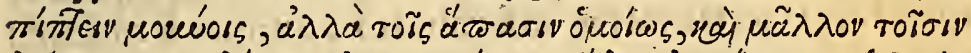

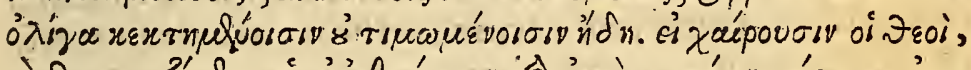

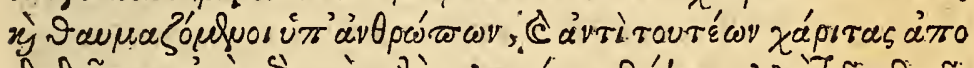

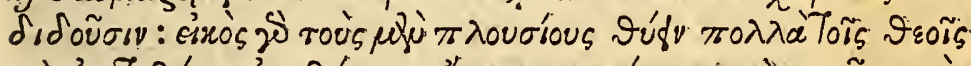

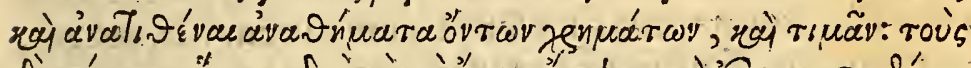

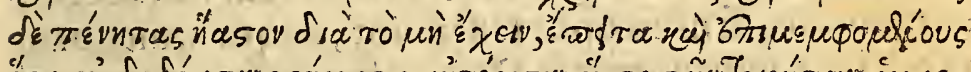

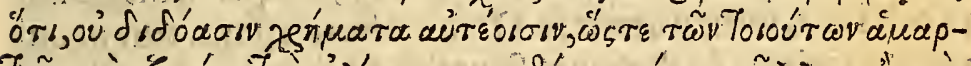

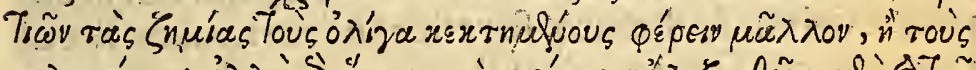

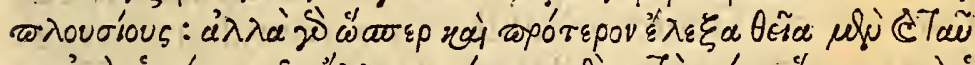

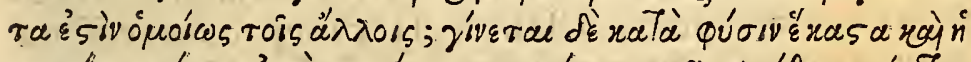

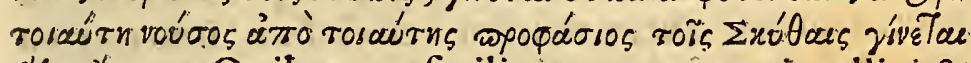
ollew épnra. Quibus, vt facilius a quocunq. intelligi \& conferri queant, ctiam latina adiungam: Amplìus autẽ plurimi Scythae Eunuchi fiüt, \& mulicbria officia obeunt, inftarq. foeminarum omnia faciunt, \& loquũtur, vocanturq. hi effoeminati. Et regionis quidem incolae caufam ad Deum referunt, coluntq. hos ipfos homines $\&$ adorant fibiipfis timentes, ne quid tale accidat. Mihi vero hi affectus diuini quidem effe uidentur, ficut \& reliqui omnes; neq. ullum aliquem alio efle diuino rem aut humaniorem, fed diuinos omnes : verũ unusquifq. corum fuam propriam habet naturam, neq. aliquis citra naturam accidit: $Q$ ua re quomodo hic affectus contingät 


\section{I B $\mathrm{B}$}

tingāt ut mihi uideretur, narrabo. Ab equitatione ipfa diuturni eos corripiunt articulorum dolores, nimirum propendentibus femper ex equis eorum cruribus; dein de claudi funt, contrahuntur r. coxeridices; cum inualuerit morbus; Medicantur autém fibiipfis hoc modo, a principio morbi veranq. uenam retro aures incidunt, quo facto fanguine multo promanante fomnus eos cor ripit prae imbecillitate, ficque obdormifcunt; quorum quidem aliqui depulfo fomno fani exurgunt; aliqui vero minime: Atq. mihi fane videntur ea medicationefe ipfos perdere: Venae enim retro aurcs funt, quas fi quis fecet ferilitatem inferant his; quibus fecantur; quarc id etiam ipfis ex earum incifione aćcidere certũ eft: Quando igitur poftea vxores adeunt, impotétesq. fe factos vident cum illis coire, primum quidem nihil moleftius cogitantes quiefcunt, cum autem bis, aut ter, aut amplius fruftra opus tentarunt, neque quicquam proficiunt, mox putant fe Dcum offendiffe; in quem cul pam reiiciunt, induuntq. fe vefte muliebri, palam fe eui ratos effe confitentes ad mulierumq. contubernia tranfeunt, earum opera traitantes. Hoc itaq. malo ditifimi Scytharum afficiütur, minime vero in fimi, imo qui ma xime \& genere \& potentia praeualent, ex nulla alia quä continuae equitationis caufa hoc perpetiuntur: pauperes uero minus quum non multum aequitent: V nde fi haec alijs diuinior cenfenda effet, non nobiliffimis neq: ditiffimis Scytharum fere folis accideret, fed effet omni bus aequaliter peculiaris, immo magis inuaderet paupe res circa cultum deorum negligentiores; fi faltem gaudent dij in hominum admiratione conftitui, \& pro hoc beneficia hominibus retribunt: Dituites enim faepius dijs facra faciunt, victimas offerunt, ftatuas erigunt coluntq. quum pecunijs abundent : pauperes autem minus id faciunt, quutn non hrobeant; quinetiamaliquan 
do deos deteftantur, qui eis opes non fuppeditent; ut verifimilius effet pauperes, ac parum abundantes hoc malo propter crimina fua puniri, quàm diuites, \& qui opibus abundant: Verum ( ficut $\&$ prius dixi) diuinus quidem hic affectus eft, fecundum q. naturam accidit, fi militer vt alij omnes; neq. alia eius caufa, quàm ea quā dixi Scythis exiftit. Hactenus Hippocrates a quo facile vnusquifq. comprehendere poteft Scytharum morbü ab Herodoto nominatum eundem effe; quem ipfe refert,\& quãdo hic eos ávad psếs vocat, vel ćvápsş, ut apud Herodotum, corrigi debet; vel vtramq. dictionem ide fignificare putandum, nimirum euiratos feu effeminatos: ficuti quoq. Scytharum vates, vtpote caftratos appellatos effe in Melpomene meminit : Quae vero Hippocrates de morborũ omnium diuinitate differit, quaeve de pauperum, $\&$ nobilium moribus, vnde Ariftoteles multa in 2. Reth. fcripta accepiffe potuit ; ita interpretari debent, tamquã a viro potius philofopho, quàm vllo verae religionis lumine praedito proficifantur. Id non eft abfq. animaduerfione praetereundum Ama zonum genus, quod ab aliquibus fabulofum reputatü eft ab Hippocrate ante verba citata apertiffime confirmatum effe; ficut etiam confirmauit 3 . de artic . textu 85. quamquam ibi neget eas côfueuiffe infantibus mafculis articulosluxare, vt claudi imbecilliores fierent: Has etenim mulieres multis faeculis perduraffe probaret aliquis, quod Eradius in vita Pemenis abbatis narrat. Amazonas foeminarum crudele genus viucnte eo abbate in Scitiam defcendiffe, multofq. patres fanctos intercmiffe, quod pluribus annis poft natum Chrifum contigit. Haec tamen hiftoria haud parum vero diffimi lis videtur, quoniā regio in qua Amazones regno funt potitae, plus diftabat ab Aegypto', quam vt potuerint in ipfius regionem uenire; praeterquam quod nullus $\mathrm{X}$ auctor 


\section{I E R}

austor fide dignis A mazonum imperium tanto tempore perduraffe tradidit; quod tamen aliquem fcripfiffe, fi verum fuiffet, rationi confentaneum effet.

Iecur anferinum in precio fuiffe antiquitus : de carne fuilla locus Plutarchi. Caupones Italos folum immerito damnari a Plutarcho. Cap: 8.

Ecur anferis apud Romanos in menfis fuiffe ce6 lebre probatum eft ab Athenaeo dipnos 9. vbi f etiam anferes ipfos faginari folitủ habetur, quod potiffimum gratia iecoris factum puto, nempe quod fagina maxime omnium crefcit, ideoq. Martialis hoc fignificans ait.

Aspice quam tumeat magno iecur ansere maius,

Miratus dices, boc rogo creuit 2 bi?

Quamobrē nullus mirari debet fi pariter fuillă carné, qui fummopere cómendét ipfiufq. folá cócoctionis dif ficultaté damnét, inueniātur multi; ex quorũ numero diuinus Galenus eiufq. fequatiú maior par's extitiffe vi detur: Ante hunc, qui vfq. adeo extulerint huiufmodi cibü, ra ros obferuaui, immo quã plures rationes recēfe 1.e poffumus, quibus antiquitus ficut, \& hifce téporibus fuem in cibü affumere relligio erat; quod plerunque ob fanitate factitafie, potiufquã ob fuperftitionem credo: \&ne fententia, fine fautorealiquo proferatur, Plutarchum adducã, qui in 4. fympof prob. 5 . rationé reddés cur Indaei camibus fuillis abftinerent fic loquitur Tó $\delta$

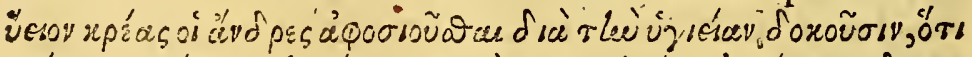

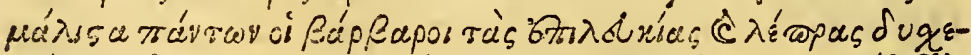

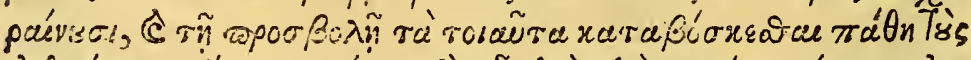

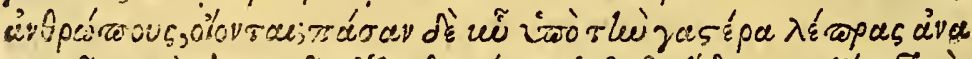
$\pi \lambda \varepsilon \tilde{\omega}$, ,

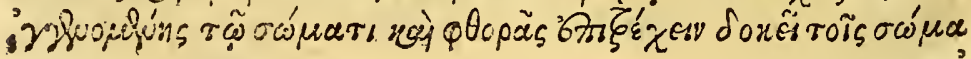




\section{$T=R T$ T}

82

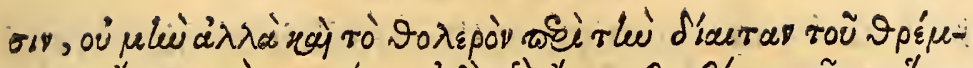

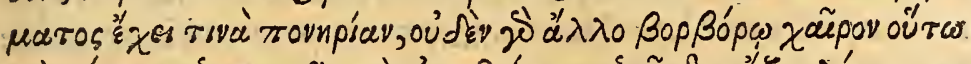

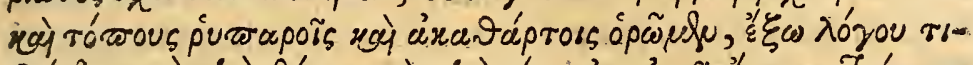

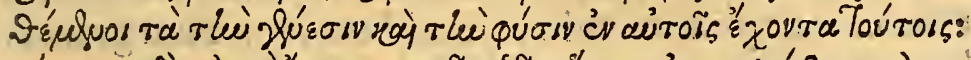

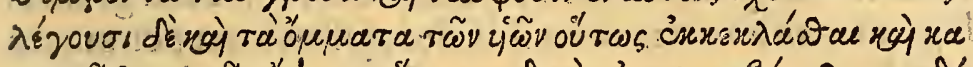

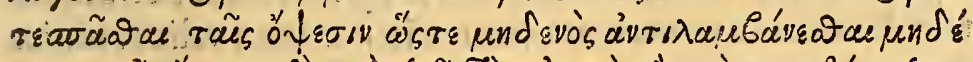
कo

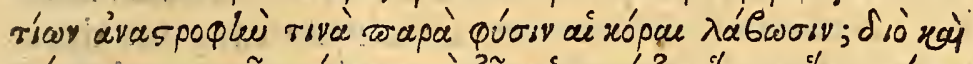

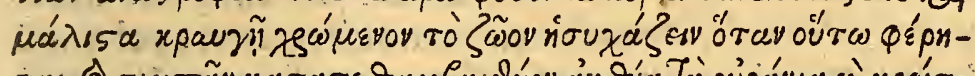

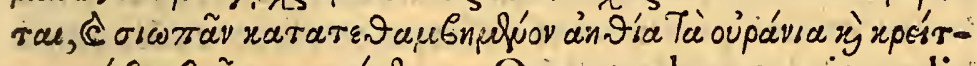

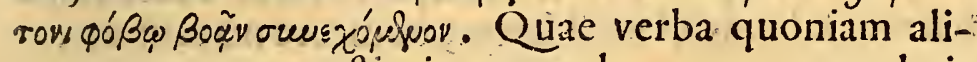
qua ex parte nos refticuimus, necdum a quoquam latine interpretata vidimus, vt a nemine defiderentur, etiä lingua noftra ponam : Carnem porro fuillam ob fanitatem quoq. reuereri ifti homines videntur, propterea quod barbari maxime omnium gentium uitiligine, ac lcpra laborant; huiufq carnis efu a talibus morbis homines confumi arbitrantur: omnem vero fuem fub vêtre lepra,ac efflorefcentijs refertam fere femper intueamur; quae nimirum ob malum quédam habitum, atq. corruptionem corpori ingenitam in corporibus fummis efflorefcere videntur : Verum enimuero huiufmet. beftiae circa victum fordities prauitate non caret; quădoquidem nullum aliud animal aeque fimo, aclutulen tis, immundifq. locis gaudere cernimus, exceptis ijs, quae generationem in his ipfis. naturamq. fimile poffi deat; ferunt etiam oculos porcorum vfq. adco inter vi dendum hebetari, atq. contrahi, ve nec ullam rem fuperiorem apprehendere, neq. coelum afpicere valeant, nifi ipfis refupine collocatis pupillae conuerfioné acquirant; $\&$ proinde animal illud, dum uehementer ftridet, tüc pracfertim fi ita feratur, quiefcere, ac tacere, $\tilde{q} \mathrm{f}$ infuetudine coelcftia uidés ftupeat, \& maiore metu, a clamåno detereatur. Sed qm Plutarchi meminimus,

$$
\mathrm{X} 2 \text { non tacebo }
$$




\section{I B E R}

non tacebo me fummopere illius iudicium mirari, qui 2. fympof. probl.ro.Italos cauponas pratitatis, ac mole ftiae incufat, quafi graeci non effent alijs deteriores, ctiã Platonis aequiffimi iúdicis fententia, qui dum graccis legé de cauponaria in I r.lib.de legibus ferret enumera tıs pluribus cauponú maximis vitijs eos ex viliori ciuita tis gente tamquam prauos omnino futuros creari mandat; At fortaffe Plutarchus ab aliquo caupone deceptus, quòd vel vinum falcrnum adulteratum, vel nouü aut recentatū pro uetere ( vt faepe cos facere côfueuiffe narrat Galenus)ei uêdiderint, ea dicere nō erubuit .

De Meliloto Cratinus expofitus : De coronis: delemnifcis. Cap. 9.

5aefitum eft apud Athenaeum in 15.dipnos: qua de cauffa Cratinus melilotum herbam $\alpha$ es Qpoupòv femper cuftodem vocarit : cui quaeftioni cum eo in loco nihil refponfum habeatur, ne lectorum animi continuo fufpenfi maneant, fciri velim inter her bas coronaric $s$ apud veteres melilotũ primas fere femper tenuiffe, ac ob id a latinis modo fertulam, modo cãpanicam fertã vocatam effe: cur vero id effet, puto quoniam coronis ad fedandum ebrietatis feruorem inftitu tis melilotum miram operam praeftabat,quando nimi-

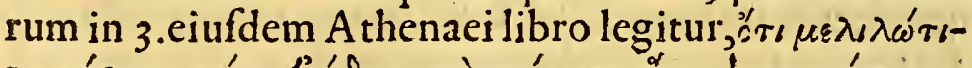

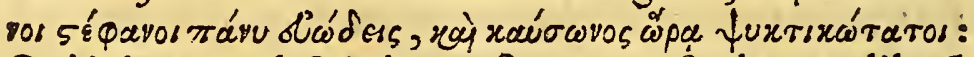
Qui igitur apud Cratinum femper cuftodem melilotủ dixit, nil aliud (mea quidem fententia)fignificare nobis uoluit, quã quod eius herbae poteftate femper ab ebrie tate cuftodiretur. Coronas autem laneas antiquiffimis temporibus, ut ait Feftus, effe fastitatas nemo mirari de bet, propterea quod fi Plutarchi, A thenaeiq. de corona rum origine fcripta attente confideremus, Veteres po- 


\section{TERTIVS. B}

tui magnopere dediti faepenumero ex ebrietate maxi mis capitis doloribus follicitabantur; nec vilum magis praefentaneum remedium experiebantur, quan vtarctis vinculis tempora ligarent:ligamina vero illa primo ex rudi \& uili materia fuiffe conficta verifimile eft, vtpo te lino lanave, non tin£ta coloria à Fefto appellata, quarum vtilitas quotidie maior apparens homines tâdem excitauit, vt (quemadmodum in rebus luxus fuccrefcere folet ) primo vtilitaté illá ornamentis quibufdá para rent, vnde coronas inuenerunt; deinde ut commoditati iucunditatem etiam annexam uellent:quo tempore $1 a$ neis, lineifq.inuolucris dimiffis coronas ex hedera, myr to, rofis, meliloto, alijfq. fragrantibus herbis texcre aggreffi funt, quae \& odore, coloreq. fenfus oblectarent, ac fimul ui refrigeratoria incendium uini \& ciborum leua rent; quod remedij genus excogitaffe medicosvalde rationi confonat, ac A thenaeus atteftatur. Nam (ut fcribit Plinius lib. 21.) apud graccos de coronis priuatim fcripfere Mneftheus, atq. Callimachus medici quae nocerent capiti, quoniam \& in hoc eft aliqua ualetudinis portio in potu atq. hilaritate praefertim. Nec his homi num vafta cupiditas delitijs fatiata eft; immo referéte Plinio, ex auro, atq. argento folia coronarū tegere, eafq. vnguentis pretiofis perfundere, \& capiti collove circúponerc coeperunt; quafi parum effet odoribus florum anatura elargitıs perfrui, nifi \& illam vincere, aut falté dehoneftare tentaffent. Habuerunt coronae fafciolas quafdam intortas dependentes, vt illis poffent fubligari ne capite laberentur, vel potius vt aliquid ornamenti

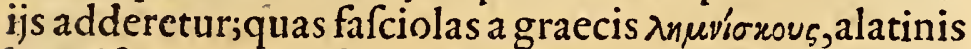
leinnifcos vocatos fcio: quamquam apud Plinium lib. 2 I. cap. 3. non lemnifci, fed lemnici falfo legantur. $\mathrm{Hi}$ vero ex varijs rebus fiebant, fed celebres erant ex tenu-. iffmis philyris earum tunicarum, quae inter corticem, 


\section{I B i 2}

\& lignum tiliae inueniuntur. Ad illarum porro fimilitudinem Celfus, Aetius, Daulus, alijq. medici lemnifco. rú nomen indiderunt inuolucris quibufdá lineis loogis retortis, quibus in dilatādis uulnerū, nec nó amplificãdis aliquorũ locorũ anguftis oris utebātur: At lemnifcos anguftas uittas uocaffe Syracufios auctor eft Hefichius.

Plinij \& Galeniloca de doloribus : Pro oculis vstio venarum temporalium: Lotio pedum: Origanus: fordes aurium
in morientibus quales.
Cap. 10.

Linius lib. 25.cap.3. memoriae mãdauit. Auos Ferimento iudicaffe afperrimos omnium cru ciatus effe calculorum a ftillicidio ueficae; Proximum ftomachi ob quem epoto gypfo C. Proculeium A ugufti Caefaris familiaré fe fe cnecaffe prodit lib.36. cap. 24. tertium eorum quae in capite deleant, non ob alios fere morte confcita : At ex aduerfo Galenus in 2. de comp. med.s.l. fcribit neminem ob capitis doloré uehementé unquam animi deliquio comprehenfum in terijffe; neq. feipfum occidiffe, quemad modum quidã coli dolore vexati fecerunt: Quinimmo vtcumq. quis capite doleat, femper eius minorem dolorem effe, quá eorum, qui coli, aut auris, aut dentis, aut oculi vexätur dolore: Inter alia vero quae antiqui habuerunt pro ve tere capitis dolore tollédo remedia, vnū erat temporũ venas inurere ab Hippocrate in lib. de loc. hom.fummo pere cōmendatũ : quo fimiliter ufos ad compefcendas oculorum fluxiones feriptum reliquit A rift. 3 I.probl.

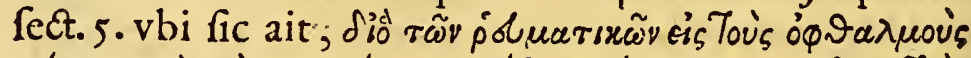

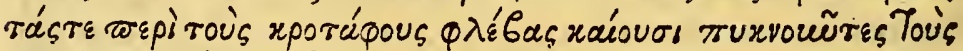

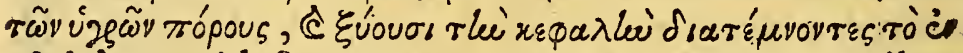

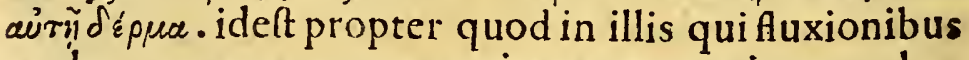
oculorum tentantur uenas circa tempora inurunt humorum 


\section{$T$ T $T$ I $\mathbf{v}$.}

morum dustus occludentes, caputq. obfcalpunt cius cutem incidentes. Quitamen hanc medicationis ratio nem damnarent, pofterioribus temporibus non defuerunt, quemadmodũ Aetius qui folos barbarislegibus feruientes hoc factitaffe memorans non medicationem ipfam, fed imprudétem potius eam adhibendi modum improbaffe videtur: Cur autem in lib.5.\& 7 . Epid. notatum habeatur pedes aqua vel igne maxime calefacere oculis noxium effe, certe videre nequeo, nifi maximam calefactionem vapores plures, quam par fit, ad caput mittere dicamus, \& propterea eos libros qui non approbarunt; aliqua ratione id effecerunt: At quod ibi dem fcribitur Origani potum oculis obeffe non vfque quaq. a veritate abhorret; quảdo A riftoteles 3 I. prob, fect. prob. 9: origanum oculis iccirco nocumentu.rn afferre innuit, quoniam tantummodo deficando cutem indurat, neq. lachrymarū ciet. Et ne aures penitus filen tio praetermittantur de illis hoc in loco adnotare placet, quod ex fententia Ariftotelis friptú rcliquit Apol lonius in hift. mir. videlicet fordes, quae in auribus nafcuntur, cū fint alioquin amarae, fieri dulces morituris, idq. in multis effe obferuatũ; cuius euentus cauffam ab ipfo in quaeft. nat. explicatam tradit, qui liber cum ho die defideretur, Iccirco putamus nos eam ibi rationem allatam, quod morituris calor natiuus extinguitur, vnde humores in capite dilutiores ac frigidiores multiplicantur; ut etiam ex lachrymis conftat, ac deftillationibus, quae tunc temporis maiores fiunt: illi igitui humo res fordibus aurium permixti dulcefcere faciunt, perinde ac lupinos aqua potabilis: nifi potius dicamus biliofos ichoras ut pote calidos, qui fordibus commixti ama rorem inducebant, morientibus una cum calore expirare, \& propterca quod relinquitur pituitae dulcius ui deri. 


\section{LI:I}

De carbonibus loca Galeni, Cafsü, Lucretï, 6 Theophrasti : Delumbricis locus Plinï ex Theophrafto correctus: Error Gazae. Cap. 11.

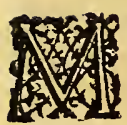

Vltos ex halitu Syrorum, fpeluncarum, ex cubilibus recenter oblitis, atq. etiā a carbonibus, tum antiquis tum noftris temporibus interijffe nemo fanus inficias ibit; quorum euentuum cauffam te nuitati fpirituum attribuens Erafiftratus iure a Galeno refellitur 7 . de vfu partiü, necnon lib. de vtil. refpir. fed neq. ipfe omnibus placere potuit, dum ea omnia \& praefertim carbonum effectus in occultas $\&$ nobis inimicas qualitates retulit; Caffium itaq. medicum ( vt vocat Celfus) ingeniofiffimum Thyberij aetate Romae aeftimatum magis laudare debemus, qui in probl. fuis carbones capitis dolorem parere non arcana ratione, fed nimio calore caput exiccăte condenfanteve fcripfit; effe naing. maiore uim in exufto carbone iterumq. $\mathrm{Ha-}$ grante Plinius quoq. lib. 33.cap.5 - affirmauit: Cur autem Caffius ad euitandam carbonum noxam eos vino pauco extingui praecipiat, eam rationé afferrem quod uinum maxime penetrans carbones non folum prauis vaporibus priuat, qui fi fuffocationc extinguantur, in ipfis retinentur; verum etiam eos, rariores ac tenuiores efficit, vt cum iterum accédantur, puriorem ac blandio rem calorem emittant; Huic rationiid non parum fauet, quod Theophrafto in libro de igne fcriptũ eft, igné fcilicet citius ab aceto, \& vino quàm ab aqua lextingui, quoniam intimius penetrans, porofq. latior es reddens, fomites vbi ignis conferuatur, melius tollit. An vero quicquam ad hunc Caffij locum faciant Lucretianiilli yerfus in 6. fic ab Oberto Gifanio reftituti.

Carbonumq. grauis vis, atq. odor infinuatur

Quam facile in cerebrum, nifi aquam praecepimus ante 


\section{$T$ B I I v .}

Aut nif membra prius pertexit frigida feruus

Aut fit odos vini plagaemanabilis mora? alüs cogitädü $\beta p o n$

Nunc poftquã Thcophrafti mentio inçidit, aliquid ex ipfo memoria dignum interferere libet, id fcilicet quod in fine ex lib. de hift. plant. notatum inuenitur ${ }_{\varepsilon}^{\prime \prime} \lambda \mu \nu \nu \theta_{\alpha}$ lumbricorum genus nonnullis nationibus connafci, ex aduerfo alias ipfis omnino carere: Habere quidem Aegyptios, Arabas, Armenios, trans Mediam, (ficenim

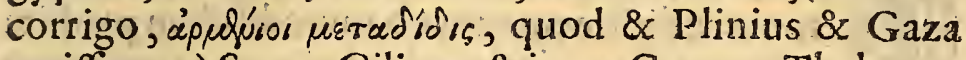
omifferunt) Syros, Cilices, \& inter, Graccos Thebanos in gymnafijs verfantes, ac Booetios omnes Carere auté Athenienfes, Phrygas,atq. Thracas; Vnde Plinij verba in fine 27. libri ex hoc loco fumpta fic corrigenda funt, quemadmodum in manufcripto Pauli Manutij codice leguntur. Sicut accepimus de tineis, lumbricifq. inefle Aegypti, Arabiae, Syriae, Ciliciae populis, ediuerfo Thraciae (non Graeciae, vt eft in vulgatis omnibus) Phrigiae omnino non innafci; Minus id mirum quàm quod in confinio Atticae Booetiaeq. Thebanis innafcuntur, cum abfint Athenienfibus. Hoc autem an peculiare illarum regionü donum fit, an potius ex victus diuerfitate nafcatur( vt ego magis reor) alijs difcutiendum relinquam, fi tamen hifce adiecero crrorem in eodem cap. a Gaza commiffum : Nam quod Thcophraftus de grano Gnidio loquens, ita fribit $\delta 10$ cótav $\delta / \delta \omega$

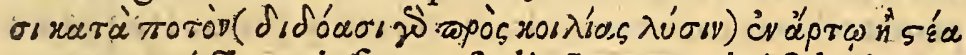

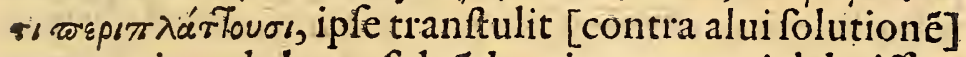
cum potius ad aluum foluédam interpretari debuiffet. Si quidem granum Gnidium apud medicos, \& pracertim apud Hippoc. nunquam non pro maximo purgato rio vfurpatum eft, fed fortafie deceptus eft Theodorus a Plinio, qui lib. 27. cap.9. fcripfir granum Gnidiumal uum fiftere, contra rationem cum fir adurens, \& contra experientiam, quamquam etiam Diofcorides eius vim 


\section{$L I B E R$}

purgatoriam magnam facit qui femen Thymelaeae gra num Gnidium effe; \& a Syris linum, vt quoq. Plinius vocarifcriptum reliquit.

Thucididis locus a Lucretio expreffus, acillustratus. Cap.. XII.

9 ram eruditionem tum ob incredibilem probita. tem omnibus admirandus in iis, quos poftremo variarum lectionum edidit libris, cogitandum proponit

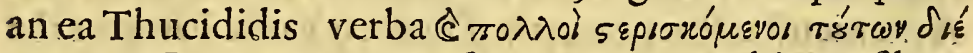
qeujov a Lucretio exaste fint interpretata his uerfibus. Et grauiter partim metuentes limina leti

Vinebant ferroprinati parte uirili

Dequa re cum iam diu ipfi fententiam meam per litteras Roma fignificaffem, humaniter fanè non nullis aliis rebus, qux in ipfis continebantur, refponfum dedit, de hac vero nullum quidem verbum fecit, ob quod ratus opinionem meam faltem ab illis imp robatam non efle, hic ponere non timebo. Homines.n.vitã membris, dum periculum confpiciút, praeponere nemo eft qui neget, porro medicisin pentiferis morbis (qui facile nifi compe fcantur, \& ferpendo fefe in vifcera propagare, $\&$ indeci to iugulari folent)ferro atq.igne, vt ftatim virus de cor pore tollant, crebro vri clarü effe cuiq. puto: Itaque ue rifmilius fir in ea fauinfma pefte a Thucidide defcripta homines ne perirent; genitalialue peftifera iam corrupta fibi amputãda ferro praebuiffe; quam permifife vt emortua fponte caderent: Rarum plane eft vt peftis aliquod membrum depafcens fponte definat nifi medicamentorum opera coerceatur; quod tanto minus in par tibus genitalibus euenire putandum eft;nimirum quae

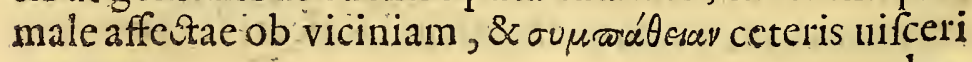
bus 
bus affectiones fuas facile impertiunt : Quando igitur Thucidides illos genitalibus priuatos cuafiffe narrat; fecundum medicos neceffarium prope eft intelligere, quod ferro illa abfcinderent; neque finerent morbum intimius penetrare, necareq. vt eueniffet fi partes a peAteinfectae, atq. corruptae, vt fponte fua deciderent expetaffent, neq. Atatim a fanis eas difiunxiffent; Ergo $L u$ cretium commendare porius debemus, qui breuitati ac obfcuritati Thucididis claritatem afferre, nec non eã pe ftem diligentius defcribere voluit. Num autem peftis haecilla fuerit, a qua Athenas Hippocratélignorum, \& herbarum odoratarú; incendiis liberaffe in ipfius vita; in Athenienfium decreto, \& apud Galenú legitur, non multú intereft fire: Attamen ipfrffimam fuiffe credere quoq. poffumus, co praefertim quod Thucididé Hippo crate iă aetate prouecto hiftoriā fuá condidiffe conftat.

Locus Virgilï fecus quam a grammaticis ex Ariftotele declar atus: Et cur ab ipfo medicina ars mut a uocatafit. Cap. XIII.

VLT I declarare conati funt cur Virgilius ma re Aquilonibus flantibus atrum fieri fcripferit eo verfu A eneid.

FluCtusq.atros Aquilone jecabat.

Quorum omnium fententias \& fi improbare non inten dam, nihilominus quid \& ego fentiam, hoc loco exponam: atq: ante alia fupponam duo prima coloris genera effe, album nempe \& nigrum, ex quibus vario modo fimul commixtis variae ac pene innumerae colorum fpecies enafcuntur : Niger color nonnumquam obfcurus, interdum tenebrofus, aliquando ater (ficut a Virgilio) nuncupatus inuenitur: atque hic quandoque ve rus, \& naturalis exiftit, quandoque folummodo talis apparet : multos enim colores apparere, \& non effe, pluribus exemplis demoftrari poffet, nifi quod:

$$
\mathrm{Y} 2 \mathrm{de} \text {. }
$$




\section{L r B R}

de columbac collo feeptici difputabant, atque in iride confpicitur, totum hoc manifeftum faceret: De vero atro colore, quoniam Virgilius, mea fententia, non loquitur, de apparente dumtaxat fermonem habebo; Quiceu in lib. de coloribus (fue fit Arift. fiue Theophrafti) fcriptum habetur hifcetribus modis apparet,

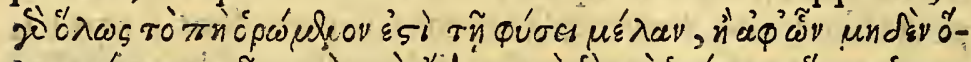

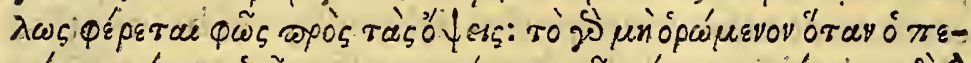

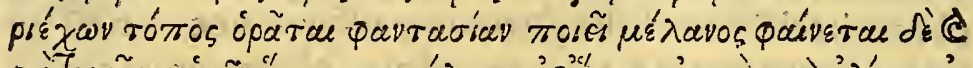

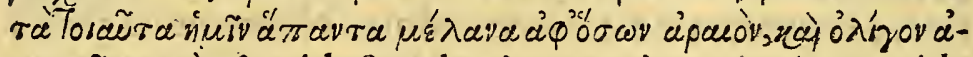

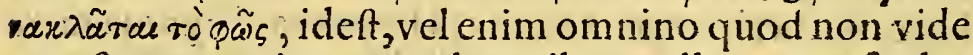
tur eft natura nigrum; vel a quibus nullum prorfus lumen fertur ad oculos; nam quod non videtur, quando ambiens locus videtur, nigri fpeciem reddit; apparent item omnia huiufmodi nigra, quibus rarum \& paucum lumen reflectitur. His itaq. tribus modis nigredine in rebus apparente proculdubio mare aquilonibus ventis agitatum vno ipforum atrum, atq. obfcurum videri neceffum eft; fed quoniam neq. primo, neq. fecundo id fieri cuivismediocriter in philofophia verfato perfpeetum eft, fequiturvt tertio modo appareat: Mare fane, \& omnis a qua cum fuapte natura alba videatur, eo quia folares radij a laeuore, ac planitie fuperficiei reflexi eã illuftrando lucidam efficiunt, a miffo laeuore, radijfq. lá guentibus fractis, atq. imminutis, iure merito albedo deperditur, contrariaq. ipfi nigredo fuccedit : Quamobrem ( $v t$ ad vergiliana verba defcendam) aquilones fuis vehementibus motibus mare perturbantes, nee nö illius planam, laeuemq. fuperficiem afperam reddétes, ita vt altera pars depreffa, altera eminens euadat, iuxta id quod Poeta 3. Aeneidos expreffit, dicens.

Et glacialis hicms aquilonibus a pperat ondas. Propter frmilem aquae inacqualitatem paucis radijs, illifq. fractis, \& imminutis incidentibus haud fuperficies 


\section{$T$ E $\mathbf{r} \mathbf{I}$. $s$.}

cies depreffae partis illuminatur,immo ab illa afperitate diullfum, \& difipatum lumen aboletur; \& propterea fuperficies aquae vimbris quodammodo plena, lumineq. prinata, nigra apparet; quam apparitione infinuaffe Virgilium apud me certum eft, ficut etiam Arif. 23 . part. prob. 23 . fieri au @toritate Homeri abunde denôftrauit: iam vero fententiam häc ex veris philofophiae fundamentis capi, quae Poetae ignota minime fuerūt, apertum crit, filibellum de coloribus magna do ftrina refertum eo in loco perlegamus, vbi haec fcribuntur,

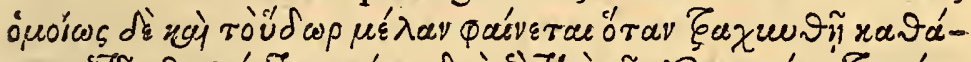

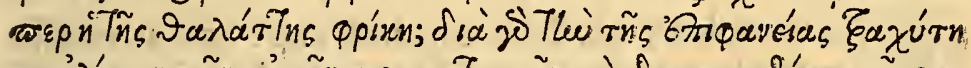

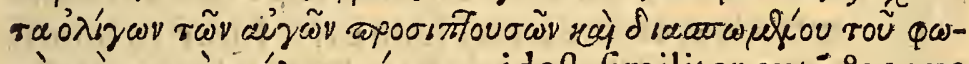

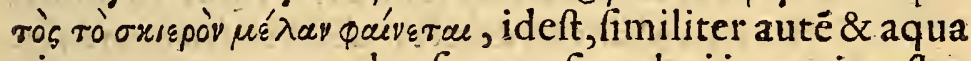
nigra apparet, quando afperata fit, veluti in maris aeftu: Nam ob fuperficiei afperitatem, cum pauci radijincidant, ac lumen diuellatur, quod vinbrofum eft, nigrum videtur, quo in loco atq. in probl . фpirns nomine vtitur, A riftoteles ad fignandam maris perturbationem, perinde ac medici idem vfurpant ad horrores \& concuf fiones febrientium fignificandas. Cur autem Virgilius 12. Aeneid. Medicinam mutam artem uocarit calminibus his.

Ille ot depofiti proferret fata parentis,

scire potestates berbarum, $p$ fumq. medendi

Maluit, of mutas agitare inglorius artes

Non defuerunt qui explicare conati fint, ita. f. a Poeta vocatam dicentes, quoniam comparata muficac, ignobilis ac parum celcbris eft; fed eorum mendacia faciliter redarguuntur, quod Homerus multis antea feculis medicum magnis hominibus dignum fecerit: Itaq. op. pofitifrme Fuluius Vrfinus doctiffimus, mihiq.ob cầdidiffimos cius mores, \& miram eruditionê, valde carus, atq. areta amicitia coniunctus in fuis collationibus mu- 


\section{I B E R}

tam a Vergilio artem medicam núcupatam infinuauit, quod tota eius vis in operationibús ac remedijs potius, quàm in fermonibus atq. eloquétia collocetur, vt nedû́ Cornelius Celfus, verum etiam Galenus vbiq. prae: dicat: vnde in medicos loquaces dicterium emanauit.

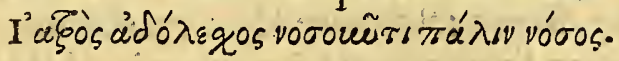

Loca Ariftotelis of Strabonis de generatione animalium in niue o igne collata at q. examinata: Locus Aristotelis emendatus. Cap. 14.

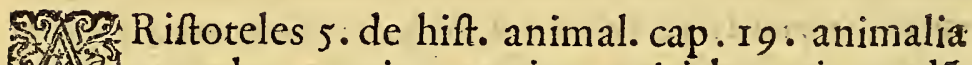

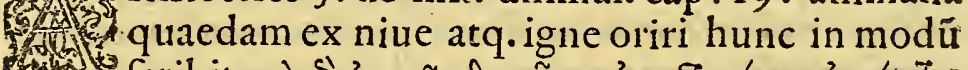
24.

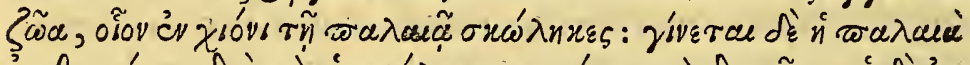
Épu

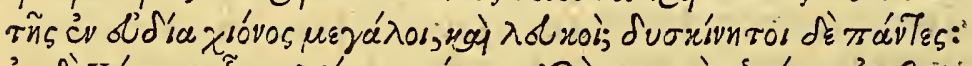

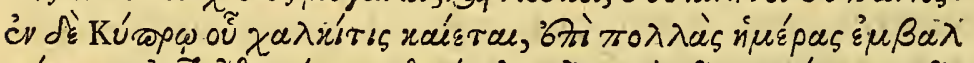

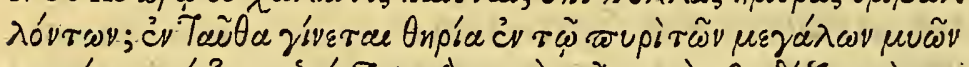

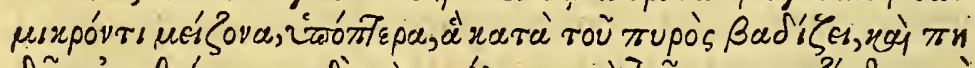

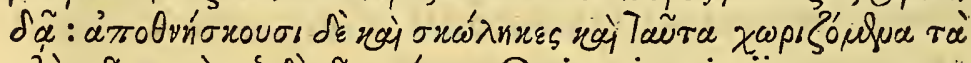

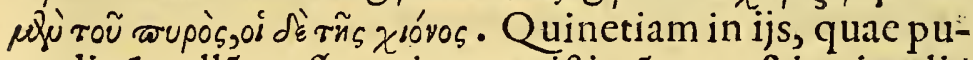
tredine nullă poffe recipere exiftimãtur naf́ci animalia nouimus, vt ucrmes in niue uetuftiore, qui hirti funt pi lis , \& rubidi. quoniā \& ipfa nix uetuftate rubefcit. fed in niue mediae terrae candidi, \& grãdiores inueniútur. Torpent omnes, ac difficultcr mouétur. In Cypro infula aerarijs fornacibus, ubi chalcites lapis ingeftus cum pluribus diebus crematur, beftiolae in medio igne nafcuntur pennatae, paulò mufcis grandibus maiores, quae per ignem faliāt,atq. ambulent. Emoritur \& hoc gentıs, \& aliud niuis alumnum, cum alterum ab igne, al terum a niue demotum eft; quae cum referat etiam An tigonus in paradoxis, non $\mu v \tilde{\omega}$, frue murium, ut in grae 


\section{$T$ E R $\quad T: I$ V S.}

$c 0, \&$ latino codice legitur, fed $\mu \nu \tilde{\omega} v$, ideft mufcarum legendum eft. A nimalia vero haec, \& praefertim ex niue generata, quoniā Strabo, ut in Armenia fiāt ; ex A pollonide monitrat, eius uerba haud Ariftotelicis diffimilia hic ex libro eius Geographiae I 2. fubiungam, ô of

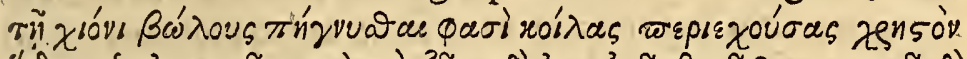

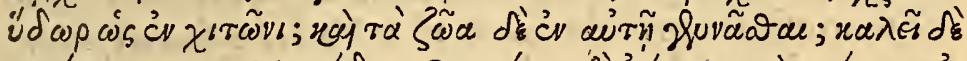

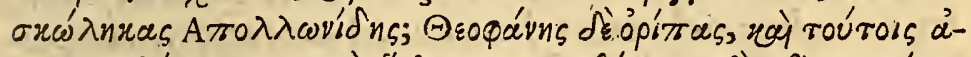

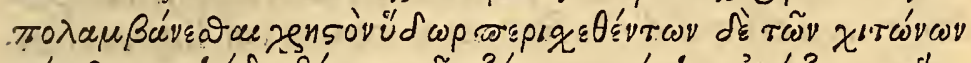

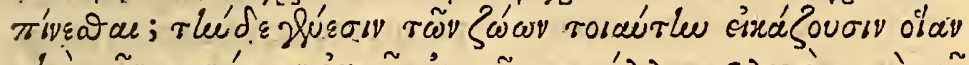

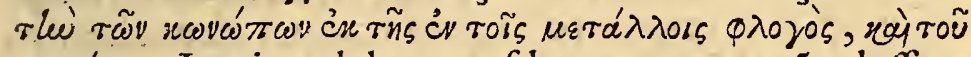

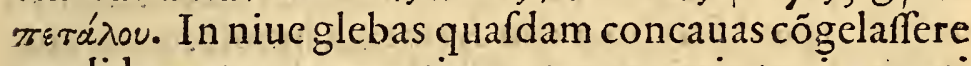
prodiderunt aquam optimam tanquam in tunica conti nentes, in niue animalia quaedá concreari, quae Apol lonides uermes appellat. Theophantes uero montanas teredines, atq. in illis aquá optimam contineri, \& ruptis tunicis bibi. Horũ animaliũ generationé talem putant qualem culicú èx flamma, \& braßtea metallorũ. Quae omnia fane creditu difficilia funt, quòd ad animalium generationé neceffario tum calor, tum humor requirútur; quorum alter ab igne, alrer a niue maxime abfunt: immo agricolae, dum femina in terra ad huc latent, hieme niuiū copiã exoptât, quo inter ceterabeneficia id cố fequãtur ne beftio lae frugibus perniciofae alantur ; fed exiftentes enecentur . Itaq. fr in niuibus interdum uermiculi confpiciütur, ex terra emanaffe ip fiofq. fefe inuol uiffe putandú : Daritcr animalia apparentia, in fornacibus metallorum potius crediderim ex terra metallis commixta, in qua nafcuntur, erumpere, quam in igne ipfo oriri ; eo maxime quod Ariftoteles quafifui immemor in 2. de gener animalium cap. 3 . ubi maturius quàm in hiftoriarum libris naturae res examinauit, nec in igne ipfo, nec in ignitis ullis, frue humidis, frue ficcis animal quodpiam gigni hunc in modum fcripfit; 


\section{I I X}

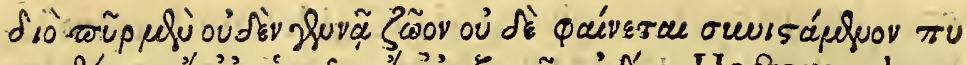

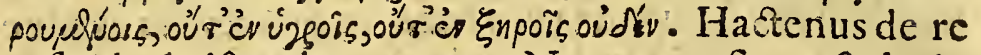
ipfa ab Ariftotele narrata. Nunc occafio poftulat in eius 5 . de hilt. fupracitatis verbis graecis maculam infi

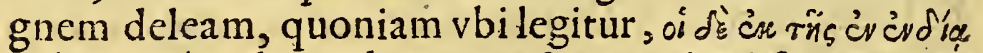
¿

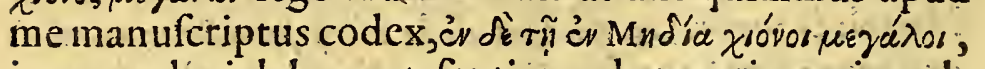
ita vero legi debere vt fentiam, duae vationes impellunt; vna eft quod nix fereno tempore vel liquatur in: terdiu.,vel noetu gelatur: \& propterea quomodo ex ipfa grandiores vermes nafci queant, non video: altera ra tio eft, quod Strabo qui in Armenia huiufcemodi animalium generationem fierifcribit, etiam regionem eă Mediae finitimam, atq. in producendis rebus fimilimã facit. Itaq. prudenter $G$ aza, vel coniectura ductus, vel optimo codice adiutus, verba in vulgatis deprauata fic tranfulit; quemadmodum ex manufcripto noftro tranf ferendum cenfemus.

\section{Infanize genus ab Aretaco medico defcriptum, Emonistratum. ' cap. I5.}

Retacus medicus in eo libro qué, $\pi \varepsilon p i z$ gríwy $^{2}$ (N) $\theta \tilde{\omega} v$ infcripfit, explicatis multis ífaniae generibus

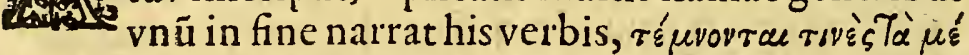

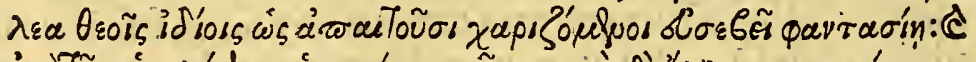

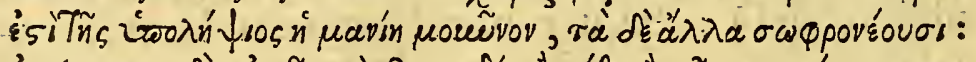

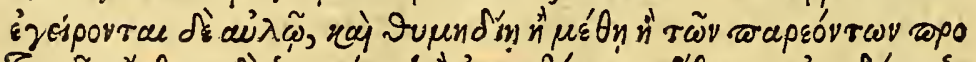

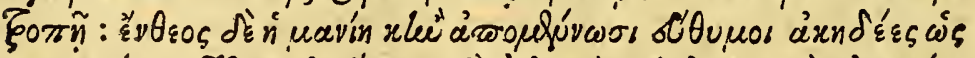

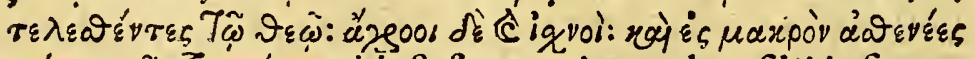

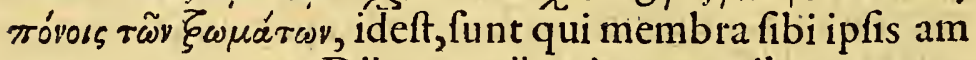
putant, tamquam Dijs proprijs earepetentibus gratam rem pia cogitatione facturi:atq. infania huiufmodi in opinione dumtaxat collocatur, cum in reliquis tempe- 


$$
\text { T E R T I V s. }
$$

rate ac prudenter degant : excitantur verótibia, animive oblectatione, aut temulentia, aut adftantium ex hortationibus: Manat huiufcemodi furor à Deorum af flatu : quod fi incolumes defiftant bono \& pacato animo funt tăquã Dijs initiacti: At decolores, macilenti,\& prae vulnerum doloribus infirmi longo tempore rema nent. Hos vero fuiffe Cybeles facerdotes Gallos vocatos, Corybanthas \& omnes eos, qui matris Deum facris initiabantur facile eft illis intelligere, qui eorum facror'um ritus, ac modos paffim ab auctoribus defcriptos in memoriam reuocarint : nunc fatis erit meminiffe facerdotis \& miniftroseius Deae cymbalis atq. tympanis curfitātes fefe furore correptos fimulare, aut etiā opina ri confueuiffe; ficq. infanientes caput rotare, genitalia abfcindere, cultris faciem \& mufculos corporis totius (ficut Catullus, Strabo Geog.x. \& A puleius in viiij. transformationum memorat) diffecare, morfibusq. feip fos impetere, quafi fagitiis fimilibus eam Deam gaude re putarent: nec aliquis mirari debet Veteres lumine Chriftianae veritatis orbatos vfq. adeo fpurciffima ac im maniffima facinora fub religionis titulo peregiffe; fi quidem Plutarchus in libro iaspi duoio ueuovíç pra uam religioné, \& fimilia, \& his peiora hominibus fuggerere exemplis Galatarü, atq. Scytharum humano fanguine Diis facrificare folitorum copiofe fatis oftêdit, vnde nó immerito apud Herodotum in Melpoinene Scy thae vi tio verterunt $G$ raecus agendi baechanalia confuetudinem negantes rationi confentaneum effe excogitare Deum, qui homines ad infaniam adigat. Porro furorem hunc inter morbos a medico antiquiffimo, \& Hippocratis doctrinae ftudiofiffimo maxime recenferi com mendo: veluti Caelium Aurelianum nequaquam improbo, quod \& in 4. diuturnarum affectionum mollitici inter morbos locum fecerit:quae licet folo animi vi 


\section{$L$ I $B$ B $\quad R$}

tio, \& non corporis nafci videatur, aegritudinem tame maximan fi quis appell at, minime errauerit, quemadmodum uocauit Iutuen alis in II. Saty. vbi fic ipfam deteftatur.

Magna inter molles concordia, non erit vllums

Exemplum in nostro tam detestabile fexu:

Taedia non lambit Clauiam, nec flora Catullam:

Hipo fubit inuenes, \& morbo pallet vtroq.

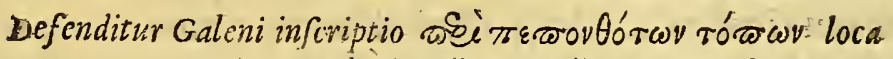
Areiaei ó Galeni collata de $\ddot{y} s$, qui corde patiuntur. Cap. $X V I$.

Vlius Cacfar Scaliger uir certe noftrorum tem porum dostifimus, ac fubtilifimus fuit; fed dum in Galenum ingenii acumen exereere nimis ftuduit, plerunq. malediccntiam fuam atq. imprudentiam detexit : vt ipfi tunc contingit; quando in primo commentariorum, fiue potius accufationum, quas in libros de plantis A riftoteli infcriptos edidit, eú dam-

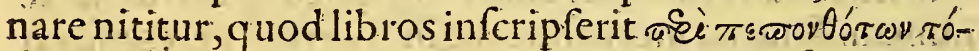
$\pi \omega v$ cú potius wé $\pi a \theta_{0}^{\prime} v \tau \omega v$ infẹtibere debuiffet: Quod $\pi \varepsilon \operatorname{cov}_{\varepsilon}$ (inquit) non amplius patiture, non igitur cget opere medici. Pulchra fane ratio, \& fubtili homine digna. Videamus itaque quomodo uir ifte Galeni doctri nam parum guftauerit, Nam quicunque antiquorum de locis affectis traetarunt, vt fecit Archigenes medico

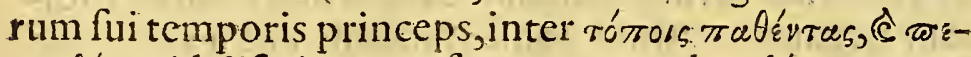

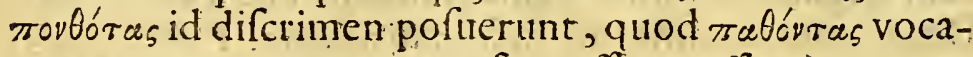
runt eas partes, quae extra fe cauffam paflonis tantum habent, atq. ea abeúte incolumes \& fanae relinquūtur:

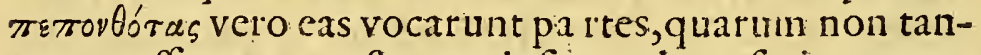
tum cauffa externa eft, quac ipfis morbum faciat, verum tiam quae propriam in feipfis ac iam fautam affectio- 


\section{T E R T I v $\mathbf{s}$.}

90.

nem licet aliquando infenfibilem retinent, ita vt etiam recedente cauffa nihilominus affectae remaneant, \& fic vocarunt quafi non modo patiantur, fed quoq. iam pal fae fint: Cũ itaq. Galenus in libris de locis affe tractationem confumat praecipue in docendo qua me thodo partes iam paffae, \& affectione propria à cauffa fibi externa, \& (vt dicunt) per confenfum occuparae di gnofci queant, iure fane we i $\pi \varepsilon \pi$ rovó $\tau \omega v$ rórwv cos inferipfit:Hae namq.proprio ac inteftino affetu laboran tes funt, quac potiffimum curationem expoftulant, non illae quae nihil in propria effentia paflac, aliunde folímodo vexantur, \& cauffa extincta nihil offenfae, aut $p a$. rum admodum remanent; $\&$ propterea øaAórtes róøos nuncupantur. Paret igitur quam iniufte Galenus reprehendarur, quem iam aetate prouectum, quando eos libros fribebat, in titulo ponendo fefellifle apud me irrationabile omnino videtur: cur autem Rabi Mofes in fuis Aphorifmis citans libros hos appellet fcientiarum libros hactenus certe diuinare non potui, ex quincto eorum librorum id mihi obferuatione dignum in primis videtur, quod quicunq. corde vulnerantur ufq. quo vitam trahant, femper mente conftent, ac fapiant, quafi neceffario inde colligatur animã rationalem minime in corde collocari: At Galeno vetuftior Aretaeus in ij. de acutis paffionibus fimile quid de corde in fyncopis trastatione fcriptum reliquit: vbi differentiam oftendens eorum, qui ore uentriculi infeftantur, \& eorum quos cordis labor aliquis exercet, de poftremis ita

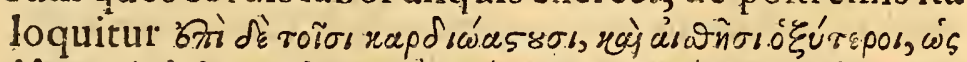

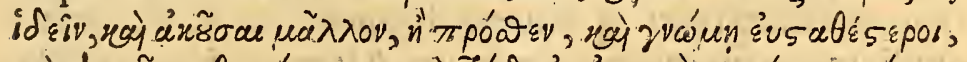

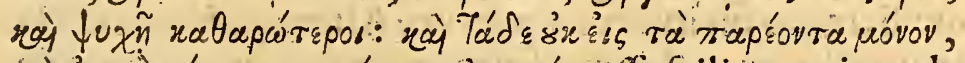

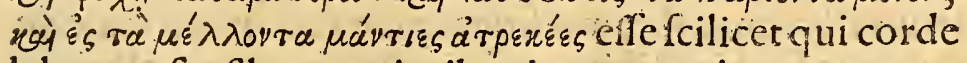
labolant fenfibus acutioribus ita, vt magis quam antea videant, audiantq, ; \& praeterea mente conftare, ani =

$$
\mathrm{Z} 2 \text { mumq. }
$$




\section{I B : R}

mumq puriorem habere, ac nedum in praefentibus di gnofcendis, verumetian in futuris exactos diuinatores exiftere.

\section{Quid fit apud Galenum ellycbnium Tarficum: \& de gofjypio. Cap. $X V I I$.}

Alenus in libro meth. 13. modum quo ad cicatricem ducuntur vlcera docens ellychniorum Tarfenfum meminit, quemadmodum etiam in 14. eiufdem tractationis libro, vbi Oedematis curandi rationem tradens f pongiam pofca madidam probat, eaq. deficiente ellychnium Tarfenfe fubftituédum mo net: Quibus in locis quid fub ellychniorum eiufmodi nomine intelligi debeat, ab omnibus fere hactenus ignoratum cft: Ego uero quae illa fuiffe ex auctoribus coniecerim in medium afferam, fententiam mutaturus quotiefcunq. meliorem quis mihi monftrauerit: Ex variis namq. linorum generibus pro lucernis accendendis elly chnia feciffe veteres apud omnes conftat, iccirco \& Tarfenfia a Galeno vocata ex huiufcemodi materia fuiffe conflata putare debemus : Inter alia autem cum

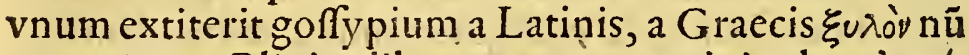

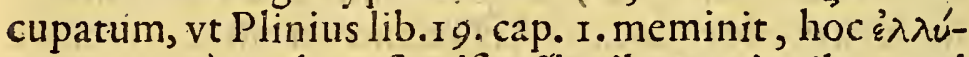
zysov rapoirov Galeno fignificafle tribus rationibus, vti credam, impellor: V na eft, quod Galenus nullibi goffy pii mentionem facit, unde nifi his locis illud defignet, ipfi ignotum extitiffe dicendum, quod tamen non admodum verifimile videtur, quando Plinij tempore Ro mae praefertim cuiq. abunde fuppetebat, \& ad uarios medicinac vfusinferuire poterat:Altera ratio,quod $\mathrm{Ga}$ lenus ellychnijs illis mollitiem prae ceteris attribuit.de goffypio fcribit Plinius nulla ipfi in candore mollitiave pracerenda : Tertia eft quod loco fpongiarum (vt Ga lenus 


\section{$T \backsim \overrightarrow{\boldsymbol{T}} I \mathrm{~V}$.}

lenus monet de ellychnio $T$ arfico) Xylinum linum, fiue goffypium aptifime in vfum medicum rcuocatur. Sed duo huic opinioni obftare fortaffe alicui videantur; AI terum eft Galeuum ellychnio Tarfico carnem excrefcé tem deprimendi poteftatem tribuiffe quae in goffy pio minime reperitur : alterum quod nullus ex Tarfo Ciliciae vrbe Xylinum linum inuectum fcribit; fed Plinius in fuperiori Aegypti parte in A rabiam vergente oriri memorat: Attamen haec dubia facile diffolui poffunt, fi dicamu's goffypium in fila redactum, quemadmodum pro ellychniis ficbat, atq. etiam hodie paffm fieri conpicitur, candem paene operam in compefcenda carnis luxuric praeftare, quam \& fila linea . Praeterea tempore Plinii in A egypto illa fila fieri confueffe,'tempore ue ro Galeni optima in Tarfo ficri caepta ficuti temporibus noftris in Cypro, in Italia, \& in alijs regionibus: Nec fane mirum videbitur fi cogitemus facile ob traCtus uiciniam ab Aegyptiis Cilices, \& ab his Cyprios, deinde alias nationes tale lini genus accepiffe potuiffe. Quod porro memoriae Plinius mandauit ex goffypio vertes facerdotibus A egyptiis gratiffimas fieri confueuiffe, ufq. etiam ad tempora noftra perdurare nemo ignorat, quando veftes illas facerdotum, quas Itali voca bulo populari cottas, rochettosve appellant, faepenumero Xylinas, \& praefertim ditiorum ac nobilium effe videamus.

Morbus Deliorum ab Aefchine defcriptus : locus Celfi notatus, \& alter Nonï emendatus contradictio Herodoti,
or Plir $\ddot{y}$.
Cap.
I 8.

Efchines rhetor nauigationem quandam Philo-
crati per epittolam fuam defcribens cuiufdam Deliorum peftiferi morbi meminit, qui quòd for 


\section{I B E R}

fan ab aliquibus ignorari poffet, hoc in loco ( vt mea ferat fententia) notum facere fudebo: Sic itaq. in lib.

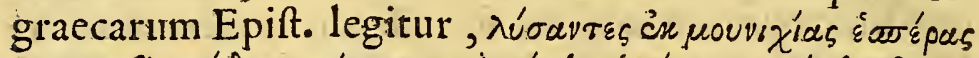

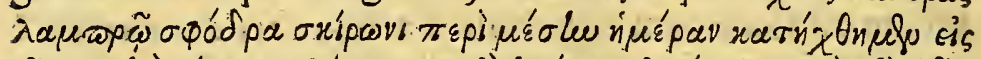

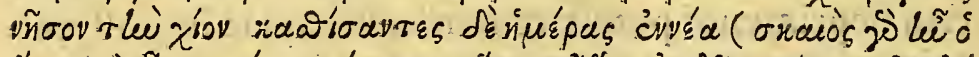

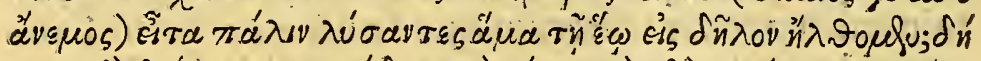

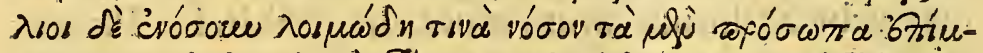

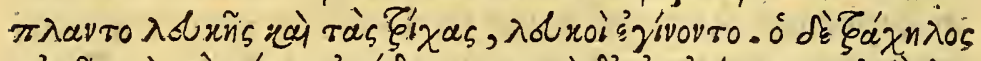

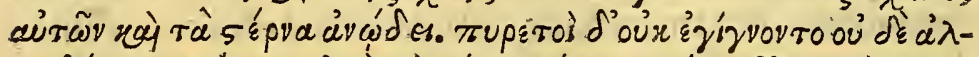

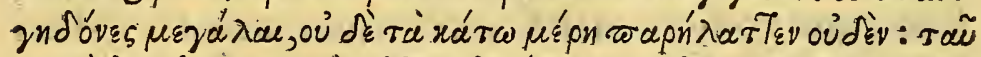

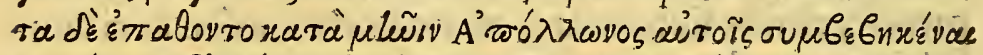

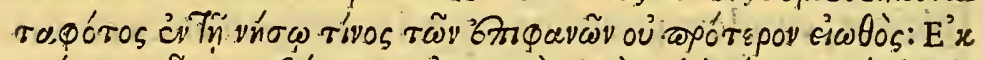

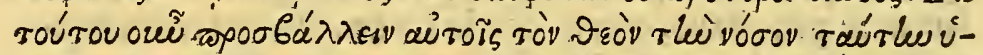

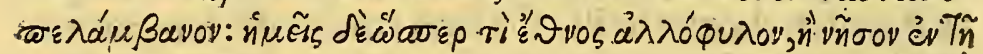

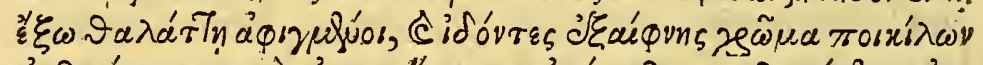

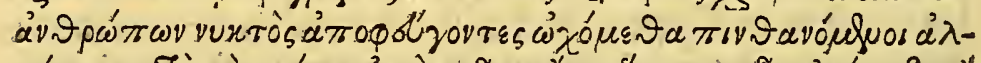

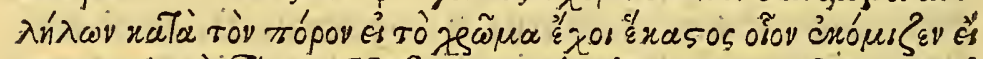

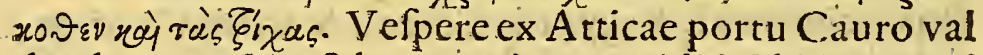
de claro perfãte foluentes circa meridié Chiū perueni mus. ibiq. dies nouem (erat enim aduerfus ventus) mo rati, deinde rurfum aurora foluentes Delum iuimus, la borabant Delij peftifero quodam morbo. Vultus quidem vitiligine plenos, capillos pariter albos habebant : ipforum autem collum, \& pectus erant tumida; febres vero non adcrant, neq. dolor es infignes, neq. inferiores partes quicquam permutatae fuerant: Atq. haec Apollinis ira fibi contigiffe credebant, cum praeter veteré confuetudinem illuftris quidam in infula fepultus fuiffet. Ob hocigitur Deum ipfis huiufcemodi morbũ mittere fufpicabantur. Nos autem tanquam externas gen tes, vel tanquam infulam in externo mari accedentes, hominumq. diuerforum colorem infpicientes, nocte fu ga: capta difceflimus, mutuo nosipfosinter abeundum percunetantes; an quifq. colorem, \& pilos, quos domo is

gerta- 
gefta uerat, haberet. Fuerunt itaq. quae tale morbi genus conditiones comitabantur, quing. primo peftilen $s$ erat; fecundo leuce feu vitiligine ora replebantur, tertio pili albefcebant, quarto collum \& peetus tumefccbant, quinto doloribus exiguis aegrotantes excrcebãtur; Aberant febres : Nunquid autem contagiofum ma lum foret,clare non explicuit Aefchines : attamen cum Delo iam relicta eius focij timerent, ne colores atq. pilos exigua mora ibi facta mutaffent, non fine ratione quis colligeret etiam contagiofum extitife : Quod vero maxime ambiguum in hac re videtur, eft, an ille mor bus fuerit leuce fiue uitiligo, an alphi, an clephantiafis alba a Plinio lib. 15. cap. 5 . vocata : Mihi fane cogitan tial ahos, atq. vitiligines, neq. peftiferos, neq. contagiofos ficri, praeterea fine tumore villo, ac fine dolore exiftere, magis inclinat animus vt putem elephantiafim, fiue lepram albam fuife, quam pettiferam, contagiofam, cuin tumore \& cú dolore fieri cóírmant Medici : quod fi cruftarum leprae huiufcemodí propriarum nulla fit mentio, ob id non neceffe videturab hac fententia rece dere, quoniam vel fub leuces nomine, qua replebantur facies, eas comprehendi non inconuenit: At id magis forfan repugnat de pilis albis dictum, quos tamen in cle phantiafi fecundum humoris naturam mutari valde rationi congruit; Videbunt doctiores quae potior fenten tia haberi debeat, interim obferuari velim Celfum gan graenam vocaffe cầcrum, ficut \& veteres omne fere ma. li quod vt cancer ferperer genus, gangraenam dixerür, vt ex Lucilio, \& Varrone docet Nonius apud quem vbi legitur. Non vituperamus cum fciamus dictum praeci di oportere, fi ob eam rem gangraena nô fit ad brachiü ventura loco dictionis [dictum] reftituendum eft [digitum] quemadmodum etiam Lypfius iuuenis ingeniofif fimusiam corrigendum monftrauit, quamquam is de- 


\section{I : E : R}

ceptus fit putans gangraenam effe morbum manus peculiarem, cum potius nulla fit corporis pars, quae illi ob noxia non fit. Ad infulam Delum reuer tor, quam eo tempore commotam fcribit Herodotus in Erato, quo Datis, vt.Delijs ipfum fugiétibus reditum patefaceret; aduerfus Eretriam Claffem, \& fimul Ionas atq. Aeolas fecum egit, cum nec prius, nec pofterius (fic enim legédum \& non quemadmodum Latinus interpres) vfq. ad aetatem ipfius Herodoti commotionem paffa foret: $\mathrm{Ce}$ terum Plinius lib. 4. cap. i 2. eandem Delum diu fuetuatam vfq. ad Varronis tépora, qui paullominus trecentis annis poft Herodotum vixit, immotam perduraf fe teftatur, quam virorum difcordiam alijs confiderandam relinquo.

Heraclitimorbus: eius \&.A Aclepiadisfententia de Vrina, Galeni ad idemlocus notatus, de Iberis dentes vrina lauantibus. Cap. 19.

Egrotabat Heraclitus, vt ipfemet in epifola ad 2. 1. Amphidamantem narrat,cumq. ad ipfum curã24um dumedici conueniffent, nec alter alteri concor daret, vt philofophus eorum infcitiamatq. petulantiam retunderet, obfcuris verbis ( vt fui moris erat) ab ipfis.

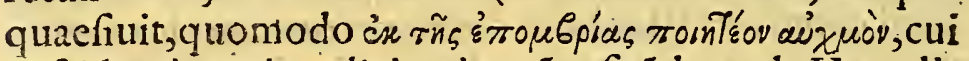
nefciétes ignari medici quicquã iefpódere,ab Heraclito iure expulfi fuerūt : laborabat enim ille vêtris hydro

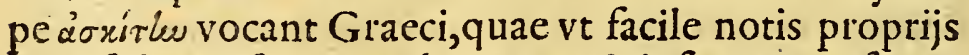
manifeftatur, fic non arduum erat \& ipfam cognofcere, \& curandi racionem ex ijs verbis intelligere : fed ante Heracliti atq. Hippocratis tempora medici empiricem tantum profitebantur, \& iccirco neq. morborum naturas, neq. veras curation um regulas nofcebant, ut iuremerito cum ipfe in huiufmodi medicos inuehatur, ofté- 


\section{$T$ E R $T$ I $\nabla$ S .}

dens nihilo fecius medicum humanos languores curare debere, atq. Deus magna mundi corpora medicatur, dum corum inaequalitates adaequat, atq. contraria contrarijs adhibet, tum ctiam ille apud Athenaeum non infulfe prorfus dixerit, ei un ia\}oiñ arav ou d'on

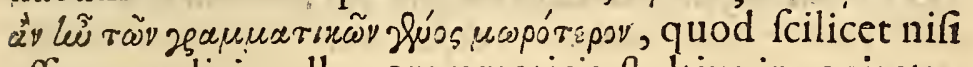
effent medici nullus grammaticis ftultius inucniretur genus. Neq. folummodo affeuerabat Heraclitus perin de hominibus medicinam, atq. Deo exercendam effe; immo \& omnia in corpore noftro fieri, ficut \& in mundo magno opinabatur: ita namq. vrinam in vefica gigni, quemadmodum in aeris fecunda regione pluuiam, quod ve hic ex vaporibus a terra elatis, ac in nubem con denfatis pluuia efficitur, fic ab efculentis, poculentisve halitus in veficam emanantes vrinam producant : Hera clicum vero hunc in modum fenfiffe austor eft in 13 . prob. fec. prob. 6. Ariftoteles; quam falfam fententiam Afclepiadem quoq. medicum olim celeberrimum fecu tum effe docet $G$ alenus in r. de fac. naturalibus libro, in cuius fine difputans aduerfus Lycum de vrinae natu ra fentire videtur id totum, quod potatur, per vrinam excerni, praeter pauca quaedam per aluum, per fudoré, aut per infenfibilem uocatam expirationem interdum exeuntia: Quod dogma verum effe, vt ipfemer ex cuidé tibus, atq. Erafiftrati au toritate probare nititur, in leEtionibus noftris, latiffimè probauimus, atq. etiã in tractatu noftro de vrina moftrabimus, vbi clare (ni fallor) \& rationibus, \& veterum medicorum, ac philofophorum auctoritatibus apparebir vrinae materiam nullam aliam effe, nifi fubftantiam ipfammet potulentam : Hic illud addam quod.Catullus in Egnatium, \& Strabolib. 3. Geog. fribunt Celtiberos, Hifpanosve confueuiffe mane lotio proprio dentes atque gingiuas ad abitergen dum nocturnas fordes colluere; quod fane magis ferri

$$
\text { A a poter, }
$$




\section{I B E R}

poteft, quam vrina in cloacis inueterata fefe lauare vt Iberos factitaffe memoriae prodidit Strabo.

Aetius redarguitur cur cast rati non fiant leprofi; loch s Aristotelis

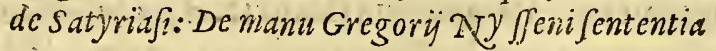

noula. Cap. 20.

Etius lib. I 3. cap. I 25.multa praeclare de elephä Fon ticorum victu memoriae mandauit, fed in duobus infigniter eum lapfum femper exiftimaui: in vno dum cauffam, qua caftrati eo morbo non tentan tur, affignare ftuduit ; in altero dum elephantiafi corre ptos generandi graria cum mulieribus aliquando confuetudinem habere confuluit: Quod in caftratis larga fiat feminis generatio, atq. non caftrati vtilem acbonü humorem in eo ita abfumant, vtilli a morbo earatione euadant, hi vero facilius capiantur ridiculum fane eft fateri : ficuti abfonum eft quos Elephantiafis exercet, multo abundare femine putare: in iis.n.qui omne mem brorum alimentum vitiacum \& corruptum habent, quo modo femen, quod vltimi, acvtilis alimenti тzр́⿱宀⿻三丨刀 eft; multiplicari poffit non video. Quare verior fefe of: fert ratio cur Eunuchi ab eo malo immunes reddantur; fiquidem praecipuaillius generationis occafio a caliditate, \& ficcitate cum iecoris, tum vniuerfi corporis habitus dependet; \& iccirco huiufcemodi affectio Aegypto familiaris traditur : Eunuchi vero frigidi atq. humi di citra omnium controuerfiam fiunt, ve nemini arduú fit intelligere hinc nafci, quod caftrati nó folum leprae, verumetiam vlli alteri morbo a calido $\&$ ficco nafcenti non facile fubiiciantur. Confulere porro vt laborantes lepra generandi gratia concumbant, ef non modo male affectusiugulare, fed etiam reliquos pefte inficere, morbofumq́. genus humanum reddere velle. Cur auté Elephantiafi 


\section{$T E R T I V S$.}

Elephantiafi ufq. adeo veneris appetitu fimulentur, non aliam cauffam puto, nifi quia vafa ipforum omnia multo \& craflo flatu, humoreve incoeto replentur, qui tam genitalia jpforum quàm ora faryris fimilia efficit: ob quod etiam oatúpsarıs \& outupias a veteribus medi-: cis tale mali genus nuncupatum inuenitur, quemadmo. dum apud Arifoteicm in 4.de gen. animal, cap. 3 - ubi

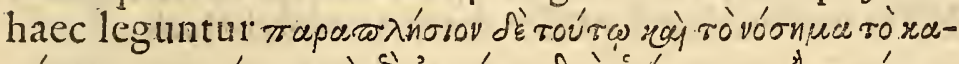

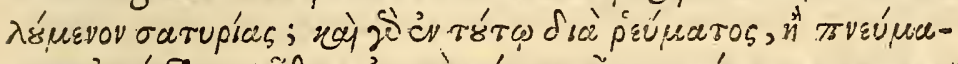

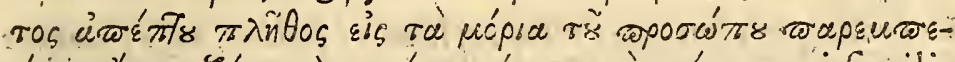

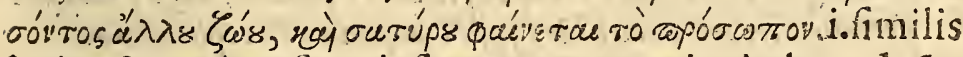
huic eft morbus fatyriafis vocatus: etenim in hoc ob fu xionis \& crudi flatus copiam uultus partes ingrediêtis, alterius animalis, \& fatyii facies apparet. Nifi igitur Plutarchus eo modo exponatur, quo in $\mathrm{r}$.lib.harum ob feruationum notauimus, excuffari non merebitur, cur Arifoteles elcphantiafis mentionem facit, quam is tépore Afclepiadis tantum qui trecentum annis plus minusve poft Ariftotelem vixit, apparuifle in fympos. tra didit. Manus a natura homini tributas fuiffelduobus ra tionibus auctor eft A riftot.4. de part. animal. cap. ro. Vna quod fit erectus, atq. ob id non cruribus, vt bruta terram prona fpectãtia, fed brachiis, \& manibus egeat: Altera quod fit omnium prudentifimus, ficq.ad exercenda prudentiae munera magna inftrumentorum copia exigatur, pro qua unae manus fufficere poffunt, népe quae non vnum, fed multa inftrumenta, ac veluti infrumentorum inftumentum fint. Arifo.fententiae ad didit acutifimus Gal.1 de vfu partium, hominem a natura manibus ornatum fuiffe, quoniam ficutiratio ipfius animo tributa eft veluti quaedam arrium ars, ipfaq́. fine infrumento fibi accómodato operari nequit , fimiliter inftrumentum omnium practantifimum dari conuenicbat. Gregorius Nyfenus auctor non ignobiA 2 lis 


\section{I B $\mathbf{R}$}

lis in lib.opificio hominis practer haec alium naturae, in extruendis manibus finem fuiffe putauit nimirum fermonem hominiomnium maxime proprium, quandoquidem nifi manus, quibus cibum pararet, atq. in os mitteret habuiffet, necelfario os fumen dis è terra cibis, $v t$ in ceteris brutis idoneum fabricare cogebatur. Os au tem eiufcemodi loquellae at . fermoni plane inceptum fuiffet unde vt loqui poffet, manus homo habuit .

De Cretae generibus locus Tlinij explicatus: fafciae, toga, mappae cretatae: error Cornarï:de gypfo Tymphaico Theophrastiloci correcti, $\delta$ alter Plinì notatus. Cap. 21 .

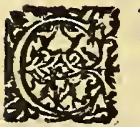

Eruffa ad faciem dealbandam antiquiffimis ufq : temporibus vas fuiffe mulieres praeter multos alios Plautus copiofe fatis teftatuseft;quod uero ad candorem atq. fplendorem ueftibus; togisve conciliandum veteres cretae quodam genere uterentur, Ifidorus in Etymolog.\& ante ipfum Plinius lib.36.cap. 17. memoriae mandauit; quo in lococum non parum obfcure loquatur, \& interdum a Galeno diuerfa feritire videatur, eius fententiam breuiter explicabo : Itaq; Latinus auctor cretae tria genera facit, Cimoliam, A rgentariam, \& Vilifimam : Cimoliarum altera erat vera a Cimolo una cycladarum infula vnde defercbatur, fic nominata; altera per fimilitudinem ita nuncupata; atq. huius plures fpecies fucrunt: aliae namq. ad medicos pertinebant veluti Theffalica, atq. Lycia:aliae in ve ftibus ufurpabantur, ficuti Sarda, Vmbrica, \& faxum uocata: Sarda aquae commixta \& eliquata ueftes ablue bantur, mox fulphure fuffi tae Cimolia uera lacuigaban tur; cumq. uiliffima effet, togis candidatorum dealbandis, illuftrandisve eam minime adhibitam puto: Vmbri ca quac preciofior habebatur, poliendis ueftibus in ufu 
erat; modo enim eliquata, modo ipfis affricata nitorem quendam gratum ceteris ueftium coloribus praeftabatnon enim folis candidis ut Sarda,fed etiam uerficoloribus inferuiebat. Saxum pumicis inftar \& ipfum candidis ueftibus fulphure fuffitis affricatum non modo albe dinem augebat, uerumetiam nitorem \& lumen quod dam, atq. foliditatem conciliabat, quo pacto mulieres hodie amylo, uel oryzae decơto ad dealbandas, folidä dasve mappas \& ucla utuntur; Hac ueteres etiam togis candorem, foliditatem, ac nitorem nec non fafcijs ca ligarum, atq. mappis comparare confucuiffe opinor, un de M. Tullius 2. Epift. ad Atticum I8. fafcias cretatas dixit; \& Martialis lib. I 2.

\section{Cretatam praetor veliet cum mittere mappam, \\ Praetori mappam furripit Hermogenes.}

Cretenfes tamen calceos ab Hippocrate 4.de artic. mö fratos, quibus monticolae in A fia \& venatores vteban tur, diuerfos a cretatis extitiffe nemo nefcit . Cimolia vero nullo modo candorem tradebat, fed alios colores preciofos, \& ueros emolliebat, nec nó fulphure cótrifta tọs quodā nitore exhilarabat, perinde ac hodie factitāt fericarum telarum textores, vbi varijs tinsturis nitore ipfis conciliant, illuftrantve : De haclocutú credo Galenum, quando denigrãdis capillis cimoliam cum alijs rebus commendat; alias namq. cimoliae fpecies aut nó nominaffe, aut vno cimoliae vocabulo in 9 . de fimpl. mcd. cóprehendifle conftat. Tot igitur Cimolias apud Plinium inuenio, quae primum cretae genus faciunt Secundum vero cretae genus eiat argétaria, quam $\mathrm{Ga}-$

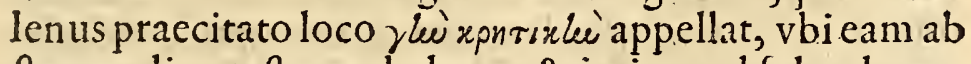
ftergendi poteftatem habere, \& iccirco ad fplendorem vafis argenteis fordidis reddendum homines vfurpaffe memorat; qua in re accufandus eft Cornarius, qui vbi Aetius lib. 2. fcribit Creticam terram facultaté abftergendi 


\section{L $I$ I B}

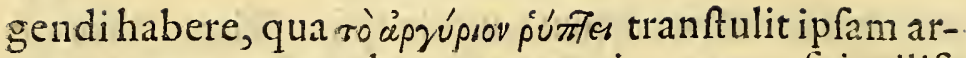
gentum exterere, ac depurare : tertium genus fuit viliffimae, qua circulos victores domibus, vel earum veftibulis praeducebant, vt effet fpectatoribus (quemadmo dum coronis etiam feneftris appofitis interdum faciebant) victoriac figna, quave feruorum venalium pedes tingebant, vt ab omnibus eos fuifie vendendos intelligeretur; ob quod Iuuenalis quendam, qui pro feruo vé ditus fuerat notans in r. Saty. fcribit .

Et ante ipfum Tibullus.

\section{Nuper in banc vrbem pedibus qui venerat albis.}

Barlara gypfatos ferre catasta pedes.

Nunguid aurem huiufcemodi cretae genere etiam facies eorum puerorum oblinerentur, qui aut venundari debebant, aut dominis inferuiebant, fequebanturve nó dum mihi compertum eft: illud certe fcio veteres puerorum fuorum vultus oblinire folitos, ne gelu, aut fole deturparentur, ve teftatur Seneca Epift. 124 . vbi pro paedagia potiuslegendum paedagogia puto, quoniam fic mancipia apud iurifperitos vocata legimus: $Q$ uo ve rofucco vngerent haud fatis fcio. Id tamen mihi perfpectum eft hodie Genuenfes mulieres, ne a fole facics ipfarum denigrentur, in aeftate folatri fuccum per linreamina expreffum vultibus inungere. Quod cum mihi Ioannes Vincentius Pinellius fingularis doctrinae, \& probitatis vir fignificaffer, perfuafit etiam veteres po tuifre huiufcemodi fucco alioquin paratu facili . ( quod fimili in re exigitur) vti. Iam vero Plinius cum Tymphaici gypfi mentionem faciat admonet, vt locú Theophrafti in lib. тв pi $\lambda^{\prime} \theta \omega \nu$ lacerum, \& corruptü, vnde fua ille acceperat, a me fore reftitutum, hic fubnectam, vbi terras alias arte fieri, alias fponte nafci fcribens, de po-

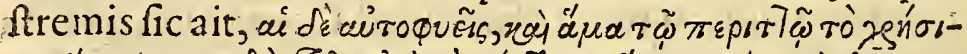

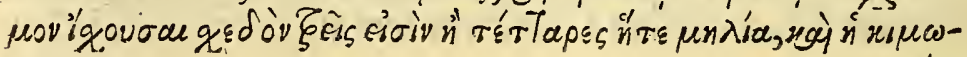
$\lambda^{\prime}$ ís 


\section{T E R T I V $\mathrm{s}$.}

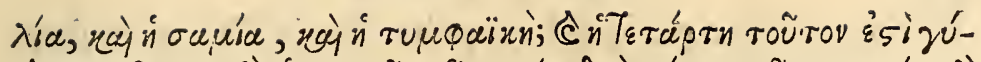

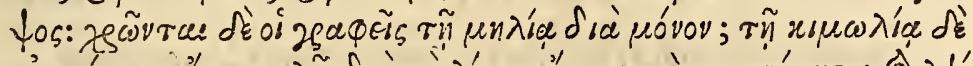

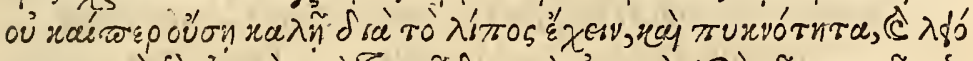

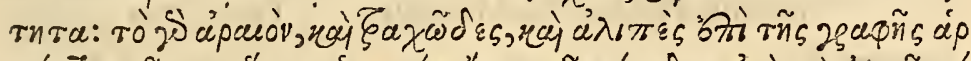

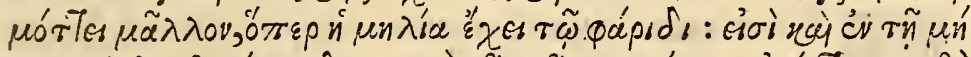

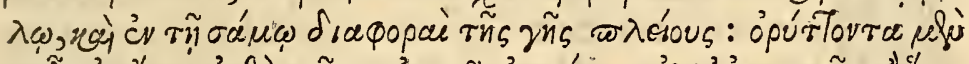

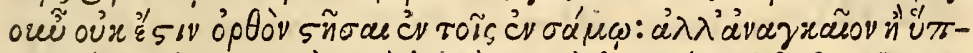

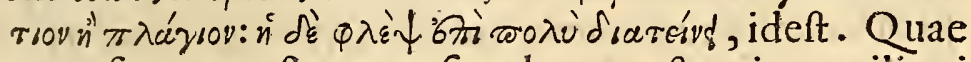
vero fponte nafcuntur, fimulq. praeftantiam vtilitati iunfam habent tres fere, aut quattuor funt, Melia, Cimolia, Samia, \& Tymphaica, atq. harum quarta gypfus eft: Melia per fe fola vtuntur pietores, Cimolia vero tametfi bona exiftente, ob pinguitudinem, denfitatem, ac laeuorem ipfi inexiftétes, nequaquam vtuntur: Nà raritas, \& afperitas, \& pinguitudinis inopia magis in pictura conueniunt. Sunt \& in Melo, \& in Samo plures terrarum differentiae, effodientem in Samo minime re ctum, fed vel fupinum, vel obliquum ftare neceffe eft, vena aut ad multũ protéditur, \& paullo poft. zes̃r

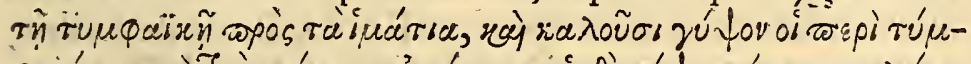

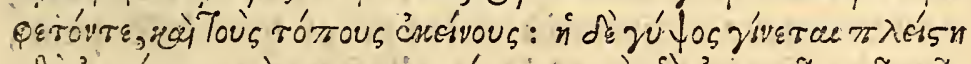

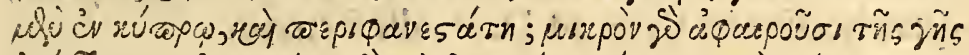

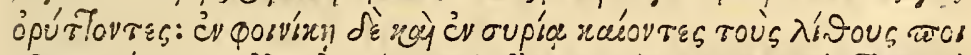

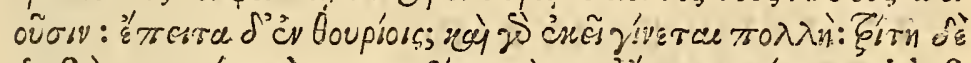

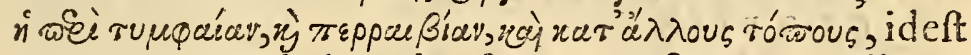
vtuntur Tymphaica ad veftes, Gypfumq. appellant, Tympheti,atq. illorum locorum incolae : fit autem plu rimus Gypfus, atq. praeftanciffmi in Cypro: Nam qui effodiunt, parum longe a terra auferunt. In Phoenicia vero, \& in Syria ex lapidibus vitis faciunt, tum in Thu rijs, tertia vero eft circa Tympheam Perrhebeã, \& alios locos. Ex quibus verbis clarc pater, vel Plinium habuiffe alium contextum, vel effe deceptum, quando 36 . lib.cap. 24. friptum reliquit Tymphaicum gypfun $e$ fumma 


\section{L}

fumma tellure peti, qđ Cyprio tribuit Theophraftus.

Menecrates medicus quis fuerit. Medici Clinici, locus Plinij mutatus, de pofcalocus suetonï. Cap. 22.

Enecratem cuius frequentem, nec incelebrem 2. mentionem fecit Galenus in medicamentorum La libris, nonnulli eum effe dubitarunt, qui Philippi Macedonû regis medicum egit, quive gloriofo quodam titulo feipfum Iouem nuncupabat, vnde poftmodum ab Agefilao Spartarum rege infaniae vitio notatus fuit : At ne horum leuiffima dubitatio alijs forfan occafionem errandi praebeat, non alienum iudicaui de clarare Menecratem a Galeno nominatum fuiffe quendam Tiberij \& Claudij Caefaris medicum, libertum fectae rationalium addictum, multifq. commentarijs edi 5. docöp tis infignem : de quo forfan nec hiftoriae repugnaret med.s.l. Coelium Aurelianum lib. x. diutur. paff. cap. 4. memicap.3. niffe: Quod vero ita le habeat praeter Galenum, qui Menecratem poft Antoniü Mufam paulloante Andro machum, \& Neronis imperium Romae floruiffe fcribit; non incertum teftimoniü affert uetus haec infcriptio, quae hodiae in Vrbe ad D. Paulli feruatur.

T I B E P I $\Omega 1$. K $\Lambda$ A $\Upsilon \Delta$ I $\Omega i$

KOYPEINAI

MENEKPATEI. IATP $\Omega i$

KAI $\Sigma A P \Omega N$ KAI I $\triangle I A \Sigma$

$\Lambda O \Gamma I K H \Sigma$. ENAP $\Gamma O \Upsilon \Sigma$

I A T P IKH $\Sigma$. KT I $\Sigma T H_{\text {I. E N }}$

BIB $\Lambda$ IOI $\Sigma$. PNS $\triangle I \Omega N$

ET EIMH $\Theta$ H. $\Upsilon \Pi$ O. T $\Omega$ N. EN

$\Lambda O \Gamma I M \Omega N$. ПO $\Lambda E \Omega N$. $\Psi H \Phi I \Sigma$

MA $\Sigma$ IN. ENTE $\Lambda$ E $\Sigma$ IOI $\Gamma N \Omega$ PIMOI

$T \Omega$ EA $\Upsilon T \Omega N$ AIPE $\Sigma I A P X H$ TO HP $\Omega O N$ 


$$
T \text { E R T I v s . }
$$

Iam vero Clinicos uocatos medicos a chirurg is eo modo antiquitus fuiffe feiunctos, quo temporibus noftris phyfici nuncupati ab ijfdem chirurgis feparantur, praeter hoc Martialis carmen.

Chirurgus fuerat, nunc est vepillo Dianlus

Coepit, quso poterat, Clinicus effe modo

fequens infcriptio, guam Romae marmorae infculptå uidi, fatis perfpectum facit,

.P.DECIMIVS.L. HEROS

MER VLA. MEDICVS

CLINICVS. CHIRVRGVS

OCVIARIVS. VI. VIR

HIC PRO LIBERTATE DEDIT. HS. Isss

HIC PRO SEVIRATV IN REMP.

DEDIT HS. $\infty$

HICIN STATVAS PONENDAS IN

AEDEM HERCVLIS DEDIT.HS. 杂条条

HIC. IN. VIAS STERNENDAS IN

P.VBLICVM DEDIT. HS. 柰余䒩I

HIC PRIDIE QVAM MORTVVS EST

RELIQVIT PATRIMONI

HS. $\infty$ 赴术

Ex qua item manifeftum effepoteft, quantum Romae (quod etiam Plinius meminit) ditefcerent medici, nimirum qui \& pro libertate fibiipfis afferenda (multi.n. erant ferui) \& pro dignitatibus in repub. confequendis ingentia precia foluebant. An clinici quoq. a Romanis dicerentur aegri decumbentes nonnulli, quemadmodum Plinius lib. 25 . cap. 5. dixiffe aliquibus vifum eft, certe non parum dubito, tametf Hermolaus Barbarus magni iudicij, \& ralae eruditionis vir ex facris biblijs quoq. id probare nitatur: Itaq. fi quis pro clinicis in Pliniano codice cronicis fubfituat, fortafle non aberret; quando non minus potuit auctor in loquendo in$\mathrm{Bh}$ terdum - 


\section{$L I \& E R$}

terdum liberati hac voce graeca fanè at ab alijs vfurpata, quam [fpafticis] uocabulo ex media graecia fumpto, nec forte a quoquā vllibi praeterquam ab ipfomet in eodem loco, \& alibi vfurpato. Nifi potius pro fpafti cis, clinicis alteri fubftituere placeat, $\mathrm{f}$ pafmis cynicis;vel fpafticis, cynicis; Si quidem medici omnes fciunt fpafmú cynicum faciei effe morbü; in quo tollendo prodef fe elleborü, fcripfit etiä Celfus lib. 4. cap. 2. fpaftici( ait Barbarus) funt quibus eft intus aliquid conclaufum có uulfumve. Mirantur nonnulli quod fcribat Suetonius Afraticum Vitellij Imperatoris libertū Puteolis pofcã vendidiffe quafi huiufmodi potus folum in medicum vfum incus, \& extra adhiberetur, ego vero minime illud admiratione dignum exiftimo, quoniám vinũ acidum aquae mixtum pro vili plebecula venale extaffe ra tioni cófonat, atq. id poficam fuiffe appellatum; nifi ma lumus Puteolis gratia aegrorùm, qui eo frequentes côueniebant. id folummodo factitatú, vt fcilicet vera po$f$ ca venderetur, quam ex aceto aquae modo pluri, modo pauciori mixto factá memorat Galenus:. Quamquá etiam antiquitus ficut efcam pro cibis, ita pofcam pro potibus effe vfurpatam inuenio. Quando, vt notat $B$ ar barus in antiquiffimis Fenti codicibus, \& in Ferentini vetufto monumento pof́culenta pro poculentisleguntur.

\section{TERTII LIBRI FINIS.}


$\mathrm{V}$ A $\mathrm{R}$ I A $\mathrm{A}$ V

\title{
I $\mathrm{N}$
}

\section{MEDICINAE AVCTORIBVS}

\author{
A TQVE ETIAM AIIIS \\ LE C I IO N V M
}

\section{Liber Quartus .}

Quifuerint apud Deteres archiatri, Go archiatrorum comites, quodre corumimunus. cap. I.

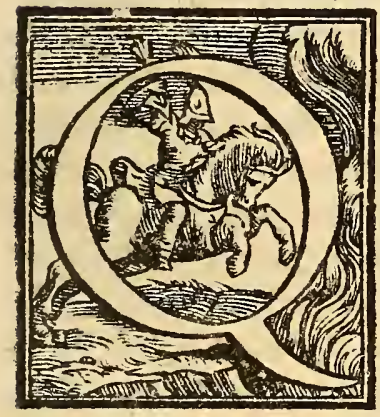

Vi Galenũ, aliofq. medicinae fcri ptores vfq.ad haec tempora inter pretati funt, omnes penè in hoc conuenerunt, vt nomen ápxí́\}ou medicorum principem, qualiq.ex cellentiffimum deffignare voluerint(Io. Baptiftam Rafarium virú tempeftate noftra eruditifimum excipio,qui in fuis Galeni commé tariorum translationibus vbicunq . occurrit archiatrũ transfert.) Id quoniam ego a veritate longe alienum remper putaui, credidiq. ap $\chi^{\prime} \boldsymbol{c}_{\text {Gov }}$ proprie imperatoris, principisve, atq. eius familiae medicum fignificaffe; qui busductus rationibus hanc opinionem conceperim, in medium proponam : videbunt deinde eruditi, acin an tiquis rebus perferutandis verfati viri num fentétia noAtra aliorum placitis anteponi debeat. Nam prime nul lum hactenus graecum, latinumve fcriptorem, qui ante Romanos Imperatores foruerit, inuenire mihi eft $\mathrm{Bb} 2$ con- 


\section{I B E R}

conceffum; qui hac apxiá̧ou voce vfus fit; quòd coniecturam non partam facere videtur,vt I mperatores effe, medicosve, cum eorum perfonae, tum familiae valetudinis curae deftinatos habere coeperunt: Sic uocem eã tunca medicis in vfum inuectam effe; quod paullo poft Tiberij, \& Claudij tempora fuiffe ideo perfuafum habeo, quoniam antc ea tempora neq. auctorum fcripta, neq. marmoreae medicorü infcriptiones Romaeferua tae vfquả hoc nomen habent.' Hanc autem graecã vocé potius, \& non latinā elegerüt, quod (ut refert Plinius) 2ib. 26. nemo Romanus medicam artem exerceret, fed omnes cap.s.

fere, aut faltem maiori ex parte graeci, atq. ij vt plurimum ferui, aut liberti eflent; vnde fi archiater vel medi cum primarium, vel medicorú principem fignificaffet, confentancum fane rationierat, vtires ipfa ante Imperatores extitiffet, pariter etiam nomen eam cxprimens aliquando vfurpatum fuiffe; quod nunyuam a me ( nifi ceteri maioris lectionis viri fecus obferuarint.) apud quempiam auctorem animaduerfum eft; quemadmodum ex altera parte valde mihi probatur, iccircoante Imperatores minime id nomen receptum fuifle, quod res abillo fignata medicus fcilicet principis nondum in Zib. 25. ftitutus foret: Quinimmo Plinius, cuius tempore iam cap. 8. archiatri nomen in vfu haberi coeperat cum Damocra tem Seruilium Mithridaticae Antidoti außtorem medi cum ipfius aetate primarium nominare vellet, non eum archiatrum, fed e primis medentium vocauit, quafi fciret nomen illud medicis dumtaxat principis conueniffe; vt his omnibus grauifimis coniecturis facile iudica-

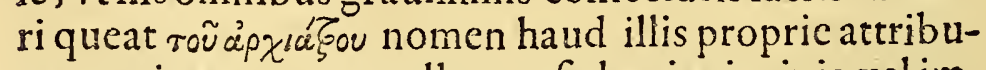
tum, qui ceteros antecellerent, fed qui principis, vel imperatoris perfonae, atq. familiae operas fuas locarent. Practerea Andromachus quem Erotianus in Onoma-

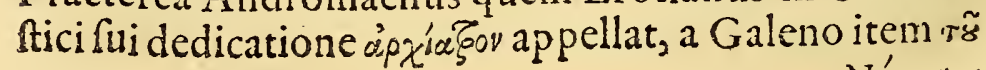
Népo voc 


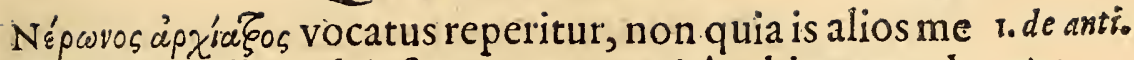
dicos,praecellere ab ipfo putaretur, qui A rchigenem ab cap.1. Andromachi tempeftate vfq. ad Traiani principatum in magna exiftimatione habitum ( quod etiam Iuuenalis infinuat ijslocis.

\section{Tunc corpore fano}

Aduocat Archigonem.

Et

ocyus Archigenem quaere, atq.eme quod Mithridates Compo(nit)

Alios anteceffife fribens, nullibi archiatrum nuncupa uit, fed quod intelligeret folos principis medicos eo no mine fuiffe vocatos. Quocirca fi res ipfa non fecundum legentis voluntatem, fed vere atq. prudenter aeftimetur, plane apparebit Erotianum, \& Galenum concorditer Andromachum archiatrum nuncupaffe, quod eã vocem vti debitúm fibi quendam titulum, nimirum cũ Neronis medicus effet, ei congruere intellexerint: Qua fimliter ratione Liuium Eutychum archiatrum uocatum credo in hac infcriptione quae olim in tabellula quadam una cum multis aliis uetuftate pene confumpris Romae ad D.Sebaftiani reperta eft .

\section{LIVIO CELSO TA B VLARIO SCOLAE MEDICOR VM \\ M. LIVIVS EVTYCHVS \\ AR CHIATR OS OLL. D. $\overline{I I}$. \\ INFR. PED. IIII.}

Sicut \& Petrus quidam archiater apud Aetium nudis verbis citatus inuenitur, quem eo titulo iudicatum, quafi Principismedicus, non autem medicorum princeps foret, ex Actii verbis facile colligi poteft; veluti quoq. Galenum in lib. de Theriaca ad Pifonem non alia ratione puto vocaffe Archiatros magnum, \& Deme 


\section{I $:$ :}

trium, atq.alios multos alioqui populares potius, $q$ cmi nentes. Neque uero illud mihi confonum uidctur Imperatores confueuiffe medicos plures conducere, atque inter eos vnum reliquis fuperiorem habuiffe, quem \& ob dootrinae excellentiam, \& ob dignitatem fibi maiorem delatam archiatrum vocarent, quandoquidem nó unum, fed plures fimul archiatros extaffe apud varios fcriptores legimus. Quis ex legum peritis quacfo eft, qui nefciat Conitantinum Imperatorem legem tuliffe, qua archiarros illuftribus priuilegiis, maximisq́. gratiis orInl. $2 r$ - nari voluit? Quis item non vidit eam legem quam Imcbia.cap. perator in hunc modum tulit. Archiatros noftri palade meta- tii, necnon vrbis Romanae \&c. Ex quibus omnibus netis!b. 2 gari nunquam poterit, quin Imperatores non unum cod. tit. fed pluies limularchiatros habuerint: ut hac ratione ar 41. chiatrum Principis medicum extitiffe credendum fit; alioquin fi aliorum fuperior quafiq. princeps fuiffet, par erat non plures uno tem pore, fed vnum tantum effe debuiffe: Quam rem manifentus adhuc Vindiciani me dici, qui Octauii Horatiani, fiue Prifciani Theodori In Epift. pracceptor fuit; necnon Caflodori teftimonia compro ad Valë. barc queunt, quorum ille archiatrorum Valentiniani comes fuiffe perhiberur : hic vero dum formam qua archiatrorum comes eligebatur. 6. variarum lib. exponit it a clare archidtros fimul plures, eosq. principis medicos extitiffe, atq. horum pracfidem, ac veluti principem non archiatrum, fed comitem vocatum oftendit, vt ne mo nifi fuae opinionis nimius amator hanc ueritatem In com.su inficiari pofit : quam Andrcas Alciatus auctor noftra per lib. tempeftate clariffimus probe cognofcens antiquos legú cod. interpretes damnare non dubitauit, quod ubi leges de archiatris loquuntur femper medicorum principes, \& non principis medicos interpretentur. Porro quatenus ad vocis ipfus etymon pertinet, etfi ufus friptorum fe 


\section{QV A R T V s. $\quad 100$}

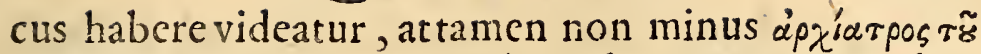

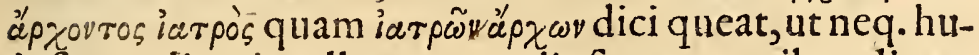
iufccmodi ratio ulla ex parte iis foueat, quibus diuerfam fententiam fequi placuit. Nunc qui effent archiatri, quodve eorum munus non admodum difficile eft percipere; fiquidem verifimile vnicuiq. apparere poteft, vt hodie faepenumero contingere cernimus; ita. etiam antiquitus contigiffe, quod qui vel artis praeftantia, uel quopiam apud Imperatores fauore pollerent, in eius atq. familiae medicos cooptarentur; atque horum cum aliquis moreretur, alter in eius locum fubrogaretur, in qua fubrogatione, quoniam interdum ob fauores nonnulli indigni locum obtinebant, ea lex condita eft, quod in Cod.lib.g.ti.de profeff.\& med.cap. Ir. habetur, ne foilicet quis in archiatrum eligi deberet nifi communi meliorum iudicio comprobaretur:nemo enim erat, qui vt archiatri locum impetraret, non omnem moueret lapidem nedum ob dignitatem, acgloriam, verum \& ob honeftiffima ftipendia, ceterave priuilegia, quibus illi fruebantur.Scribit Plinius annua ho rum medicorum ftipendia apud principes fuiffe CCL. HS. quae ad monetae noftrae rationem redacta faciunt ungaricorum V I L X. Semuncialem unum, duodenarios nouem, duplos quattuor, fimplum vnum: Quae tamen non omnium archiatrorum merces erat, cum in legibus habeatur archiatros ab Imperatoribus praeter alimenta fubminiftrata, quampluribus aliis pri vilegiis atque fauoribus donatos effe; qux omnia mercedis infat, quod multi forent, ipfis donabantur : perinde, ac temporibus noftris medici aliqui in Pontificis Romani curia, \& in aliorum Principum domibus ob fo lamfportulam aliasve gratias operam fuam medendo exhibent. de iis fermonem factum a Galeno puto ubi in 9. de plac. Hipp. \& Plat. alios lucri cauffa medicinam 


\section{I B E R}

exercerc voluife, alios ob honorem, alios ob fibi legibus conceffam immunitatem, ac reipub. vacationem. Iam vero illorum munus quod effer ex loco cod. citato cap.ro. fcire vnicuiq. licet, vbi ex uerbis illius legis aper te dici poteit archiatros cum a populi commodis cómo da reciperent falaria, non folü principis familiae, eiufq. perfonae inferuiffe, uerumetiam pauperibus fine vlla mercedis fpe obfequi, nec turpiter diuitibus inferuire obligatos fuiffe; Dicebatur vero archiatros \& archiater vcluti ex auctoribus, atq. fuperiori infcriptione, fubfequenteve patet, quae Romae in vetufto lapide feruatur adhuc.

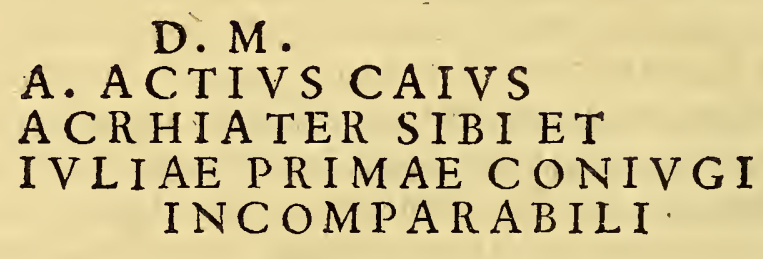

Erantitaq.archiatrimedici illi omnes, qui principis fumptibus conducti eius perfonae primùm, deinde aulae omni, poftemo cunctis paupcribus arte propria Ro mae operã praeftabant; quorum archiatrorũ princeps quidam fenior prudentia, \& doetrina praetantior eligebatur, cuius fententia \& auctoritate omnes de re me dica obortac diffenfiones ftatim dirimebantur ; isq. comes vocabatur, \& prae ceteris maximam principis curam gerebat, eiufq. veluti imperium quoddam, \& poteftatem magnā obtinebat, vt ex Caffiodori citato nuper teftimonio abunde perfpectumeft: Nolo propter hoc omnino inficiari, quin in vrbe medicorú collegia quae dam, \& fcolae inftituerentur, quorum qui alijs praefide bat, archiatros interdum uocaretur, vtex infcriptione Liuij Celfi fuperius allata', \& ex legibus colligi poteft, verum- 


\section{QV A R T V s. IOI}

verumtamen qui frequentius in ore hominum verfaba tur archiater, is erat, quem defcripfimus.

DeCydni funit aqua loci Plutarchi, Galeniés aliorum collati. locus Plutarchiex Galeno restitutus, locus Hipp. emendatus. Cap. 2.

15dnus Ciliciae fluuius eft tranfiens per mediam 16. 3. omni alia doctrina praeciariffmis forentem; cuius fluuij aquam frigidam, atq. afperam effe narrans Strabo Geographiae 1 4. eã tum belluis, tum hominibus neruos craffis humoribus occupatos habentibus altxiliari fcribit,poft quem Vitruuius, necnon Plinius ex Caffij Parmenfis fententia eandem aquã cruribus podagrico rum affufam dolores leuare feripferunt: Quae omnia nunquid vera fint, certe dubitari iure poteft, non modo quia frigidum neruis aduerfari pro comperto habết medici, fed etiam quòd Galenus in lib. de cauffis proca tarchticis Alexandrum magnum aeftiuo tempore dum fe in Cydno flumine lauaret conuulfione, ac tremore, torporeve captum fuiffe tradit, quemadmodum pofterioribus faeculis Fridericum Ocnobarbum Imperatorem eodem flumine lotum interiiffe fcribunt hiftorici . Nifi igitur dicamus contra Q.Curtij auctoritatem $\mathrm{Cy}$ dni aquam blădo quodam frigore, vt Paufanias fcribit pollere, \& vim detergendi infignem fub voce $[\xi a \chi u]$ a Strabone, \& interdum ab Hippocrate defignatam obti ncre, quorum illo dolores ab humore calido nafcentes mitigentur: hac vero humores ipfi neruis elidatur, quo modo podagricis, \& neruorum fluore tentatis opem fe rat intelligere arduum erit : Quod fi interdum experientia comprobatum eft frigidum affúum contullioné

$\mathrm{Cc}$ foluere, 


\section{I B E R}

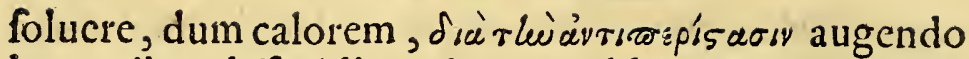
humoribus diffipădis aptiorem reddit, nō propter hoc Cydni aquam iuuare credendum, alioquin de quampluribus alijs aquis frigidis idem forct afferendủi : Neq. etiam immodico eius frigore dolores confopiri dicendum, propterea quod potius fic articulis \& neruis nocu mentum quam auxilium inferretur: ob hoc enim dicebat Hipp.de podagricis loquës in lib. de vfu humidorú

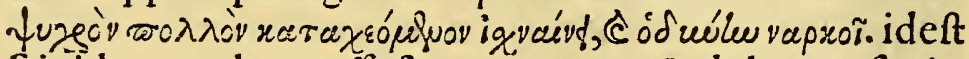
frigidum multum affufum, extenuat $\&$ dolorem fopit. Alexädrum autem ac Fridericum id paffos fuiffe puto, quoniam fortaffe nimis labore, vel aeftu calefasti aquae frigidae fefe immerferunt: Cautum enim eft medicorum praeceptis, ne quis dum magnopere calet in frigida lauetur, quoniam tunc corporis meatus valde aperti ingreffum facilem noxio humoris frigori permittunt; atq. ita nerui calorq. natiuus non parum offenduntur. Aquam autem Cydni non modica detergendi facultate praeditam effe Plutarchi teftimonio cófirmatur, qui libro, in quo de fitorum oraculorum caufas quaerit, vt demonftraret poffe aquas, \& fpiritus terrae inueniri, a quorum archana quadam poteftate animi humani ad futura praenofeenda difponerentur, alia alijs conuenire \& non omnia omnibus multis exemplis hac oratio-

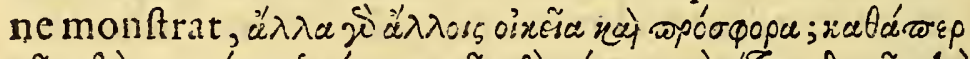

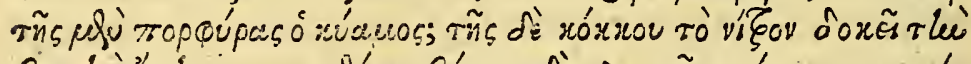

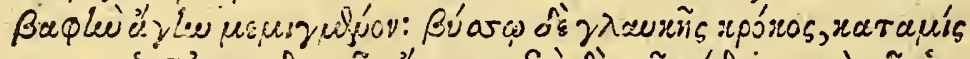

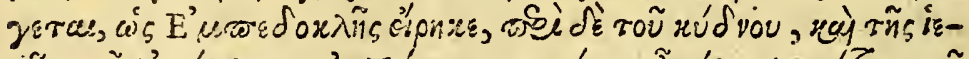

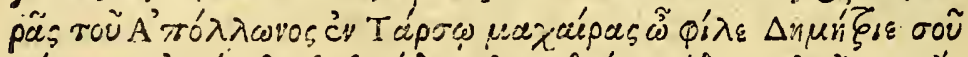

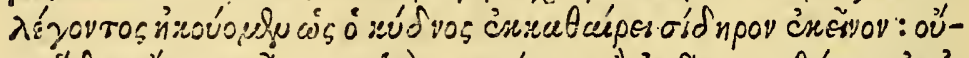

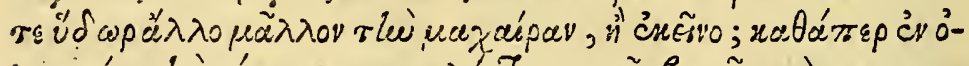

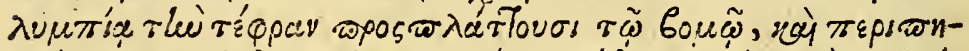

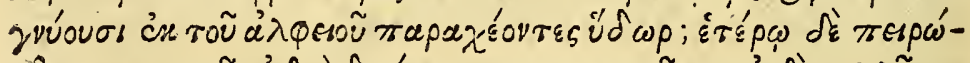

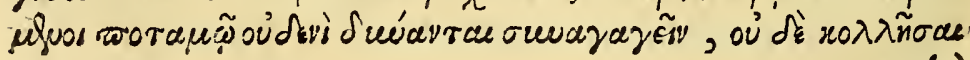




\section{Q V A R T V S. $\quad 102$}

Tleu téspav . ideft. Alia enim alijs propria \& conuenien tia quemadmodum purpurae faba, \& grani infectorij nitrum videntur tineturam commixta ducere. Byffo auté Glaucae crocus mifcetur, vt dixit Empedocles. Defuuio Cydno, \& de facra Apollonis in Tarfo machaera o amice Demetrie te narranté audiuimus, quod Cydnus ferrum illud depurgat, neq. machaeram vlla alia aqua magis quam illa:quemadmodum in Olympia cinerem arae affingunt, \& aquam affundentes Alphaei cinerem circum denfant; alio vero flumine id tentätes, nuilo poffunt coniungere, neq. cinerem conglutinare. Vbi manifefte declarat Cydni fluuij aquam dctergêdi, repurgandive (cum terrum ex quo machaera Apollinis facra in Tarfo conflata erat, fola depurgaret) vim magnam habuiffe. At hic admoneor vt paullo ante ci tatü Plutarchi verba corruptum in graeco Bafilienfi co dice locum reftituam: vbi cnim is ficcitatem calori affociatam (piritum attenuare, aetheriumq. ac purum eff-

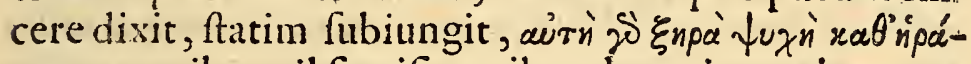
$x \lambda n$ rov; quibus nil fignificantibus, hunc in modum cor-

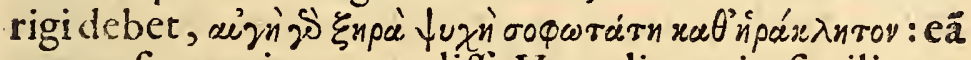
namq. fententiam protuliffe Heraclitum in fimili prope difputatione fcriptum reliquit Galenus eo libello, in quo temperatura corporis, animi mores fingi probat, vnde etiam locus Hippocratis emendâdus eft, in r. lib. de diaeta, vbi in omnibus codicibus latinis, \& graecis;

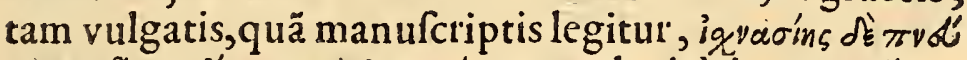

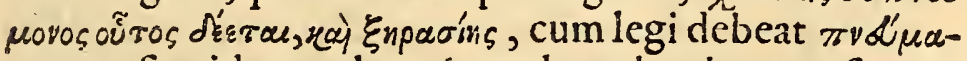
ros, fiquidem pulmonem ad prudentiam conferre nulliafferunt, fed fpiritus, qui quan-

to ficciores, \& fubtiliores funt,

tanto mentem acutio

rem faciunt.

C. 2 Loci 


\section{I B E R}

Loci Lrifotelis, en Herodoticollati . Darÿluxatio a medico Graeco curata. Cap. 3 .

Mnenfac fubtilitatis (ut ait Plinius) vir Arifto2. 19 teles in I I. Politicorum lib. Lacedaemoniorum tho Reipub. inftituta examinans inter cetera illi uitio uertit, quod lenatorbus per omnem uitae aetatem de rebus magnis iudicia ferre liceret, cum in fenectute id non fine periculo fieri poffit: quoniam(ait is ) wळøs $x_{y}^{\prime}$

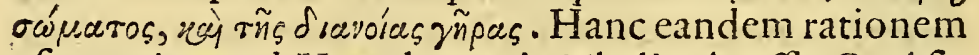
vfurpauit apud Herodotum in Thalia Atoffa Cyrifilia, \& Darij uxor, quae a Demodene medico Graeco ul cere prauo in mámilla curata, uiroq́. fuo, ve bellú Grae ciae inferret aftuto eius medici ita patriam reuifere fperantis confilio perfuadere conata inter multa alia haec

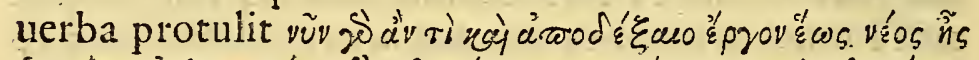

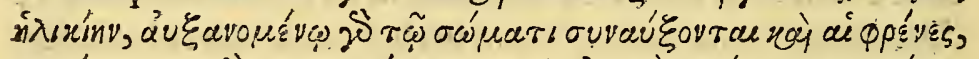

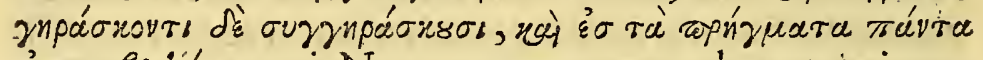
anape $\lambda$ lúovras; i. Nunc, autem, quando actate iuucnis es fi opus furcipias, (nam augefcente corpore fimul \& prudentia crefcit, fenefcente uero, confenefcit, atque ad omnia opera hebetatur) unde non immerito apudprifcos prouerbio decantatum habctur.

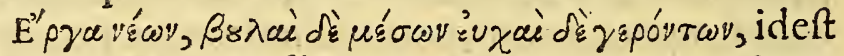

Opera ius:emum,conffilia autem mediornm, preces verofenum. quem verficulum Bocthus poeta in Athenodorum feniorem fic apud Strabonem in 14.mutauit.

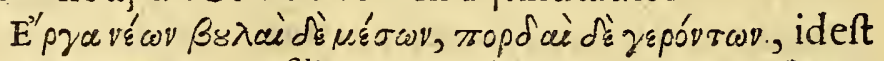

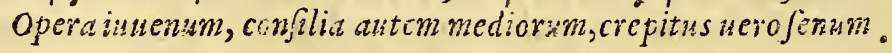
A thenodorus autem contra ipfum (६póvтas $\delta_{\varepsilon} \mu \varepsilon p o ́ v \tau \omega v$ ) fue tonitrus fenum dici iuffr. Sane haec omnia non de animae fubitantia, quam alioquin immortalem credimus, fed de illius operationibus, quae ab inftrumentis magna ex parte dependent intelligi aequius eft, etfi me 


\section{QV A R T V. $\quad 103$}

dici,ac praefertim Galenus aliter fenfife inueniatur. De mocedis mentio iam impellit me, vt quam is apud $\mathrm{He}-$ rodotum citato loco in curando Rege Dario operam praeftrtit, hifce fubiungam. Darius enim in venatu ma gnam offis tali luxationem paffus, vbi a medicis A egyptiis, qui omnium primi ea in arte putabantur uarie tra ctatus effer, nec illi in torquendo retorquendove quicquam proficerent, quin potius malum augerent; $\mathrm{De}-$ mocedes Crotonienfis Graecis medicamentis vtens \& lenia, poft acria admouens Darium, qui feptem noctesiam nihil dormierat, \& perpertuo doloris cruciatu pene confectus erat, tandem fomni compotem fe cit, breuiq. deinde tempore incolumem prorfus reddidit, cum iam pofthac validum fe fore ad incedendum de fperaffet. In qua re an folis medicamentis, an ctiam ma nibus os tali reftituerit bonus medicus, ex Hiftorici fer mone non admodum conftat: mirum tamen fit, fi medi camenta tantum (quemadmodum ex uerbis colligi pof fe uidetur) adhibuerit in eo prefertim luxationis genere, quod quando uehemens eft, ab Hippocrate, \&. Galeno omnium difficillime fanari traditur. Atqui nec de his, neque de maioribus adhuc antiquorum operibus multum mirari debemus quandoquidem eos in chirurgica, qua Clinice prius seperta fuit, pofterioribus omnibus valde fuperiores extitiffe Homeri atq. aliorum teftimoniis faciliter conuincitur.

Hippocratis o Ariftotelis loci collati, Galeni de demoftratio nibus libriqui fuerint, ó quae fymphonia a Nemefiocitata. Cap. 4 .

Voniam Hippocratem noftris adnotationibus, 6. \& emendationibus illuftratum, non ita cito, vt 3.-. optamus, ederefperamus.interim aliqua ex ipfis 


\section{I B R}

in hũ c librü fparfim protulimus, vt eruditi, quid in ipfo praeftaturi fimus, ab hifce coniicere valeant. Itaq. Hip pocrates in lib. de aer, aq. \& loc. Alianos \& Europaeos inter fe diftinguens illos ingenio magis, minus vero for titudine valere foribit, cuius euentus duas potiffmum rationes aflignat; alteram quod Afiae regio maximam acris temperati clementiam obtinuit, nullifq. propemo dum mutationibus fubiicitur : Europa contrariũ quod ve ingeniorum bonitati, atq. méti magnopere confert, fic animorũ fortitudini, qui a mutationibus magis excitati ualidiores fiunt, nullum adiumentum praebet: al teram quod Afiani femper regum imperijs fubiesti fue runt, Europaei vero non modo non feruierunt, verum etiam fere femper liberi extiterunt. Nam qui bello, \& armis non fibi quicquam, fed dominis omnia compara refciunt, negligentiores euadunt; quemadmodum cete ri fpelucri proprij inflammati quidvis animofe audent. A riftoteles frmiliter lib. 3.polit. cap. 1 o. \& lib. 7. cap.7. Hippocratem fecutus Afianos artibus, \& mente excellere quidem, at animis nihil a natura ualere, \& propterea tyrannis cótinuo inferuiffe fcribit: ficut Europacos ob regionis firigiditatem mente, ac artibus inferiores, animis vero, \& fortitudine fuperiores, ob idq. nullius regis imperiū paffos effe: inter quos graecos veluti medijs, non minusartibus, \& intellectu, quàm ar'mis, \& animorum viribus pollere. His vero, atq. multis alijs rationibus demonftrare conatus eft Galenus Hippocra tem, Platonem, \& Arifotelem animam noftram fi non ipfiffmam corporis temperaturam, faltem eius fequacem cxifimaffe : quam fententiam multis iisq́. grauiffmis argumentis damnauit Nemefus in 3. Cap. lib.de hominis natuma fub Gregorii etiam Niffeni nonine ab aliquibus falro uulgati: $Q$ no in libro cum multa ex $\mathrm{Ga}$ Leni commentarijs de demonfrationibus inferiptis adducat 
QVA R T N S. 104 ducat, quae nil prope mutata in lib.de plac.Hip.\& Pla. necnon in libello quod animi mo.feq. cor. temp.ac aliis editis legantur, fit ut facile mihi perfuadeam Galenum

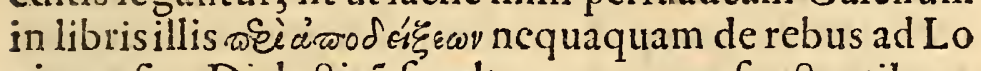
gicam, fiue Dialecticá facultatem tantum fpectantibus, quemadmod um inepte arbitrantur nonnulli tractaffe, fed praccipue earum rerum plurimas fub oculis ratione, \& fenfu po nere tentaffe, quae apud medicos, \& phi lofophos in controuerfiam trahuntur, veluti eft de fede ac partibus animae quaeftio, de affeçuuu gencratione, $\&$ cauffis, de uenarü $\&$ arteriarum principiis, de tefticulorum ufu aliaq́ue huiufcemodi plurima quod fimiliter videtur confirmaffe Rabi Mofes. 25.V. partic. aphorif. vbi hunclibrum probationes appellat. Quo in loco illud quoq. adnotare placet librum Galeni de placitis Hippocratis \& Platonis cumpwriay effe uocatum ab eodem Nemefio, quafi ipfius tempeftate fub hoc titulo ab alıquibus legeretur, cum in illo fummorum virorum concordantiae declarentur: Vixit vero Nemefius Gra tiani, \& Theodofii temporibus quando Maximus philofophus Platonicus.Libanius, Bafilius, Gregorius Nif fenus, aliig. plurimi praeclarifimi uiri forucrunt quae tempora ab aetate Galeni paullo plus I 50 . annisabfue runt, vt ob hoc non paucam fidem Nemefii fcriptis adhibendam cenfeam.

De putarninibus fabarum, of quid fit oar pror Ltbenaco. Cap. s.

1. Vod Theophraftus in 5. de caufis plătarum cap. (2.) 2 I. Tribit fabarum putamina tadicibus,autger 2.2. minibus plantarum novellarum appofita ea. rum vitam penitus tollere, etiam a Clemente Alexandrino Stroni.3. \& ab Apollonio in mirabilib, hiftoriis cita- 


\section{I B E R}

citatủ ex quincto de caufis naturalibus, (quafi ficliber ille inferibereturiantiquitus) inuenio; qui cum addant domefticas gallinas ijfdem putaminibus iugiter vefcen tesfterilefcere, neq. id a Theophrafto traditú fit, eiufce modi fententia non exiguã mihi fufpicioné parit;quêadmodum item nó admodum probo Pythagoreos iccir co fabarum efum vetaffe, quod comeftae mulieres infoe cundas reddant; quoniam, ut meminit Galenus, fabae fi belle nutriunt, \& flatulcntae funt, potius foeconditatem, quam fterilitatem inducere debent: Fabam ue ro appellatam effe per excellentiam a Clemente Alexä drino in loco citato óa proy non miror, quando fic in ufu fuiffe apud ueteres puto, vnde Galenus in 2 . de fac. ali. legumina recenfens, primã fabam collocauit; verficu-

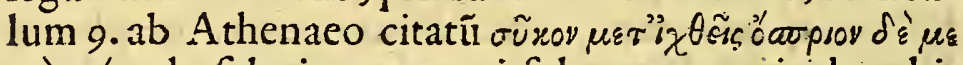
rà xpéas de faba interpretari foleo, quam uiridem his quoq. temporibus homines poft carnes loco bellariorum efitant, quamve etiam hodie a vulgo Graecorum cous prov paffim uocari intelligo.

In Acrotboracis fignificatione Clementis Alexandrini locus emaculatus, cur lawri folia poft cenans adbiberenitur:ebrietatis

praecautiones Plinijlocus emendatus. Cap. 6.

S. Riftotelcm in 3. probl. parti. probl. 2. manife7. 26. cium ferre tentant, fed in iudicando aberrant; quafi medii fint inter fobrios, \& temulentos; quorum illi iudicandi uim firmam, \& incorruptam habent ; hi uero adeo vino obruti, \& fepulti iacent, vt neq.iudicare, ne que fecũdum animi corporisve facultates operari que2nt. Erotianus in Onomaftico ubi $\theta \omega \omega_{p} \xi \iota v$ ab Hippocra te ösvotrooíav vocarifcribit ảxpo fópnrzas etiam vfq.ad tem 


\section{Q $\vee$ A R $T$ V S. I 5}

pora fua, eos appellatos fubiungit, qui non multum vino repleti funt. Plutarchus quoq; in 3 . fympor. prob. 8. Ariftotelis fententiam examinansidem, quod is om nino fentire videtur äxpot $\omega_{\text {paras. }}$. corpus nô adeo diffolutum habere, quin, \& moueri, \& fecundum ipfum ali quatenus operari valeant;at corum difcurfiuam vim mi nime liberam efle; nempe cum iudicium phantafras, \& non rationem fequatur. Itaq; non video cur Alexandrinus Clemens diuerfa fentiens in 2. paedagogi ảxpo$\theta$ ćpaxe minime rationcm, ac memoriam offenfas gere. re fcribit. Nam fenibus chriftianis, ve vino vtantur eoufq; indulgens, quoad áxpot cópres terminum non tranf

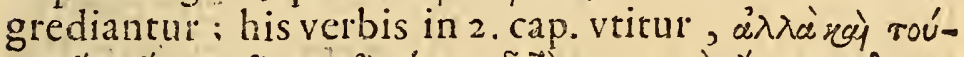

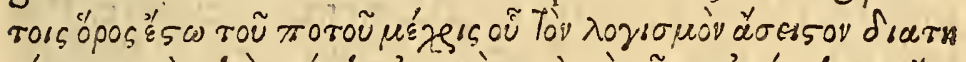

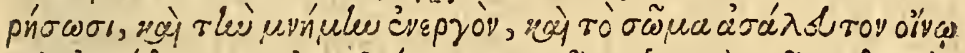

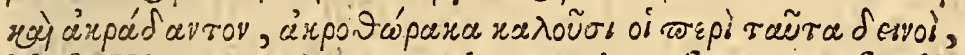
ideft. His autem in potando terminus fit, quoufq. difcurfum immotum feruent, \& memoriam efficacem, \& corpus vino inconcuffum \& immobile acrothorace vocant circa haec periti. quo in loco uerum illius uocis ufum omnino ab ipfo ignoratum perfpicitur, nificon

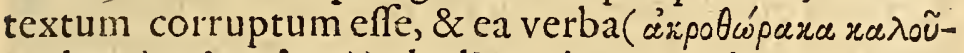

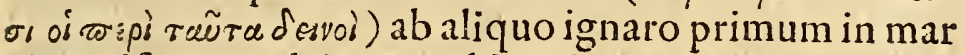
gine adfcripta, deinceps a librario inepte interferta fuiffe velimus, quemadmodum plures fimiles vulgata cius auctoris commentaria habere apud doctos conftat. Legimus apud Athenaeum in 4 . veteres inter bel laria poft cenam interdum etiam folia lauri adhibuiffe, quod pluribus rationibus factum puto, fed potifrmum duabus hifce, tum vt ui foliorü exiccatoria fumi ad caput elati abfumerentur; tum etiam vtodor vini, ac cibo rum qui folet facpenumero à paftis hominibus grauis emitti,abfconderetur; id quod Martialis in 5. facete, \& clare admodum nobis indicauit.

$\mathrm{Dd} \quad$ Foetcre 


\section{I B E R}

Foetere multo Myrtale folet rino, sed fallat vt nos, folia denorat louri, Merumq; cauta fronde non aqua mifcet; Hanc tu rubentem prominentibus venis Quoties venire Paule videris contra, Dicas licebit. Myrtale bibit laurum

Vt quoq; euitarent antiqui ebrietatem interdum lauro hedera anetho, fimilibufq; alijs eos coronatos inter potandum legimus : alij pumicem tritum, alij amygdalas amaras, alij brafficam praemandebant, quafi non pracftaret ebrietatis turpitudinem fobrietate cauere, quam eam fuccis, alijsve medicamentis occultare. Plinius lib. I 4. cap. 2. de Apianis vitibus loquens ita fribit. Vina primo dulcia aufteritatem annis accipiunt, $\&$ rubra fiunt. Nulla magis vite gaudet; in quibus duo funt quae non immerito eruditorum animos turbare poffunt, vnum, quod vina alba a principio, vetuftate nổ rubra, fed vel pallida, vel flaua, vel fulua redduntur, quemadmodú Galenus docet 5. de tu. val. \& I 2. meth. Alterum quod poftrema illa verba quid fignificent, $o b$ fcurū eft. Itaq; reftitui-debent, vt in manufcripto Pauli Manutij omnium poft Ciceronem eloquentiffimi codice inuenitur. ita 5. Vina primo dulcia, aufteritatem annis accipiunt. Ethruria nulla magis vite gaudet .

Tuberes apud antiquos quieffent. locus Tlin̈̈ notatus. Cap. 7 .

Vi fuerint apud maiores noftros tuberes inter malorum genera relati, neminem qui apertè de fi meam fententiam explicuero, id faltem proficiam, vt alij ad veritatem indagandam, meq; fententiam melio- 


\section{QV A R T V S. $\quad 105$}

rem proferendam excitentur. Ne igitur temere quicquam affirmare videar, notas aliquas tuberum $a b a u-$ Etoribus latinis tradicas ante alia indicabo; Tuberes ex Africa regione calida primum allatas, fcribit Plinius lib. 15. cap. 14. vbi fructus proferre baccis, quam malis fimiliores' ftatuit : idem quoq; lib. 16. cap. 25 . \& lib. 17. cap. 16. tuberes poft amygdalas cum armeniacis, \& proecocibus florere, (vt Columella lib. Ir. in fine cap.2.) quafi cum ijs etiam maturarentur fructus', \& melius inferi pruno filueftri; atq. malo cotoneo, quam granis feri memorat. Martialis lib. I3. auctor eft tuberes in agro Nomentano prouenire folitos, quae regio inter Romana fuburbia pro calida, \& aprica habetur. Palladius vcrolib. Io.titul. 14. tuberum fructus dulces facit, menfeq́; Septembris eos granis feri, nec non etiam omnibus malorum generibus prunis, \& cotoncis inferi folitum tradit; quas omnes notas fi ijs arboribus conferamus, quos decem ab hinc annis plus, minusve ex Alexandria in Siciliam primum, mox Neapolim tranfue tos; ob idq. albercocos Alexandrinos nuncupatos effe fcimus, facile iudicabimus tuberes veterum hosmet albercocos extitiffe. nam ij funt arbores nonadmodum procerae magnitudinis, foliaq; armeniacorum fere gerunt, florent ftatim poft amygdalas, inferuntur praecocijs, perficis, \& prunis; feminantur granis Septembre, \& OAtobre, fed infitione meliore fiunt; nafcuntur locis calidis, \& apricis, gelu corrumpuntur : ficcam terram fed arte irroratam amant: frustus nuce pontica paullo maiores rubeos, cutelcui, ac dulces fuauefq. ferunt, vt cuiq. intelligere liceat huiufmodi arbores fructufq. maxime cum veterum tuberibus conuenire, nec quicquã repugnat, quod Domitiano prius quã iugularetur feptêbris menfe oblati fuerint tuberes, quoniam eos adferuatos

$$
\text { Dd } 2 \text { ea arte }
$$




\section{I B E R}

ea arte effe credendum eft, quam Palladius loco praeci tato monftrauit, neq; inferend um eft, Palladium, quod in libro menfis Oftobris tuberes feruandi rationem do ceat, eos tunc maturari voluife: quoniam hac in re auEor ille certam legeni non feruat, cum etiam in libro A prilis zyzipha quae autumno maturátur feruädi modum indicet. Martialis item quamuis tuberes cum ma lis punicis adnumeret non propterea putädum eft eum innuiffe, quod eodem tempore maturarentur. Immo hoc diftico:

Lect.a fuburbanis inittuntur apyrina ramis,

Et Dernae tuberes, quid tibi cum Lybicis?

Forte dicere voluit, fe ad amicum duo pomorum genera miffife, vnum nuperrime ab arbore lectum, alterum domi quidem, \& ipfum natum, fed integrum arte conferuatum. Porrò Plinianum codicem lib. I5 - cap. I4. vbi tuberum duo genera habentur, corruptum omnino, ac loco tuberum legendum effe zyziphorum fufpicor, quoniam Columella lib. 9. cap. 4. albam, \& rutila zyziphum agnofcit. Galenus zyzipha 2 . de alim. fac. appellat, nullus autem duo tuberum genera fuiffe fcribit. Sericum vero colorem Plinio rutilum, vel rubrum effe, quem alibi Siricum \& ipfe, \& Aetius, \& Paullus A egineta vocarunt, fatis Barbarus in Plinianis caftigationibus declarauit.

De Menta locus Aristotelis ex Hippocrate illufratus o correEtus Plinï alter ad idem notatus, \& ex sucretio explicatus. - Cap. 8 .

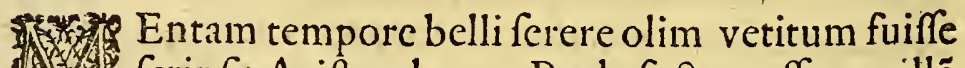
4. fcripfit Ariftoteles 20. Prob. fea. cauffamq; illä 2*x putauit, quod huiufmodi herba corpora humana refrigerando genitale femen corrumpat, ficq; vires, 


\section{QV A R T S. $\quad 107$}

quibus in bello maxime opuseft frangantur: quo in lo

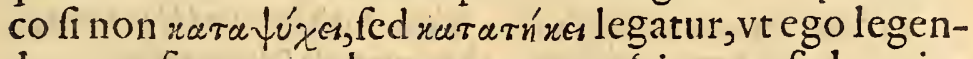
dum cenfeo, quando menta non refrigerat, fed potius colliquat Hippocratis fententiam tranftuliffe alicui videri poffit, qui in 2. respi draírns hunc in modum, de mé

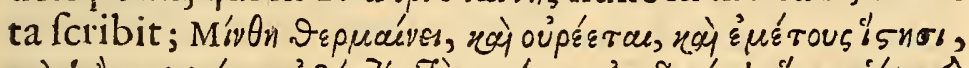

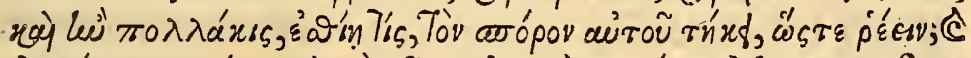

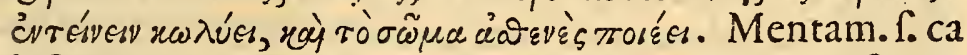
lefacere, vrinam concitare, vomitus comprimere, fiq; ea faepenumero quis vefcatur, illius femen, ab ipfa ita liquari, vt fluat ad haec tentiginem arcere, imbecillumq; corpus facere; fimili prope ratione Plinius lib. 20 . cap. I4. mentam femen humanum deprauare, atq; generationi ineptum reddere tradit: quod ficuti illa immifta lasti quo minus coeat, concrefcatue, prohibet; ita femé condenfari $a b$ homine in cibo fumpta non finit, vbi legendum effe [cohibendo genituram denfari], \& non [genitalia] vt. in vulgatis habetur qui vis mediocriter doctus facile conijcere poffet. Nifi genitale pro genitura Plinium \& ibi, \& cap. 2 I. eiufdem libri vfurpaffe, conftaret. Quantum vero, ad fterilitatem refferat, vel nimia geniturae liquiditas, vel immodica craffities, præ ceteris elegătiffime, dixit Lùcretius in 4 . hifce verfibus.

T.am steriles nimium craffo funt femine partim: Et liquido praeter iustum, tenuique vicifsim. Tenue, locis, quia non potis est, adfigere adhaefum, Liquitur, ex templò, co reuocatum cedit ab ortu: Crafsius boc porrò , quoniam concretius aequo Mittitur; aut non tam prolixo pronolat ietu; Aut penetrare locos aeque nequit; aut penetratum; Aegrè admifcetur muliebrifemine femen 


\section{$L I B E R$}

Aristotelis error de Epilepfia. Hippocratis locus ad id notatus, Serü̈ error, Aristotelis alter error, de Sale, \& nitro: brenis adnotatio, de caufsis res duratas diffoluentibus. Cap. $\mathbf{9}$;

W. Riftoteles fect. prob. 3 I. quaerens cur homines Why foli vel maxime inter animalia oculis peruertan-

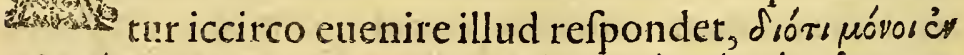

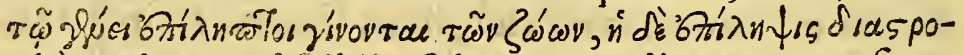
qui товє̈. quod filicet foli in animalium genere fiunt cpileptici, cpilepfia vero oculorum peruerfionem indu cit. Hanc vero fententiam omnino falfam effe, vt putem, duo faciunt, vnum eft quod ipfemet Ariftoteles in libris de animalibus nonnulla recenfet, quae iifdem morbis, quibus homines, tentari fribit, vt oues, Alterum, quod in libro de facro morbo, qui vt Hippocra tis a Galeno in r.progno text: 4 . \& lib. an fanguis in arter. contineatur, nec non a Caelio Aureliano lib. I. paff. chron. cap. 4. citatur, fcriptum eft oues, \& maxime capras epileptico morbo non parum obnoxias effe, quod certe de ouibus valde uerifimile uidetur, nempe quae caput in terram fere detinentes halitus pratios ac humiditatem craflam facile in caput trahant, \& fubinde morbum facrum incurrant. At caprae, quae alto ca pite, ut plurimum pafcuntur,ficcaeq. funt, ac perpetuo febrire traduntur; quomodo ouibus magis cpilepfiae, quac a larga pituita gignitur, exponantur, non admodum intelligo. ${ }_{0}^{5}$ Nifi dicamus, ut Plutarchus in Rom. prob. capras ceteris animalibus magis comitiali morbo tentari, ob meatuum anguftiam, quam arguit uocis tenuiras, atq; ctiam eodem morbo facile capi cos, qui caprinis'carnibus ucfuntur . ob quod facerdotibus eã carnem uetitam fuiffe tradunt. Itaq. fententia Arifotelis 


\section{Q V A R $T$ V s.}

telis fic moderari debet vt in feet. 10. probl. prob. 43 .

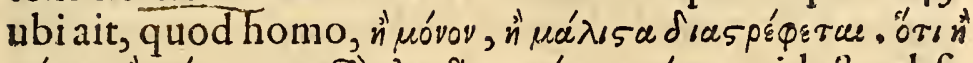

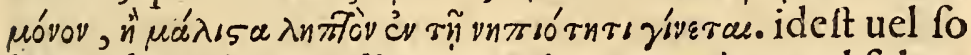
lus, uel maxime oculis peruertitur, quoniam, uel folus, uel maxime in infantia epilepticus fit; qua ratione in libro de fomn. \& uigil. praeceptum dedit, ut non folum pueri, uerumetiam nutrices a uino, \& praefertim. nigro abftinerent, tamquam id magis, quam album ad caput euaporet. Hic animaduertere placet feruium in 3. Georgicorum grauiter pecaffe, qui ubi Virgilius ait.

Contactos artus facer ignis edebat.

Putauit facrum ignem effe, quem graeci ispàv vórov uocant, cum iepá vóros, nil aliud fit, quam cpilepfia tocata: Ignis uero facer apud latinos idem fit, quod apud Arabas formica, apud G1 aecos Herpes, apud Scribonium zona, apud Plinitam zofter, \& Circinus. De hoc morbo facro fcriptum eft a Platone I I de legibus; fi quis feruum, uel phtifi, ucl calculo, uel ftranguria, uel facro morbo, aut aliqua alia uulgaribus, ignota longa \& curatu difficile aegritudine laborantem alicui, qui neque medicus, neque gymnaftua fit, uendidetit, licere emptori intra fextum menfem ipum redhibere excepto facro morbo, quo laborantem emptor intra annum reftituere poteft. Cauffam uero cur hunc mor bum exceperit, puto, quia alii enumerati morbi fex menfibus dignofcuntur, \& fere incurabiles euadunt; epilepfia uero, fiue morbus facer, uix intra an num uerè difcerni poteft; atq. curatu difficilis euadit. Et quo niam Ariftotelis mentio eft fubiungam hifce quandam illius of citantiam quam alioquin perfpicaciffimus in 4 . meteorol. lib. commiffit, ubi indurata quibus cauf fis diffoluantur exponens, de fale, \& nitro haec dixit, 


\section{$L I B$ E R}

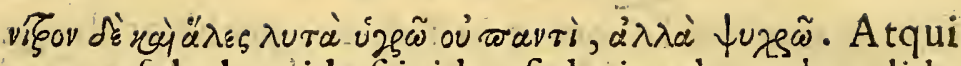
ea non folo humido frigido, fed etiam humido calido diffolui fenfui manifeftum eft; nam, \& fi vinum, \& aqua calefaıta à quibus clare fales, \& nitrum foluuntur, poffint quodam modo frigida, humida appcllari, cum fint fub genere aquae, acillius propriam qualitatem nempe frigiditatem quantumvis mutata nunquã penitus amit tant; de oleo tamen calido id affirmare non poffumus, nempe quod ipfemet Ariftoteles in eodem libro, non fub genere humidi aquei, fed aerei, cui perpetuo iundta eft caliditas a perte collocauit, ab illoq. tam fpontaneo, quam calefacto falem liquefieri experientia quotidie comprobatur. Quare melinserit fic de duratarum rerum diffolutione ftatuere. Quae a frigido ficco concre fcunt, vel à moderato, vel ab immoderato omnem humiditatem exprimente talia reddütur; fimiliter, \& quae à calido ficco concrefcunt, vel à moderato; vel ab immo derato omnem humorem confumente. Concreta à fri gido ficco moderato, vt glacies, vina, ferum, \& vrina à calido ficco fimpliciter; \& etiam, calido humido 'foluun tur. Concreta vero ab immoderato, aut fimpliciter in folubilia funt, vt adamas, \& aliae gemmae, aut non nifi à vehementiffimo calore foluuntur', quemadmodũ plu rima metalla; \&z cornua, quae magno calore mollefcût. Concreta vero à calido ficco moderato: à calido, humi do,\& frigido, humido foluuntur; vt fales, manna, \& nitra, quae ab aqua calida actu , \& à vino poteftate calido nec non ab oleo calido foluuntur. Concreta ab immo derato, vt lateres, fictilia, aut non foluuntur, aut folum modo ab ijs humoribus, qui maxime penetrant, ficut fuccus citri \& acetum acerrimum elambicatum, aqua uitae, \& fimilia, quae aliquos lateres, lapidesve foluunt; quod forfan ignotum fuit Ariftoteli, quamuis ex ipfo ratio huius habeatur:nam cũ neget ipfe fictiles liquari; 


\section{Q VARTIS.}

proprerea quod aqua eius meatus, per quös fpiritus exi uit,penetrare nó poteft, manifeftum eft quod fi aliquis humor adeo fubtilis inueniatur, vt eos ingredi queat, ctiam ex eius fententia poterunt liquari : inueniuntur autem facile hifce temporibus, quibus ars chymica Ari fotelis tempeftate ignorata, cuius opera fubtiliffimi ac maxime penetrabiles humores efficiuntur, in facilem vfum tracta, quafiq́. perfc tra eft.

\section{Loeus Hippocratis, ex Gellio restitutus, \& alter defenlius. Cap. 10.}

Vlus Gellius noc. lib. 3. cap. 16. haec verba ex

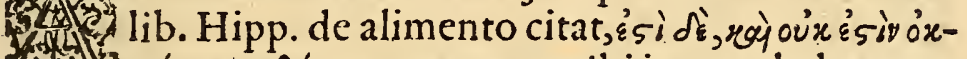

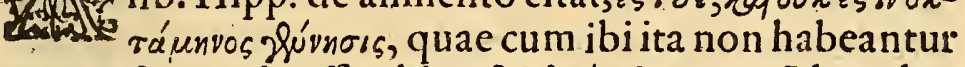
puto reftitucnda effe, vbi poft [ $\varepsilon^{\zeta} \varsigma$ है $\left.x \pi \hbar \omega \sigma \cdot v \sigma \mu\right]$ haec ha-

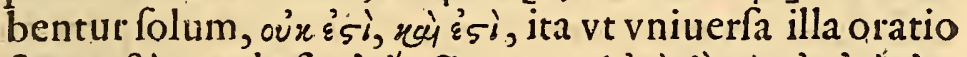
fic confituenda fit, ह்ऽ हैx

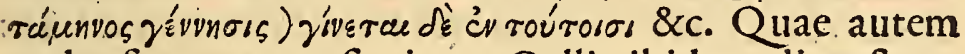
verba fequuntur etfi etiam a Gellio ibidem diuerfa po nantur, placent tamen magis vt funt in vulgatis Hipp. codicibus. Explicatio porro ipforum verborū licet obfcura admodum fit, ac Sabinus diligentiffimus, vt faepe eum vocat Galenus Hippocratis interpres illa clariora

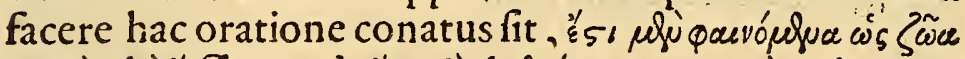

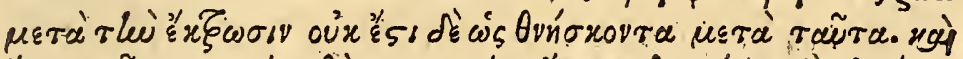
हैร non abfurdum tamen mihi videtur Hippocratem nil aliud docere voluiffe, quam quod octimeftris partus, nó propriè generatus, fed impropriè tantum dicatur quafl potius abortus, quam vera generatio fit, quod enim putarunt aliqui Hippocratem uoluiffe docere quod alibi non fuperuiuant nati octano menfe, aliqui vero fuperfitcs fiant, qucmadmodú fcribit Ariftoteles in AegyEe pto 


\section{I B E $\mathbf{R}$}

pto fieri poffe: id fane placitis Hippocratis nequaquam confonum eft, qui in libro de octimcltri partu móltrat, fieri non poffe, vt nati in ostauo méfe fuperuiuant. Cri minantur aliqui Hippocratem, quod in iufurando cauerit, ne quis medicinam exercens mulieri vtero geren ti, abortiuum medicamentum propinaret, cum tamen ipfe in lib. de natura pueri fripferit fe famulae cuidam grauidac, ne apud alias mulieres infamaretur, confuluif fe, ve faltando genituram deijceret; quod factum Hippocratis ego hac ratione tueri foleo, quod foetus nondum animatos corrumpere, vel quo minus vitam adipifcerentur impedire ijs temporibus, quibus nondü chri ftiana lux apparuerat liceret; at iam animatos, \& viuen tes minime offendere fas effet, atq. hoc ita fuiffe locupletiffimus teftis eft Ariftoteles lib. Polit. 7. Cap. 16. Qui tamen 7 . de Hifto animal. ne foetus animaretur, docuit poft coitum locos oleo cedrino, aut fimpliei cữ thure ceruffave effe vngendos. De Hippocratis, \& Gel lij loco cum iam fentétiam meã ftatuiflem, eamq. Clau dio Puteano communicaffem; is retulit Muretū quoq. eum locum reftituiffe, iccirco ad ipfum feripfi, vt cuius saram eruditionem, accrimumq.iudicium femper plu rimi feci, eius opinionem explorarem. Tandem Muretus hocce dedit refponfum.

\section{ANTONIVS MVRETVS. HIE- RONYMO MERCVRIALI. S. P. D.}

Vm tuae litterae, ad Vrbem allatae funt; Tibur iam omnes, vt nos quotannis facere folere fcis, fecefferamus, eò illas accepi biduo, aut triduo fo rius:Tibure autem, neq. Hippocratem habebain, neq: Gellium.expectandum denuo fuit, dum Roma acceffe- 


\section{QVARTV s.}

rentur. Allatis; ecce tibi aliud incommodum : corripit me febricula, nō illa quidem, vt cuentus poftea docuit, periculofa: fed. quae tamen animum nonnullo metu fufpenfum ab omni fcribendi cogitatione auocaret. Hæc ideo, ne mireris me ad tuas tardius refpondere.Lo

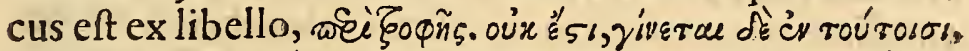

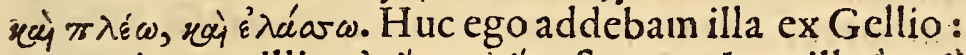

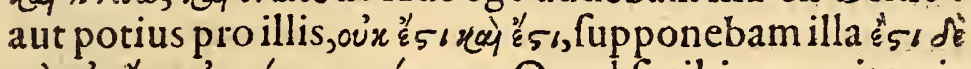

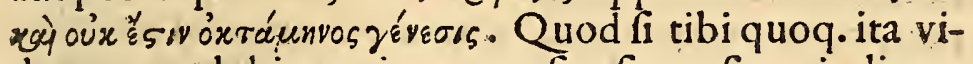
detur, non dubito quin verum fit; fin tu fecus iudicas, nunquam mihi dubium erit, quin tua fententia verior fit. Semper enim non in his modo rebus quarum tua propria poffeffio eft, fed in omni literarum genere, iudi cium tuum libentiffime anteponam meo. Vale, meq; ama, \& certo tibi perfuade, te a me mirifice \& amari, \& coli. Tibure. Kal. Septemb.

M D LXX.

Quae fint paleales vuae, 2f fabriles apud Caclium Aurelianum. Quac menfae frigidae Plutarcbo, o cius locus
emendatus.
Cap.
I.

Vae fint apud Caelium Aurelianum lib. de acu tis paffionibus vuae paleales, \& quae apud cundem vua fabrilis, cuius meminit faepius adhuc multi dubitant. Ego vero ita exiftimo plures fuiffe mo dos veterum in feruandis vuis. Nam primo feruabantur in ollis fictilibus, atq. in doliis inclufae, uinaceis ftipatae circumfudantibus, ut manifefte docet Plinius. Seruabantur quoq. appenfae uariis modis, non tantum ad efcam, uerum etiam ad faciendum paflum appellatü, atq. alia potus gencra. Ex uua namq. refupina fufpen$f a, \&$ in uafis fuis feruata, ac thecis naturalibus cuftodita uinum acinaticum Veronenfe adeo celebratum, \& Imperatoribus aeftimatum fieri confueuife teftatur

$$
\text { Ee } 2 \text { Caffio- }
$$




\section{I B E $R$}

Caffiodorus i 2. Variarum. Ad haec refert Columclla inter multos feruandarum uuarum modos hunc extitif fe fére praecipuum quando in labello fictili nouo paleis quain ficciffimis cribratis, ut fine puluere effent impleto, unac condcbantur, deinde labellum luto paleato cir cumlinitum in tabulato ficciffimo palcis ficciffimis obruebatur. Has uuas paleales Coelium uocaffe puto nimirum quae humore fuperuacaneo fpoliatae aegris im pune concedi poffent: nifi potius eas appellet paleales, quae colore funt paleis fimiles, cum praefertim addat, recêtes, eo quod illae ui quadam adf̂trictoria magis pol leant, quales puto fuiffe cydonitas a Columella uocatas. Porrò quae fuerit uocata uua fabrilis non admodum difficile eft diffinire, fi quidem ea erat, quae in offi cinis fabror um ferrariorum fufpédebatur, ut igne, atq. fumo exiccata diutius poffet fana conferuari, Idq. innuit ijfmet Coelius 4. lib. de diuturnis paff.cap. 3. dicens fabrilem uuam effe dictam uapore fumi ficcatam. Vt enim dolia uinorum ad fumum poncbant antiqui, praefertim Maffilienfes ac Narbonenfes quo citius uetuftefcerent, ac innoxia magis redderentur. Ita uerifi. mile eft uuas fumo exiccatas conferuare potuiffe, atq. ob id fabrilcs nuncupaffe. Quam rem uidetur non obfcure expreffiffe Plinius lib. 14.cap. 2. ubiloquens de uuis ut conferuarentur, ita fcribit. A lijs gratiam, qui \& uinis affert fumus fabrilis, ijfq. gloriam praecipuam in fornacibus Africae Tiberij Caefaris auctoritas fecit. De huius generis uua Horatius 2. fer. fatyr. 4. .

\section{Reftius Albanam fumo duraueris vuam.}

Cur vero eas in coeliacis, $\&$ alijs uentris defluxionibus commendet, ratio eft, quia fumus, \& calor officinarum fabrorum ratione ferri, quod ignitur affiduo, non modo exiccat, uerumetiam facultatem quandam adfricto riam, \& corroboratoriam immittit, quae in huiufcemo u. : 


\section{QVA I Y s. III}

di affectionibus non parum conferunt . Cafeum fimiliter fumo exiccare confueuiffe Maiores teftatur Martialis hoc difticho.

Ton quemcunque focum, nec fumum cafeus omnem, Sed Vel abrenfem, qui bibit, ipfe sapit.

Quod Athenaeus. 4. dipnos: ex Dromea parafito friprit. Prohoemiū cenac in Chalcide fuiffe illuftrius quä totum Athenienfium apparatum, fub nomine prohoemij oftreorum copiam, \& varietatem indicans, Veteres in principio cenae oftrea praebere confueuiffe môftrat, quod etiam prae ceteris uidetur teftari Plutarchus. 8. Sympos. 9. ubi haec leguntur a nobis in quibufdam ut

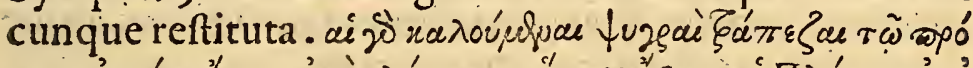

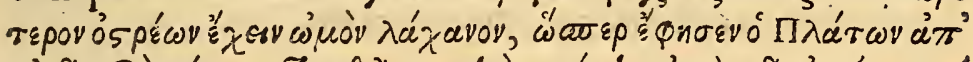

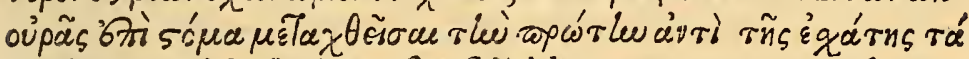

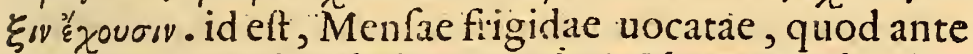
oftrea, olus crudum habent, vt dixit Plato a cauda ad os translatac primum pro vltimo ordine habent. Ex quo conicere quoq. I icet menfas frigidas vocatas, quas nüc acetaria Latini appellant, \& antiquitus in vltimo menfae ponebantur,tem pore Plutarchi coepiffe primo loco in menfas ferri, cui etiam adftipulari videtur Martialis, qui lactucam prius vltimo méfae loco pofitam, fua aeta te ante alias dapes efitatam teftatur hoc difticho.

\section{Claudere quae cenas lactuca folebat auorum}

Dic mibi cur noftras inchoat illa depes?

Vixit autem Martialis iifdem temporibus, quibus Plutarchuscum alter fub Domitiano, alter fub Traiano, qui Domitiano poft Neruam fucceffit floruerit vt hac ratione potuerit vierque ufum acetariorum eo tempore innouatum nobis fignificaffe. Hactenus quae ego cé feam : Scd ne eruditos vlla ex parte defraudem, vtque habeant quomodo in variis rebus diiudicãdis ingeniũ, \& iudicandi vim excrcere queant, fubiungam his aliam 


\section{I s $\mathbf{x}$}

eius Plutarchi loci correctionem pulchram quidem, \& Hierónymi Mei uiri acutiffimi, qui cam excogitauit, eximia doctrina vere dignam, Eft vero illa huiufmodi,

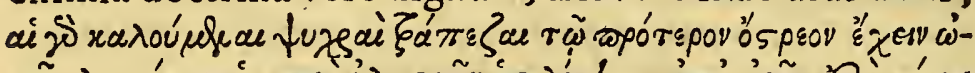

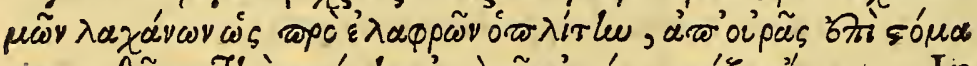

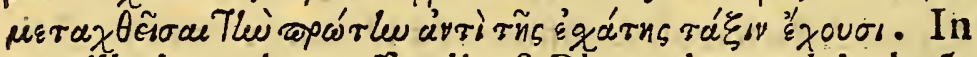
qua illud quod me offendit eft. Plutarchum ad declarādas nouorum morborum cauffas inducere nouú ufum ciborum, Atqui oftrea ante alios cibos comedendi vetus fuit confuetudo, ficut $\&$ herbas loco cenae vltimo

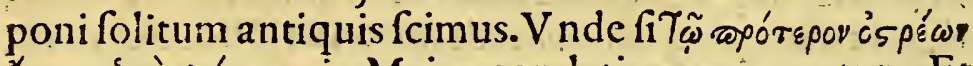

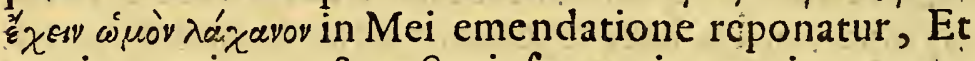
gratiam maiorem, \& auctoris fententiam verius, atque aptius forfan affequebatur tota oratio.

Qui fint apud medicos Ichores. Locus Iulï Pollucis de norbis emendatus. Fauorini erratum, fudor fan-

$$
\text { guineus. Cap. } 12 .
$$

Chores frequêter in oris medicorum verfari ne mo ignorat. Ar qui fint ij pauci om nino intelligunt, iccirco hac in re fententiam meam declarare audebo non aliunde quàm ex ipfis auctorum probatiorum fcriptis acceptam Homerus in 5 . Illiados fub his verfibus .

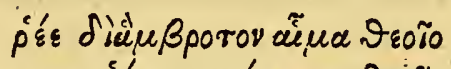

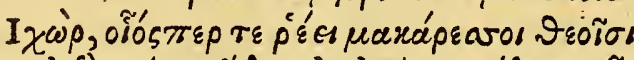

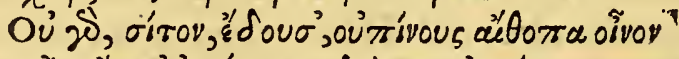

Thंs oủvex' àvá́

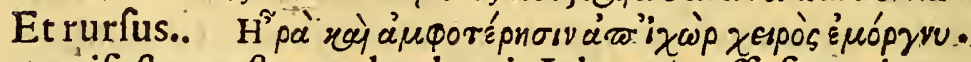
manifeftum eft quod voluerit Ichorem effe fanguinem Deorum, qui cum nec pane, nec nigro vino vefcantur, vt homines, iccirco fanguinem humanum non gignüt, fed ichorem.Hipp.2.Epid. circa principium.4.de ratio- 
ne victus text.1. 6. Epid. Commento.2.tex.38.Ichorés (vt fentit $G a l . i n$ iis commentariis) appellauic aquofas, atg. tenues humiditates, a corpore emanantes, quae prout à variis humoribus fecernuntur, fic varias qualitates, \& appellationes habent, dum alii biliofi Ichores, alij melancholici vocantur. Hippocratis fententiam aemulatus Plato in Timaeo dixit, ichorê fanguinis effe blandum, ferum, acidae vero, melācholiae ä2grovvi.ferū. Ceterum A riftoteles vnum folũ ichorum genus agnouiffe videtur, atq. id nil aliud effe voluiffe quàm fangui nem imperfectum, vel in ferum conuerfum, vt eft apud ipfum videre 3. de Hift. animal. Cap. 19. immo in 2. de part.animal.Cap.4. Frriptum reliquitichorem effe partem aqueam fanguinis, vel nondum co tam, vel corruptam. Vnde 4. metheor. Cap. 7. dixit fanguinem ichorofum non coagulari, quod huiufimodi fanguis fit pitui ta, \& aqua, cum neq. coctus, neq. a natura fuperatus fue rit;\& Cap. Io.ichorem veluti ferum, vinum, lixiuium, \& a lia aquae naturae cffe ftatuit. 1o. etiam probl. prob. 2.quaerens cur homini maximc omnium animaliiu fanguisa naribus cfiluat, id euenire refpondet, quoniam cerebro humidifinmo eft , unde fit ut fanguis capitis humiditati plurim $x$ cerebri commixtus ueluti ichor euadat, \& fubinde uenis facile effluat. Eft igitur Arift. Senté tia ichorem effe aqueum fanguinem, uel partem fangui nis aqueam, incoctam, uel in ferum mutatam. Itaq. duplex hoc ichoris genus, uel per folam cruditatem factũ, uel per corruptionem, \& in ferum mutationem. Ex primo per coutionem poffe fieri fanguinem aperte fcribit Arift.3.de hift.animal.Cap. 19.Celfus lib.5.Cap.27.appellauit ichorem fpeciem faniei tenuem fubalbidam ex malo ulcere emanantem. Diofcorides uero Cap.de cor no fuccum foliorum corni uiridium dum uruntur emanantem uacauit ichorem, qquem quafi imitatus Aetius 


\section{I E I}

cochlearum muccum, \& ipfe ichorem nücupauit. Iulius Pollux lib.4. Onomaft. Cap. 25 . ubi de morbis totius corporis loquitur ichorem videtur appellaffe morbum quendam capitis ulcerofum, fed fufpicor fubeffemen-

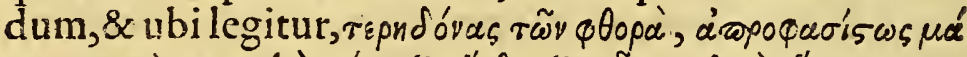

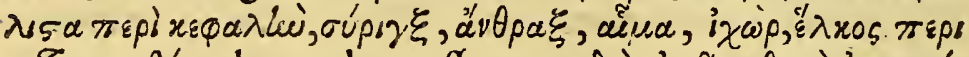

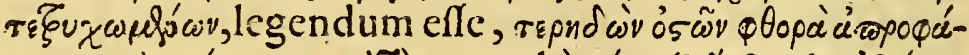

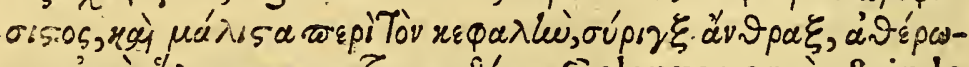

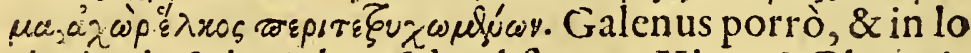
cis citatis, \& in 6.de tuêd.ual.fecutus Hipp. \& Platonis fententiam de qua etian 8.de plac.Cap.7. videtur omnino cenfuiffe ichores, nil aliud effe quam tenuiorem atq. acuofiorem partem vnius cuiufq. humoris, ficut enim in lacte adefererum, quod nil aliud habctur, quam pars ea fanguinis humidior quae in cafeum, uel in buty. rum verti nó potuit, pariter etiam in fanguine atq. aliis humoribus tam fanguini mixtis quàm feparatis reperitur, quaedam pars aquofior, quae in fubftantiam humo ris verti nó potuit, exąte lero proportione refpondés, $\&$ ichor vocatur, ac eiufdem facultatis eft femper, cuius eft proprius humor, ut Gal.4.Acut. 1.6. Epid.có.2.text. 28.\&.2.de temp.nce nó Paullus Lib.r.Cap.100.ex Dio clis fententia clarifime céfuerunt, neq. folum eiufdem qualitatis funt, verumetiam prout vna cum fanguine al ter, ucl alter humor abúdat magis, fic ctiam illius.ichor copiofior extat. Et ne decipiatur quis in ichoribus dignofcendis fcitu dignum, vbi aliqui humores a fanguinefegregati funt facile effe dignofcere illorum ichores, quando craffiore parte confpiffata, facile humidior, \& tenuior fefe prodit. At vbi fanguini permixti funt, dificilius eft dignofcere. Ideo fanguinem ex uenis extractum cótemplarioportet, qui poftquam coagulatus eft, duas fubftantias tenues monftrat, unam qux magis eft in fumma, quamve materiam potulentam effe, \& vriná

profitemur 


\section{QVARIVS.}

profitemur;quoniam fi feponatur in vafe, \& vrin ac com paretur, eft eiufdem coloris, atq. fubftantix; ; Alteram quae eft vicinior fanguinis lubftâtiae coagulatae, quae ve medij quodam modo coloris eft inter vrinam, \& fan guinem. Haec igitur fecunda eft ichor totius illius maffae fanguinis coagulatae, in qua prout hic, vel illic humor abundat magis, fic huiufcemodi ichor huius, vel itlius humoris naturam atq. facultatem refert. Hoc cum

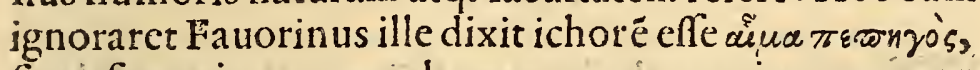
fiue, fanguinem coagulatum, errans turpiter cum non fit fanguis coagulatus, fed ea pars humiditatis tenuis, quae a fanguine coagulato feparatur, quod fi fanguis re periatur aliquis, qui totus ferè incoûtus ac tenuis exiftat, ita quod nulla eius pars coaguletur ichorofus fanè nuncupabitur, cuiufinodi vocaffe Arift. diximus.4-meteorol.Cap.7.qui in nulla alia re circa ichores a medicis mihi difcrepare videtur, nifi quia in humoribus aliis ab ipfo fanguine fimiles ichores haberi explicite non mon ftrauit. Nam etfi medici ichores in fanguinem verti negent, poffumus tamé dicere Ariftotelem quoque id cm cenfuiffe de illis qui fiunt per fanguinis corruptionem, $\&$ in ferum degenerationem, quăquam poftea eos qui fiunt ex fanguine non.concocto; ; nec a natura euicto in fanguinem per concoctionem mutari voluerit, quod fortaffe neq. medici ipfi negaturi funt, quando Gali6. de tu.val. docere videtur apertiffime quomodo ichores frigidi, \& pituofi a capite in ventriculum delabentes, tü ope medicamentorum, tum ciborum, tum etiam ipfius caloris natiui opera fint coquendi, atq. in melius commutandi . Ex his ergo omnibus non eft arduum intelli= gere quomodo potuerint aliqui fanguinem fudare. $\mathrm{Vt}$ eueniffe interdum referunt Arift.3. de hift.animal.cap. 19.3.de partib.animal.cap.5.Theophraftus in lib.de fudoribus ex fentêtia Monae medici,\& Gal.in lib.de vti- 


\section{$L$ I B E R}

li refpir. Nam haud quaquàm fanguinem verum, fed fanguin is ichorem exiuiffe venarum meatibus rationi confentaneum eft.

Galeni explicatus locus. Alter Plutarchi mutatus, \& ex Celfo atq. Galeno explicatus. Historia Sabi-

ni pxoris notatu digna.-

Cap. 13.

Alcnus ro.de fimp.med.Cap.r.Xenocraté dam nans quod fercora aegris voranda daret probrum ait grauius effe rompoфágov. id eft ftercori uorum audire, quàm fellatorem, aut cinaedum; fubiun

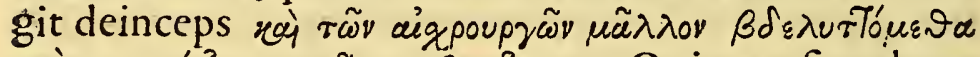

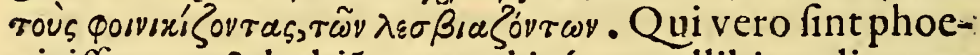
niciffantes, \& lesbiãtes apud iplum nullibi explicatum habetur. Egoitaq. reperio fpurciflimam quādam apud Phoenices libidinis fpeciem extitiffe, qua viri cunnos milierum lingebant, quave interdum impuriffimos homines Romanos vfus effe memoriae mandatum eft. Nã Seneca lib.4.de beneficiis Cap.3 r. Quid tu ait, cum Ma mercum Scaurum confulem faceres, ignorabas ancillarum fuarum menftruum ore illum hiante exceptare, \& lib.r 3.epift.88.nuper inquit. Natalis tam improbae lin. guae, quam impurae in cuius ore foeminae purgabantur. Hos cunnilingos frequentiffime diffamatos, apud Martialem eft reperire, quos fortaffe phoeniciffare dice batur, quod labia fanguine rubea faepiffime gererent. vnde Martialis lib.r.Cunnum Carinus lingit, \& tamen pallet. Dehoc meminit Lucianus, in Apophrade, \&

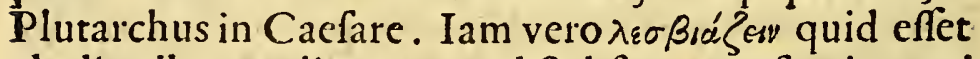
ab aliquibus explicatur, quod.fobfcoenum fuerit,turpi tudinis genus, quo viri inguina puerorum vel virorum ore, \& labiis tractabant, irrumatio alias vocata, \& ficuti phoeni- 


\section{Q.}

114

phoeniciffantes labra rubicunda faciebant, fic le sbi antes alba,ob quod Catullus ad Gellium .

Nefcio quid certe est, an uere fama fufurrat.

Grandia te medï tenta uorare uiri,

Sic certe ést clamant Virronis rupta mifelli

Illa demulfo labra notata sero.

Hefychiustamen aliter videtur fenfiffe, fed qua auctoritate aut ratione ductus ignoro, fimile his portentum re fert Suetonius de Lucio.P.Vitellij filio, qui alioquin in nocens, \& induftrius amore libertinae perinfamis fuit, cuius faliuis melle commixtis; nec clam quidem aut ra ro, fed quotidie ac palam arterias $\&$ fauces pro remedio fouebat.Eft apud Plutarchum in lib.de praeceptis fanitatis locus non fine animaduerfione practermittendus;vbi monet cos qui aegrotos inuifunt, vt diligenter $a b$ ipfis, cauffas aegritudinis inquirant $\mu$ noopıs

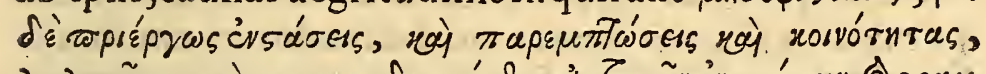

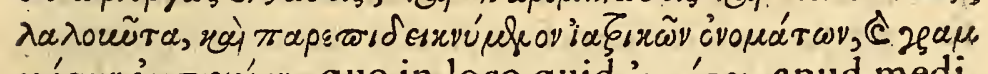

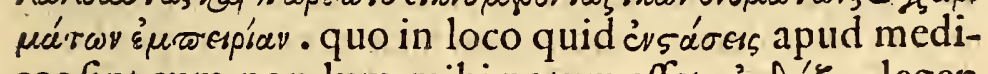

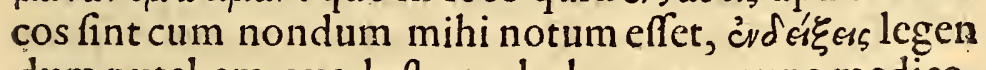
dum putabam, quod eft vocabulum commune medico-

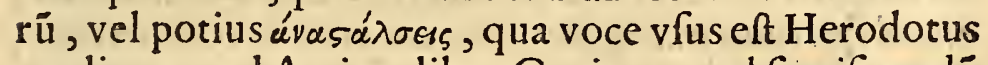
medicus apud Aetium lib.5.Capit. I 29.ad fignificand cibi fubtractionem, \& fi mendofe apud Aetium legatur àvas á $\sigma \$ \varsigma$. Ceterum Nicafius Ellebodius, \& in medicorum, \& in aliorumlestionibus verfatiffimus, magnoq́ue iudicio praeditus textum integrum effe, nec vllo mendo fcatere perfuafit, quandoquidem Afclepiadem, qui Democritum fecutus morbos ex atomorum in vacuos meatus ingreffu, obftrufioneve gigni docuit, huiufmodi ingreffum, infixionemve "ै"v $5 \alpha \sigma \nu$ verofimile eft vocaffe: quod primo colligitur ex Celfo, qui in prohemio $\mathrm{li}_{\text {r }}$ brorum fuorum tradit Afclepiadem contendiffe fieti aegritudines vbi manantia corpufcula per inuifibilia fo 


\section{I B E}

ramina fubfiftendo iter claudüt: Deinde ex Caelio $\mathrm{Au-}$ reliano, qui in prohem. lib. de acutis paftait Afclepiadem diffinifle phrenitim effe corpufculorum ftationé, fiue obftrustionem in cerebri mébranis : Galenus vfus

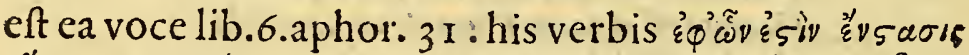

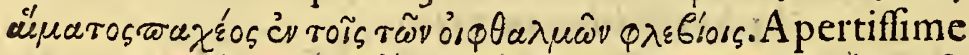
autem omnium quid proprie effet $\varepsilon v_{5} \alpha \sigma s$ declarauit Caflus medicus, quem ideo Afclepiadis feetatoré fuiffe conuincitur, quia frequentifime eam vocem vfurpauit;is enim probl.76.quaerens cur in dolore capitis tin-

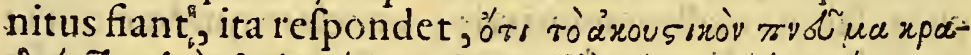

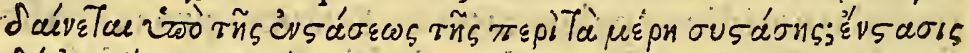

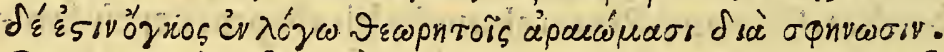
Quae porrò effent Methodicorum roเvótntes omnes fere medici norunt, quando clarum eft eius factionis medicos ad quafdam ab ipfis uocatas communitates nempe 5 z yov, rẫ uavò omnes morbos reducere confueuiffe . A tqui таре́ uт̃ $\omega \sigma: \varsigma$ fuit Erafiftrati medici dogma; qui vt locupletiffimeteftatum facit Celfus in prohem. librifui,\& Galenusin Cap.3.eius libri, in quo difputat an fanguis in arteriis contincatur, hoc profitebatur, quod firitum in feipfis dumtaxat arteriæ continerent, \& quod vbiin ipfas a venis pulfo fpiritu transfunderetur fanguis (quæ vocabatur $\pi \alpha \rho^{\prime} \mu \pi \pi \omega \sigma \varsigma$ ) in Aammationes, \& alij morbi fuboriebantur. Hifceomnibus adiicerelibet, quod refert idem Plutarchus in fine eius libri, qui infcribitur épw cum utero gereret, atq. dum aliae mulieres fecum lauabantur, vteri tumorem celare optaret, co unguéto, quo ruffas, \& aureas comas reddebant, uniuerfum corpus ab utero liniuit.Id uero, ut ait auAtor habebat, $\lambda$ ías $\mu \alpha$

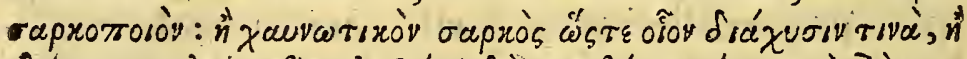

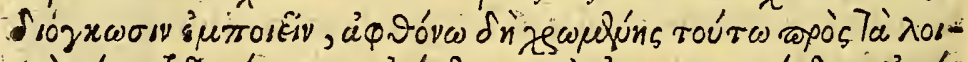

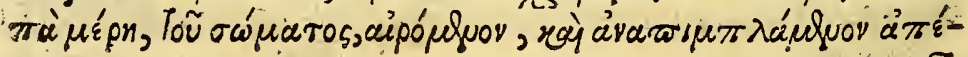
хритี⿻ 


\section{Q V a R T V. $s$.}

rputze Tov Tйs yaspos örrov. ideft pinguitudinem carnis effecticem, wel carnis laxatiuam, ita ut ueluti diffufionein quandam inflationemve ingeneraret; Quo cum large in reliquis corporis partibus uteretur; id tumefactum, \& repletum uentris tumorem occultauit. Quod autem effet illud medicamentum certi nihil tradi poteft, quando fcimus innumera prope modum eiufmodi extitiffe apud antiquos medicamenta; poffumus tamen conijcere ex eorum genere fuiffe, quae magna caloris vi, aut humores ex alto ad fummum trahendo,aut ex ip fis diffufis flatus gignendo cutem, \&omnem extimain corporis partem in maiorem molem attollunt, qualia funt rubificantia, \& ueficas inducentia, calx fcilicet, auripigmentum, thapfia, fulphur: Hacc enim aliis rebus commixta, ueteres ad capillos excolendos, \& pulchriores efficiendos adhibuiffe notatum habetur apud $\mathrm{Ga}-$ lenum, atq. Oribafium.

Plitarchi locus restitutus de fignis peftis ex Hefiodo, \& Hippocrate, Strabonis ad idem locus Empedoclis Hiftoria diucrfo modo

à Plutarcho, \& Laertio relata. Quid fuerit äTrous Empedoclis, \& Laertio, \& Galeno. Cap. 14 .

Lutarchus in initiolib. de deffectu Oraculorum declarans quomodo paruae res interdum magnarum fint indicia, medicinam in cxemplum profert, quam duobus fignis aeftatem peftiferam figni ficare, nimirum aranearum copia; \& ficus folior um ver norum cum cornicis pede fimilitudineff fribit ; quonia vero Hefiodus in 2. de operibus, $\&$ diebus tradir, ficus folia corni cis pedibus fimilia. veris noui argumenta ef fe, atq. idem quoq. Hipp. 6. Epid. fect. 7. confirmat. Vnde fi veritati confona Plutarchi fententia effet, fequeretur femper debere aeftatem peftilentem effe, curn 


\section{I B E $\mathbf{R}$}

femper vere folia ficus fint talia, ad credendum impellor Plutarchi locum mendofum effe, atq. ita reftituen-

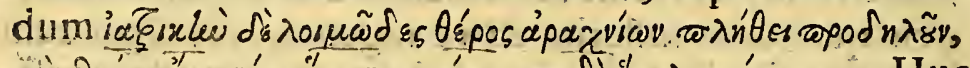

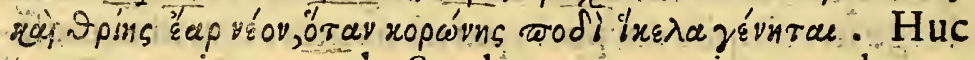
quoq. pertinet quod a Strabone memoriae mandatum eft lib. Gcogr. 3. Hifpanis haud effe peculiarem mufca rum multitudinem, quam facpe confequi peftis confue uit, vt R omani interdum, in Cantabria aliquos fint con ftituere coacti, qui mufcas venarentur, \& fecundum mẹ furā capturac mercedem acciperent. Nam $\mu$ wõv potius fiue mufcarum, quam $\mu \nu \tilde{\omega} v$, feue murium quemadmodum legunt alij, ibi fcribendum efle vt credam, facit Plutarchi auctoritas, cum mufcae araneis fint fimiliores, \& ratio, quòd mures gignantur a ficca putredine, quae aerem non cótaminat. Accedit Plinij auctoricas, qui lib. I o. cap. 27 . fcribit Elacos Myagrum Deum mu fcarum inuocare confueuiffe ipfas um multitudine peftem afferente. Eft $\&$ apud Laertium in Empedocle, hiftoria a Timaeo excepta, \& à Suda repetita, quod fcilicet Empedocles Etefijs aliquando vchementer flantibus adeo, vt fruges corrumperent excoriari afinos iuffit, factifq. vtribus cos collibus, \& montium verticibus admoueri ad cohibendos flatus, ceffantibusq. ventis ab euétu rei $\varkappa \omega \lambda u \sigma a ́ v \varepsilon \mu a v$ vocatum effe. Haec hiftoria quo niam parum fide multis digna videtur, ea fane verifimi liorem exiftimo, quã Plutarchus in lib. wei $\pi 0 \lambda u$ opu

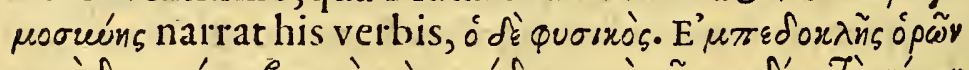

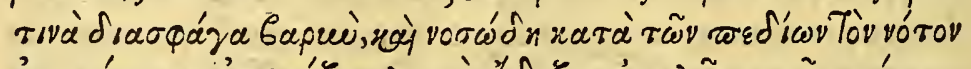

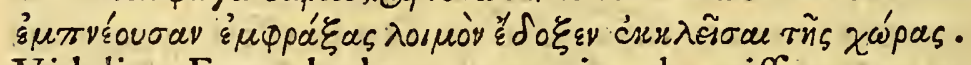
Videlicet Empedoclem cum animaduertiffet grauem quendam, \& peftiferum auftum per montis fciffuram in campos, mitti obftructa ea peftem a loco auertiffe. Quid porrò̀ èfet ártyous Empedoclis, quo ille ve Laertius \& Sudas narrät, dicebat hominem fine pulfu \& fpiratione 
ratione triginta dies feruari,a quoquam explicatum nố inuenı. Galenus fanè lib. 6. de locis affect. cap. $5 . \mathrm{mc}$ minit Heraclidis Pótici libri, qui ảmvoús infcriptus erat, v̈bi is, vt videre é,affeetiones explanabat, quibus aegri abfq. refpiratione pulfu, aliove vllo motu reddebãtur. In hoc itaq. libro forfan ab Heraclide monftratum cft, quid fuerit, nunquid medicamen, an potius (vt ego exi ftimo) morbus.vteri praefocatio vocatus, vel ipfi fimilis. Quicquid fit hoc certum puto apud Laertium non [A $\pi$ voũv igitur Heraclitus] fed [Heraclides] nec, [abfq. ftrepitu aut putrefactione] fed abfq. Spiratione, Ex Su$\mathrm{da}, \&$ Craleno effe legendum; apud quem eundem Heraclidem, cuius Laertius meminit, fignificari opinor.' Quamquam etiam vbi Sudas habet $\ddot{\alpha} \sigma \tau, o v, \&$ Laertius

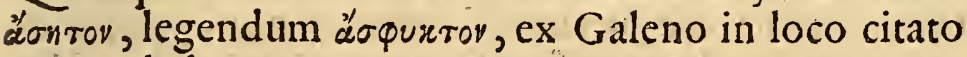
cerrum habeam.

Plinï locus emendatus, Hippocratis locus à Plinio citatus; or explicatus. Cap. Is.

2. Pponam loci Pliniani non inutilem emendatio1. nem in quo explicando mirum eft Hermolaum 20.2. Barbarum doctiffimum adeo infigniter dormitaffe lib. n. I6. cap. 20 . fic in omnibus fere codicibus fcriptum reperitur. Harum generi non decidūt, oleae, palmae, lauro, myrto, cupreffo, pinis, ederae, rhododen dro, \& quamuis herba dicatur fabina rhododendrum, vt nomine apparet a graecis venit, A lij nerion vocarüt, alij rhododaphnon fempiternum fronde rofae fimilitudine caulibus fruticofum . Putauit Barbarus rhododédrum a Plinio herbam fabinam dici, quod fanè a verita te longe alienum eft, quando rhododendrum, \& fabina multum differunt, ipfeq. Plinius lib. 24. cap. I I. dicit rhododendron tempore fuo nomē latinum nō inuenif 


\section{I E R}

fe, quam tamen Apuleius poft Plinium lauream rofam vocauit. Itaq. fic Plinianus contextus reftituendus eft hederac, rhododendro, \& (quamuis herba dicatur) fabinae. Rhododendrum vt nomine apparet, a Graecis venit. Nam Plinius vult diccre etiam fabinae non decidere folia \& quia de arboribus erat fibi fermo, iccirco addit ea verba ('quamuis herba dicatur) deinde perfequitur rhododendri tractationem. Hunc vero locum etiam Melchior Guillãdinus herbariae rei, omnifq. eru ditionis vir peritiffimus, ita ante me reftituerat. Y $: \mathrm{mi}$ hi carior, \& certior effe debeat emendatio, quia in eandem cum uiro acri iudicio praedito fententiam fortunaquadam inciderim. Ad haec. Plinius Iib. 38 cap. 5 . feribit Hippocratcm tradidiffe non prandentium exta celerius fenefcere, uerum id remedijs non epulisceciniffe, quod multo utiliffma fit temperătia in cibis. Hip pocratis fimilem fententiam nullibi adhuc inuenire mi hi licuit, nifi in 2. acutorum morborum vietus lib. ubi fcriptum eft eos, qui prandere confueterunt, fi prandiü demiferint imbecillos fieri, ignauos praecordiorũ doloribus torqueri, ac ueluti fufpéfa uifcera gerere, quod etiam in libro de ueteri medicina fufius dixit. Quem lo cum fi Plinius nobis indicare uoluit, aliter quam fecerit $B$ arbarus eius uerba erunt interpretanda, quod fcili cet prădiũ intermiffum uoluerit Hippocrates fecundũ Pliniũ ijs nocuiffe, quia moorbis detincbãtur, \& curatio nis gratia temperatè uiuebant; non autem iis, qui ualetudine fruebantur, ac inter epulas quotidie uerfabantur, quibus alioquin utile erat a prandio abftinerc cum lautiffime ferè femper coenarent. Nifi magis placeat. (quemadmodum in lib. artis ueteris fcriptum eft)dicere. Aliis prandiuin conducere ob neceffitatem, quia fi non prandeant offenduntur, $\&$ non his qui aut ob uoLuptaté, aut oḅ aliquem alium cafum alterutrũ faciūt. 


\section{Q $v$ A $\quad$ R $\quad$ T $\vee$ s.}

Loci Hipp. restituti, E collati Lucretio Arist. locus reftitutus, o alterdeffenfus. $\quad$ cap. 16.

N principio eius Hippocratis libri, qui कीं zovñ.

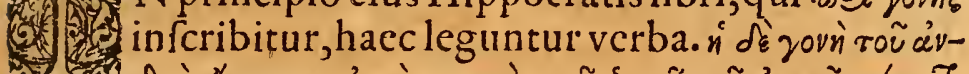

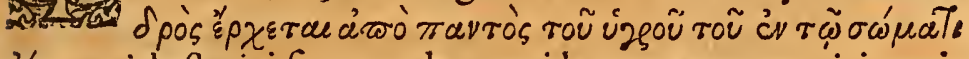
sóvros, ideft viri femen ab omni humore corpori inexiftente proficifcitur, quae non paucam eruditis multis difficultatem peperere, non fatis intelligentibus quomodo a quolibet humido fecernatur femen: fed cum ip fe legerim in vetuftiffimo Vaticani codice non cirò $\pi$ av

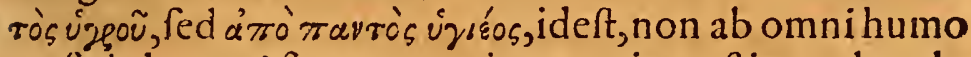
re, fed ab omni fana corporis parte:ita reftituendum lo cum, atq. omnem ambiguitatem tollendam putaui, ratio eft, quoniam inferius Hipp. non tantum ab omni hu more, verumetiam a folidis, \& mollibus partibus, tandemq. ab vniuerfo corpore femen emanare fcribit. Ad haec Arift. i. de gen. anim. cap. 17. vbi aduerfus Hipp. non paruam habct de femine difputationem monftrat eius fententiam fuifle (quod etiam alibi Hipp. fenfiffe reperitur) femé tantum a partibus integris nó mancis, atq. deprauatis proficifci, argumento, quod claudi (quâ quam hoc non femper fieri vult Hipp.) ex claudis nafcantur, quoniam a partibus vitiatis femen non ducatur. Hipp. autem opinionem etfi Ariftoteles ibi cuerte re omni ftudio contendat, eam tamé aliquädo in Prob. fe cutus videtur, ficuti i 4. fect. quando reddens cauffam cur venere vtentes refoluuntur atq. debiliores reddun tur, idem ait quod Hipp. quoniam filicet ex vniuerfo corpore femen profuit, $\&$ paucum ex multo nutrimen-

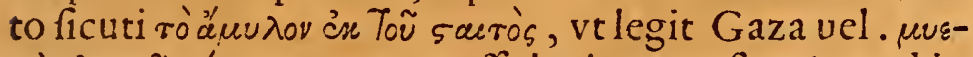

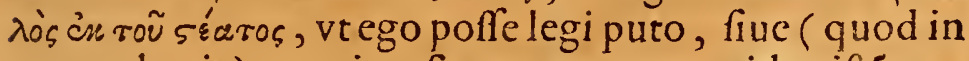
I 3 prob. ait) quoniam femen paruum quid exiftés ma gnam vim habet, fi quidem ex multo paucum côflatur,

$$
\text { Gg Theo- }
$$




\section{I B E $\mathrm{R}$}

Theophraftus 5. de cauffis. Pli. cap. 7. foribit viti fi medulla extrahatur, vuas abfq. acinis fieri, atq. cum euen tum illis fauere, qui femen abomni corporis parte duci putant, eandem Hipp. fententiam veluti antiquam habuit Lucretius in 4 . hifce carminibus.

Ex bomine bumanum femen clet vna bominum vis

Quodfimul atq. Suis eiectum fedibus exit

Per membra, atq. artus decedit corpore toto

In loca conueniens neruorum certa

In eodem Hipp. de genitura libro haec foripta inueni-

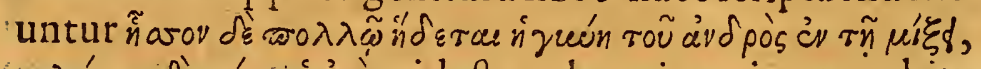

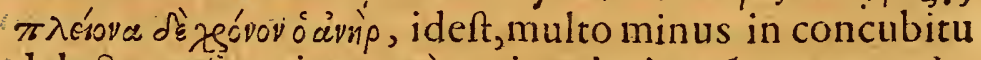
delectatur toemina, quàm vir, pluri auté tempore vir. Sed poftrema in manufcripto antiquoleguntur, $\pi \lambda \epsilon^{\prime}{ }^{\circ}$ va êzévor ño óvinp, videlicet mulieré minus in coitu uiro delectari, fed diutius ipfo perdurare in voluptate, quod veriffrmum effe ca ratio perfuadet, quoniá vir calidior (quicquid fenferit Parmenides) muliere exiftens uelo ciores motus obtinet, quorum merito ardentius \& citius defideria fua terminat; mulier uero ut eft frigidior ad cunita, atq. tardior, fic in uol uptate finienda frigidi ufcule fe habet, ac perdurat magis: id Mef.Salina profti tutae libidinis foemina fatis aperte declarauit, quae $\&$ fi centies in die uiro fefe commıfcuerat, potius tamé delaffatain, quam fatiatam fe praedicabat. Ad hoc irem al lufiffe potuit Tirefias ille, qui iudex electus ad decerné dum Iouis ne, an I unonis maior effet in concubitu voluptas, fententiam tulit, uiros ardentius mulieres pertinacius, amare, atq. concumbere. Sic namq. Arabum opinio ent intelligenda, quando maioré mulieri, quàu viro voluptatem tribuunt: fcribit ibidcm Hippocrates, ex quacunq. corporis uiri parte plus prodierit in genituram, quàm mulieris; quod partus ille magis patriadfimilabitur: Vndecunq. vero a corpore mulieris plus venerit 


\section{QVARTVS. II8}

venerit, mulieri fimilior euadet. Quam fententiam, ficut \& quamplurimas eius libri alias Lucretius, qui pri mus rerum naturas Romana lingua explanauit,ac plurima ab Epicuro, Democrito, \& Hippocrate mutuatus eft-hifce verfibus explicuit.

Semper enim partus duplici de femine conftat, Atq. vtri fimile est magis id quodcunq. creatur, Eius babet plus parte aequa quod cernere possis, siue virum fuboles, fiue eft muliebris origo.

Porro in lib. de natura pueri, quem effe ueluti partem: quandam libri de genitura facile ex finc vnius, \& alte-

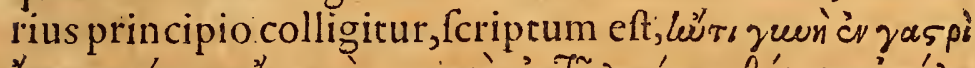

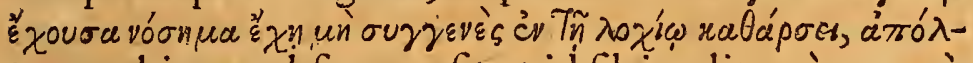

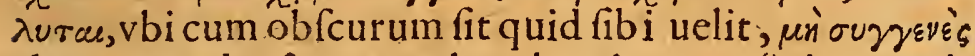
clarum euadet fi quemadmodum in manulcripto anti-

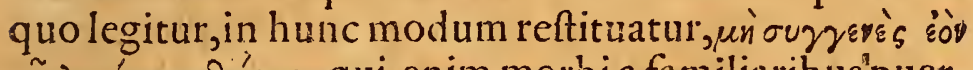

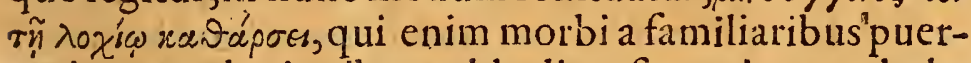
perio perturbationibus ualde diuerfi contingunt letha les fere funt, quod neceffarium fit aliquam magnã adel fe cauffam, quae morbũ inducat, nec a naturalibus purgationibus uincatur, quaeve \& purgationum moleftiis, \& partus laboribus adiecta malorum prauam focietat e gignat. Addam hanc coronidem, illud eueniffe libro de natura pueri, quod multis aliis Hippocratis comm e tarijs côtigit, qui trāfmutati,imminuti, atq. aucti funt, uel prioribus illis feculis, quando circa libros homines negligentiores erant, uel quando Hadriano imperante a Capitone, \& Diofcoride in unum collecti funt. Nam praedicto libro apud me compertum eft totam eam par tem importune interfertã fuiffe, ubi longofermone de cauffis differitur, quibus terra, \& aquae nonnullae hic me calent, aeftate frigent;quandoquidem neq. praefen ti materiae quicquam fere conuenit, nec ullo modo ei difputationi aptari poteft, quam de augumento planta 


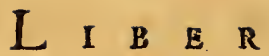

rum tả in fupernis, quàm in infernis partibus inftituit. Itaq. uidebunt eruditi an tota ea tractatio fit ex eo loco tollenda, atq. in librum de aer aq. transferenda in eã fcilicet partem, quae olim lib. de uulneribus capitis ma le interiecta confpiciebatur, Athenaeus 7. Dipnos re-

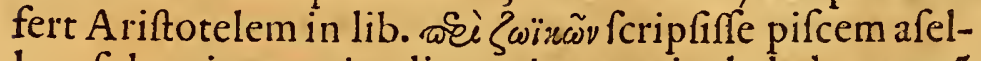
lum folum inter animalia cor in uentriculo habere:quã rem ex anatome falfam effe probare conati funt Ronde letius, \& Saluianus . Ego autem cum intelligam hoc fie ri non poffe, ut cor ibi fit, ubi cibi coquuntur; Philofophum adeo ftupidum fuiffe, vt hoc uer um putaret, nun quam crediderim; iccirco fi id unquam fcripfit Ariftoteles, nil aliud fignificare uoluit, quam irnmenfam eius animalis uoracitaté, magnamq. ftomachi rcfpectu cordis amplitudinem; ficuti namq. eos qui uentrem fere non habent prominetem dicimus in dorfo illum gerere: fimiliter pifcem qui magnum ftomachum haberet, cor pufillum, dixit A riftoteles cor in uentre habere. Cle mens Alex. 2. Paedagogi cap. I. uoraces inquit, \& eos qui mentem in uentre infodiunt affimilari afino pifci, quem A riftoteles dicit, folum ex alijs animalibus cor in uentre habere.

Quoties ueteres in die manducarent.

Cap. 17.

1) Nter do S Antonius Muretus uir elegãtiffim us , \& doctiffi mus in hoc laborauit, ut etiam quater in die manducaf fe interdum probaret; in quo certe non fefellit. Attimen ego hanc rem fic ftatuendam exiftimo. Graecos, \& praefertim Hippocratis tempore nullam hiufce confuetudinis legem firmam habuiffe; fed multos ter, plures femel, plurimos bis cibum fumere confueuiffe; ut 


\section{Q V A R T V S.}

Cardanus omnino deridendus videatur. Qui quod tépore Hip pocratis ter; \& plus ederent; totidem etiam cacaffe in com.in fecund.prognof.fcripfit.Id autem clarif fima Hippocratis auctoritate confirmatur, qui in 2. de rat.vist.in acut, morb. ubi fanorum hominum confuetu

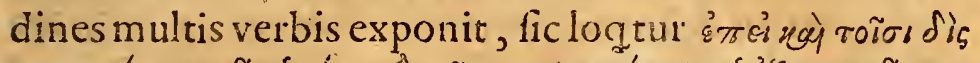

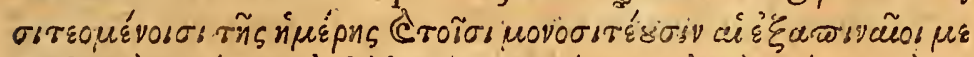

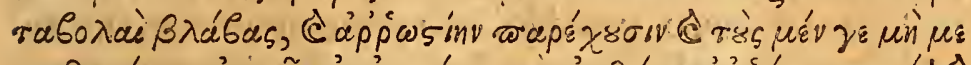

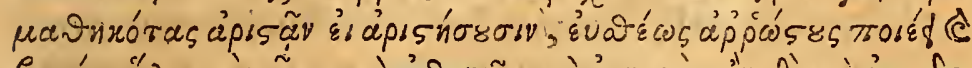

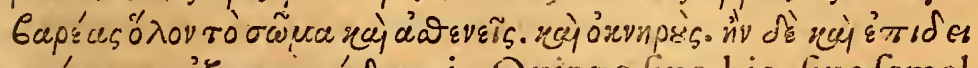

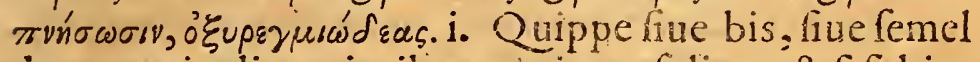
duntaxat in die, quis cibum accipere folitus eft, fi fubito confuetudinem mutauerie, noxam, imbecillitatemq. fubibit:Etenim prandium affimens, qui id non confueuit, protinus imbecillus, grauis, aegrotus, fegnisq. red-

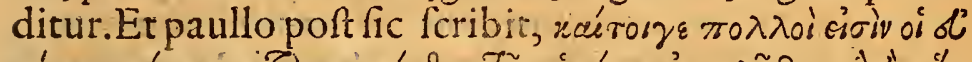

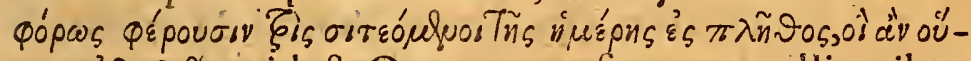
$\tau \omega s, \varepsilon^{2} \vartheta \omega \omega \tilde{\omega} \sigma i v$. ideft. Quamquam funt nonnulli quibus nihil moleftiae affert, ter in die cibo repleri, praefertim fi ita educari confueuerint. Ex quibus, \& alijs multis eo in loco fcriptis facile colligitur, mores ho ninum graecorum in comedendo diuerfos fuife. Quod uero Plato miratus fit Siculosatq. Italos bis in die impleri cibis, ita plane intelligendü eft quod rari effent, qui ufq. ad fatietatem quotidie bis cibum caperent, cum Hippo

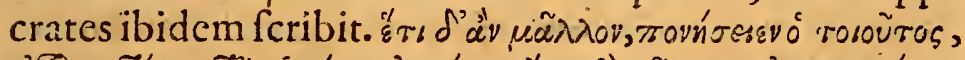

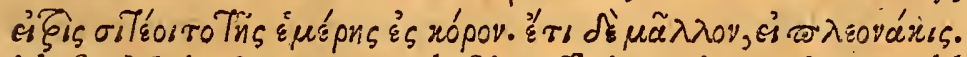
ideft, Maiori tamen moleltia afficietur is : qui ter eadé die ad fatietatem vfq. cibum ingefferit, ac multo magis fi crebrius etiamnü affumpferit ; Vbi fatietatem ciború frequentatam in die eadem maxime obeffe docens, mo net quoq. non fuiffe hanc eorum hominum confuetudinem; quod fimiliter innuit A riftoteles in probl. vbi medicos concubituris praecipere folitos, vt parce vefpe- 


\section{I B E R}

re manducarent, fcribit: Sed clarius hoc teftatum fecit Plutarchus, qui 8. fympof. 6.tradit olim infames fuiffe, qui ante coenam quicquam edebant, quemadmodum etiam Hippocrates in lib. de aer, aq. \& loc. pranfores infamia notatos ait. Immo ibidem a Plutarcho notatũ eft ảxpá ueteribus fignificaffe, atq. alterum dictum effe ämio roù áxpárov. i. a mero, quod folū cũ pane ucteres mane fumebāt;uel ảmò tñs árparías. i. ab incōtinētia qua notabătur id faciētes; altcrum uero quafi $\rho a ́ s o v$. ideft facilimum, quod faciliter pararetur, vt ex his omnibus colligaturquam rariffimos fuiffe Graecorum; qui pluries in die cibis implerentur, quãquã multi etiam ter efitarēt. Ceterum Romanos ita affueuiffe puto;vt frilicet maior hominum pars femel faturarentur, atq.id vefpere, mane vero aut modicum quid, aut nil omnino fumerent; rariffimi ter efitarent.Quod certe Horatij, Martialis , \& aliorum, qui Romanos mores pofteris tradiderunt, pro bare poffem fcriptis;fed vnum Galeni teftimonium mihi fat erit.Qui in lib.de tuend.val. 5 . fenes nutriendi rationem exponens, fatius effe ducit illos ter cibum fumere atque illud fastitaffe $A$ ntiochum medicum, ac Telephum grammaticum monftrat, quafi hoc praetcr communem aliorum viuendi morem effet. In 6. quinetiam cuiufdem tractationis lib. eorum victus rationé docês, qui negociis diftricti funt, côfiderari mandat melius ne fit in diefemel, an bis comedere; atq. hoc ex confuetudi ne diffiniri debere, quafi certo fciret homines Romae (nam in lib. illo ad Romanos, vt plurimum fermonem habere certum eit) modo bis, modo femel comedere, ra riflime vero ter, vt ctiam ex Cornelio Celfo in principio librorum fuorü de medicina intelligere poffumus, nec non ex Plutarcho, qui in loco nuperrime citato, fcri ptum reliquit prifcos Romanos moderate prandere fe- 


\section{Q V A R T V S.}

orfim, cum amicis vero coẹnare côfueuiffe. Ideoq́. coenam quafi roorveve, id eft communem ab ipfi us appellatā effe. Quod vero de ientaculo, \& comeffatione, à Latinis auctoribus memoriae mandatum eft. fic accipio pue ros ferè folos ipfo vfos perinde ac hodie, vbiq. fere gentiumghoc vfurpatum eft, vt pueri fummo mane femper aliquid cibi capiant,ea propter in Curculione Plautus facit Phedromum adolefcentulum Veneri ientaculum vouerë;fimiliter, \& in Truculêto Dhronefium meretrix fic ait. non nouiftiobfecro.

Qui illic apud me erat buius pater pueri, ille est, ufque ad ient aculum.

Iußit ali.

Idem fignificauit Martialis lib. I 4.hoc difticho.

Surgite iam pueri uendit ientacula pistos.

Criftatae quae fonant undique lucis aues.

Praeter pueros, fenes tantum valetudinis gratia vtebãtur ientaculo, nullos alios vnquàm vfos puto; quod fi ali qui erant, qui vterétur protinus, tamquã incontinentes notabantur : ita quoq. de merenda apud $A$ franium, \& alios, quae erat, vt Nonius docet, cibus poft meridiem fumptus, cenfeo dicendum ficuti \& illos non parua infa mia affectos exiftimo, qui comeflationes feu cibos poft coenam fumebant, atq. comeffatores nomine indecoro vocabantur; vt non mirum fit, Clementem Alexandrinum in 2. Pedagogi vehementer in pueris quoq. prandiola, coenas, epulas, atq. merēdas, quac omnia árárwas id eft, charitates aliqui appellabant damnaffe; Quemad modum pariter mirum alicui videri nó debet, fi Aulus Vitellius Imperator luxuriofiffimus, \& incontinentiffi. mus, epulas fuas faepe trifariam, interdum quadrifariā difperciebat in ientaculum, prandium, coenam, vtcomeffationem, quibus omnibus, ficut ait Suetonius, vomitandi confuetudine fufficere poterat. 


\section{L $\quad$ I}

De Priffana, Er aqua bordei Arabum.

Cap. Is.

X hordeo Achilleio ab Hippocratc.3. de morbis 2. $\&$ Ariftophane vocato hoc eft magno, \& opti mo, ut in linguis exponit Galenus, atque etiam Theophraftus.3. de communis plant. cap.17.8. de hift. cap.a.apud veteres Graecos, \& Latinos primo factos in uenio panes(quamquā Athenaeus hunc panem deterri mum o mnium hordeaceorum facit) Graecis olim in ma ximo precio habitos, Romanis uero, vt Plinius lib. 8. refert damnatos, ob id feruis, \& gladiatoribus alédis de-

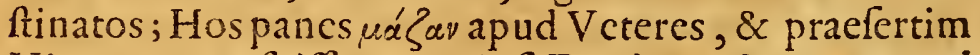
Hippocratem fuiffe puto, \& fi Erotianus Mazam apud Hippocratem fastam putet ex omni farina cum oximel le, aut pofca, aut mulfa, aut aqua. Far quoq. efficiebatur atq. id erat hordeum incifum, quod etiam in vfu habebatur, pracfertim alendis cohortalibus auibus, vt habemus a pud Columellam lib.8. Cap.4-5. 1 1 atq. Palladiú lib.r.cap.28.Fiebat, \& farina, quae aquae cocta puls ap pellabatur, \& interdum lacte mifcebatur. quemadmodum meminit Galcnus lib.de attenuante vict.cap.6.De hac fcribit Plinius eam Graecisignotam fuiffe, efficieba tur quoque polenta $a^{3 \prime} \lambda$ øros a Graccis nuncupata, quam Plinius auctor eft Romanis olim ignotam, apud Grac cos vero celebratam cxtitiffé, népe qua ipfi milites fuos alerent in hoc a Romanis damnati. Conftabat haec uariis modis, fed laudatiffima ex reccnti hordeo modice frixo, deinde molis fracto, \& poft aqua perfufo, ac cocto. Fiebat praeterea ptifrana, quã quá ptifianam etiam ex oryza \& tritico fieri confucuiffe memorant Horatius.2.fer.Galenus ı de alim. facul.\& Plinius lib. 1 8. Fie bat ulcimo aqua, de qua apud Arabas Auicennã Auerroem, \& alios celcbris eft mentio, quamquä fub nomine aquae hordei prifanam quoq. complectantur Arabes

apud 


\section{Q VART V s. I I I}

apud graccos vero, \& latinos, nunquain fere habcatur mentio aquae hordei nifi lub nomine cremoris ptiffanae. Igitur alijs omiffis de ptiffana, \& aqua ordei verb. faciam, quoniam de his medici in primis agunt. Ptiffanam inuenio apud graecos atq. latinos feriptores fuiffe nomen rebus multis commune. Nam primo omnia frumétacca deglubata, ac piftillis dccorticata ptiffanae

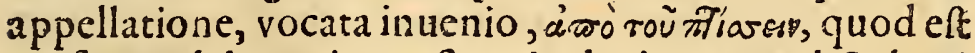
pinfere, vel decorticarc; fic enim legimus apud Galenũ I. de alim. facult. 6. \& 9. ptiffanam ex chondro, quae erat fpeciesZeae, dix ox ros nec non triticeam, de qua etiã

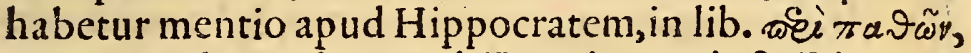
qui maior de morbis apud Herotianum infcribitur, \& Ariftotelem primo probl. 38 . Plinius autem lib.r 8.cap. 17. mentionem facit ptiffanae oryzae, de qua loquens Horatius 2. fer. dixit vas ptiflanarium oryzae. Columella quoq. lib. 2.cap.7. videtur demonftraffe, quod ex femine quoq. lini, ficut ex hordeo fieret ptiffana. Di cebatur fecundo ptiffana,de omnibus his non folum crudis, \& deglubatis,fed etian coctis aqua veluti monftrat Plinius loco citato, \& Galenus 8. meth. \& 7. cap. 6. vbi docet parandum effe chondrum coctum inftar ptiffanae. Tertio dicebatur propric de hordeo, vel decorticato folum, atq. deglubato, ficut monftrare videtur Pollux, de quo Martialem locutum puto, quando 12. lib. fcripfit in Panicum.

Frumcntum, milium, ptiffanam, fabamq. folebas vendere.

Et de quo loquitur Con ftantinus lib. 7 . vbi pro curatione doloris capitis boum laudat ptiffanam crudam, vel etiam de hordeo decocto. Ptiffana vero ex hordeo decocto apud Galenum lib. de ptiffana ita efficiebatur: hordeum mundatum, decorticatum, integrum non cötufum, ve monet Galenus loco citato, \& Auerroes 5.col lest. 31 . in aquae purifimac ponebatur ro. partibus, $\mathrm{Hh}$ apud 


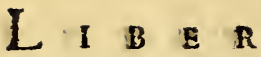

apnd Confantinum lib. 3. Geopon.atq. Paullum Acginetam lib. r.cap. 78.quindecim, atq. fic ad ignem ma xime ebillicbatur quoufq. hordeum intumeferet, deinde ad lentum ignem coquebatur, quoufq. totum hor deum colliqueferet, atq. aqua illa fucculeta euaderet. Sicq. ptiffana fimpliciter, ptiffana hordei, ptiffana tota, ptiffana non colata apud veteres appellabatur; quemadmodum fcribit Gal. 1 . de acut. 26.28. 1. de alim.9. vbi etiam dicit coquos faepe confueuiffe ptiffana haud tantum coquere, quantum erat neceffe. Quod fi hace ptiffana percolabatur facculo, vel ftamine, ita vit pars fucculenta remaneret, terreftrior uero, \& lignofior abij ceretur iam non amplius fic uocabatur, fed ptiflana colata, vel faflaránns zu $\lambda_{10}$, idef fuccus ptiffanac nuncupabatur, ita quod apud Galenum duplex tantum erat ptif fana hordeacea, non colata, fiue tota: \& colata, vel fuccus hordei (hordeatam uocant Itali) \& haec é illa aqua hordei, in quam dicit Auicennas ingredi de corpore hordei. Ent tamen fciendum, ut habemus a Galeno in lib. de ptiffana, \& ab Auicenna fen.r. quarti. Veteres quando in ptiffana requirebant uim abfterforiam con fueuiffe eam parare ex hordeo non decorticato, quod docet Gal. lib. de ptifsana, \& I. de alim. facult. cap.9. Atq. de huiufmodi ptifsana loquitur Plinius lib. 22 . cap. 25. ubi dicit. Ptiffanae, quae ex hordeo fit, laudes uno volumine condidit Hipp. quae nunc omnes in Ali cam tranfeunt, contra quanto innocentior eft halica. Hipp.tantum forbitionis gratia laudauit, quoniam lubrica cx facili haurirctur, quoniam fitim arceret, quoniam in aluo non intimefceret, quoniam facile redderetur, \& affuetis hic cibus in febre bis die poffet dari, tá tum remotus abiftis (diatritarios a Galeno damnatos, qualis fuit Thefsalus intelligit) qui medicinam fame exercent. De hac eadem loquitur Galenus, quando. Hipp. 


\section{QVAR S S. 122}

Hipp. commendationem ptifsanae, quam habet t. de. acut. 23. \& per totum librum exponit. Gondiebaturr autem ptiffana variis modis, modo aceto,pipere, melle, fapa, cimino, amy. miodo alijs; peffimus omnium iudica batur ille; quando partum coquebatur; \& fapa, vel melIe,\&cimino miffébattur,potius ait Gal. I. de fac. alim. cap. g.cyceon appellandus, ( erat cnim cyceon, vt notat Erotianus, potio farinae commixta, vel, vt Gal.docet 6. Epid.com. 6. tex. 5. Homerumac Hippocratem vfurpafsé, mixtio cibi \& potasis nec non polentae, \& vini) quàm ptifsảnà; de qua locutuim puto Hefychium, quando petifsanam dixit êfe Cyceonem, \& ctiam A picium Opfodaedalum in 4 . vbicondituram ptifsanae re cenfet. Nos cerrtée melius eam laste feminum melonum, vel amygd. dulcium, \& laccaro condinus. Praeter häc ptifsana apud latinos, \& a rabas fiebat aqua, exhordeo tam decorticato, quàm nó decorticato, \& eft illa in quã dicit A uicennasnil de corpore hordei ingredi. Accipicbatur pars una hordei electi,\& emundati, aquae par tes 20. ac bulliantur quoufq. pars quinta remaneret, deinde colabatur atq. exprimebatur; abiesto hordeo fola aqua exprefsa referuabatur pro vfu. Hanc Celfus cremorem prifsanae dixit libro 3 . capit. 7. \& alio in loco,vbi inuicem vini cremorem ptifsanae dat. Vnde patet omnes Galeni interpretes hallucinatos, ubi

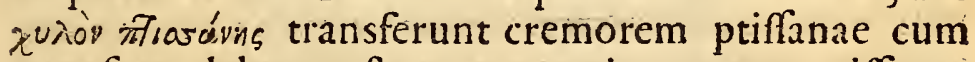
transferre deberent fuccum, quoniam cremor ptiffanae apud latinos cft aqua hordei expreffa.non fuccus ipfius fubftanciae hordei, ut apud Galenum. Nec me latet apud A rabas extetitife diuerfas menfuras in facienda aqua hac, quando A uicennas, Mefues, \& A uerroes praé dietam moftrarunt.Auenzoar uero, \& Halliabas aliam. Sed hoc euenit pro ut magis, uel minus nutrientem, ac refrigerantem cam reddere ftudebant. Itaque fi quan- 


\section{I B E $R$}

do placebit parare hanc aquam pro aegrotis, eamq. magis nutrire optabitur, curandum erit, ut multa portio hordei apponatur, ueluti ontaua, aut decima, ac mul tum bulliat; fin magis curae erit refrigeratio; paucior erit hordei portio, ut uicefima, atq. non tamdiu bullie tur. Ceterum quam ex farina hordei aqua covtam fieri confueuiffe monet Auicenna, non uideo in ufu fuiffe apud Graecos, puto ta men ipfam Latinos habuiffe, atq. hanc fuiffe eam, quae Romae publice uendebatur, fub nomine polentae, de qua etiam mentio eftapud

Gal.r. de ali. facul.9. \& lib. de atten. uict. 6 . quãquam etiã ficri poteft, ut ptiffana ap

pellaretur, quam ex pluribus rebus, ut tritico Oryza parari confueuiffe iam diximus.

F I N I $S$. 


\section{A L E X A N D R I}

$T R A L L I A$ N I

DE L V M B I C I S

E P ISTOLA.

\section{Nunc primum Graece, \&Latine edita.}

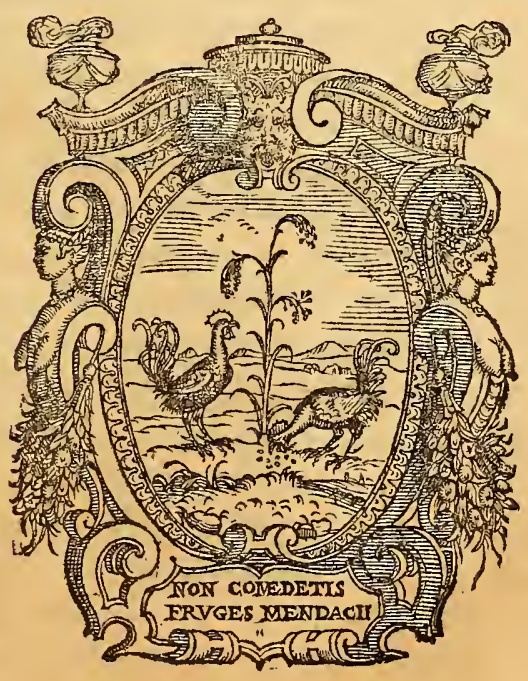

$V E N E \mathcal{T} I I S$,

Apud Paulum of Antonium Meietos Fratres. $M D L X X$. 
$136: A Z: I A$

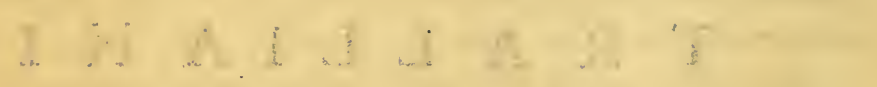

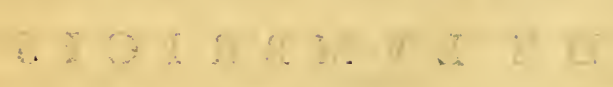

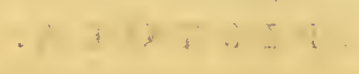

$$
\text { andiomumitate }
$$




\section{CLARISSIMIS VIF IS \\ PETRO IVSTINIANO, \\ IACOBO FOSCARENO DOCTORI: \\ ET I ACOBOSVRIA NO:}

\section{Hieronymus Mercurialis. S. D.}

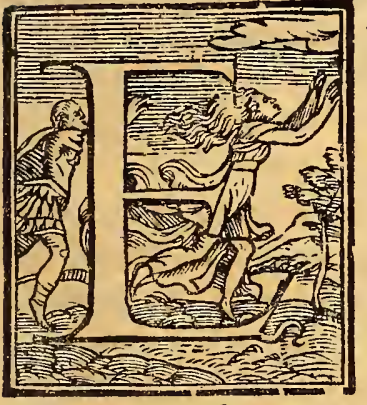

$X$ quo inter tot praeclarisfimos buivfce gymnasÿ profeffores, ut ego quoq. cooptarer a uobis, dignus babitus sü, id Semper cogitaui, ut animi meigratitudinem aliquando apud uos testatam facerem:-Sed hactenus nibil mibi contigit cuius perpectae conditiones plane vota mea explere vifae fint. Ne tamen quodoccafionis inopia factum eft, ingratitudine potius factum putetis, aliquod veluti probemium futurarum mearum erga vos actionum tradere ftatui, non quid veftris in me maximis beneficys hoc teftimonio vlla ex parte reponfurum me confidam, fed ut ex buiufcemodi exiguis rebus quam voluntatem ger am, ó id aliquan. dopreftaturus fm, intelligatis. Etenim cum libros quatuor variarum in medicina lectionum a me olim Romae collectos edere a multis. qui gymnafticam meam anno elapso editam, magnoq. eruditorum applaufu receptam fcientes idem his $e$ uenturum Sperant, coactus effem; forentque ex auditoribus meis plurimi. quiobnixe peterent, vt illis quam manufcriptam haberem Alevandri illius Tralliani fummi medici de Lumbricis epiftolam Graecam, fimul atque Latinam nec non aliqua explurimis quae feci de rebus medicis reponfis coniungerem, non potui omni ex parte deeffe ÿs, qui a me iure quodam omnia exigere videntur. itaque refponfis in aliud tempus dimisis, epistolam fub veftris nominibus publican- 
dam curaui,perfuafum habens hac nuncupatione non parum auctoritatis illi acceffurum effe. Quod niamque fit Alexandri epiftola primo iudicat codicis Vaticani a quo illam accepi, vetuftas, deinde fribendi modus, atque orationis character, poftremo Arabum foriptorum fides, qui cum quaedam, quae folum in hac epifola reperiuntur, eo pacto citent, quo res Tral liani confueuerunt; fanè videntur ipfam veluti illius genuinam agnouiffe. Veftrum igitur erit hanc qualemcunque alacriter Juf cipere, maioraque ( $\int$ Deus dabit ) certo in dies a me expectare. Valete Patauy Kal. Nouembris.

$M D L X$. 


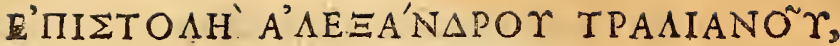

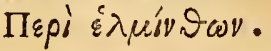

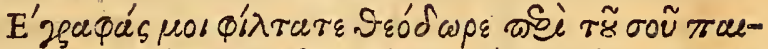

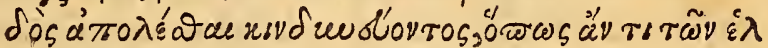

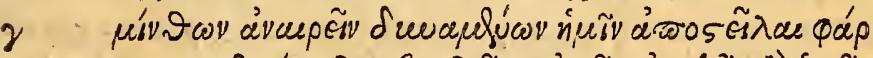

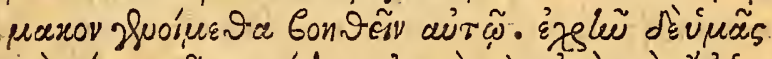

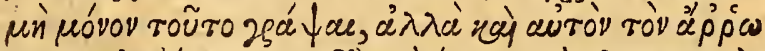

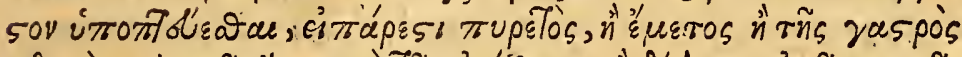

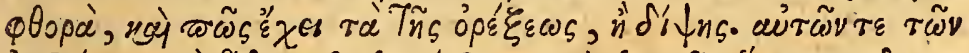

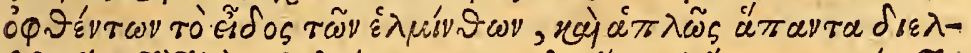

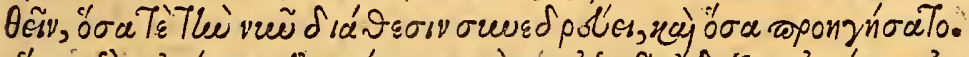

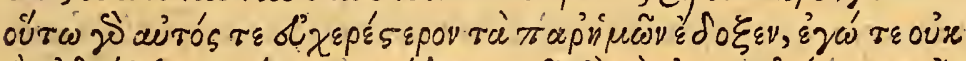
äv \&̇ ¿́ñ

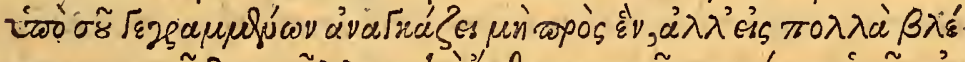

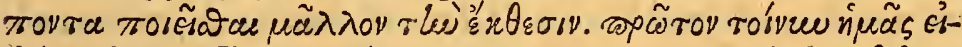

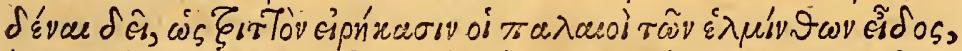

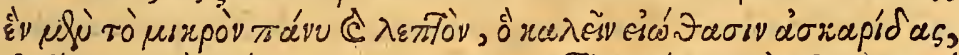

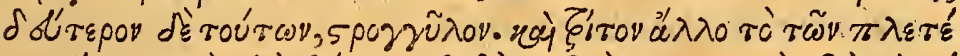

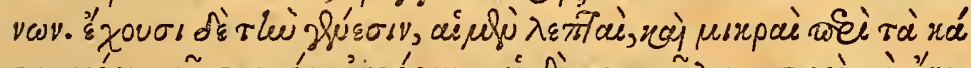

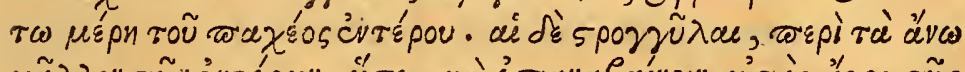

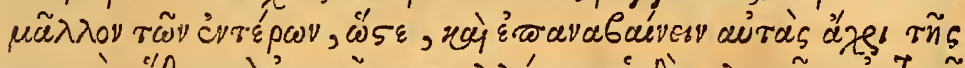

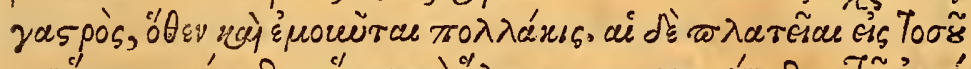

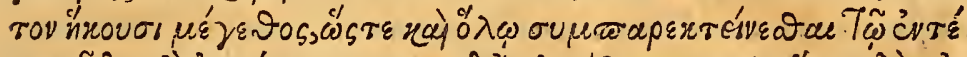

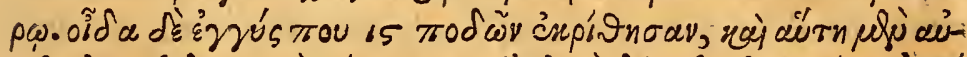

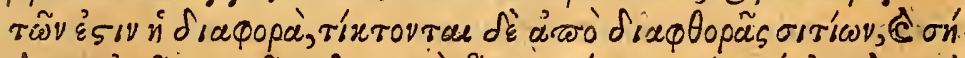

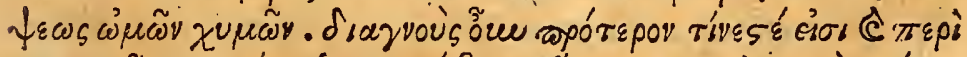

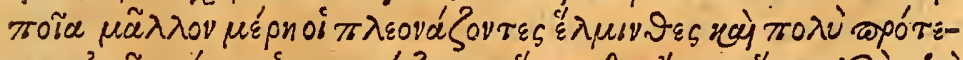

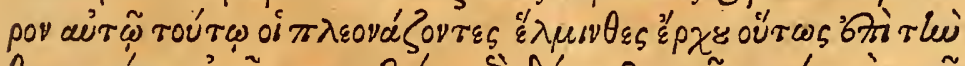

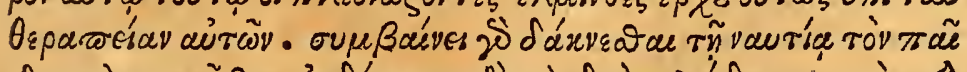

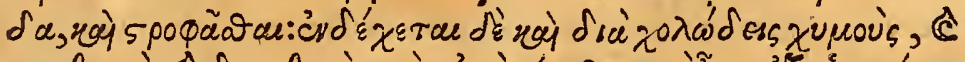

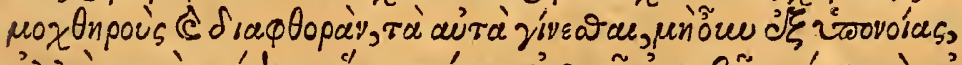

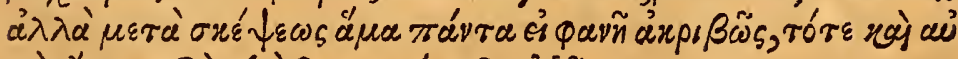

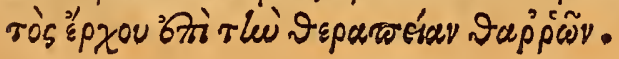

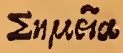




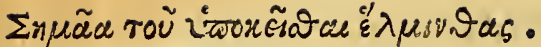

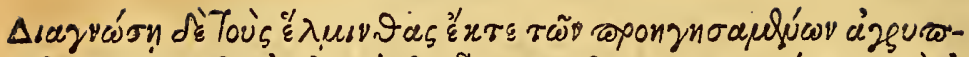

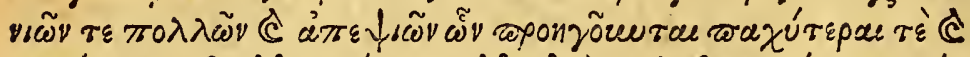

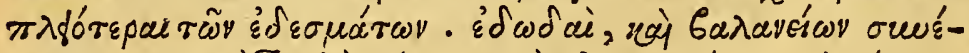

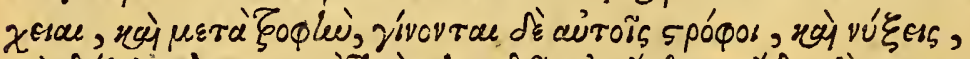

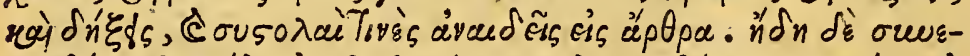
Xorfóor $\tau \tilde{\omega}$ wá

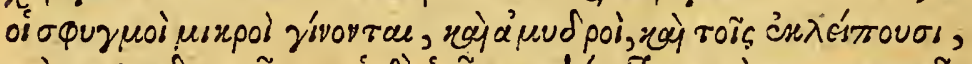

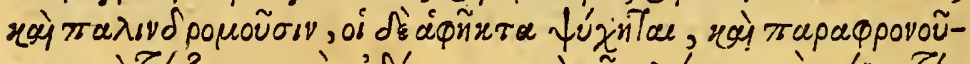

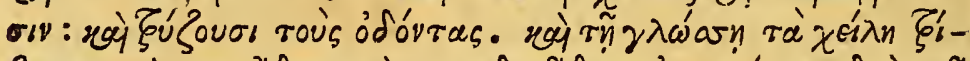

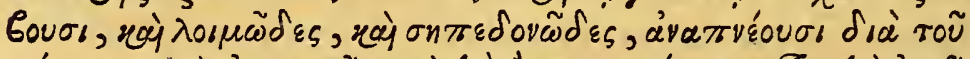

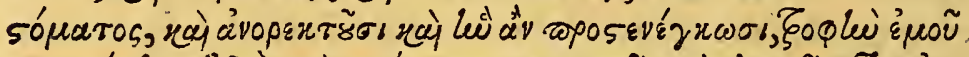

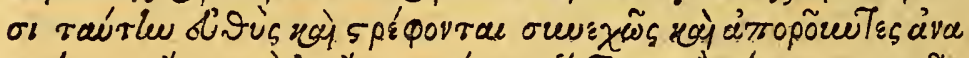

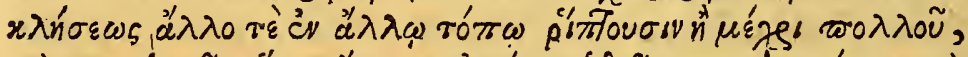

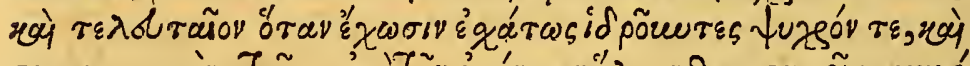

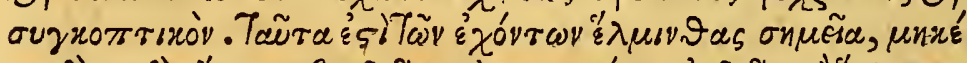

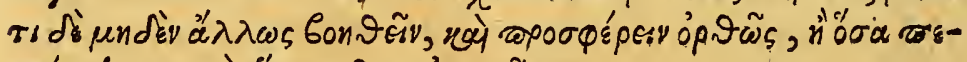

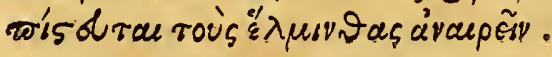

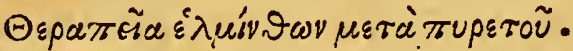

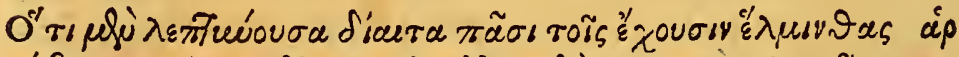

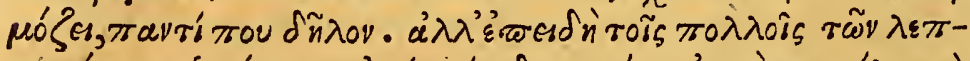
тw⿳ór

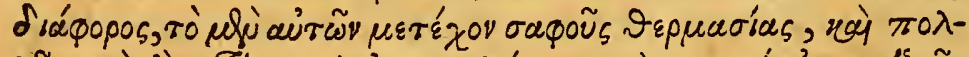

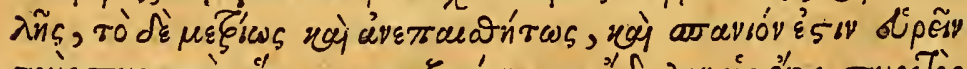
Toús TUP

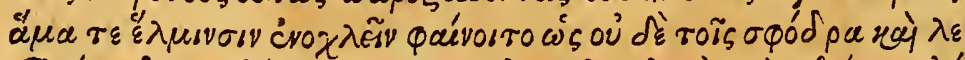

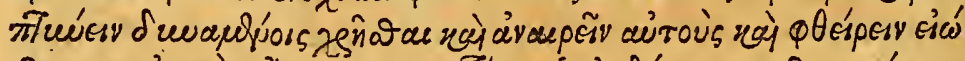

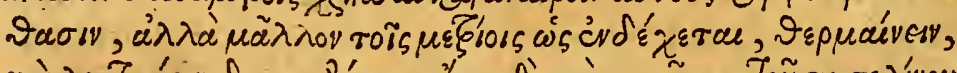

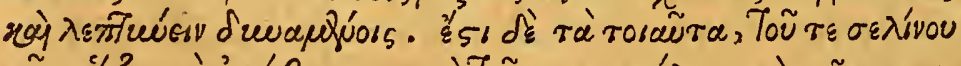

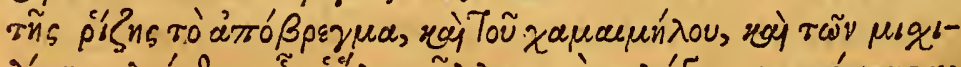

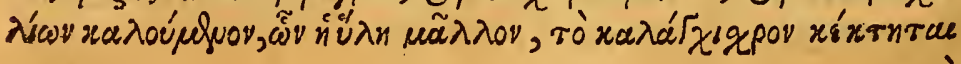




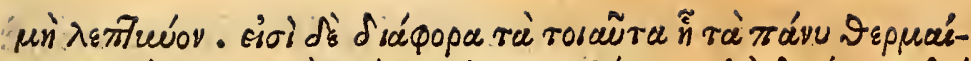

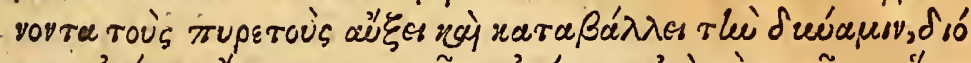

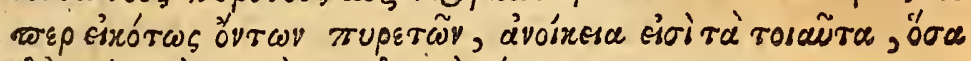

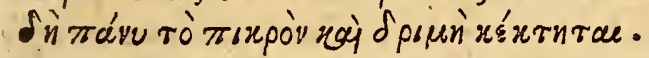

\section{Mepiviragwañs zaspós.}

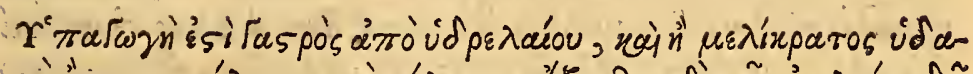

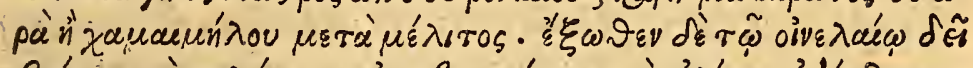

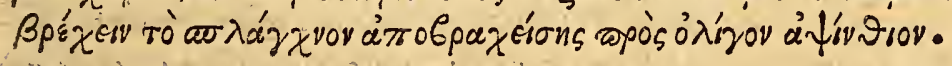

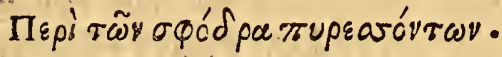

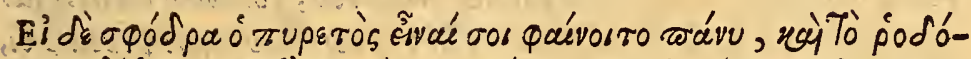

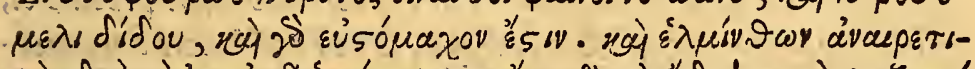

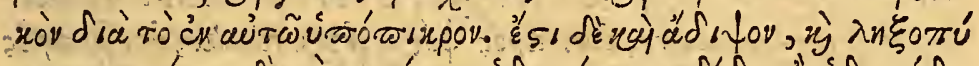

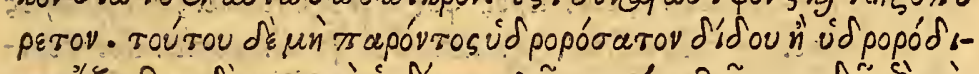

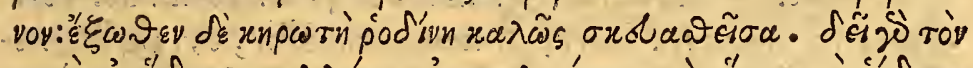

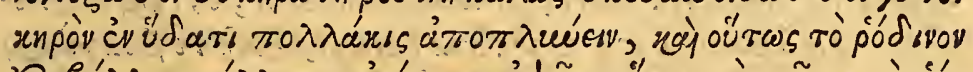

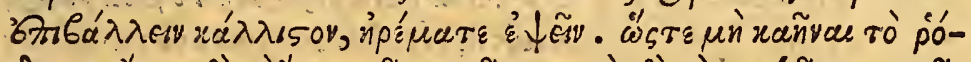

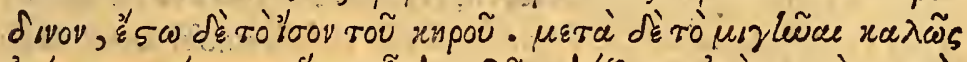

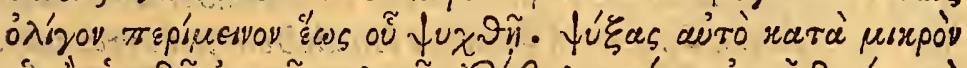

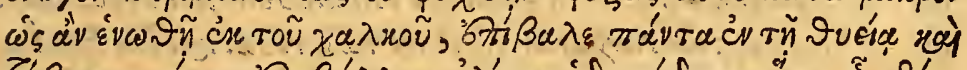

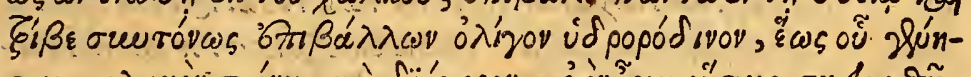

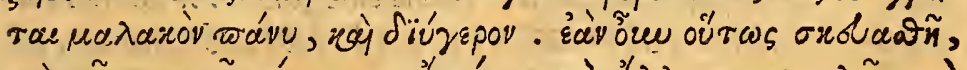

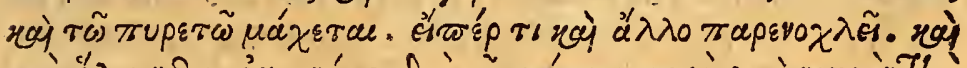

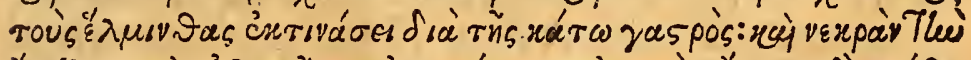

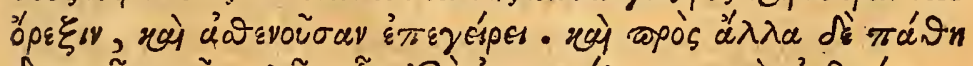

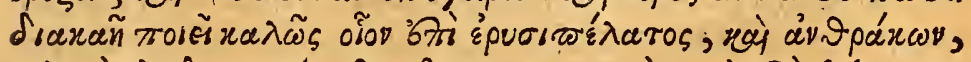

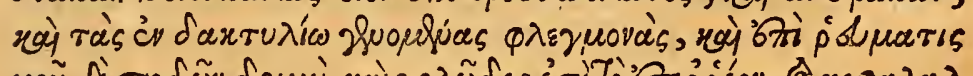
$\mu 0 \tilde{~ d}$ '

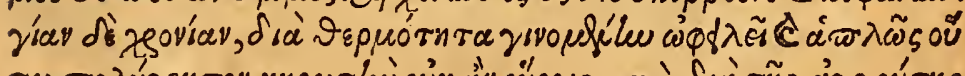

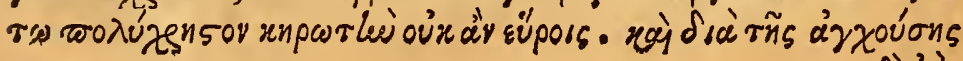

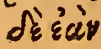




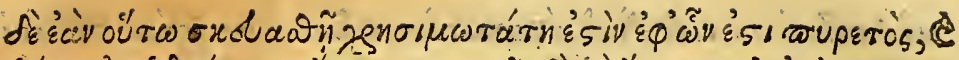

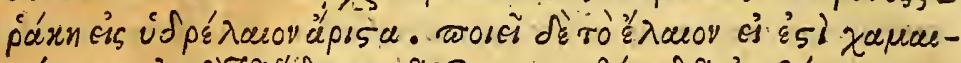

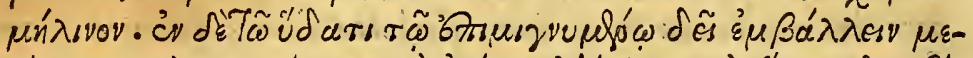

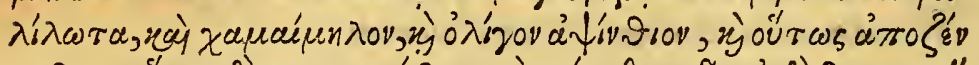

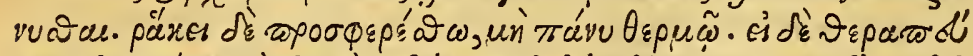

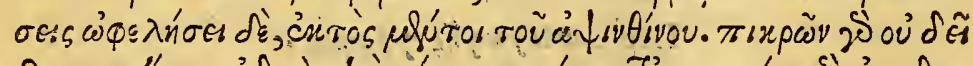

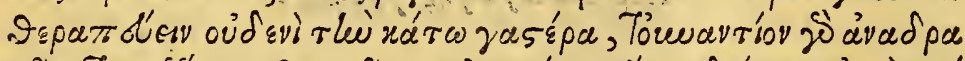

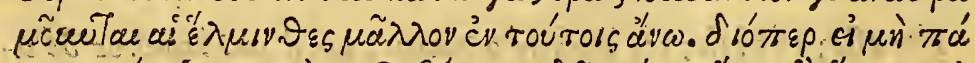

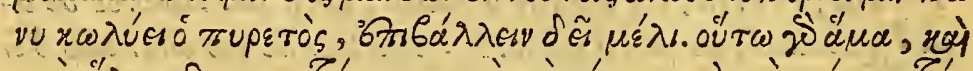

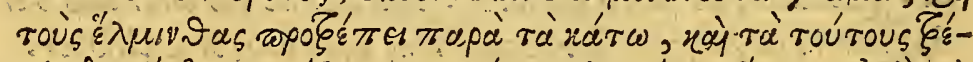

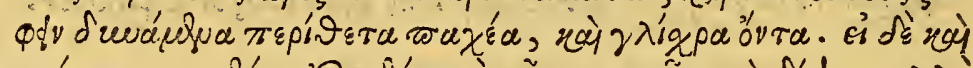

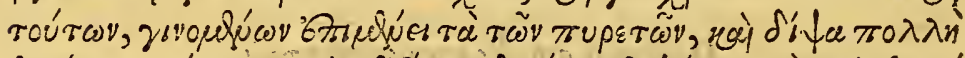

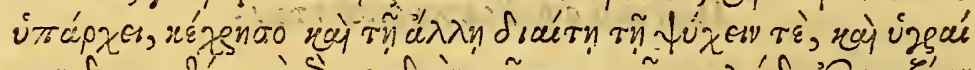

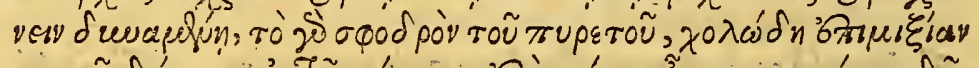

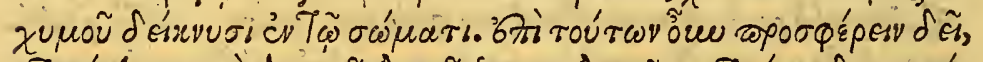

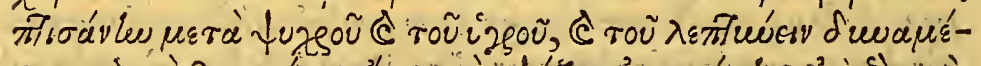

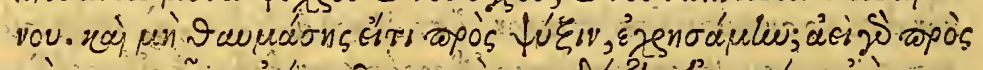

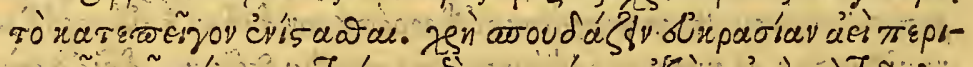

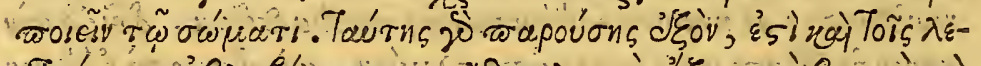

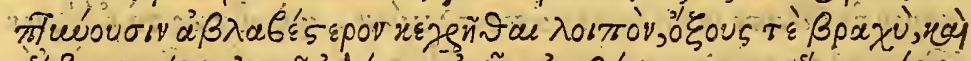

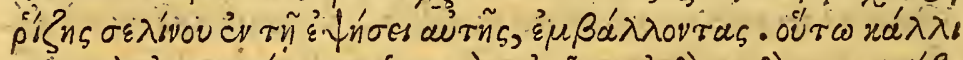

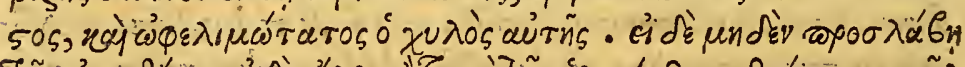

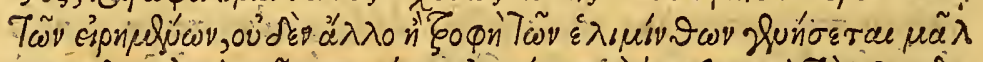

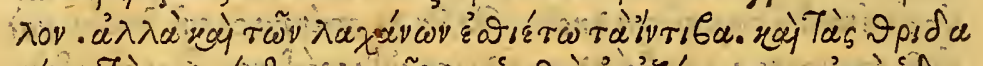

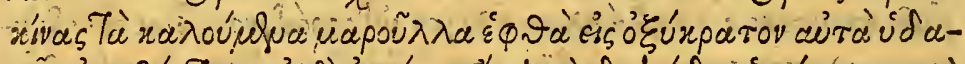

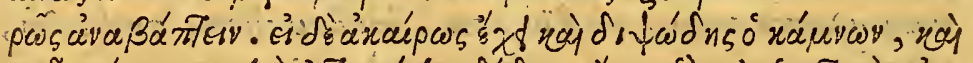

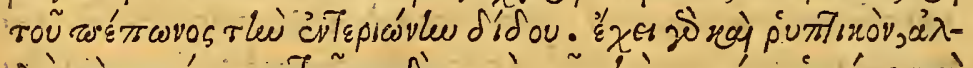

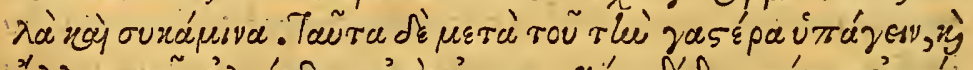

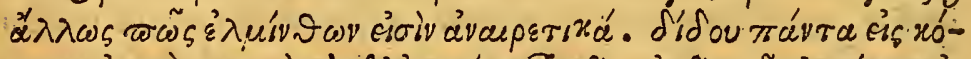

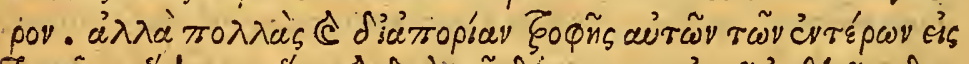

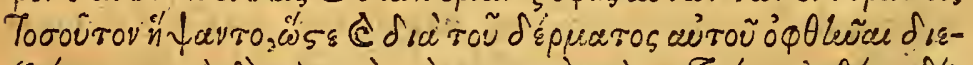

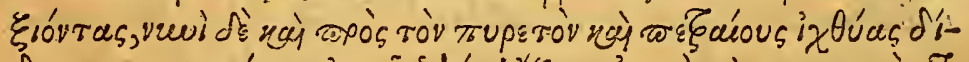

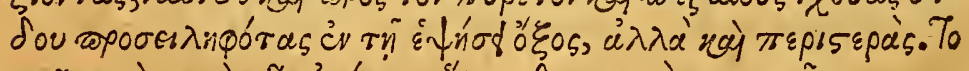

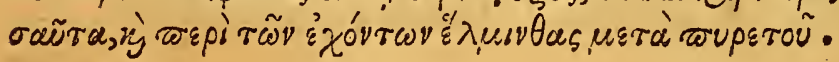




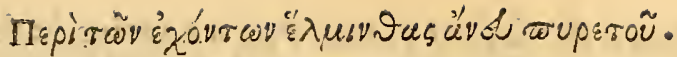

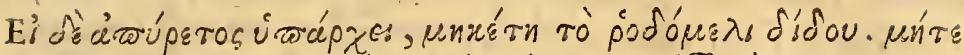

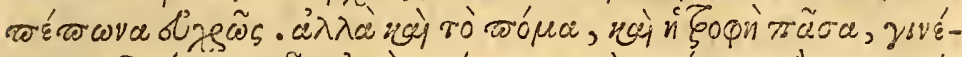

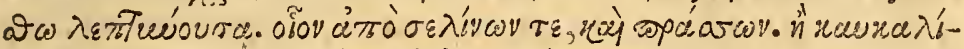

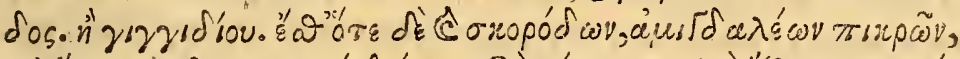

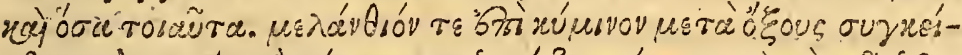

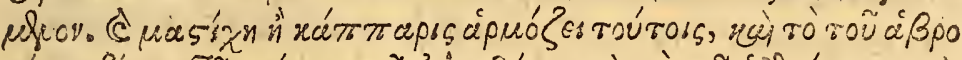

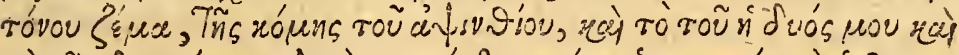

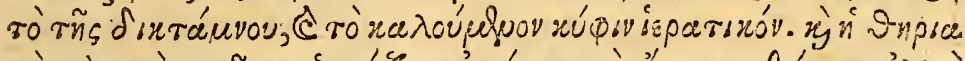

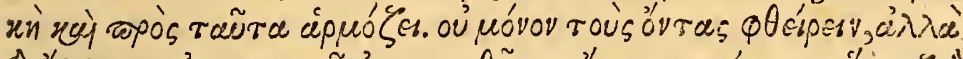

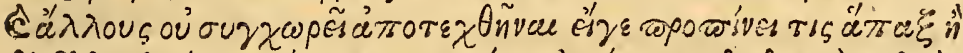

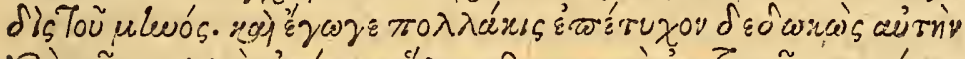

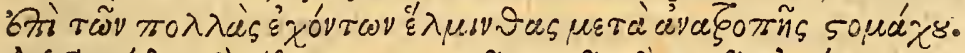

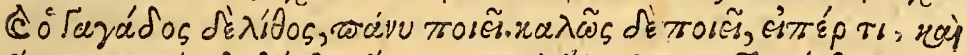

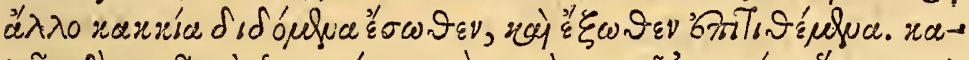

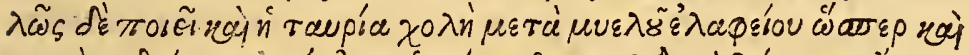

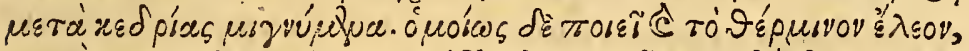

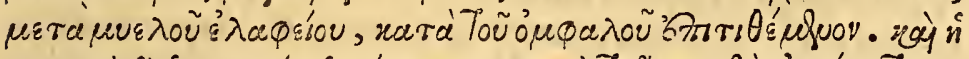

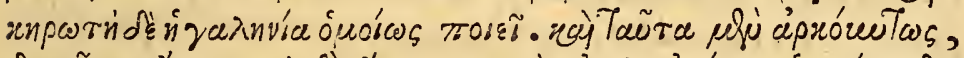

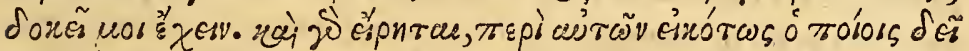

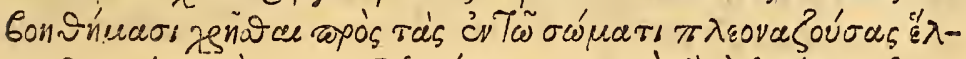

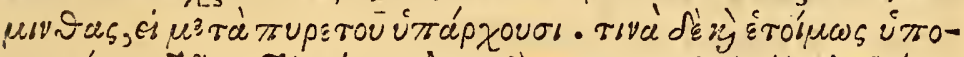

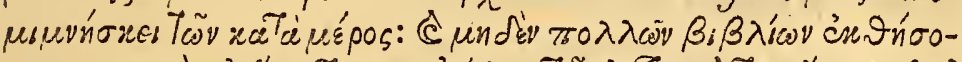

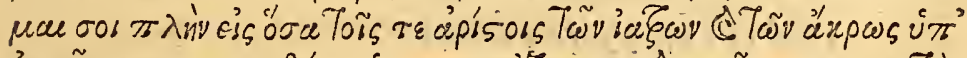

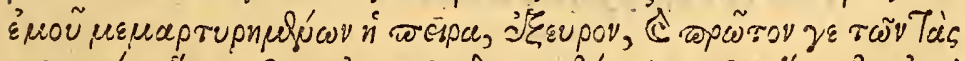

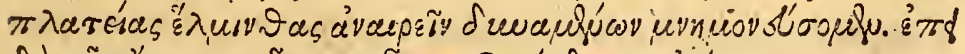

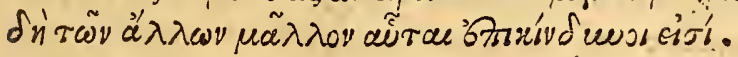

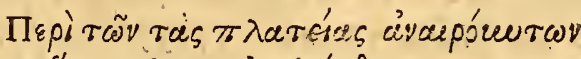

$$
\begin{aligned}
& \varepsilon \lambda \mu s v \vartheta a s, a^{\prime} \lambda \varepsilon \xi \xi^{\prime} \dot{v} \delta \text { pou. }
\end{aligned}
$$

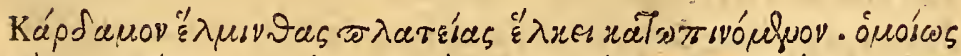

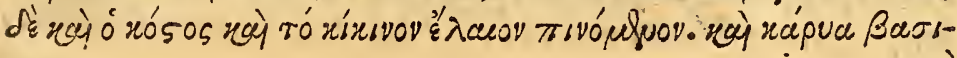
Ii $\lambda_{\text {srx }}$ 


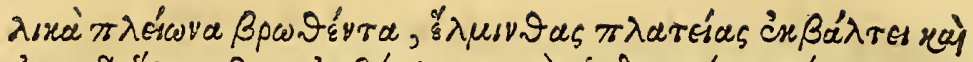

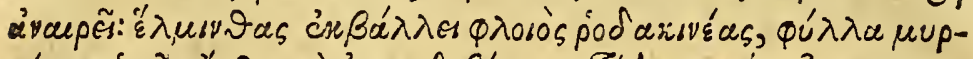

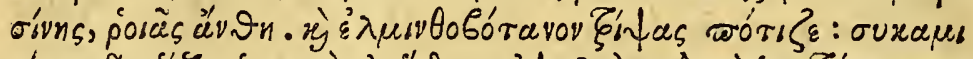

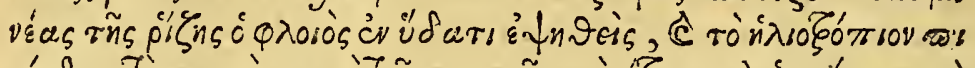

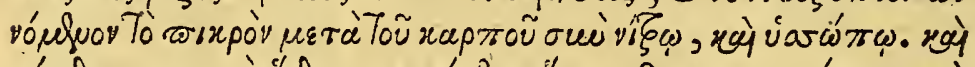

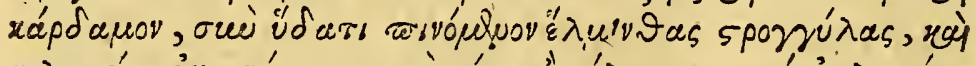

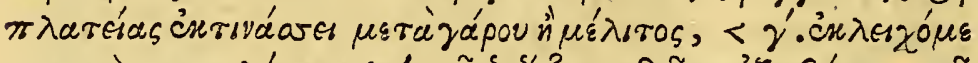

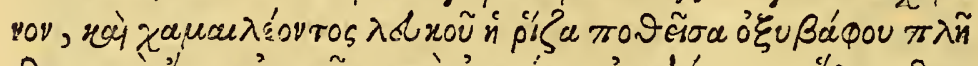

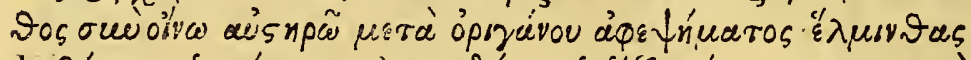

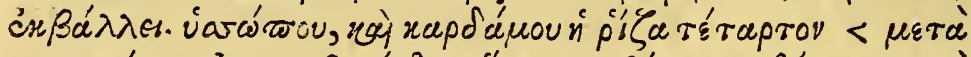

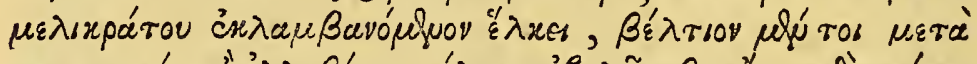

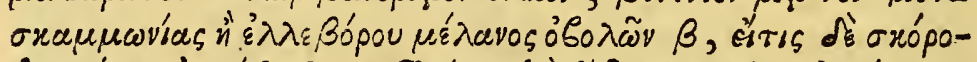

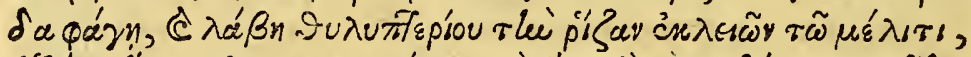

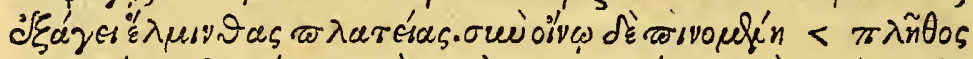

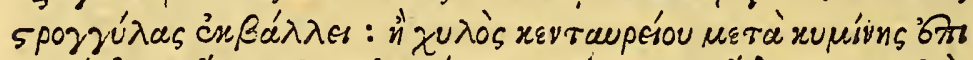

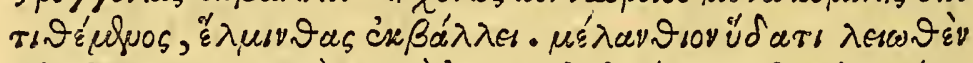

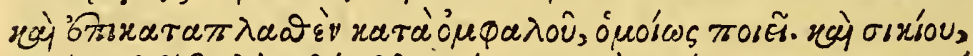

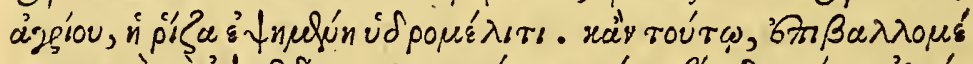

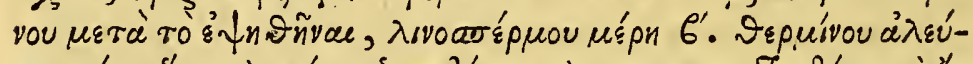

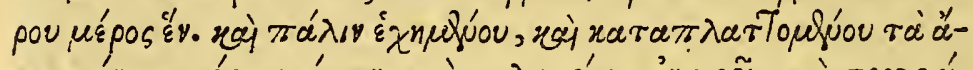

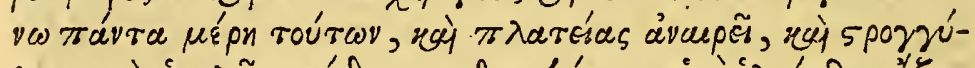

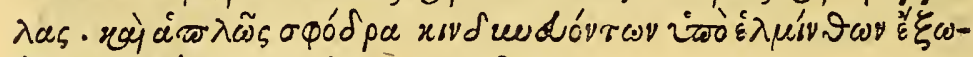

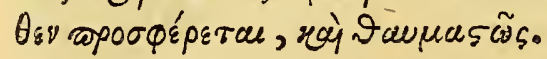

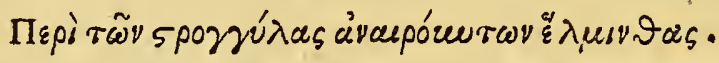

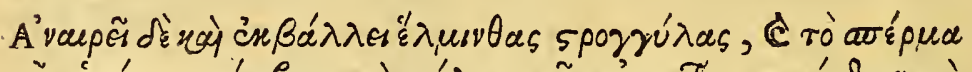

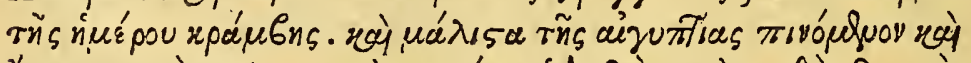

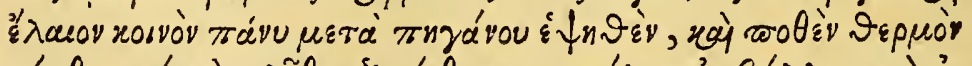

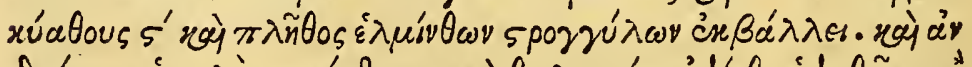

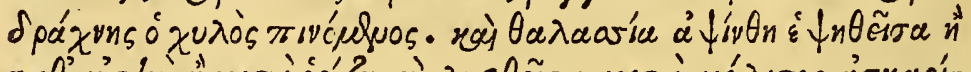

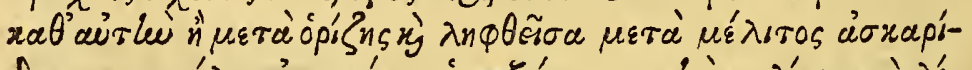

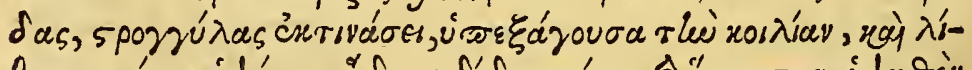

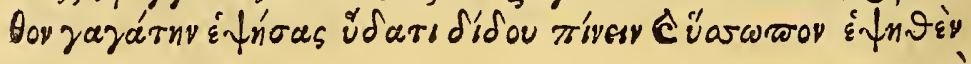
$\mu \varepsilon \tau \alpha ’$ 


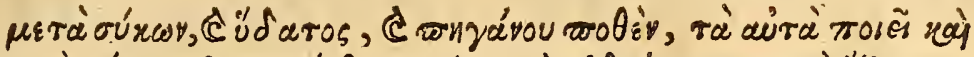

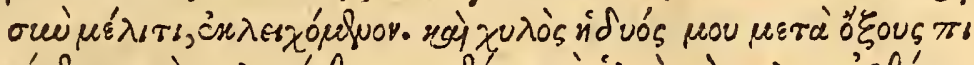

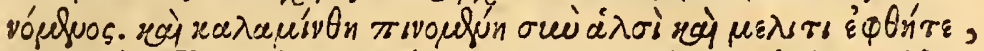

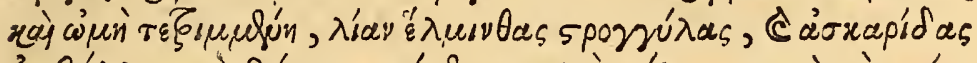

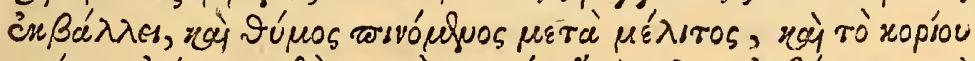

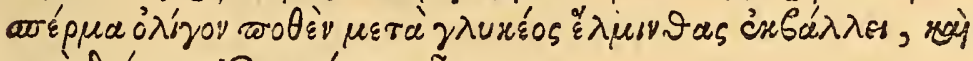

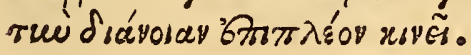

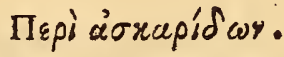

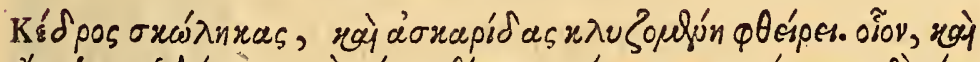

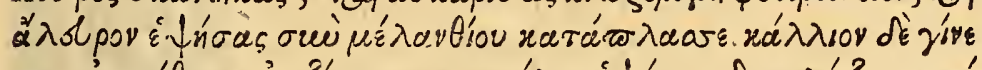

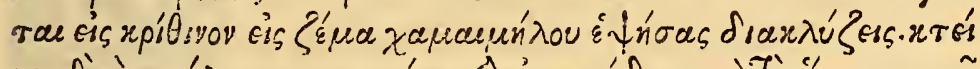

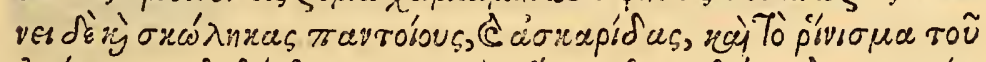

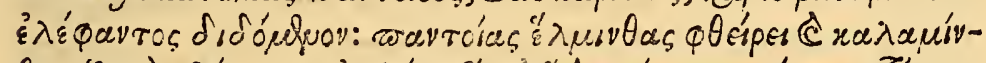

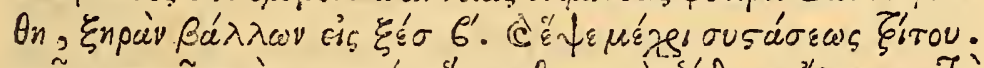

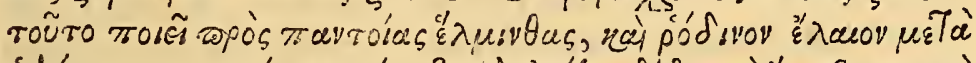

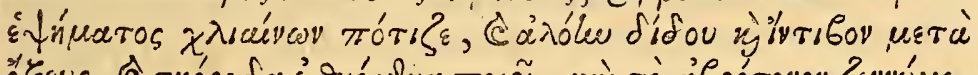

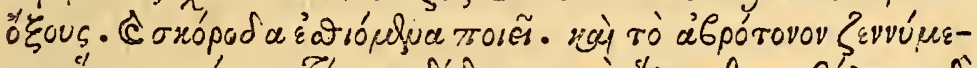

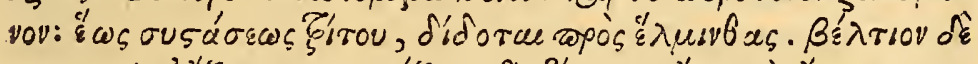

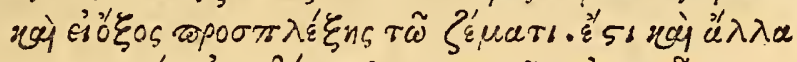

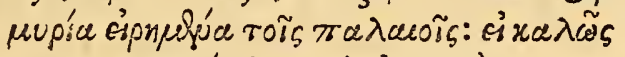

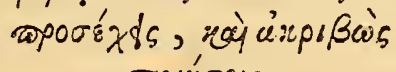
ஐoinoss.

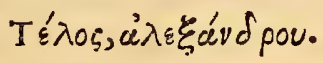




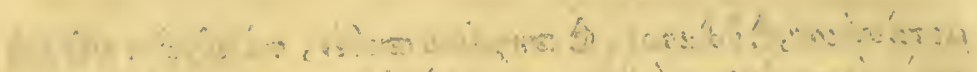

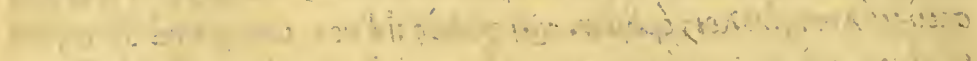
nitis $=$

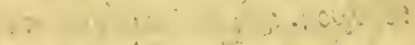

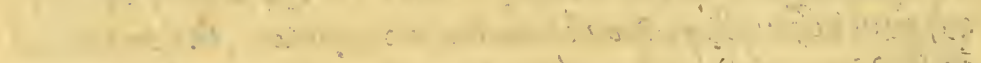

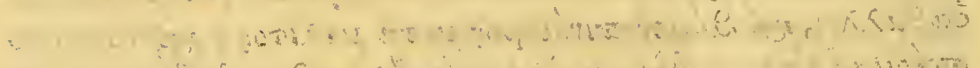

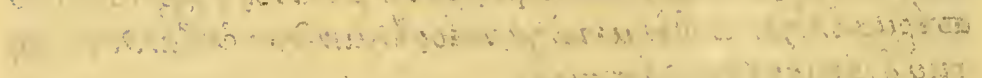

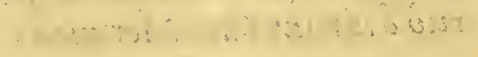

\section{$\therefore \quad \therefore$}

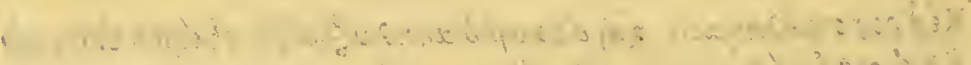

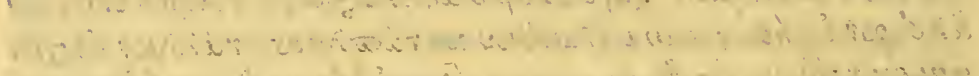

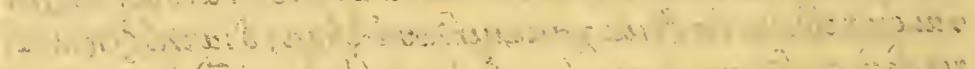

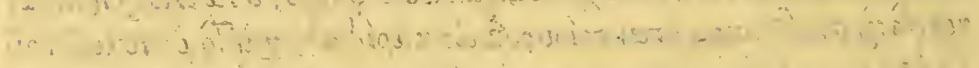

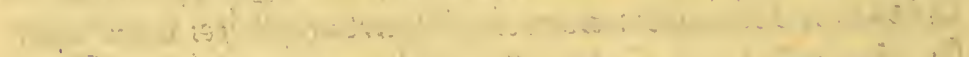

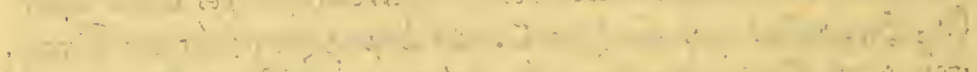

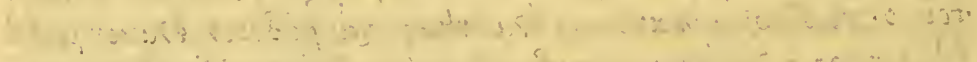

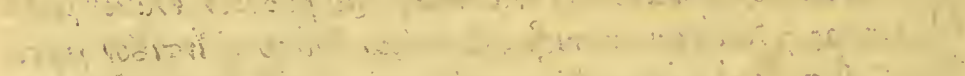

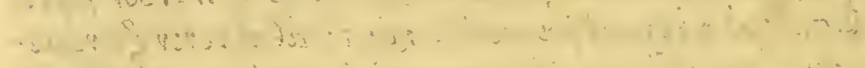

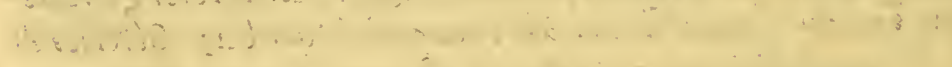
$\therefore$ !

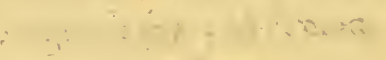

$$
\begin{aligned}
& \text {, } 7=2+10:-2
\end{aligned}
$$




\section{ALEXANDRI TRALLIANI \\ EPISTOLA DE LVMBRICIS:}

EX ANTIQVISSIMO CODICE

VATICANAE BIBLIOTHECAE

NVNC PRIMVM LATINA

R E D D I T A.

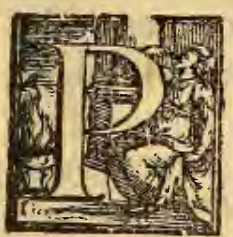

ER literas a me Theodore amicinime efAlagitafti, ut Puero tuo iam a uentris animalibusiugulari periclitanti medicamen to aliquo ex iis qux lumbricos necant mif fo fuccurrere uelim. A tqui non hoc folum uos adme fribere opus crat, fed \& acgrotum ipfum confpici, fi febre tentetur, fi uomitus, aut uentris fluxus adfit; nec non quo pacto fame, fitiue teneatur; Ad haec uermium ipforum infpectorum formam, ac (ut uni uerfim dicam) omnia enarrare conueniebat, quae affeAionem praefenté comitantur, quaeq. eandem praecefferunt. Sic enim, \& tibi fcripta noftra uifa fuifent fa ciliora, nec plura fimul congerere mihi neceffum fuiffet. Nunc uero cum Icriptis tuis nil diffinitum habcatur, non unius tantum, fed multorum confideratione habi ta fententiam meam exponere cogor. I taq. vobis primo fciendum eft: veteres tria uermium genera tradidiffe, unum paruum admodum, atque tenue, quod afcaridas nuncupare confueuerunt; alterum rotundum; tertiun teniarum; fiue latiorum. Generantur autem tenuaj, \& parua animalia circa inferiores craflinterini partes: rotunda potius in inteftinis fuperioribus, ita ut ipfa vfque ad uentriculum afcendant. vnde \& faepenumero vomitu reijciuntur; ceterum lati uermes interdumad tantam magnitudinem accedunt, ut vniuerfo intefino 
coextendantur. Conftat quandoque excretos $\mathrm{cffe}$, qui fexdecim pedum longitudinem prope aequarunt. Atque haec eft ipforum differentia.Gignuntur porrò ex ci borum corruptione, ac humorum crudorum putrefactione. Cum igitur primo cognoueris qui fint, \& circa quas potifimum partes fint vermes qui abundant, tum curationé ipforum aggredere. Accidit namq. ut puer naufea mordeatur, ac torqueatur, at idem etiam a bilio fis, \& prauis humoribus, nec non a corruptione efficitur. fi igitur tibi non furpicanti, fed diligenter confideranti fimul omnia exacte apparuerint, tunc ipfe ad curationem confidenter accedito.

\section{Signa animalium in uentre exifentium.}

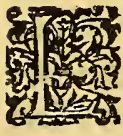

Vmbricos cognofces, tum uigiliar um, tum crudi tatum praecedentium copia, quas plurimorum, atq. craffiorum eduliorum éfus, nec nó affiduae eaeq. poft cibum balinea antecedunt. Fiunt vero ipfis tormina, punctiones, morfus, \& quaedã ad articulos tur pes contractiones; funt etiam qui hac affectione detenti lumbricisq. plurimũ crefcentibus, pulfus paruos, ob/cu ros habeant;aliquibus deficientes, rurfumq. redeuntes fiùt.Alii frigefiunt, delirant, dentibus fremunt, iabiaq. lingua premunt. Ad haec ab ore peftiferũ nefcio quid, \&xutridú efflant, in appetentia laborant, \& quécunq. cibum offeras, eum ftatim vomunt. Continuo vertuntur, \& quafi nullum decumbendi commodum fitum inuenientes in alium, atq. alium fubinde locum feipfos diu iactant . Deniq. cum in extremo funt, frigidis fudo ribus, ac animi defectionibus follicitätur. Haec funt eo rum quos uentris animalia infeftant, indicia; quibus nulla alia ratione auxiliaberis, nec quicquam aliud cum fructu praebcbis, nili ea quae lumbricos necare cre duntur, exhibeas. 


\section{Lumbricorum cum febre curatio.}

\section{A Ttenuantem viuendi rationem omnibus lumbri}

cos habentibus conuenire vnicuiq. clarū eft.fed quoniam etiã apud vulgares attenuantium quarumlibet non vnum difcrimen eft; fed variae, ac diucrfae differentiae, quando eorum aliud manifenta ac infigni caliditate pollet;aliud moderate, \& infenfibiliter ca lefacit; Item raro contingit quin febres exaccrbentur; Conftat quod ubi febris cũ lumbricis vexat, non rebus magna attenuandi facultate praeditis,etiam fi animalia illa interimere, \& corrumpere confueuerunt; fed potius cum ijs, quae vtcunq. contingit moderate calefacere,ac attenuare poffunt; cuiufmodi funt aqua in qua radix apii, \& chamemelum, \& ea, quae vocantur mifchilia fint macerata, quorum materia potiusi vifciditatem, quàm attenuandi vim poffidet (eiufmodi autem diuerfa funt) quandoquidem, quae multum calefaciunt, ut febres augent, fic virtutem deijciunt; iccirco merito febre exiftente ea minime congruuut, quemadmodum amara, $\&$ acriafunt.

\section{Deventris fubductione.}

T Iquatur venter cum hydrelaeo, vel cum melicra1 to aquofo, vel cum chamemelo, \& melle:extrinfe cus vero madefaciendum eft uifcus vino, \& oleo, in quibus abfinthii modicum fit maceratum.

De $\ddot{s} s$, quivehementer febriunt.

Fen I vehemens febris adeffe tibi videatur, tum rofaceum mel praebeto; nam \& ftomacho accómo datum eft, \& ob exiguam quandam fibi inexiftentem 
ftentem amaritudinem lumbricos interimit: Praeter haec fitim leuat, \& febrem foluit. Eo vero deficiente hydrorofatî propinato. Extrinfecus ceratum rofatum optime paratum conueniet. Oportet enim ceram in aqua facpius abluere, atque ita optimum rofaceũ inji= cere, atque lente coquere, ita ut rofaceum non combu ratur, ( fint autem cerae, \& rofacei pondera paria)tum poftquam exacke mixta fuerint, paruin defiftes, quoufque refrigererur; cum autem paullatim ipfum refrigeraveris, donec unitum fit, ex aeneo uafe omnia in mol tarium coniice, ac ualenter tunde. rofacci parum infun dens, quoufq. ad modum molle, \& liquidum euadat. fi igitur in hunc modum paratum fit febri, fi quid aliud, aduerfatur, \&lumbricos perinferiorem uentrem ducit,emortuâ, \& imbecillã appetendi uim excitat:ad alias fimiliter feruidas affectiones veluti eryfipelata, car bones bclle facit: \& infămationes ano innafcétes, \& acres, biliofasve pedũ fuxiones, inueteratosq. capitis do lores, ex caliditate ortos iuuat: Et(vt vno verbo dicam) nullü aliud ceratũ ita multis vfíbus accốmodatum reperies. Ceratum etiã ex Anchufa fi eodem modo paretur, vbi febris follicitat, vtilifimum eft : Panni etiam hydrelaeo imbuti optimi funt. Efficax autem eft oleũ, fi fit chamemelinum; in aquam vero quae oleo mifcetur, melilotum, chamemelum, \& abfinthij modicũ iniicere oportet, atque, ita fertuere; fed lana non multum calida applicanda eft. Q Liod fi etiam ventrem laueris, remoto tamen fi voles abfinthino, utilitatem attuleris. neque vlla amara per inferiorem ventrem cuiquã adminifrabis, quoniam animalia ex aduerfo potius ad fuperiores partcs in hifee recurrunt: \& iccirco nifi febris mulum $r$ hibeat, mel iniciendum eft, népequod limul, \& lumbricos, \& quxcunque craffa \& viuda ipfos nutrirc apta funt, deorfum trahat. His autem om 
nibus peractis, fi febris, \& fitis magnitudo adhuc perfeuerct, vtere etiam reliquo victu, qui refrigerare, \& humestare queat. Vehementia namque febris bi liofi fucci mixtionem in corpore indicat. Quamobré his ptiffanam cum aliquo quod refrigerare, 8 humeAtare, atque attenuare valeat offerre neceffum cft; nec te admiratio capiat, fi tefrigerantium ufum commendem, quoniam femper ei quod magis vrget, obfiftendum eft; ftudendumq́ue femper vt corporis bona temperies inducatur, nimirum qua praefente tutius de cetero attenuantibus vti licet, veluti fi parum accti, apijve radicis inter coquendum inieceris, fic optimus ac utiliffimus eius fuccus euadet. Verum enimuero fi nihil praedictorum infit, nil aliud efficietur, quàm lumbricorum nutrimentum. Ex oleribusintybum, \& laEtucas marullas vulgo distas coetas, oxiicrato aquofo intinctas comedat. Quod fi aegrotus vexetur, fitiquue cxerceatur, peponis interiora offer : abfterforia enim facultate nô caret, quin, $\&$ mora exhibeas, quippe quae non modo aluum ducant, verumetiam aliquo pacto animalia eius interimant. Omnia vfque ad fatietatem concedito. Quandoquidem faepe obferuatum eft ea ob alimenti inopiam. ita inteftina laceraffe, vt per ciltim ipfam egredi vifa fint. Ad haec propter febrem faxatiles quoque pifces, qui in costura acetum praehabuerint dabis, fimiliter, \& palumbos. Atque tot difta fint de iis, qui a lumbricis, \& febre fimul tentantur.

\section{De ïs quos fine febre lumbricivexiant.}

We I aeger febre careat, neq; rhodomel, neque pe. ch. ponem prompte concedas, fed tã potus, quàm cibus omnis atten uatorij fint, ueluti a pium, $8 z$ porrum, uel caucalis, uel herba bifacutum uocata. In- 
terdum etiam allia, am y gdalac amarae, atque fimilia. Melanthium, ciminum aceto conditum, nec non mafiche, uel capparis. Conuenit his, \& decoctum abrotani, comae abrinthij, maioranae, dictamni . Cyphi item facrificior um uocatum. Practer haec theriaca non folum ad exiftentes lumbricos, interimendos ualét, ucrü etiam eorum generationem inhibet fi quis femel, uel; bis in menfe eam bibendam praebeat. Et ego faepius eam in magnam cum fomachi fubuerfione lumbricorum copiam habentibus felici fucceffu exhibui: facit multum, \& lapis gagates. Belle quoque faciunt fi quae alia granatorum grana data intus exteriufq. applicata. Multum ualer, \& fel taurinum, medullac ceruinae; qué admodum, \& cedriae commixtum. Pariter iutuat oleũ lupinorum. cum medulla ceruina umbilicoinunetuin, ficut \& Galeni ceratum. A tque de his fatis mihi dictũ uidetur. Nam de ipfis fufficienter dietũ eft, quibus au xiliis aduerfus animalia in corpore exuberantia uti oporteat, Gi febris adfit.Quaedam tamen particularia libenter monebo, neque multis libris exponam.Sed ea tantum, quae, \& ab optimis medicinae auctoribus, \& a mefumma experientia comprobata inueni. Primum igitur eorum, mentionem faciam, a quibus lati lumbri ci occiduntur, cumab iis minus, quàm ab aliis pericu lum impendeat.

\section{Deÿs quae latos lumbricos necant.}

Afurtium potu fumptum latos lumbricos deor (7) fum trahit, fimiliter \& coftus, ac oleum ricini1. num bibita. Nuces quoque regiae magna copia deuoratae, lata uentris animalia iugulant, atque expel lunt, ficut \& mali perficae cortex, myrti folia, maliqúue punici flores. Ad haec herbam lumbricariam, fiue corallinam 
rallinam tritam bibendam dabis. Mori radicis cortex aqua costus deinde potatus, nee non heliotropium paruum cum femine, nitro, ac hyffopo bibitum; naftur tium praeterea, tum rotundos, tum latos lumbricos ex trahit, fi cum gari, uel mellis drachmis iij. lambatu r. Chameleonis albi radix oxybaphi pondere in uino au ftero cum origani decouto pota lumbricos eiicit, quod fimiliter facit hyfopi, \& nafturtii radix quatuor drach marum pondere cum melicrato exceptae, fed melius cum fcammonii,fiue ellebori nigri obolis duobus.fi ue ro quis falia edat ac filiculae foeminae fumat radicem cum melle terens latos lumbricos educit, \& eadem radix drachmae pondere bibita rotundos pellit. Centua rii fuccus cum cimino impofitus, lumbricos eiicit.M elanthium aqua maceratum, \& emplaftri, forma umbilico appofitum idem facit; idem cucumeris filueftris radix cum hydromelle elixata, cui fi etiam poft elixationem iniece rimus feminis lini partes duas, lupinorum farinae unam, ac deinceps iterum coquatur, \& fuperioribus omnibus partibus emplaftri forma adhibeatur, tam latos, quàm rotundos lumbricos necat, quinimmo iis omnibus indifferentes, qui a quibufuis uentris animalculis magno periculo follicitantur, extrinfecus adhibetur, ac mirifice auxiliatur.

\section{De ÿs quae rotundos. lumbricas occidunt.}

Nterimit atque pellit lumbricos rotundos, brafficae domefticae, ac praefertim aegyptiaefemen ruta coctum, calidumq. potumdrachmarum fex pon-
roún dere rotundos lumbricos expellit. Portulacae fuccus potatus, ac abfinthium marinum elixatum, vel folum, ucl cum oriza melle acceptum afcaridas, \& rotunda animalia 
animalia ventrem foluens educit. Lapidem gagatem aqua coctum bibendura pracbeas. idem operatur hy ffo pum cum ficubus aqua, \& ruta potu fimptum, atque etiam cum melle lambendo acceptum. fuccus menthae cum aceto bibitus, calamentum fale, \& melle bibitum, tam coctum, quàm crudum, ac ualde tritum lumbricos rotundos \& afcaridas eiicit. Thymum cum melle potu acceptum, necnon coriandri femen modicum cum paffo bibitum lumbricos educit, menternq́ue plurimuin agitat.

\section{De afcaridibus.}

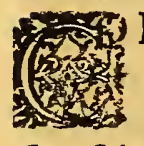

Edrus vermes, atq. afcaridas clyfteri infufa occi dit, Vinum, \& farinam cum mclanthio fimul co quens emplaftri forma adhibe, melius autem. fit; fi hordeaceam farinam in camomeli decoeto incoquens clyfterem pares. Occidit vermes quoslibet, afcaridasq. etiam eboris rafura data vermes omnes perdit; \& calamentum;aridum fextariis aquae duobus inijcito, tum coquito, ufq. ad tertiae partis confiftentiam hoc au xiliatur aduerfus quofuis lumbricos. Oleum rofaceum cum defruto tepefaciens potandum praebeto. Dato quoq. aloem, ac intybum cum aceto. Allia manducata profunt. Abrotanum cbullitum ufque ad tertiae partis confiftentiam aduerfus ventris animalia datur; melius autem euadit, fr acetum decoctioni admifceatur. Sunt mille alia a Veteribus memoriae tradita fi recte adhibeas, ac exacte componas.

Alexandri Epifolaefinis. 


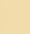



COUNTWAY LIBRARY OF MEDICINE

RC

46

M54

1571

RARE BOOKS DEPARTMENT 
